\title{
A NEW WAY. NIUE
}

A resilient and sustainable architectural response

to Nives natural hazardous and harsh environment

By

Anthony Liuvaie Freddie

A 120 point thesis submitted to the School of Architecture and Design, Victoria University of Wellington, in partial fulfilment of the requirements for the degree of Master of Architecture (Prof.)

Victoria University of Wellington: 

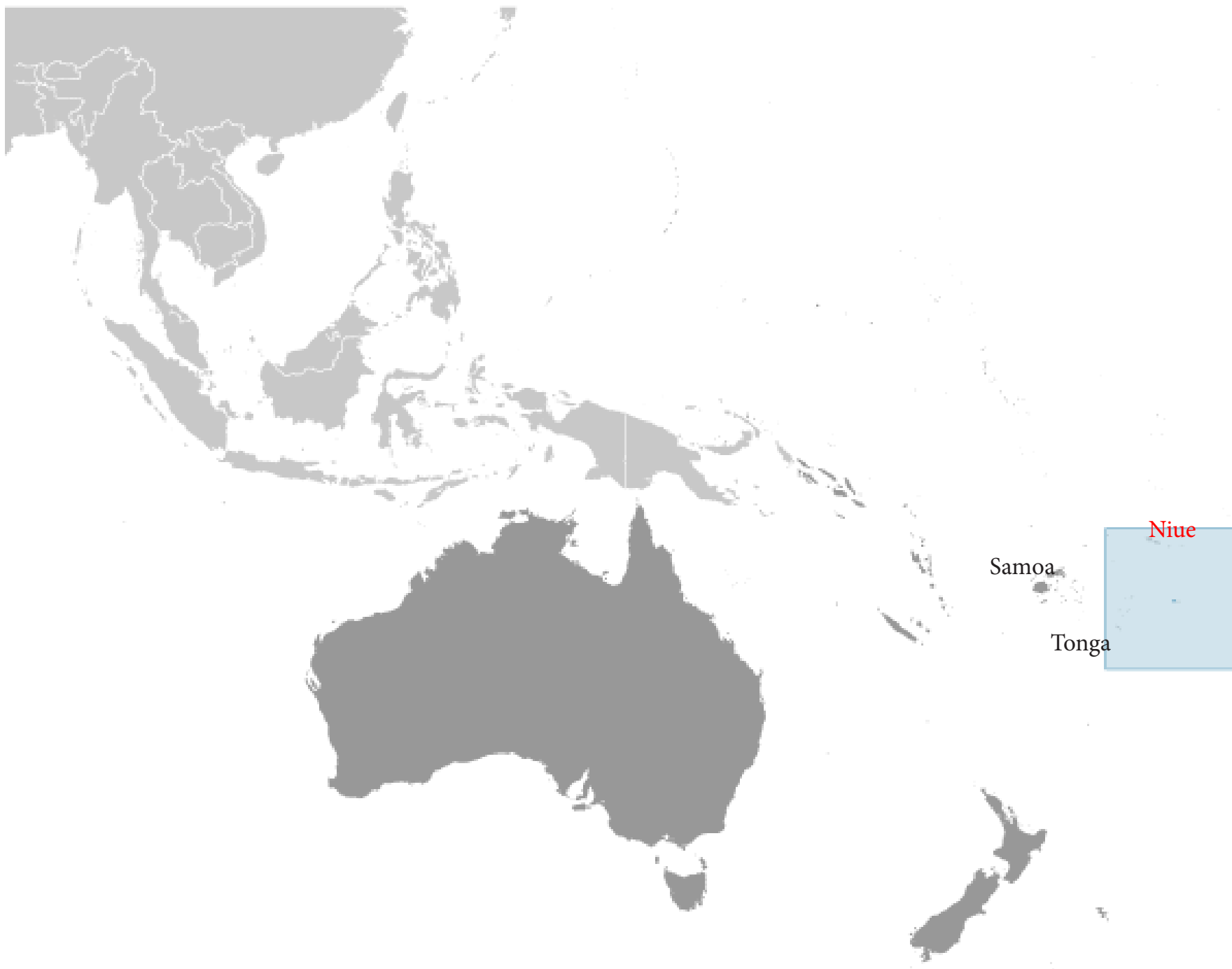

₹. 


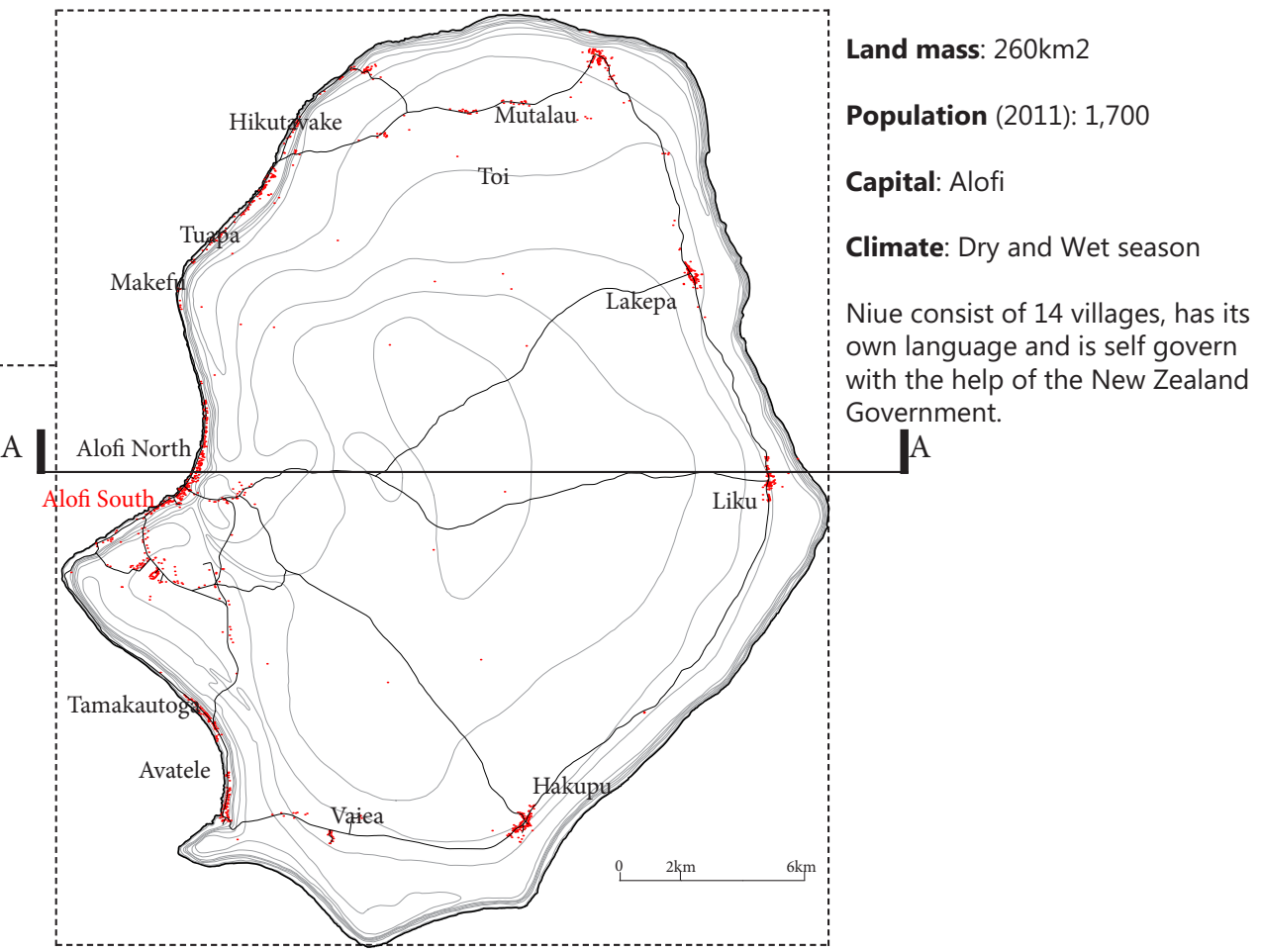

Niue map

Niue is well known as one of the largest upraised coral atoll in the world situated in the middle of the South Pacific within a triangle boundary of Tonga, Samoan and Cook Islands. From New Zealand, it is located towards the north eastern side of the International Date Line and is 11 hours behind the Greenwich Mean Time.

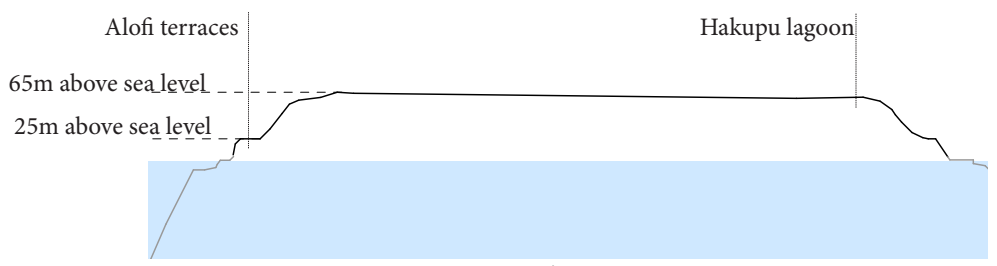

Section A-A 


\section{A NEW WAY. NIUE}

A resilient and sustainable architectural response

to Nives natural hazardous and harsh environment

By

Anthony Liuvaie Freddie

A 120 point thesis submitted to the School of Architecture and Design, Victoria University of Wellington, in partial fulfilment of the requirements for the degree of Master of Architecture (Prof.)

Victoria University of Wellington: 


\section{ABSTRACT}

With the increase in climate change, small Pacific nations such as Niue face significant risks from rising sea levels and the increased intensity of natural disasters such as tropical cyclones. These extreme weather events have caused severe devastation therefore threatening the fragile economy, and social and cultural fabric that make up the identity of Niue, a Pacific nation. This is evident in the decline of the island's population. A current issue faced by Pacific nations such as Niue is the lack of contemporary vernacular, sustainable and resilient architectural solutions to the environmental and economic issues these nations face. Further compelling this situation is the lack of research and study of Niue's traditions and cultural practices, vernacular architecture and natural environment. This issue has negatively affected urban renewal and developmental projects, most of which have been formulated based on individual's experiences, outdated attitudes and approaches or the findings of research conducted through pan-Pasifika or western lenses. The devastating outcomes of Cyclone Heta in 2004, which struck most of the costal edge of Niue, particularly the South side of the Capital Alofi, Aliluki and destroyed the national hospital, the national museum, the Niue Hotel and Amanau apartments brought to light the seriousness of this issue. From then until now, Aliluki which once was the centre of Niue has been stigmatised by cyclone destruction, and deteriorated into a barren ruin overgrown by nature.
This thesis aims to document and preserve through this project, local knowledge associated with Niuean building traditions and cultural practices; develop a design method that leads to a contemporary architectural solution informed by the local culture, traditional practices and contextual situation; and develop a viable architectural solution that contributes to increasing the resilience and sustainability of Aliluki to future disasters and enhances the economic prosperity of the community through an increase in social, economic, and cultural opportunities.

The design thesis argues that understanding Niue's traditional values, practices, and contextual situation will help identify resilient and sustainable vernacular architectural solutions for Niue's cycloneprone environment. This is done through two stages of the research: Theoretical grounding and a one-month field research and site studies in Niue. All the key literature, case studies and key findings were then explored, tested and developed through the urban re-development of Aliluki and a design of a cultural centre that will be used as an evacuation shelter in the event of a devastating tropical cyclone. In search for a better and safer future, this research will hopefully contribute towards the survival of the people and traditions of Niue, who has for several decades, struggled with the forces of modernisation. 


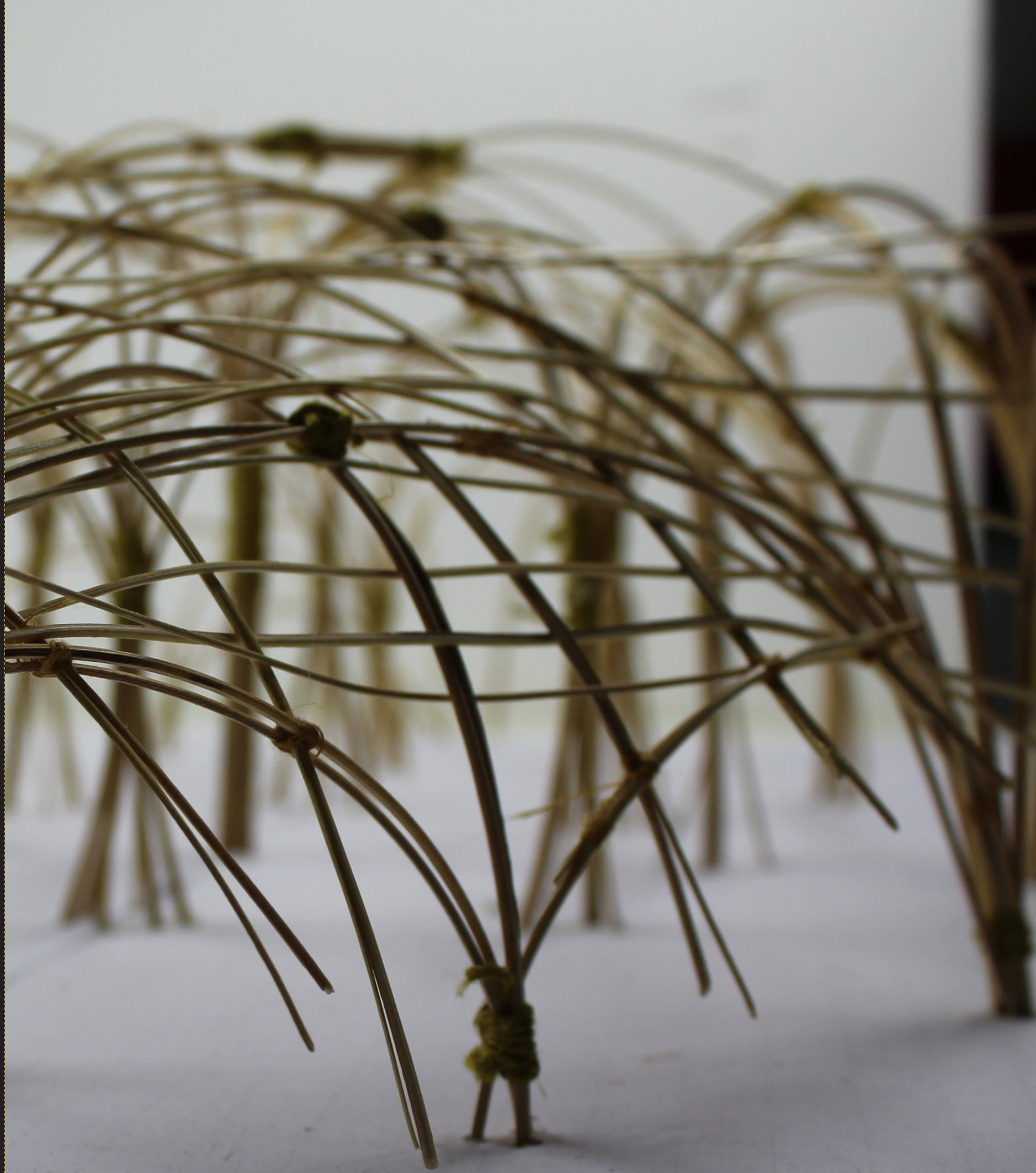




\section{PREFACE}

Growing up in the village of Hakupu, on the tiny island of Niue affectionately known as The Rock, life was tough but at the same time relaxing, safe, and free. In 2004, Cyclone Heta struck Niue; I still remember vividly the car ride down the coastal villages to witness the extent of the damage. What greeted us was shocking especially the sheer devastation on the Southern part of Alofi, Niue's capital. It was like being in a scene in an action movie, where a whole city was bombed, and everything was completely flattened, except the instigator was the sheer force of mother nature.

Our family migrated to New Zealand in 2006 for better educational opportunities. I had always enjoyed a passion for drawing and design. I worked my way through high school and tertiary level where I am now studying towards a postgraduate qualification; however, I was and am always thinking of my homeland Niue. When it was time to selecting a topic for my research, I knew that I had to do my design research on Niue. From the start I didn't know exactly what I was getting myself into, but I knew that I have to give back to my home island somehow. This eventually led to the birth of this research. I feel indeed privileged to be in this amazing journey where through the findings of this study, I will contribute to documenting an important part of Niuean history and the rebuilding of the coastal part of Alofi that was ravaged by cyclone Heta. 


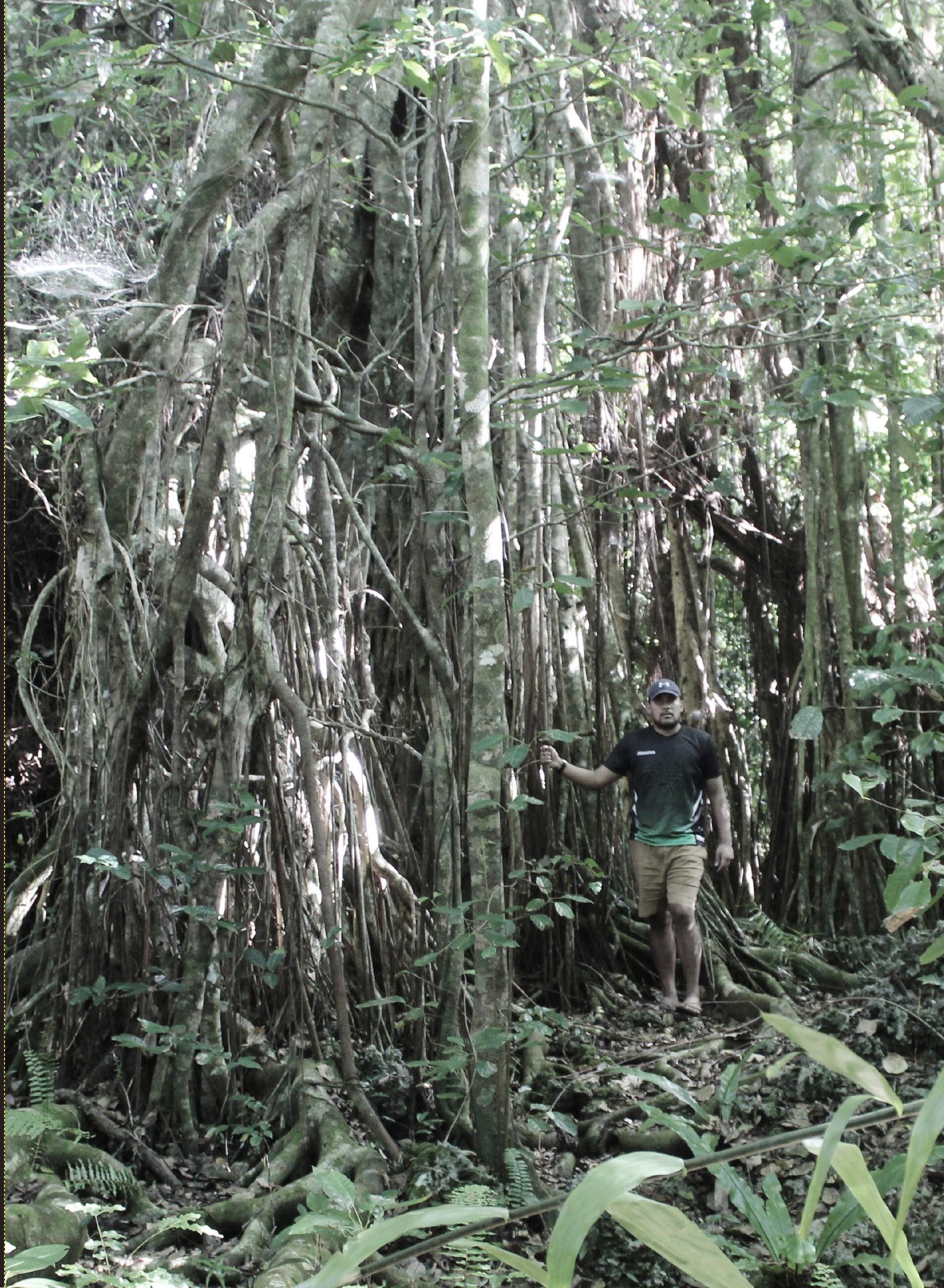




\section{ACKNOWLEDGEMENT}

Fakamua fakaue kehe fakaalofa noa he Atua ha kua maeke ia au nei ke fakakatoatoa haaku a tau fakaakoaga kehe faahi ta palana.

Firstly, all glory goes to God for blessing me with this opportunity to conduct and complete this design research.

I would like to personally acknowledge the Ministry of Foreign Affairs for funding the field studies of this research, the officials from the Niue Government and community including the matuas for their support and collaboration during my field work back in Niue, and the Niue High Commissioner- Hon. Fisa Pihigia and Victoria University for their major contribution towards my participation in the two internationally-recognised conferences in Wellington and Vietnam.

To my supervisor Shenuka de Sylva, thank you for your invaluable knowledge, encouragements, support and for ever being very patient with me. Your guidance and expertise have been invaluable for not only my research but for my personal and professional growth.

To my university family, thank you for riding this journey with me, especially our final year together. All the late nights working away in the studio, trying to figure out what we were doing, the funny banters and yarns, late night coffee and fix runs and the most the unexpected conversations that led to great design ideas- has finally come to fruition. I wouldn't be in this position without you guys so thank you.

To Te Ropu Awhina for the on going support in my university journey, thank you very much.

My friends outside of my University circle, your help and encouragements throughout my years of studies is greatly appreciated. My achievements are possible only because of your unyielding support.

To my family, fakaue lahi for your support and help throughout my life. Special acknowledgements to Uncle Okko and Aunty Lati for being my parents here in Wellington, and cousin Niva. To my siblings, Randy, Lawrence, Telson, Hugo, Sontel, and Laifone, I am forever grateful for your constant support, for keeping me grounded and standing by me. Lastly, to my parents Mere, Sonny and Teresa, your unconditional love and guidance have made me who I am today. I cannot take credit for this research alone, it's as much as yours, as mine so as others who have been part of this journey. 


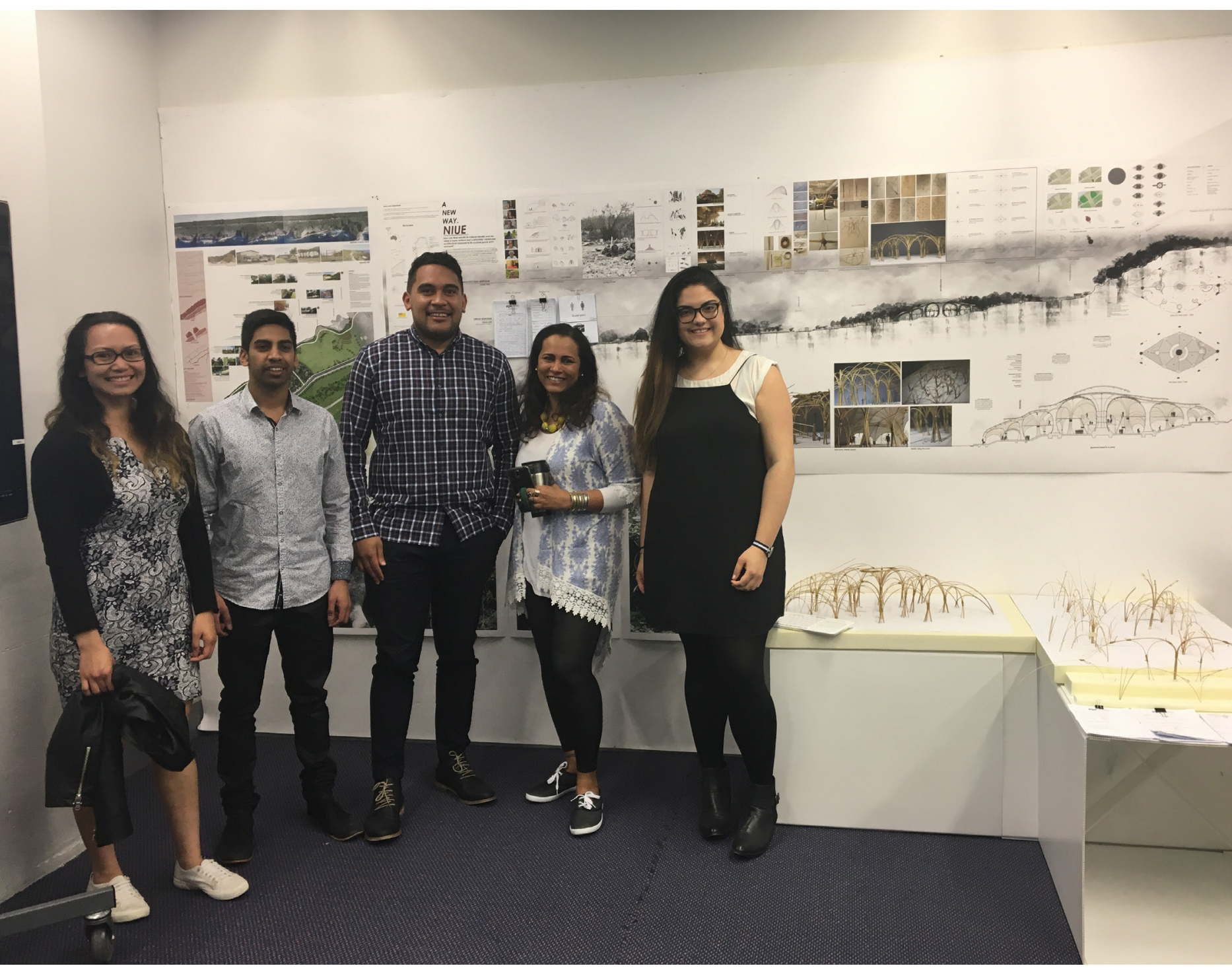

Figure 3. Photograph of author with the Ovava tree* (Previous) 


\section{TABLE OF CONTENTS}

01. INTRODUCTION

1.1 Existing Situation 3

1.2 Research questions 11

1.3 Research aims and objectives 13

1.4 Research methodology 15

1.5 Structure of thesis 17

02. LITERATURE REVIEW

2.1 Local Context and its impacts

2.2 Architectural identity 31

2.3 Global Context: Lessons learned from the Pacific and Asia 37

2.4 Cyclone design principles $\quad 41$

2.5 Key lessons and findings $\quad 43$

03. CASE STUDIES $\quad 48$

3.1 Urban case studies

3.1.1 Urban resilience. A study of Contruction, Chile 51

3.1.2 Urban sustainability. A Study of Regen village 53

3.2 Architectural case studies

3.2.1 A study of architectural sustainability. Green school Bali 55

3.2.2 A study of the pacific vernacular architecture (Architectural resilience)

3.2.3 A study of architecture and culture. Brambuk Cultural centre 61

04. LOCAL CONTEXT $\quad 68$

4.1 Contextual study of Niue $\quad 71$

4.1.1 Historical

$\begin{array}{ll}\text { 4.1.2 Geographical } & 73\end{array}$

4.1.3 Current demographic $\quad 75$

$\begin{array}{ll}\text { 4.1.4 Political } & 77\end{array}$

$\begin{array}{ll}4.1 .5 \text { Economical } & 78\end{array}$

$\begin{array}{ll}\text { 4.1.6 Climatic } & 79\end{array}$

4.1.7 Existing Infrastructure $\quad 81$

4.2 History of Disasters 83

4.3 Impacts of disaster on the island

4.4 Cyclone Heta and its destruction 87

4.5 Aligning with Niue governments visions

$\begin{array}{ll}\text { 05. SITE ANALYSIS } & 94\end{array}$

$\begin{array}{ll}5.1 \text { Potential site } & 97\end{array}$ 
$\begin{array}{ll}5.2 \text { Chosen site } & 101\end{array}$

$\begin{array}{ll}5.3 \text { Disaster risk analysis } & 107\end{array}$

$\begin{array}{ll}5.4 \text { Existing site analysis } & 115\end{array}$

$\begin{array}{ll}\text { 06. } & 126\end{array}$

6.1 Questionnaires 129

6.2 Participatory design 131

6.3 Interviews

07. DESIGN PROCESS

7.1 Site development

7.1.1 Preliminary design

7.1.2 Critical reflection

7.1.3 Developed design

7.1.4 Critical reflection

7.2 Architectural development

7.2.1 Preliminary design

7.2.2 Critical reflection

7.2.3 Developed design

08. FINAL DESIGN

09. DESIGN DISCUSSION

9.1 Masterplan discussion

9.1.1 Disaster scenario

9.1.2 Day to day scenario

9.2 Architecture discussion

9.2.1 Cyclone resistant structure.

9.2.2 Sustainable design.

9.2.3 Application of design.

9.2.4 Community construction.

9.2.5 Disaster scenario.

9.2.6 Day to Day function.

10. CONCLUSION 
$4(2) \times 12$

$\sin 20$ 


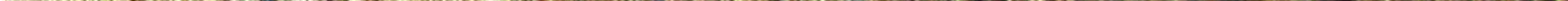




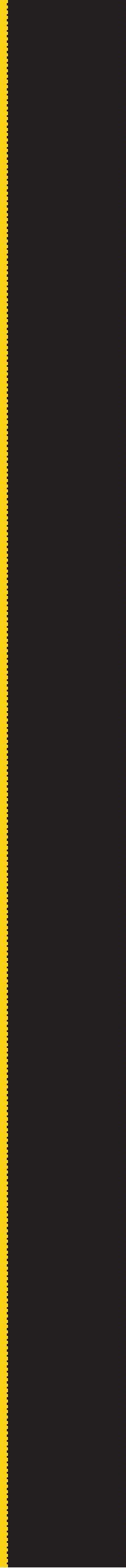


1. Introduction 


\subsection{Existing situation}

'Savage Island' was the name given to Niue by early colonizers due to the fierceness that visitors encountered from the local warriors who fought to protect their tiny island home from foreign invaders (Tregar, 1893). The resilience and tenacity of the Niuean people, which ensured the island's sovereignty from colonial dominance, had also enabled human inhabitation of a harsh island environment for several generations prior to the arrival of European explorers to the Pacific. Known as the 'Rock of Polynesia' Niue is one of the largest raised coral atolls in the world with an area of 269sq.km. Formed entirely of coral limestone and with no lakes or rivers, fresh water can only be harvested through deep bore wells, and in addition, its soil is considered unsuitable for large scale cultivation of most varieties of crops. The steep limestone coastal cliffs that lift Niue $24 \mathrm{~m}$ above sea level along with the coral reefs that surround it entirely, with just a single break, makes fishing and other methods of food collection an arduous means of livelihood for the islanders.

Niue's geographical location in the Pacific region does nothing to ease the difficulties of inhabiting it; lying in the path of numerous natural weather events, cyclones and droughts are regular occurrences causing havoc on the already fragile sustenance sources and living environments of the island's population (Change, 2006). Recent studies on the impacts of climate change in the Pacific region have shown 
an increase in the frequency of droughts and cyclones due to global warming and studies on climate change and food security in the region have identified the impacts of likely adverse weather conditions on food production and the fragile situation of small Pacific island nations of Niue (Barnett, 2012; UN, 2008).

Extreme weather events have for several years had direct and indirect devastating impact on Niue, and their continuity, with increased frequency and intensity, will most certainly result in the possible abandonment of this small island by its current youth and future generations, who have a relatively safe haven with steady educational and economic opportunity in New Zealand, which has granted Niueans citizenship (Government of Niue, 2016). While natural disasters have significantly undermined Niue's economy and its socio-cultural fabric, factors such as climatically inappropriate and westernised building methods, materials, and planning practices have all contributed to the widespread damage resulting from natural hazard situations as cyclones, and to the demoralising effect of ongoing damage to lives, property, public infrastructure and livelihood sources that have driven Niueans to find safety and security in New Zealand. The devastating outcomes of Cyclone Heta in 2004 on Niue is a good example of this situation; it not only destroyed valuable infrastructure and the islands fragile ecosystem but also caused an exodus of
Niueans to New Zealand upsetting the steadying in population numbers Niue was experiencing at the time and desperately needed to sustain the future of the country (Barnett, 2012).

The worst damage from Cyclone Heta, and the Tsunami-like wave surges that resulted, was experienced in Aliluki, the more modern built up south of the island's capital Alofi, established on a highly exposed stretch of the island. The island's national infrastructure including its only hospital, national museum, public library, the Niue Hotel and the government-owned housing development Amanau Apartments were completely destroyed (Change, 2006). Other parts of the island, where local communities had established themselves several generations back in naturally protected areas, and followed low built architecture traditions, experienced less damage. This situation sheds light on the seriousness of the issue of inappropriate methods and practices and the importance of traditional knowledge and resilient practices to a developing nation as Niue and its fragile economic situation including the issues of a declining population. Today, New Zealand continues to support Niue's economy and provides more than $50 \%$ of its GDP through various budget support programmes in addition to economic aid estimated at NZS\$13.8 million for 2016-2017 (NZ Ministry of Foreign affairs and Trade, 2017). 


\section{CYCLONE PRONE ENVIRONMENT.}

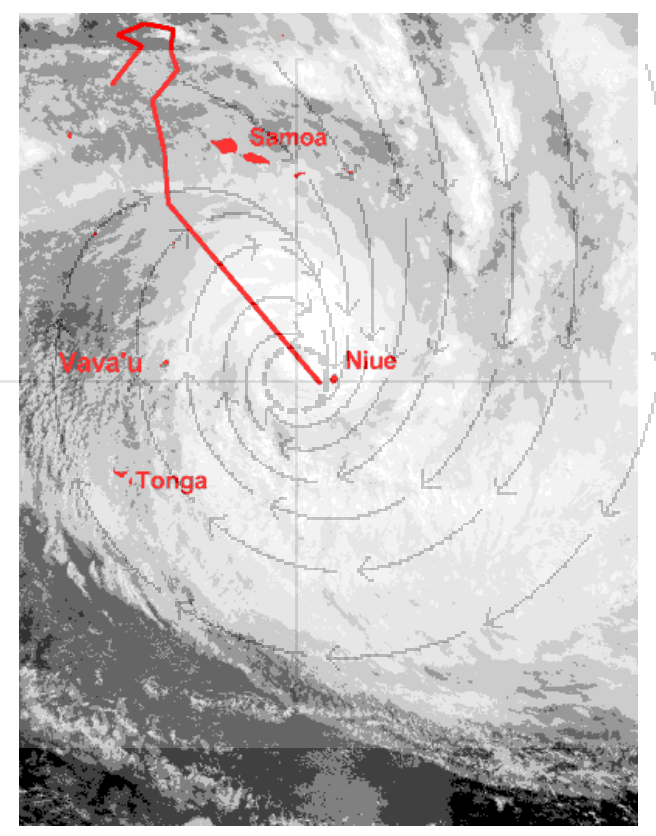

Proposed Site: Aliluki

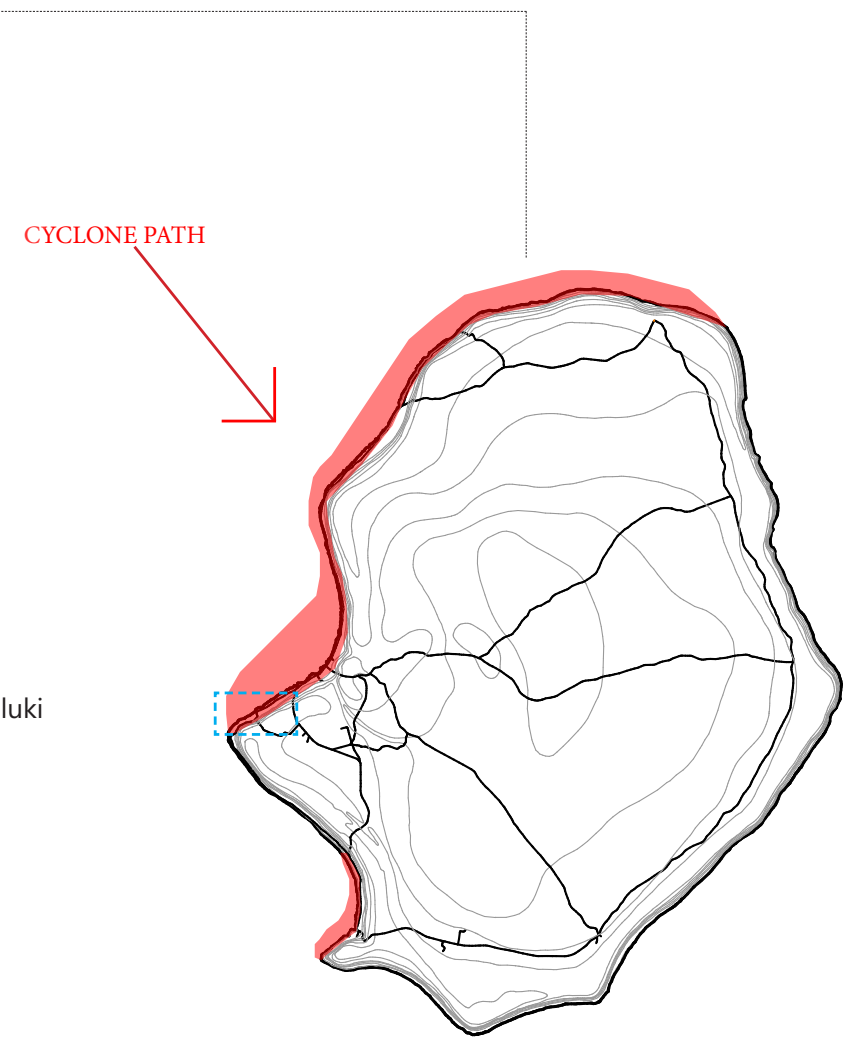




\section{DECLINING POPULATION.}
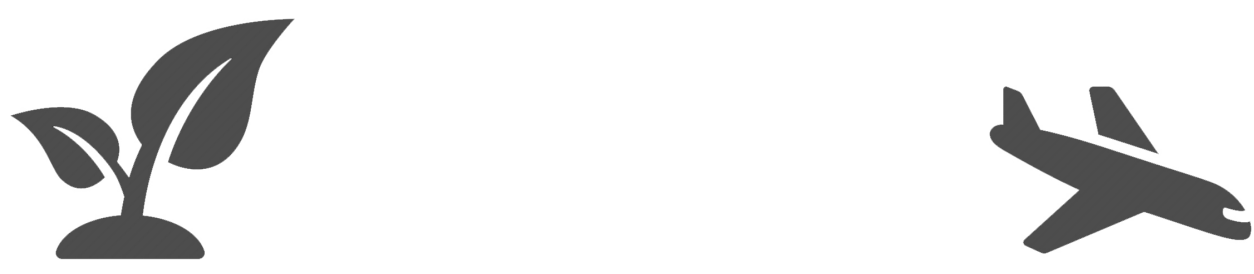

Environmental conditions

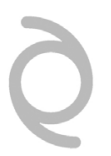

Constant Cyclones

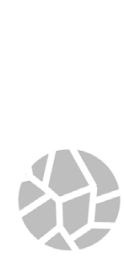

Poor soil conditions

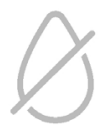

Constant drought<smiles>[BH3-]</smiles>

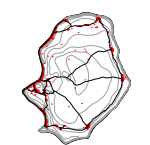

Niues terrain

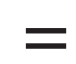

Communnity hardship
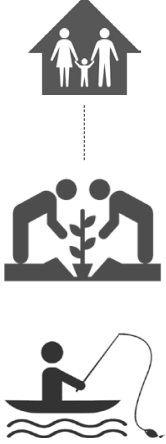

$=$

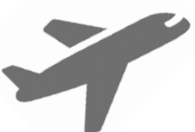

Economical growth

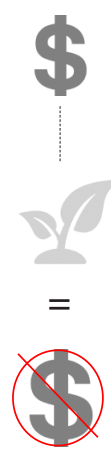

$=$

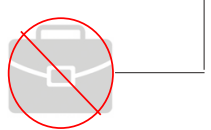

Ease of access

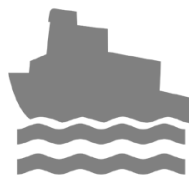

BOAT RIDE

Before 1970 Niueans only way to travel was through a boat that came three times a year

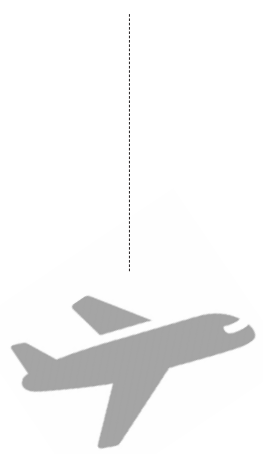

FLY AWAY

The introduction of an airport and also the fact Niueans were New Zealand citizen meant that it was easier to leave the country. 


\section{LACK OF CONTEXUAL STUDIES}

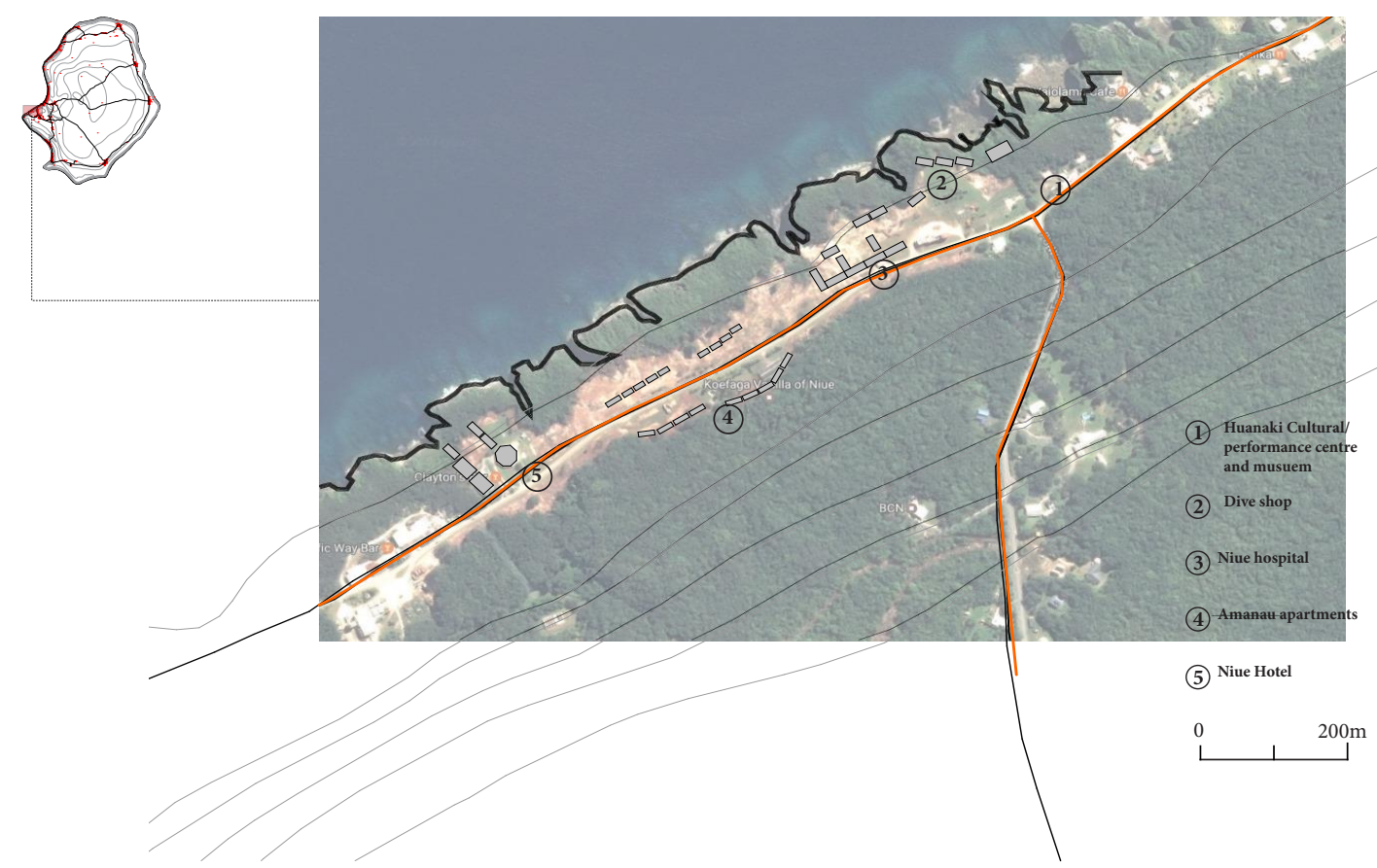

Existing site before Cyclone Heta

\section{RE D A C T E D}



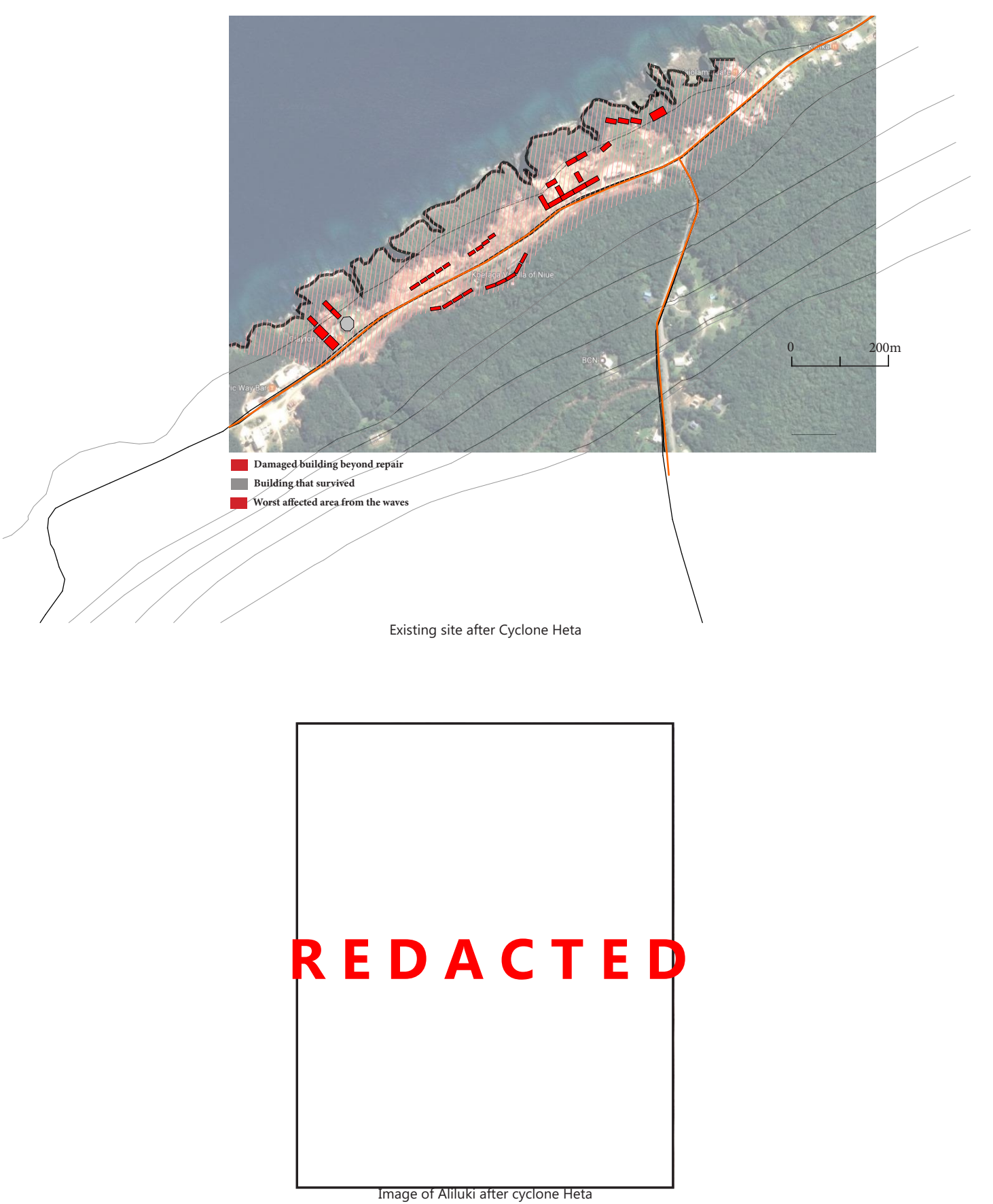

Figure 10. Diagram of Ailuki after Cyclone Heta*

Figure 11. Drone image of Aliluki existing site.(Over) 


\section{- 5 -}

\section{-}

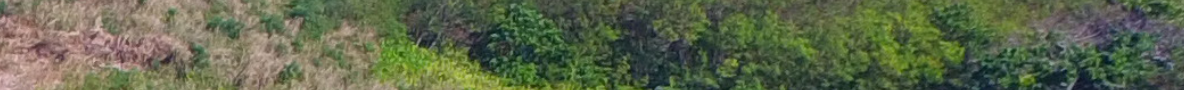

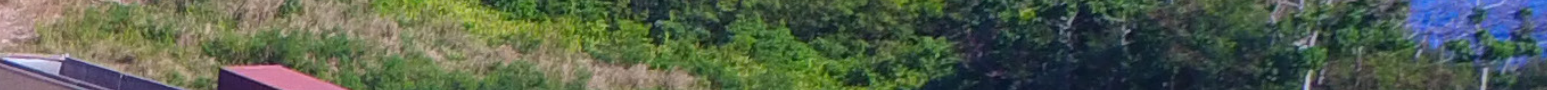
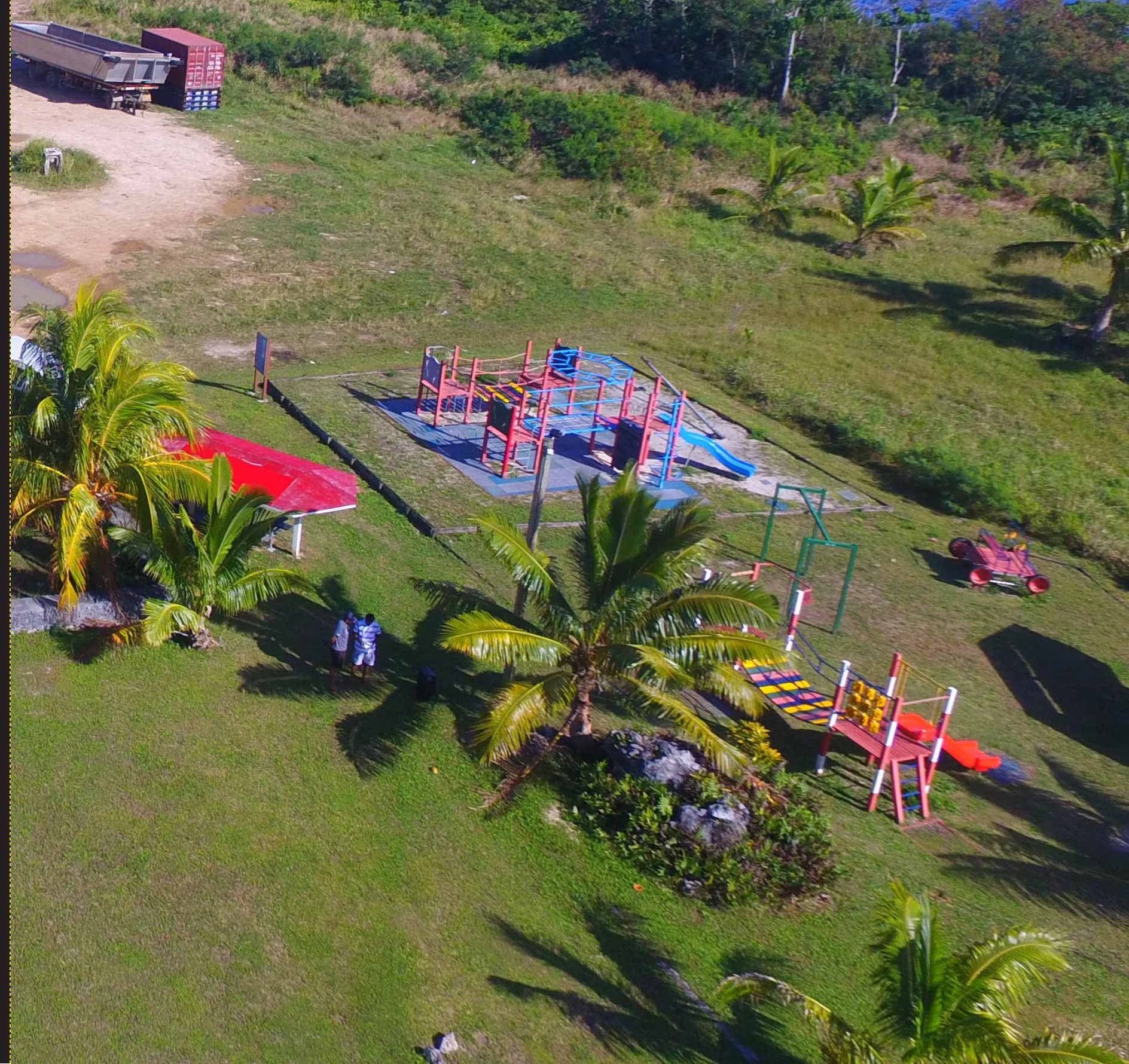
1.2 Research Question 
How can Niue rebuild its cultural identity and develop a more resilient and sustainable, vernacular architectural response to its cyclone prone environment? 
1.3 Research Aims \& Objectives 
1. Document and preserve through this project local knowledge associated with Niuean building traditions and cultural practices.

2. A design method that leads to a contemporary architectural solution informed by the local culture, traditional practices, and contextual situation.

3. Develop a viable architectural solution that increasing the resilience and sustainability of Aliluki to future disasters and contributes to the economic prosperity of the community through increased opportunity. 
1.4 Research Methodology 
This research will employ multiple methods of data collection.

First, it will critically look at literature reviews on contextual studies, vernacular architectural principles, architectural identity, global context on disaster preparedness and cyclone key design principles.

International existing case studies will be analysed to understand how other communities or architects have address the issues raised by the literature review to learn and to position the research with a more theoretical and real-world grounding.

Next, this research will then look at field work which will be split into two categories: An extensive site analysis of the current site will be done to help understand the current climatic and environmental condition of the place to help understand the physical context of the site.

The second part of the field work will involve a multiple participatory design process which will include semi structured interviews, design workshops, questionnaires and ethnographic studies with Government, NGO and the community to help understand the cultural practices, community issues, and context of the Niue. Doing research in Pacific communities requires the researcher to demonstrate awareness and competency in Pasifika cultures and values as outlined in the following key documents (HRC, 214; Otago University, 2011). From this participatory design process, a programme will become an outcome which will then feed into the next stage of the process.

Lastly, an extensive iterative design process will be carried out to test the different ideas based on the research done that addresses the research question which will establish design criteria.

Iterative design testing will be done through the following: participatory design, master planning, sketch designs, 2D and 3D modelling, and physical models which will be created. These will help understand the strengths and weaknesses of each design ideas. From these design testing, formal design critiques from different architectural practitioners and top New Zealand academics will be held to guide the research and design proposal in the right direction and also help refine the proposal. 
1.5 Structure of thesis 


\section{A NEW WAY. NIUE}

Existing issues.

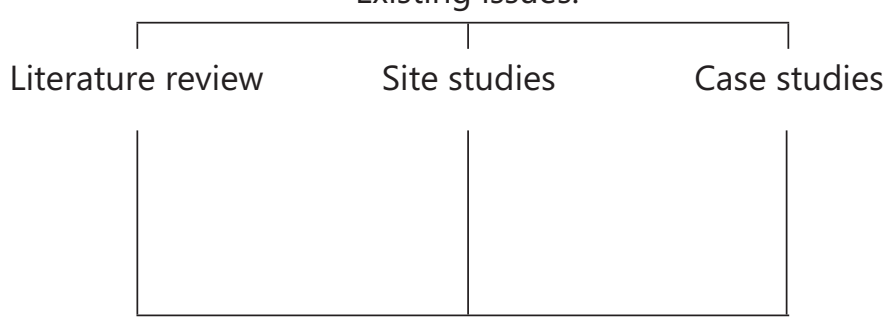

Design research.

\section{Conceptual design.}

Design iterations

Critical reflection.

Design review one.

Field research.

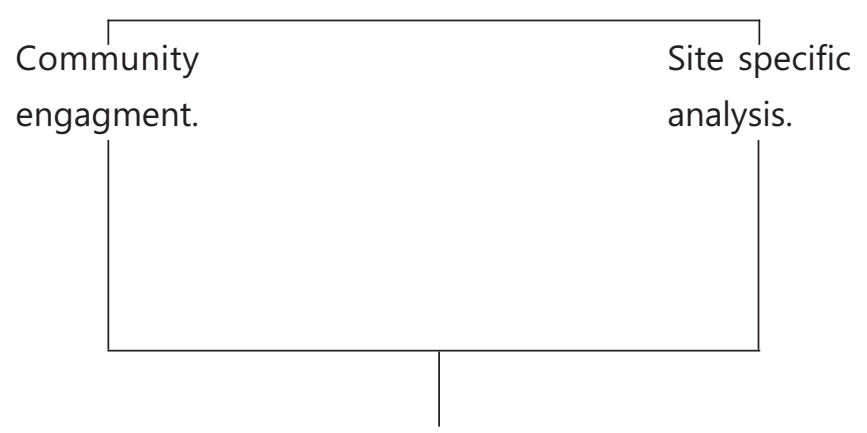

\section{Developed design.}

Design iterations

Critical reflection.

Design review two.

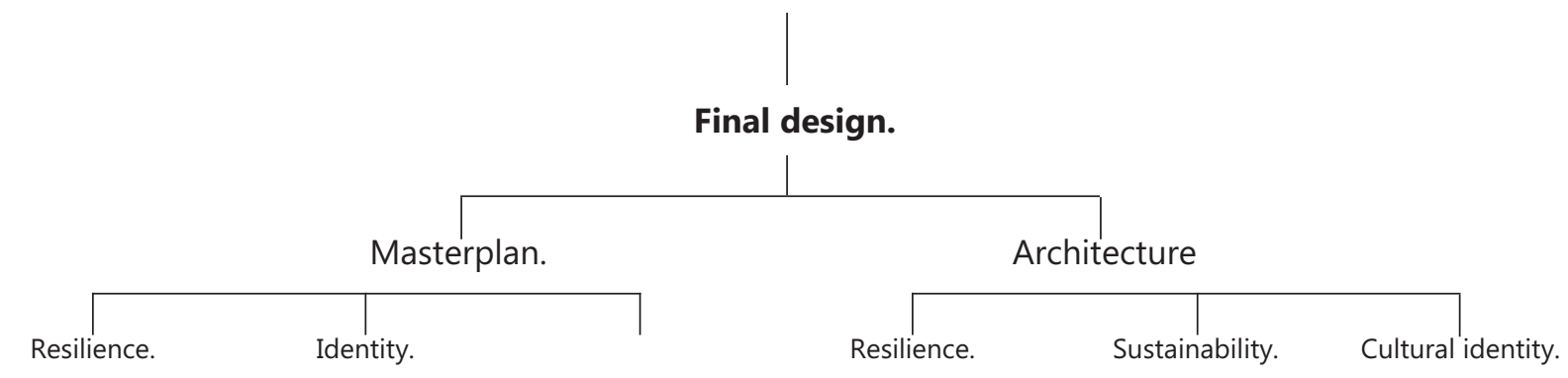




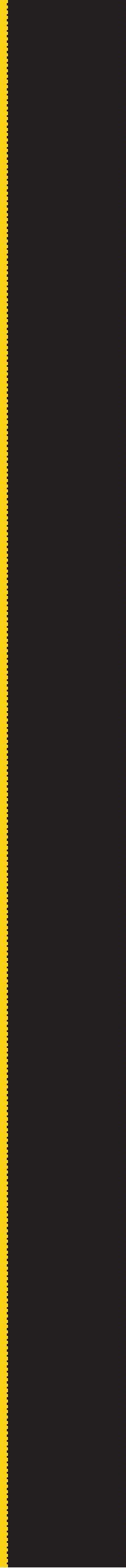


2. Literature Review 
The study examines notions of Niuean vernacular

architecture and its role in informing architectural

knowledge, principles, and practices used in the

construction of buildings and infrastructure.

factors or characteristics specific to a culture or

and the central role that identity plays in the

location that should be taken into account in any

decision making, design or construction. The

literature used is drawn from the international

body of literature on the topic, especially in New

Zealand, Australia and Asia including the limited

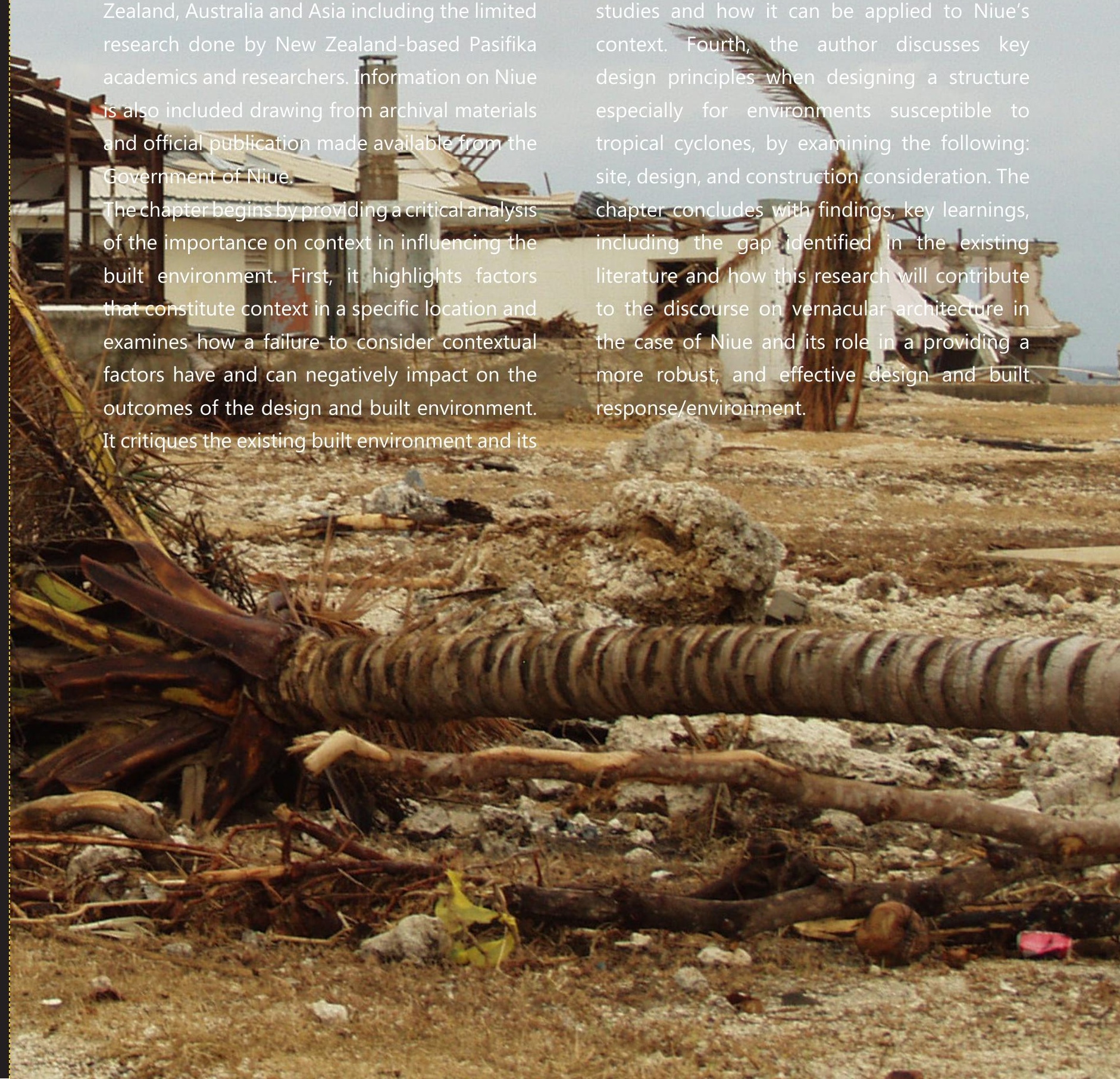

are presented drawing from important lessons

from disaster recovery, disaster management 


\subsection{Local context and its impacts}

Designers have a social responsibility to deal with the needs, issues, and problems that their clients and communities are confronted with (Guaralda, Caldwell, \& Rittenbruch, 2015) 
If there is a better understanding of:
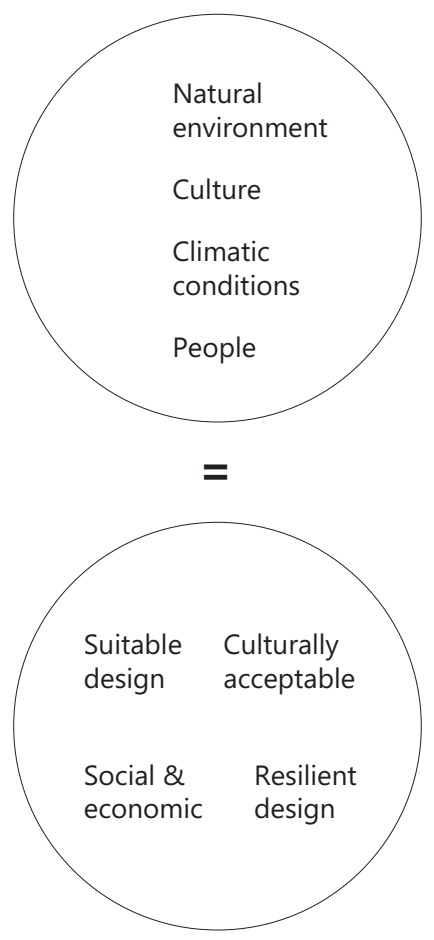

This leads to a better outcome that fits in with the local context of a place 
The dearth of research on architecture in Niue has resulted in a rather haphazard approach to the planning, design, and construction of local residential housing stock and other buildings and infrastructure. The widespread and indiscriminate replication of western knowledge and practices used in the built environment in Niue has had negative impacts on the island's development for several decades. Modern development endeavours have been formulated based on individual's experiences, outdated attitudes and approaches, or the findings of research conducted through Pan-Pasifika or western lenses (Barker, 2000). Schnoor (2016) contends that in the case of Samoa, architecture in its capital, became more "westernized" when it gained independence in 1962. He further argued how over the years, architecture has leaned towards a 'ubiquitous modernism' with no acknowledgement of regional culture. Likewise, McKay (2018) also asserts that the Pacific has been left out of the discussions and assessments of world architecture conversations.

As a result, the lack of critical assessment of urban renewal and redevelopment projects, their sustainability and resilience to natural hazards, particularly since the 1990s and following the devastation caused by Cyclone Ofa (Barker, 2000) resulted in widespread damage to these developments in 2004 following Cyclone Heta (Change, 2006). In addition, the unique contextual characteristics of Niue have made it a testing ground for a range of ad-hoc and experimental projects. However, the lack of evidence-based design and building practices has meant that these projects too have not benefited the people (Barker, 2000). The conditions that contributed to this situation is the ongoing and gradual westernization that has taken place over several decades, through processes of Christianization, European education systems, modernization, and since of late globalization (Change, 2006). This has contributed to the undermining of the value of traditional knowledge and practices causing these to be ignored, discarded and eventually forgotten. This situation has also cultivated a preference for imported ideas, practices, materials and technologies some of which are not suited to the local context or culture or is often applied to the Niuean context without adaptation or modification to suit local environmental conditions and culture (Change, 2006).

Context is therefore paramount in any design environment. These include recognizing the culture and knowledge, taking into account the local climate, environment, and conditions, utilising local materials, and most importantly meeting the needs of the local population. In the case of Vietnam as argued by Ly and colleagues, it must satisfy a growing demand for housing while confronting the issues of climate change, 
extreme weather events, nature conservation and cultural heritage (Ly, Birkeland, \& Demirbilek, 2010). The benefits of taking into account the context in a design environment is highlighted in research (see for example Feaunati, 2014; Taylor \& Conner, 2014 among others). Feaunati (2014) argues in the case of Samoa that culturally and environmentallyoriented design is not only critical in bringing new hope for affected communities but is also immensely beneficial for future sustainable development: culturally, economically, and environmentally.

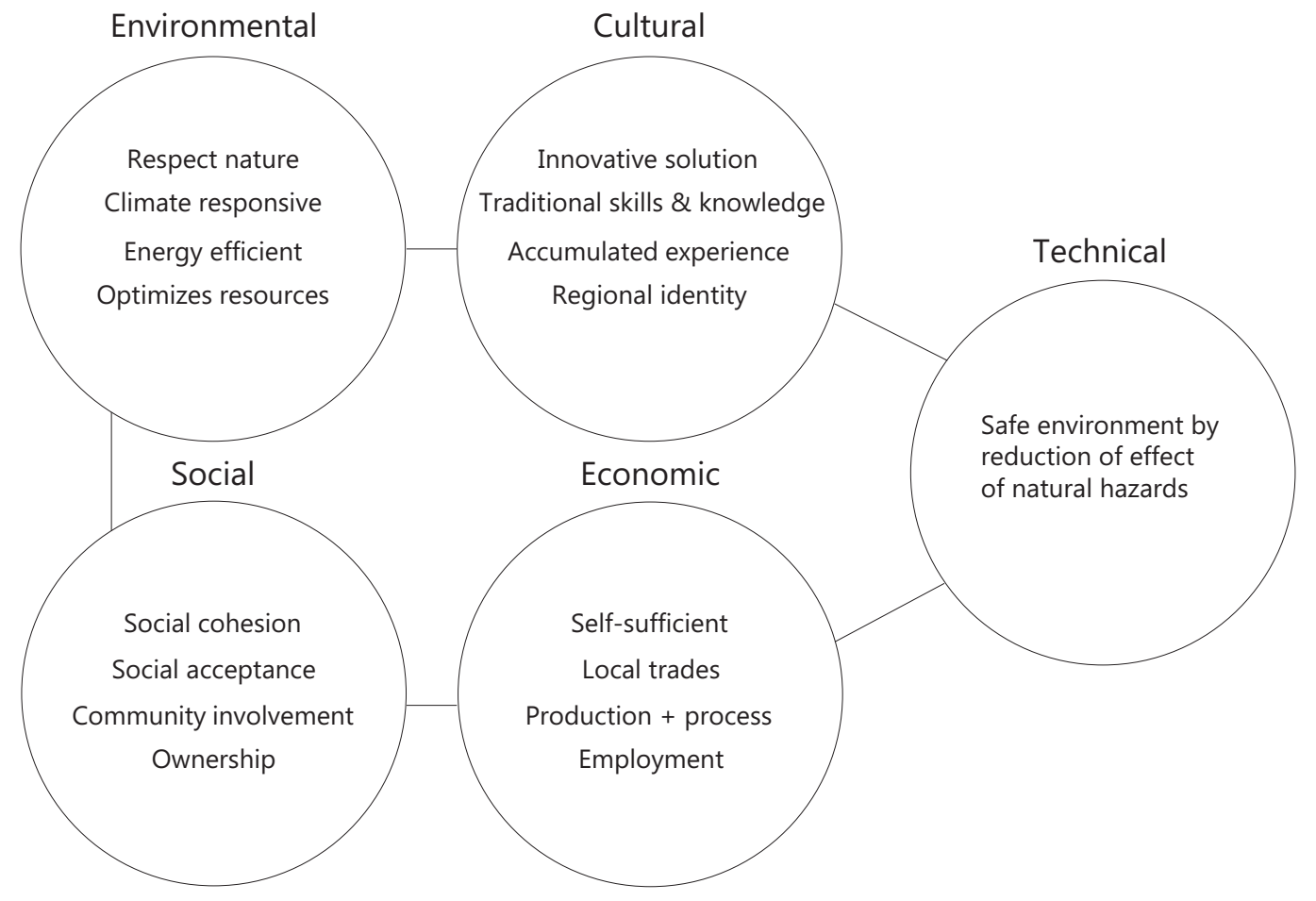

Benefits of Vernacular Architecture 
An examination of archival material from the Government of Niue on the history of Niue's developments highlights the negative impact western ideas and practices have had on Niue's built environment and development. Currently Niue imports most, if not all, of its building materials except for the aggregate used in the foundation of buildings, albeit the availability of some materials locally (Change, 2006). The damage caused by collapsed buildings and debris in natural hazard conditions have demonstrated the disastrous effects of using heavy and solid materials such as concrete or sharp flyaway materials as sheet iron roofing, in volatile environments as Niue. What is not readily acknowledged in post disaster analysis is how these imported materials and poor adaptation of non-vernacular construction systems have exacerbated the fragile economic situation in Niue by increasing the damage to lives, property and the natural environment (Oliver-Smith, 1996) Sourcing resources locally by growing and manufacturing the materials needed for building projects and devising new vernacular planning and design solutions using local knowledge and skills, offers huge advantages both for developing local capacity and improving livelihood opportunities and thereby the country's economy (Barker, 2000). Such processes also ensure quicker recovery from disasters and greater resilience both in the short and long term (Oliver-Smith, 1996). Additionally, land in Niue is scarce and every effort must be made to explore sustainable and resilient methods for redeveloping sites destroyed by natural hazards and reducing the damaging effects of natural hazards on living environments, livelihood sources and public infrastructure. Reviewing the issues Niue faces and identifying sustainable methods and practices to replace current practices is urgently needed and essential for improving the resilience of local communities and for ensuring a sustainable future for a small island nation which is currently under serious threat.

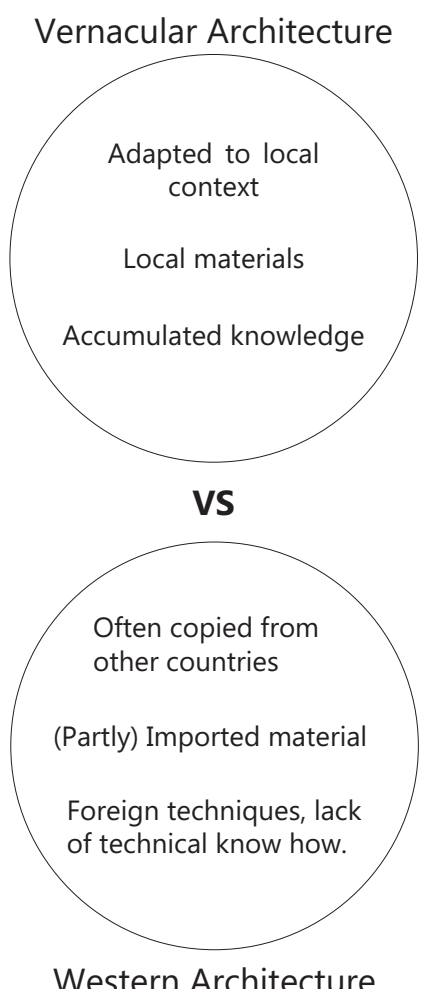

Vernacular Architecture and its Role on Contextual Studies 

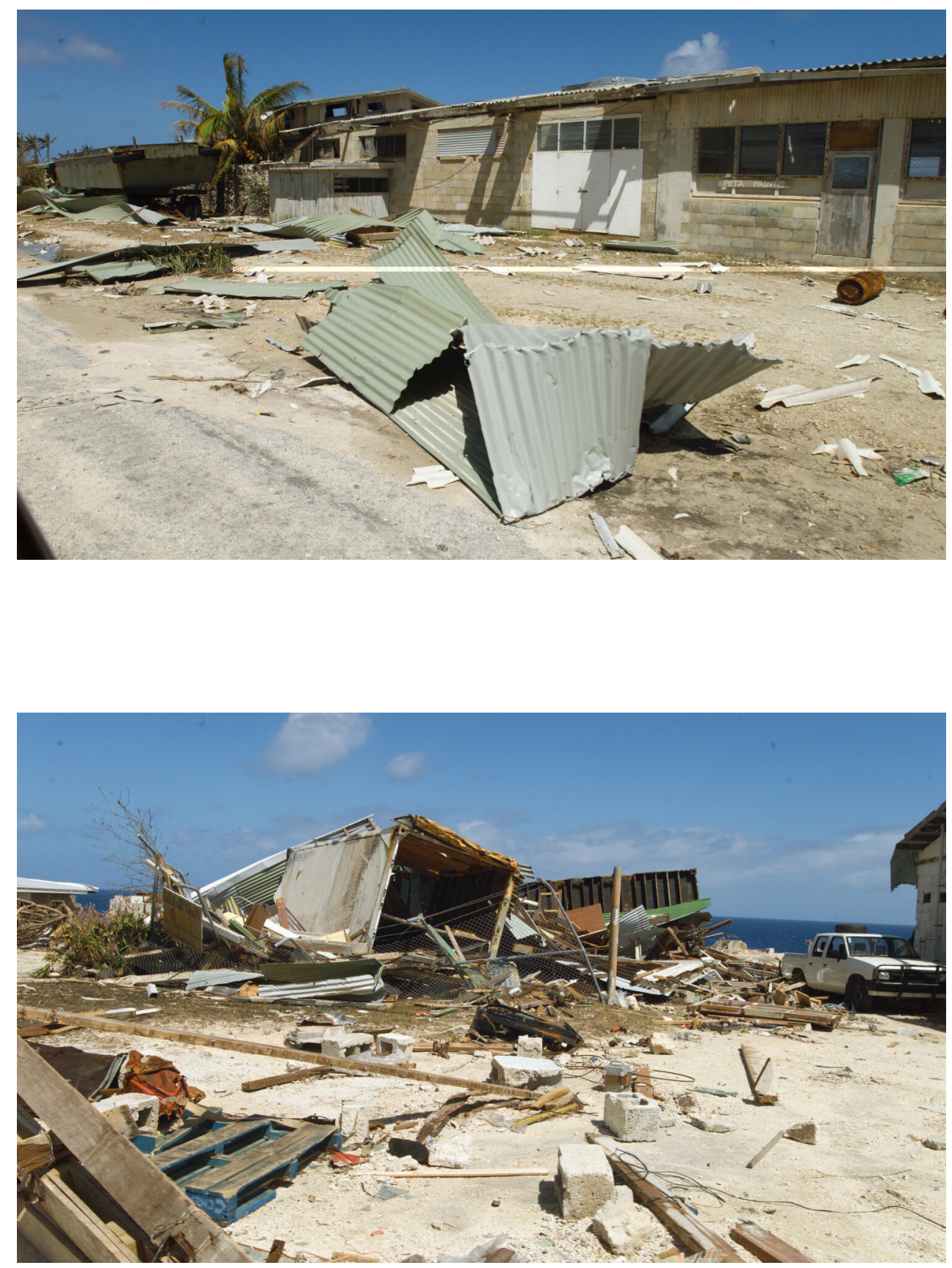

Figure 17. Photo of ripped corrugated roof in Amanau

Figure 18. Piles of destroyed construction material in Alofi 


\subsection{Architectural Identity}

Architectural identity refers to an intangible relationship between architecture and culture. It is the manifestation of a culture in a physical built form but it is also seen as the relationship between culture and space. Where the space occupied directly reflects the cultural practice of a place. (Sheida, 2004). 
The literature confirms the domination of western knowledge and practices in architecture or rather the complete subjugation of knowledge that does not emanate from the west. As critiqued by (Schnoor, 2016, p.286), "In these decades, architecture has tended towards a ubiquitous modernism without reflection of regional culture." Taylor and Conner (2014) in their popular work on the South Pacific contends that Pacific vernacular architecture and structures emanating from these should be seen as an alternative to Westernized built form. Their ideas render strong support for the development, and recognition of a distinct architectural identity for the Pacific and the countries making up Pacific nations. The focus and motivation for the development of an ethnic or national architectural identity has emanated mainly due to the invasive nature whereby western knowledge has been superimposed on others including Pacific nations- these critiques provided by numerous scholars highlight the essence of developing country specific architectural identity. Architectural identity refers to an intangible relationship between architecture and culture (Sheida, 2004). It is the manifestation of a culture in a physical built form, but it is also seen as the relationship between culture and space where the space occupied directly reflects the cultural practice of a place. Both these aspects contribute to the architectural identity of a place.

Developing a national identity can be problematic as there are multiple factors that need to be considered. Designers therefore may give weight to different factors and may exhibit bias depending on their own predispositions. Referring to the case in Bali, Diasana Putra, Lozanovska, and Fuller (2015) pointed out that in the construction of houses for tourists, the developments impacted on 3 aspects- the setting, spaces and forms of the house- that are components of an architectural identity. Tran (n.d.) argues that architectural identity is not static. Likewise, Mahgoub (2007) posits that "cultural identity is a meaning making process, multiple identities exist at the same time and transforms from one state to another adjusting to external pressures and circumstances" (p.70). However, despite these, insights by the great master builder Frank Lloyd Wright offer useful insights and guidance: his philosophy is relevant with the aspiration of the masses, concerned with human values and emphasizes social culture in each of his design. Wright's ideology and principles include the understanding of ornamental elements, the usage of materials, local expression and style compositions and the designing of space articulation and form with regional appearance. These in essence can offer a useful guide necessary to create a national architecture identity. 
TThe current architecture and built environment in Niue are dominated and heavily influenced by western methods. From residential, churches, community halls and large public infrastructures, all these buildings have strong characteristics of westernize methods of building. In order to begin to understand what the true characteristics and identity Niuean architecture is, this section will take a step back further to the post Christianization and colonization period to try and define and pin down what Niuean architecture is. This is important because pre-Christianity strips away the influence of westernize methods. The current issue with looking beyond pre-Christianity period is the lack of literature and local knowledge that has been recorded on this topic. Therefore, an interview-based method with the elders was employed to begin to understand these early accounts. This will be achieved through semi structured interviews with key informantsdrawing from the rich cultural knowledge and expertise of matuas (elderly male and female) in the Niue community, and also archival records from the Government of Niue.

Architectural identity of Niue can be understood in two aspects:

\section{Relationship between culture and space.}

According to the elders, settlements way of living was greatly influenced by warfare and the harsh environmental conditions. Each settlement would stay in Taues (protected fort like the function of the $\mathrm{Pa}$ in traditional Maori society) which consisted of caves or safe well-hidden flat areas of the land during times of warfare and cyclone seasons.

At other times, locals would travel like nomads around island in search of place to gather and hunt for food. An area will then be chosen based on the following criteria: abundance of crops, rich hunting grounds, natural shelters, and safe from potential enemies. A chosen area would be cultivated and used until resources have run low or in the worst case, invasion or encroachment from incoming enemies then the settlement would be moved as residents move on to the next area.

From historical accounts (Loeb, 1971; Smith, 1983) it is evident that the landscape, cultural, and natural environment plays a big role in how Niuean's occupied space. The way of living was a means of survival. To get a better understanding of this way of occupying landscape, and space as an architectural construct, this research examined the Aboriginal culture and traditional architecture. According to the accounts by Memmott, 2005), Aboriginal vernacular architecture is known for the close and intimate relationship that people have with the landscape. Australia with its vast planes of fields, the Aboriginal were a known as nomadic people, foraging the vast planes in hunt 
of food. They would have "little time to invest in the construction of shelters, and the natural qualities of the chosen camping site are of paramount importance in enhancing residential comfort" (Memmott, 2005, p. 5).

The landscape in a sense was the built environment that the Aboriginal people occupied. As noted by Memmott, "the architecture was supplemented by a highly structured use of space as well as a complex geography of place (Memmott, 2005) and there was preference for open living with minimal structures. "Society [had] a certain spatial logic" whilst space [had] a certain social logic to it" (Memmott, 2005)

\section{Similarities}

- Nomadic people

- Temporary residence

- Intimate relationship with the landscape

- Spatially the landscape was the connection between Architecture and culture

- The natural environment was the architecture and it provided space for the occupants to hunt, gather and take shelter

- Open living with minimal structures were preferred.
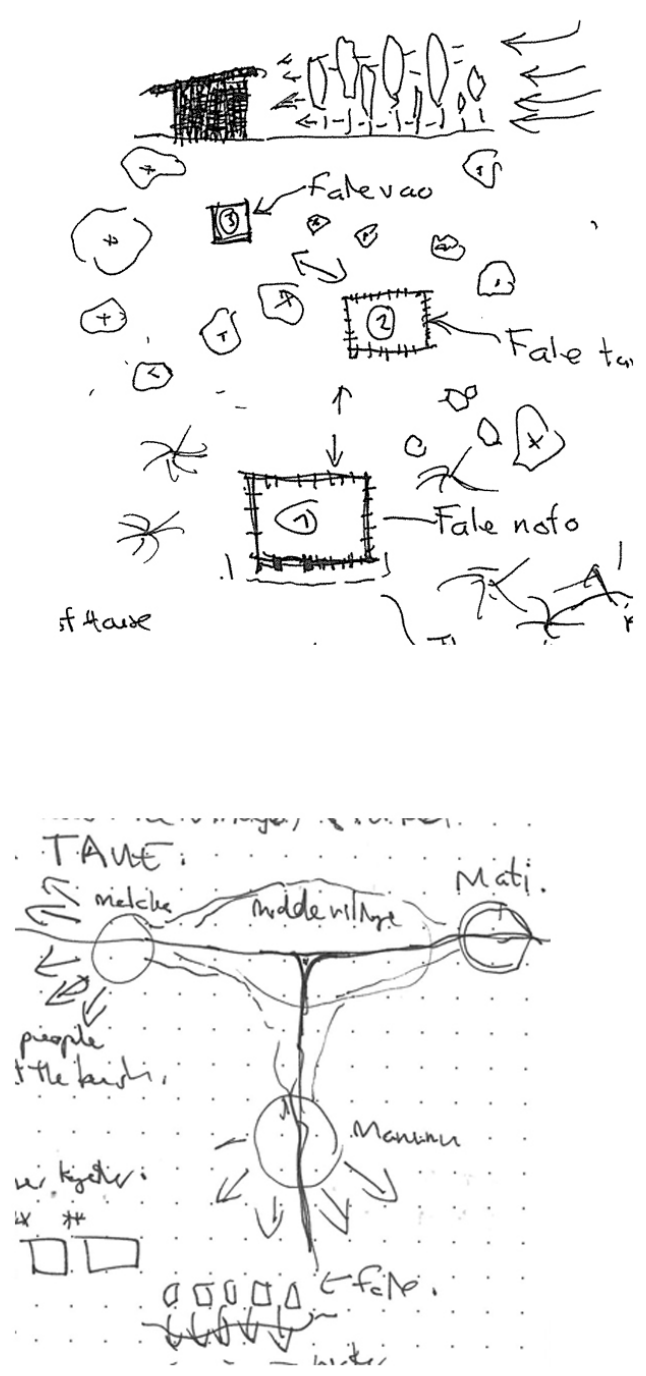


\section{Relationship between culture and a built} form.

According to the elders, there was no built form that reflected the true essence of Niuean architecture, and pointed out that caves were the main form of shelter as it was a natural resource that was readily available, and which protected people from cyclones and other forces of nature. Therefore, to gain a better understanding of the direction of what Niuean architecture is as a built form, the research looks at literature on Pacific architecture to start to shape and form an idea of a built form that is shaped by the culture and context of a place. A study done by Austin provides some clear direction as it identifies what Pacific architecture signifies and symbolizes as a built form (Austin, 2001).

\section{Characteristics of Architecture on the Islands}

- Architecture of spaces open to the sky rather than closed room,

- Sticks and grass as against mud and stones,

- Poles against walls,

- of single cell pavilions rather than labyrinth complexes,

- Buildings raised in the air on stilts rather than sunk in the ground,

- Temporariness as against permanence,

- Tension and weaving rather than compression and buildings,

- Outdoor existence and ocean voyaging as against life grounded in the land. 
It is clear from the literature examined that the architectural identity of a place is shaped by multiple factors with culture playing an important role. To begin to understand an architectural identity of a place, one must understand the role of culture, climatic conditions, and the social construct of a place. As pointed out by Mahgoub (2007) in the case of Kuwaiti, the construction of identity is constantly shaped by the current struggle to be modern and at the same time the desire to return to its roots. A degree of open mindedness is therefore required given the nature of multiple variables at play. Countries including Niue when constructing its architectural identity needs to respond simultaneously to global and economic imperatives including local social and environmental factors while at the same time hold on to cultural values and beliefs pertinent to their national identity. 


\subsection{Global context.}

To overcome the problems Niue faces it is essential to draws from lessons learnt from the wide range of studies conducted in the Asia Pacific region following recent natural disasters as the 2004 Asian Tsunami, 2008 Wenchuan Earthquake, China, 2008 Cyclone Nargis, Myanmar, 2010 and 2011 Christchurch Earthquakes, New Zealand, 2011 East Japan Earthquake, 2013 Typhoon Haiyan, Philippines, 2016 Cyclone Winston, Fiji, to name a few. The vast body of research that has emerged in recent years related to disaster preparedness, recovery and reconstruction globally (Hallegatte, 2009), in Asia (Johnson, 2016), (Ly, Birkeland, \& Demirbilek, 2010), (World Bank, 2006), (Sanghi, 2010); and the Pacific (Lyons, 2010 ) World Bank publications (Anderson, 2012), (Roberts, 2008), (McKay, 2018); and Cayford (2017), and Feaunati (2014) in the case of Samoa, provide some valuable insight on reconstruction processes including post disaster governance structures and governance issues, funding and donor organizations involvement, disaster preparedness, and methods for building community resilience. Some key lessons learnt from the extensive reconstruction efforts following the disasters shed light on 
the top down and bottom up approaches to rebuilding (UNISDR, 2015), and (Daly, 2016). The multiple actors ranging from governments to local councils, local and international donors, religious organizations and insurance companies involved in rebuilding processes is important and the consequences of this on the speed and success of recovery efforts (UNISDR, 2015). In addition, they highlight the impact of the lack of coordination across various organizations and at various levels, inequality in distribution of funds and development benefits, non-accountability and unsuitability of development projects to culture and context, the disempowerment of poor communities through these development endeavors. They also highlight the significance of being prepared for disaster and having in place well considered disaster risk reduction and recovery strategies as well as rebuilding strategies (Daly, 2016). The Sendai Framework for Disaster Risk Reduction 2015-2030, the outcomes of the United Nations World Conference on Disaster Reduction in Sendai in 2015 and these studies reinforce the need to act 'with a renewed sense of urgency within the context of sustainable development and poverty eradication, and to integrate, as appropriate, both disaster risk reduction and the building of resilience into policies, plans, programs and budgets at all levels and to consider both within relevant frameworks' (Hardy, 2010).

The next page identifies some key lessons for consideration in the planning for future disaster preparedness and recovery in Niue. This is not an exhaustive list but key points identified for the purpose of devising a sustainable solution for a resilient architecture that could help address or reduce the risk of natural hazards that may affect Niue from developing into disastrous events, prevent the loss of life, and minimize damage to property and livelihood sources. The intention of this table is to ensure suitability of the development projects and strategies for Niue and thereby contribute to building the resilience of local people, local economy and infrastructure, and local environments. The main aim of development projects in Niue should be deliver outcomes that benefit locals, preserve the integrity of the natural environment, and build local capacity to contribute to the sustainable development of Niue. To achieve the above, it is critical that the indiscriminate transplanting of western knowledge and methods and technologies should be avoided at all costs. 


\section{Key Lessons}

- Funding: high dependence on NZ, international governments, donor organizations and private insurance for recovery after disaster due to underdeveloped capacity and opportunities for economic growth and food production

- Relocation: no ideal place to relocate to after a disaster other than to NZ but this can only cause severe negative consequence to Niue's economy and future existence as a sovereign nation

- Top down and westernized approaches: likely to be imposed in situations of external funding through bureaucratic processes, however these may not align with local aims and needs

- Imported materials, methods and skills: Very costly and does not build capacity and resilience at local levels

\section{Key Actions}

- Local engagement: communities to take ownership of all future development endeavour at various levels and capacities to ensure suitability and sustainability

- Positive contribution to the local economy, socio-culture and environment must be demonstrated by all development projects

- Localized knowledge: clear understanding of local environments, capacity, traditions, local resilience structures, suitability of new technology and materials to Niuean culture and context to be demonstrated by all actors involved in the planning and implementation of development projects

- Tried, tested and adapted: technologies, methods and materials tested in similar environments conditions and adapt to suited local conditions. 
RED A C T E D

RE D A C T E D 


\subsection{Cyclone Design Principles}

This section analyses key cyclone design principles that should be embedded into design and construction for cyclone prone environments. Given the increase in the frequency and severity of tropical cyclones in the Pacific including Niue, future design and construction of buildings must be responsive to these changes. Ankush (2007) examines critical failures of buildings and key lesson learnt; underlying principles to combat these failures are proposed under 3 categories: site consideration, design consideration, and construction consideration. 


\section{Site Consideration}

- Choose area where there is natural buffer minimizing the full cyclonic force.

- When building on hilly regions, avoid construction along the ridges.

- Avoid natural long and narrow valleys.

- When building on coastal area, locate building above the likely inundation level.

- If on flat land, construction should be on stilts.

\section{Design Consideration}

- A simple square building is best

- Any other forms, corners require additional strengthening

- Avoid row planning when building a cluster of buildings

- Cluster arrangement avoids strong winds

\section{Construction Consideration}

- Hip roofs at 25 to 40 degrees are best as they are more cyclone resistant,

- Avoid flat roofs,

- Minimize the use of an overhang,

- Openings needs to be properly secured,

- Ensure extra bracing on roof and walls,

- Deeper foundation required for pile foundations. 


\subsection{Key lessons and findings}

\section{Summary}

Studying and understanding the vernacular architecture of a place is important. From the literature examined on vernacular architecture, it highlights its centrality in shaping, informing, and influencing the built environment of a country. It argues on the importance of placing context and embedding these at all phases of a project. Context put together, establishes a framework and sets of principles and values that then form the architectural identity of a country. Through exploring the literature, and the case study, the findings can be used to develop Niue's architectural identity. Lessons learnt from the Pacific and Asia also provide some insights into understanding vernacular architecture and its use in ensuring more responsive design necessary to enhance architectural resilience (Cayford, 2017). The combined use of vernacular architecture and key design principles for cyclones is crucial in future construction if buildings and infrastructures are to withstand the vicious forces of tropical cyclones while at the same time meet contextual requirements. This includes the following:
1. Identify, improve and build local capacity.

2. Improve and diversify livelihood sources.

3. Safeguard traditions and traditional knowledge. 4. Utilize traditional knowledge effectively to improve living environments.

4. Develop building technologies to suit local conditions, skills and capacity.

5. Adapt modern and proven technologies, methods and systems to local conditions.

6. Utilize traditional craft (e.g. weaving, lashing) to improve design and construction.

7. Grow and source building materials locally.

In the case of Niue, it is important to note that donor partners play an influential role in the design environment- it is crucial that they transition from a rather imperial to collaborative attitudes if they are to make sustainable gains in their pursuits.

However, despite the lessons learnt, the current lack of research on vernacular architecture in the case of Niue highlights the importance of this research. Development and use of this knowledge can then be used to inform the approach to planning, designing and construction that consider the local realities or lived experiences and expectations of the people in which the built environment is situated. 


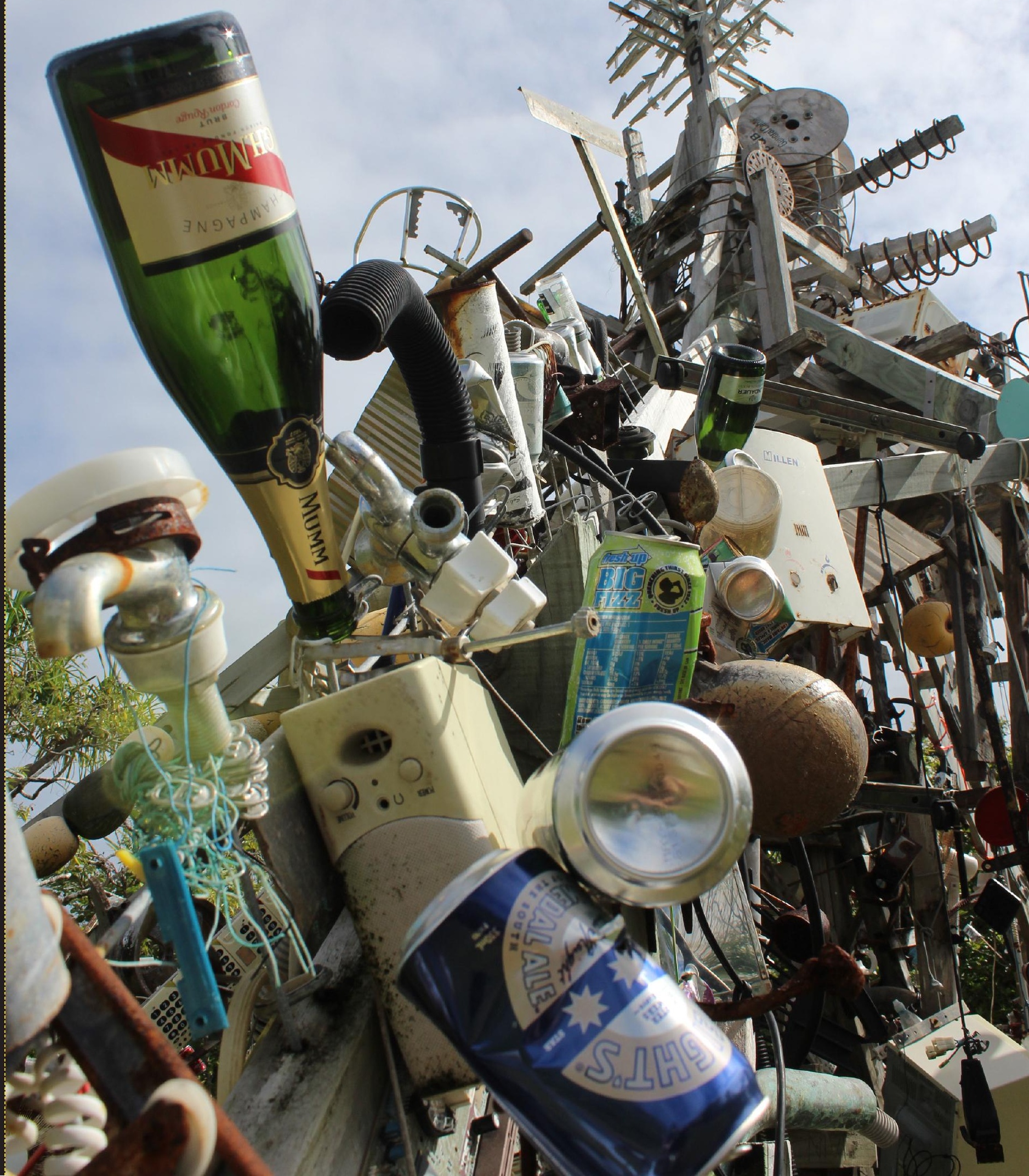




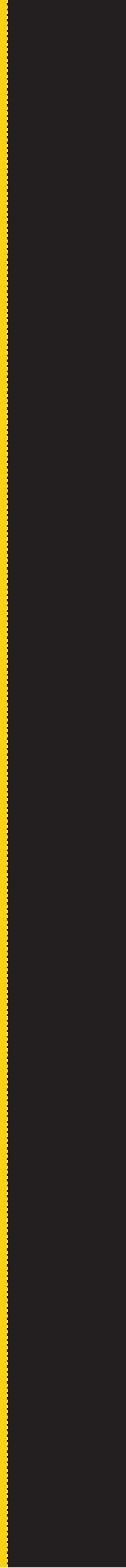


3. Case Studies 


\section{CHAPTER OVERVIEW}

While the literature review is important to frame the design research, it is also imperative to look at relevant existing examples of architectural design approaches and strategies, from the design phase to construction. This is pertinent in order to ensure that the research is grounded in the real lives of real people who will be impacted upon and influenced by resultant architecture. The following chosen case studies have been separated into two categories, urban scale and architectural scale. The urban scale case studies are chosen to address of the focus on designing for resilience and sustainability. Designing for resilience is vital for any coastal area in Niue, as it ensures a safer and more resilient design for future Tsunami-like waves and Cyclonic winds. Designing for sustainability is also imperative to ensure the survival of the rural and fragile community such as Niue.

The architectural scale case studies focus on precedents that have dealt with cyclone resistant structures in the Pacific, architectural sustainability and architectural identity and culture.

These case studies were specifically chosen to showcase innovative methods of designing for a specific context: disaster resilience, sustainability, and community. They also highlight the implications and challenges of architectural design suitable for small, rural communities, like Niue. 


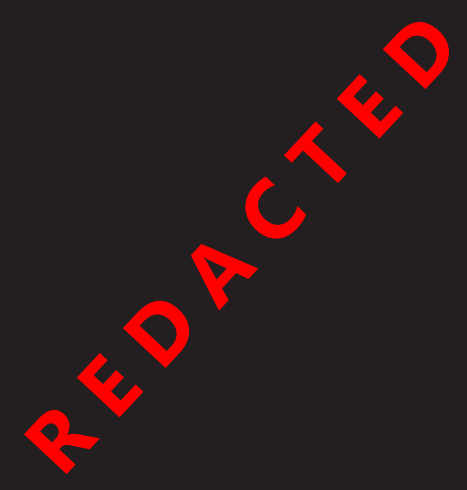




\section{RE D A C T E D}

\subsection{Urban Scale}

\subsubsection{Urban Resilience}

Project: Post-Tsunami Sustainable Reconstruction Plan for Constit ucion

Location: Constit ucion, Chile

Architects: Tironi Asociados, Arup, Fundacion Chile Marketek, Universidad de Talca, ELEMENTAL, Jose Luis Rissetti 


\section{RE D A C T E D}

\section{The Project}

The city of Constitucion (Chile) was hit by an 8.8 magnitude earthquake in 2010. The natural disaster cause $12 \mathrm{~m}$ tsunami waves that destroyed $80 \%$ of the city. The small city suffered damages in all levels, from public infrastructures, to failure of essential services such as water supply and electricity and worst of all over 100 people passed away during the disasters.

The design that the architects proposed was to reactivate the coastal area by replanting a forest.This acted first as a flood mitigation measure, to control flooding in certain areas of the city. Secondly, it reestablished the connection of the people to the river by introducing new public spaces. Thirdly, and most importantly, the forest is a natural tsunami barrier for the inner city, designed to create friction and dissipate the energy of the first wave of any future tsunami's, such that any water that does get inland will be of lower energy and cause less damage to infrastructure and disruption to people. (Post Tsunami, 2016)

"A forest, on the other hand, doesn't try to resist the power of a tsunami. It dissipates the impact instead. In the face of geographical threats, you have to find geographical solutions." Architect, Alejandro Aravena

\section{Advantages for Research}

- A more greener and sustainable solution.

- The solution was not only to create resilience for the people, but it also focused on the social and cultural issues of the area.

- The solution was self-sustainable, cost-efficient and it enhance the identity of the coastal area.

- The design process highlights the importance of involving all the stakeholders in the design process to ensure a fairer and a community orientated solution.

\section{Disadvantages for Research}

- The feasibility of the forest as a natural barrier can only be tested through another Tsunami which could be very unpredictable on judging if the design works effectively or not.

- Depending on tree selection, the re-growth of trees after a tsunami may be a long and tedious process. 


\section{RE D A C T E D}

\subsubsection{Urban Sustainability}

Project: Regen Village

Location: Almere, The Netherlands

Architects: EFFEKT 


\section{RE D A C T E D}

\section{The Project}

Effekt, an architectural firm, has proposed a Regen village concept where it is a self-sustainable village that minimises the way people live. The proposal focuses on two aspects that a self-sustaining community needs: agriculture and energy production. The agricultural elements include food production through the introduction of greenhouse, vertical farms, hydroponic systems, aquaponic system and livestock all working in tandem to create a selfsustainable cycle. The energy production elements include systems such as biogas, biomass, wind turbines and solar as a main energy source. All these systems are interconnected to a smart grid which powers the village all year round.(Frearson, 2016)

\section{Advantages for Research}

- The interconnected approach of energy production and agriculture working together hand in hand to create the self sustainable system.

- Its ability to adapt and use traditional methods of agriculture and energy production through the introduction of new technologies that can drive sustainability to new levels.

- The layout of the village is informed by the self-sustainable system and intended to create a community, where there are lots of shared (communal) space.

\section{Disadvantages for Research}

- The concept may be considered as unrealistic, and it is only suited for colder environments.

- The systems and technology may be costprohibitive (too expensive) and high-maintenance in the long term. Skilled workers would be required to maintain the new technologies in the village.

- The glass house concept won't last in Niue as its too fragile for the harsh conditions of Niue. 


\section{RE D A C T E D}

\subsubsection{Architectural Sustainability}

Project: Green School, Bali

Location: Badung, Mengwi, Indonesia

Architects: PT Bambu, Ibuku 


\section{RED A C T E D}

\section{The Project}

The Green school in Bali changed the way Bamboo was seen as a building material. The way the design pushed the use of bamboo to new limits, with each form and curve unique to each bamboo pole, was revolutionary. It re-created a new image of bamboo as a sustainable building material option.

The founding architects understood the fast growth of bamboo and wanted to involve the community in the process. They did this by asking and allowing the Balinese community to grow the bamboo that would be used for the construction of the school, and paid for the labour and materials needed by the community to grow and harvest it. This gave the community a local income.

The architects understood the importance of involving local craftsmans, carpenters, weavers, master carvers of the local Balinese community in order to create a truly unique architecture.

\section{Advantages for Research}

- The advantages of this case study is the involvement of the local community throughout the design and building process,

- The use of local craftsman throughout the construction process,

- The use of bamboo as a viable sustainable building materials,

- The unique design outcome of green school Bali and how it created a new Architectural Identity for the area.

\section{Disadvantages for Research}

- The design itself does not consider cyclone resistant structural solutions.

- The idea of using a bamboo as a building material in Niue can only be tested through trial and error to see if it the species required for construction grows. 


\subsubsection{Vernacular Architecture \& Resilience}

Project: Traditional Samoan Fale, traditional Vanuatu Tamma, traditional

Fijian Bure

Location: Samoa, Vanuatu, Fiji.

Architects: Unknown. 


\section{RE D A C T E D}

\section{Samoan Fale}

A Fale has a steep rounded roof with a lot of roof ceiling space. The roof structure is woven, bended in tension, and tied to the main core structure which includes heavy timber posts. The roof is all tied down to the supporting members on the outside to form the overall structure. The Samoan fale is an impressive building, dominant in scale and stature, and known to have withstand the forces of strong tropical cyclones

\section{Fiji Bure}

The Fijian Bure has a steep and curved oval roof formed with the roof structure bent in tension and tied together to the main structural columns that grounds the building. There are only a few small openings to the Bure, and the entry to the building is low, but once inside, there is a large and generous space for people to reside.

\section{Vanuatu Tamma}

The Vanuatu Tamma is smaller in scale but is one of the most effective and secure ways of building a house to withstand the forces of the wind and rain during a Tropical Cyclone. The roof structure uses timber poles that are naturally curved, supported by the middle of the ridge beam. It is then tied together with a collar tie to stop the roof from snapping out. The roof structure itself is grounded by planting it into the ground with everything tied together. The entry to the house is also made small and low to prevent uplift.

\section{Advantages for Research}

- Each building has been uniquely designed to withstand the cyclone but also to fit in with the local environment and meet the social and cultural needs of a community.

- The designs shows the underlying key principles of designing to withstand cyclones.

- The study shows that its important to study the local context in terms of the neighbouring pacific to gain better understanding of cyclone resistant structures.

- Shows how vital understanding vernacular architecture is to create a better design outcome.

\section{Disadvantages for Research}

- The case studies shows only the traditional methods and design and it doesn't consider the more contemporary architecture as it is a new age. 


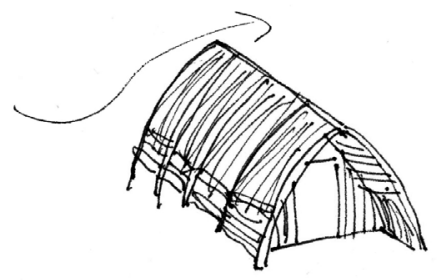

FORM
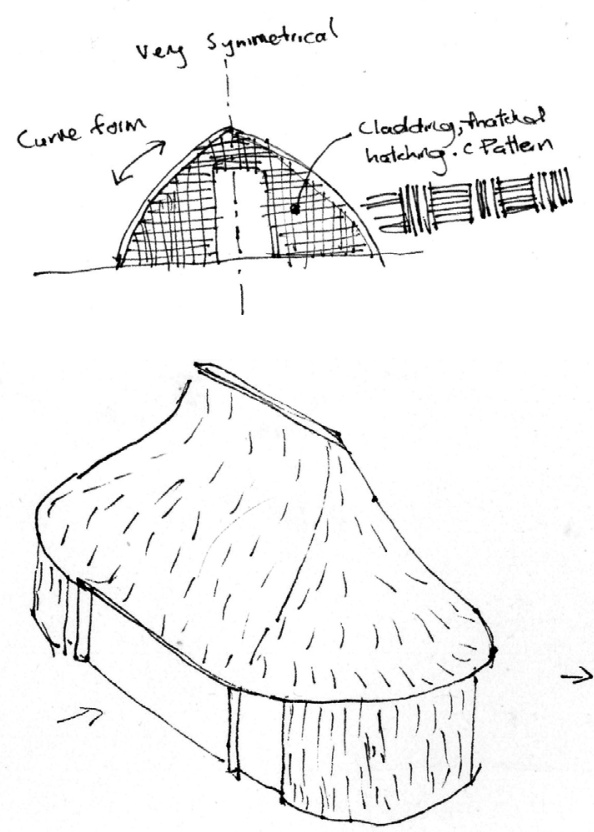

FORM

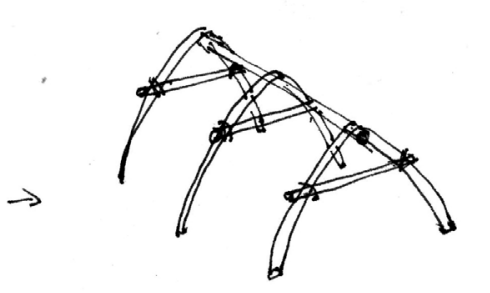

S TRUCTURE

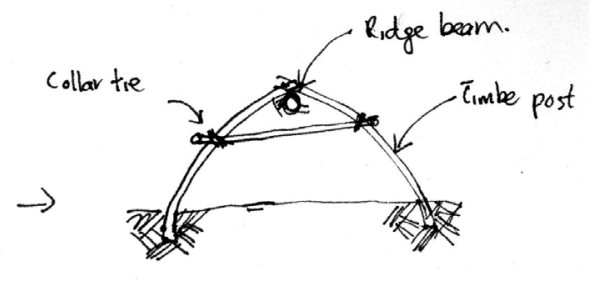

SECTION
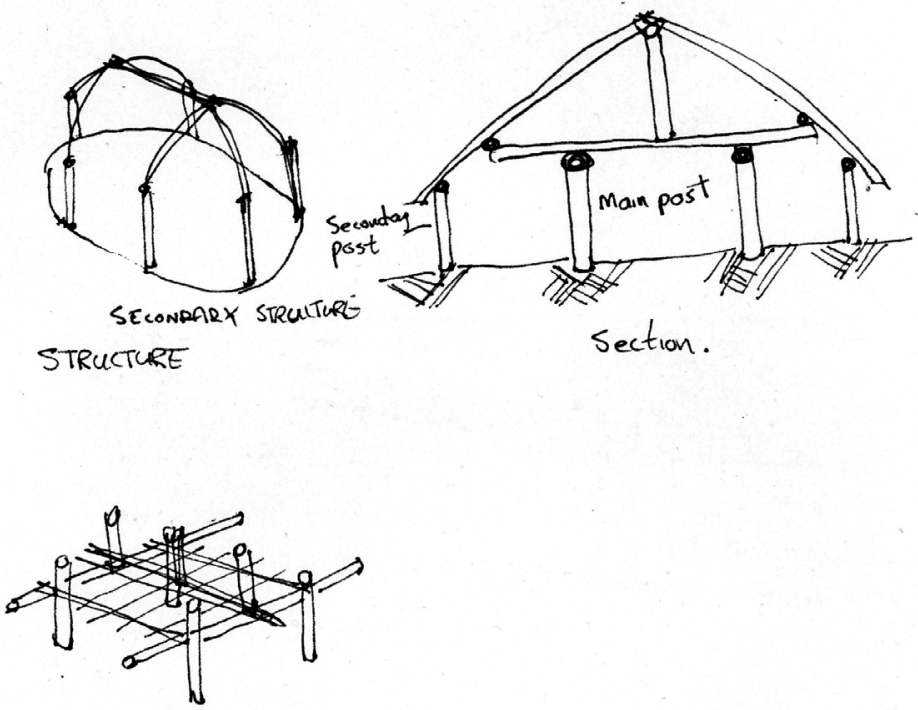

Main Structure

Firan Bure.

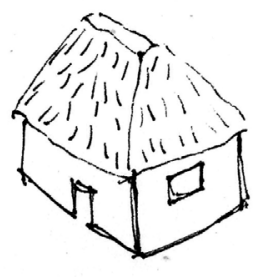

Fon....

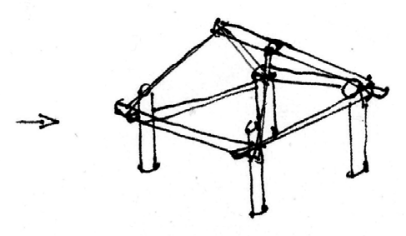

structure

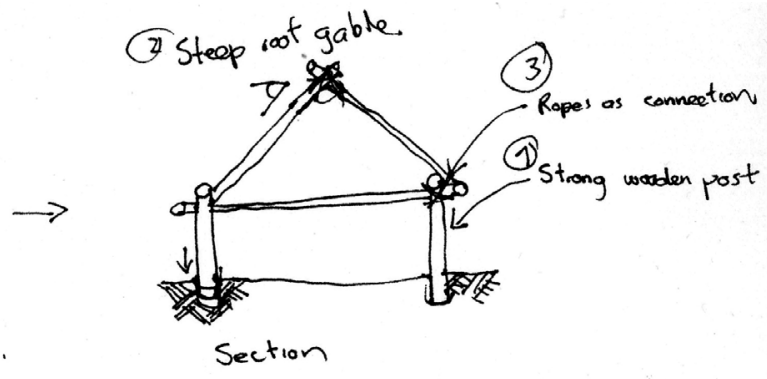

Figure 35. Study of the structural qualities of Vanuatu Tamma* (Top)

Figure 36. Study of the structural qualities of Fiji Bure* (below)

Figure 37. Study of the structural qualities of Samoa Fale* (Middle and Right) 


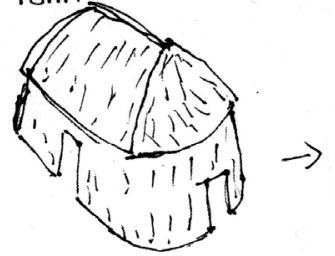

Form

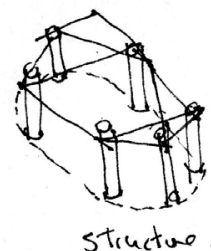

structue

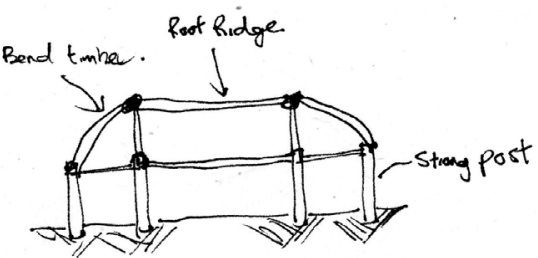

\section{Key Learnings}

- The use of curved roof are key in deflecting and minimizing the damage caused by the full force of the cyclonic winds.

- High-pitched roof also allows the wind to flow around the structure of the building

- The method of weaving the secondary structure together allows the building to breath, to bend, and mould to the cyclonic winds whilst still maintaining its structural integrity.

- Tying the structure together allows the important structural joints to move, twist and react to the force of the wind while still maintaining its structural integrity.

- Connection to the ground is vital in grounding the building. As shown through the examples, there are a lot of connection back to the ground.

- Low openings are important to avoid uplift in the structure of a building during a cyclone.

- Allowing some of the wind's force to flow through the building is important as it equalizes the pressure which decreases the likelihood of the structure being blown away.

- The cladding such as roof thatching is to be made of easily replaceable materials such as coconut leaves, sugarcane leaves as it creates less debris and is easily replaceable. 


\section{RE D A C T E D}

\subsubsection{Architectural Identity}

Project: Brambuk Cultural Centre

Location: Halls Gap, Australia

Architects: Gregory Burgess Pty Ltd 


\section{RE D A C T E D}

\section{The Project}

Aboriginal Architecture for centuries was related • more to the vast landscape rather than a built form. • The colonisation of Aboriginal land by Britain lead to a misunderstanding that aboriginal people had • a lack of architectural identity. Brambuk Cultural Centre was one of the first projects to acknowledge and use Aboriginal culture to create an architecture that reflects the culture and the landscape. Described by the architects, the centre's design is founded in both the traditional Aboriginal shelter (stone circles of the western district) and in Aboriginal art. The plan is formed out of five rough circles which represent the five Koori community groups which constitute the client.

\section{Advantages for Research}

Community engagement in the design process. The design is unique and reflects the culture and the local context of the place and its people.

- The use of local material as the driver for the design and introduced materials working around the narrative and the local materials.

Utilises passive design principles through a large umbrella roof structure that acts as shelter and openings through the structure to allow for crossventilation.

\section{Disadvantages for Research}

- The architecture does not consider cyclonic conditions.

- The cultural centre is a western approach of manifesting an cultural idea.

- The involvement of the indigenous people stops at the design phase.

- The architects who design the center are of western background which questions the legitimacy of the design and its reflection of culture. 


\section{CASE STUDY SUMMARY}

\section{Urban Case Studies: Key Learnings and} Actions

- A more ecological approach is key to creating a sustainable and resilient response to small Islands such as Niue.

- Collaborations between different stakeholders, government organisation, NGO and community is vital in the reconstruction process of a place after a disaster to ensure a more resilient and sustainable response.

- The advancement of technology means that there are viable sustainable options that can be used in Niue in order for Niue to become more sustainable.

- A resilient response also needs to consider the social and cultural needs of the community to ensure community sustainability and resilience are met.

\section{Architectural Case Studies: Key Learnings and Actions}

- Vernacular architecture not only is locally suited for the community and culture, but it is also designed to withstand local climatic conditions and natural disasters.

- Pacific architecture highlights a clever adaptation and resilience to natural disasters and needs to be investigated more to understand its design principles and how it can be adapted and used in the contemporary context.

- Utilising local materials through the construction process is better for the community because it gives them a source of income, a sense of local empowerment, a more sustainable approach and a wellsuited design for the climate and the culture.

- Bamboo is the best viable and sustainable material for Niue and needs to be explored more as a viable building material.

- Involving the community in the design process and the construction process is vital as it gives them the power and ownership to build or rebuild during a disaster.

- Understanding the culture, the local context and people is important when designing for communities such as the Niuean people. 


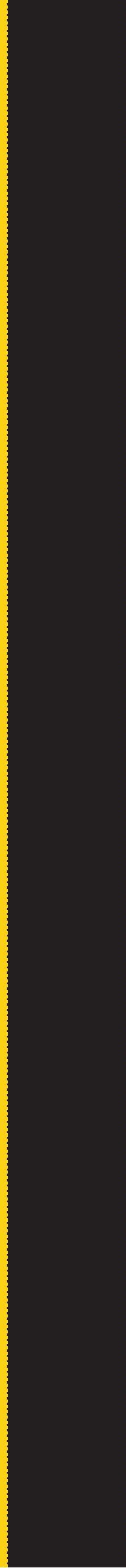


4. Local Context 


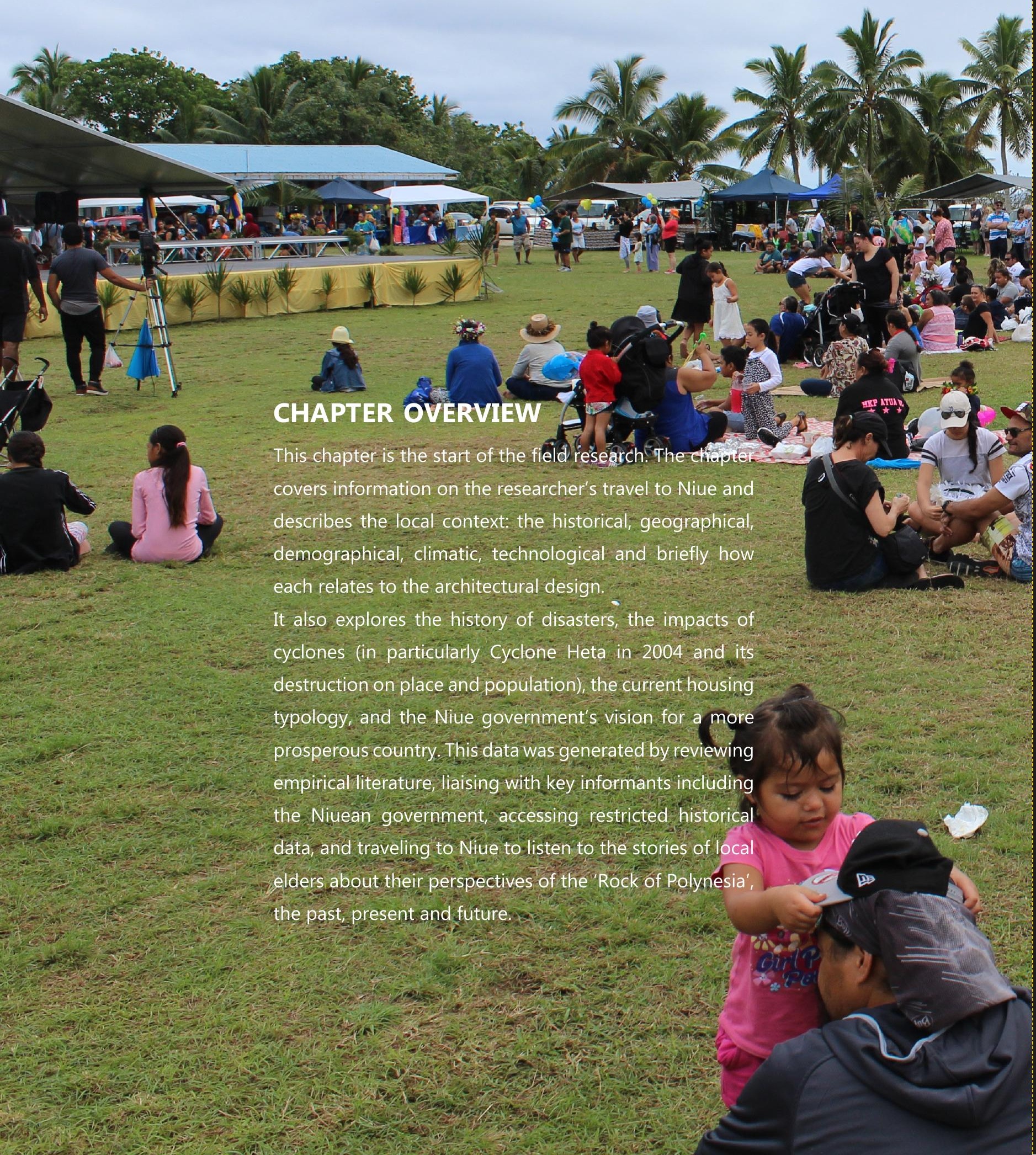



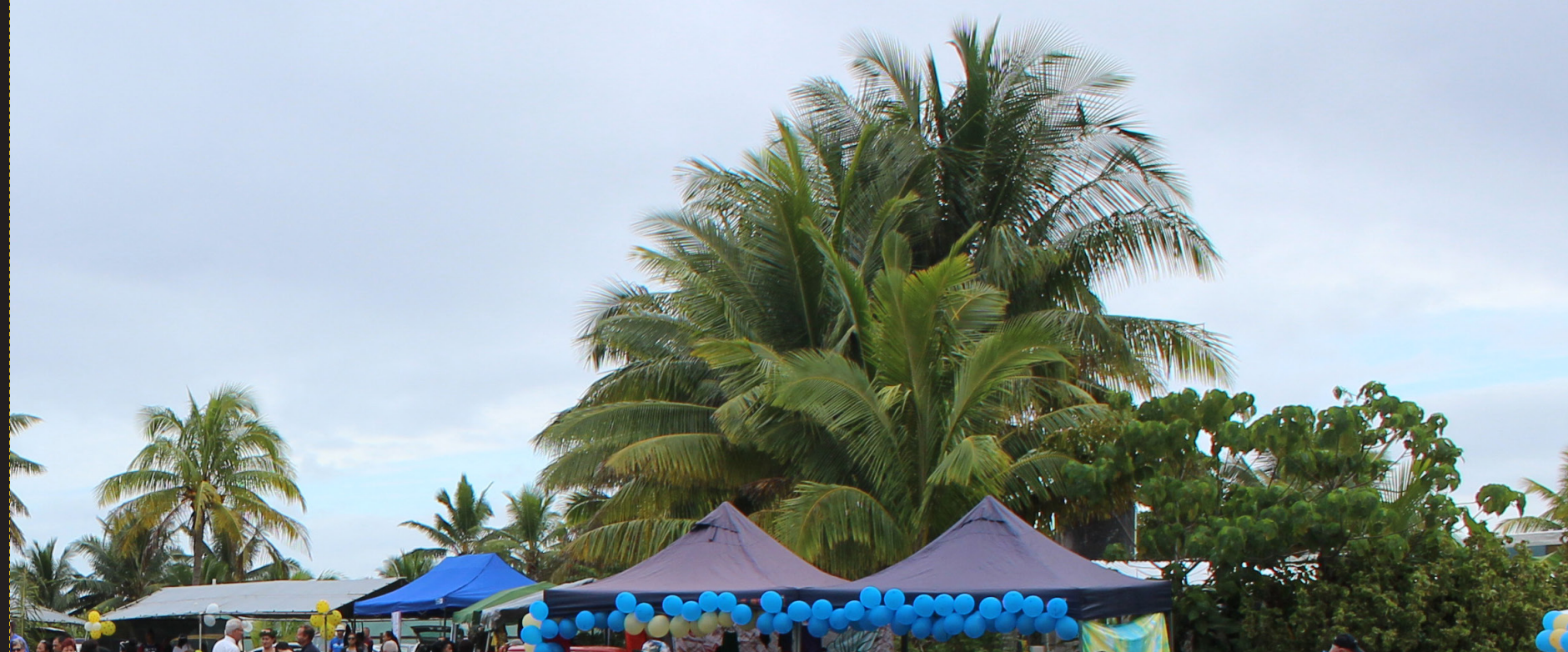
2)

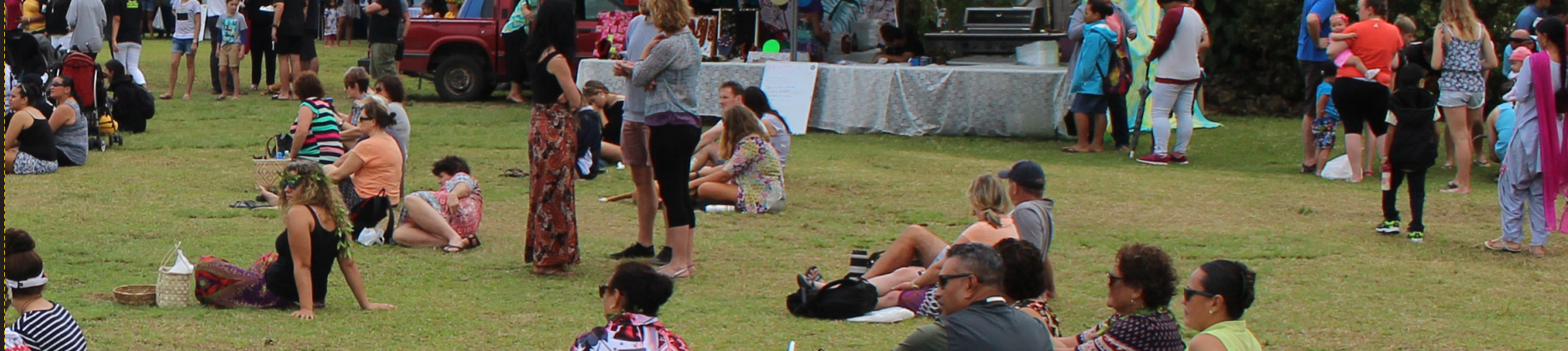

( )

a

ㄴ.
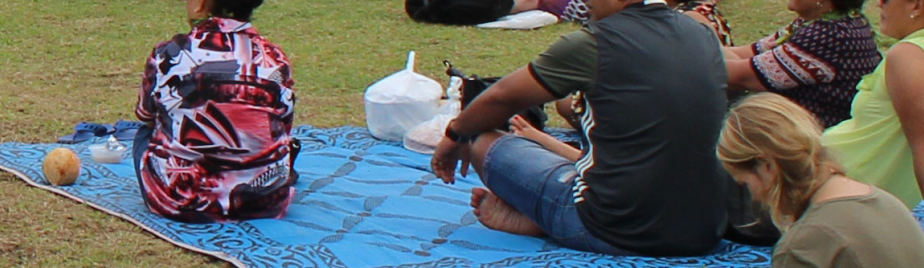


\subsubsection{Historical Context}

Niuean historical accounts is scant and are documented mainly by early European visitors. Migration as conveyed by oral traditions tells that Niueans originally comprised of early migrants from three Pacific Islands: Samoa, Tonga, and Pukapuka in the Cook Islands. This is reflected in the diverse linguistic patterns and cultural practices of the inhabitants. Once settled, the culture of the inhabitants was heavily shaped by warfare and kingship within the Island with a significant influence imposed from the island's harsh and rather unforgiving natural environment. The island was geographically divided into Tafiti (South) and Motu (North) when a 'Tafiti warrior murdered an individual from the Motu tribe' (Smith, 1902).

The culture of warfare which ravaged the island's inhabitants and the concept of "nonofo he pouli" (staying in the dark) all changed when the Reverend John Williams arrived in Niue in 1830 and took two Niuean men to Samoa and trained them to be missionaries (Loeb, 1926, p. 43). In 1846, Peniamina, one of the two Niuean men along with a Samoan missionary, Paulo, returned 
to Niue and introduced "the good news" namely Christianity, to the island and its people. The introduction of Christianity into Niue is noted as one of the most important occurrences in Niuean history and played a significant role in shaping Niue's identity (Chapman, 1982). Prior to Christianity, people lived in scattered communities with location influenced by proximity to family land for subsistence living and traditional hunting and fishing grounds vital for the sustenance and livelihood. The construction of the churches resulted in the internal migration of people from these scattered satellite communities to a centralized location establishing what is known today as the villages.
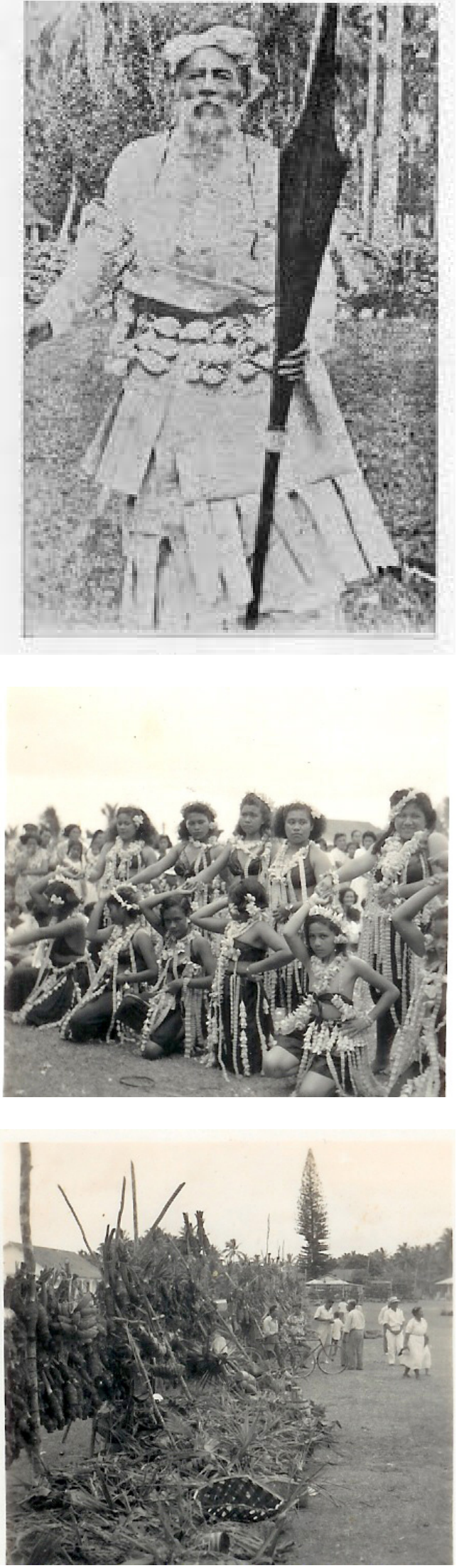

Figure 40. Alofi South show day in Niue* (Previous)

Figure 41. King Togea, Niue's third king (Top right)

Figure 42 Women of the village performing traditional Ta me (Middle right)

Figure 43. A traditional Galue for the village (Bottom right) 


\subsubsection{Geographical Context}

Known as the 'Rock of Polynesia' Niue is one of the largest raised coral atolls in the world with an area of 269 km2 (Change, 2006). Formed entirely of coral limestone with no lakes or rivers, fresh water can only be harvested through deep bore wells, and its soil is considered unsuitable for large scale cultivation of most varieties of crops (Change, 2006). Steep limestone cliffs lift Niue 24 $\mathrm{m}$ above sea level, and coral reefs form a nearcontinuous line around the island, with only one break in the West coast allowing fishing and transport vessel access in and out of the island. Niue's geographical location in the pacific region does nothing to ease the difficulties of inhabiting it; lying in the path of numerous natural weather events cyclones and droughts are regular occurrences causing havoc on the already fragile sustenance sources and living environments of the island's population (Change, 2006).

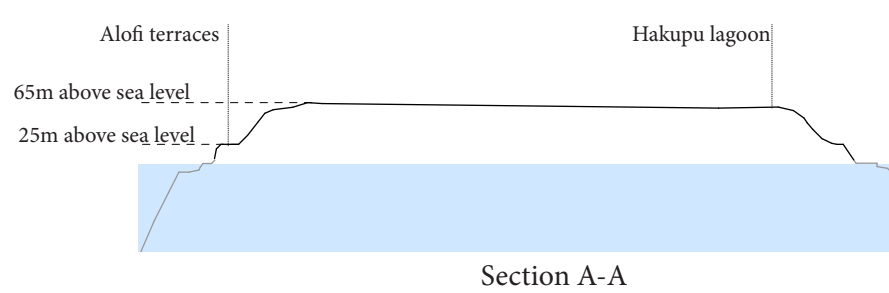

Top point

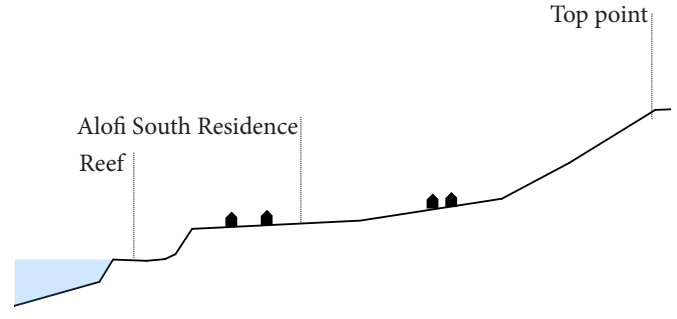


West Coast geopraphy
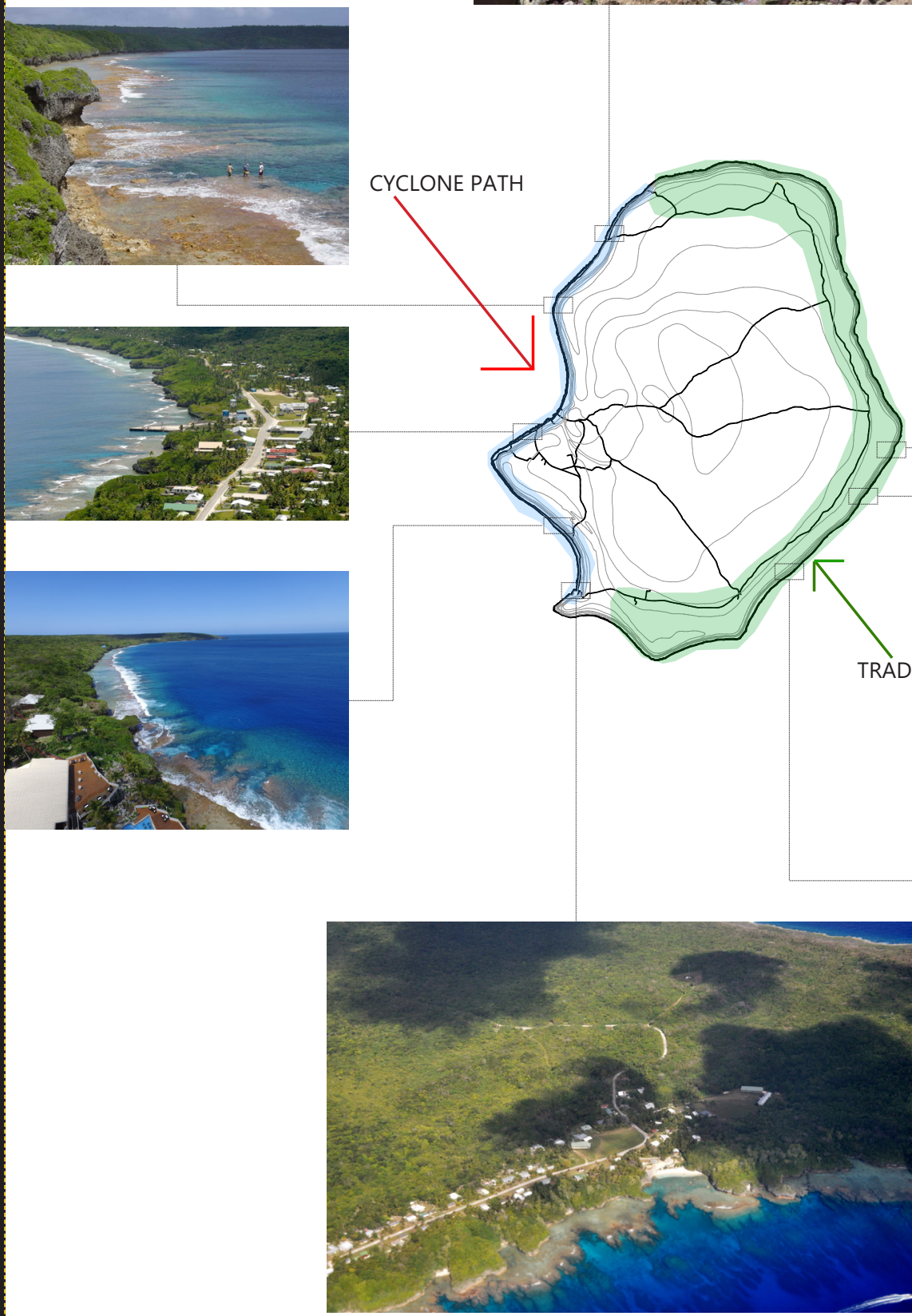

East Coast
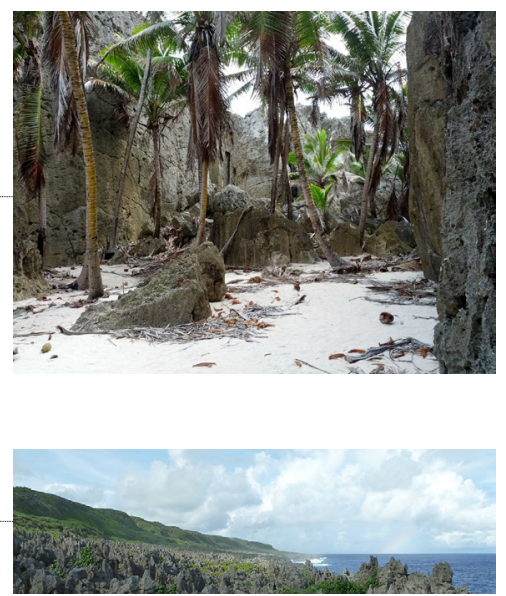

TRADE WINDS

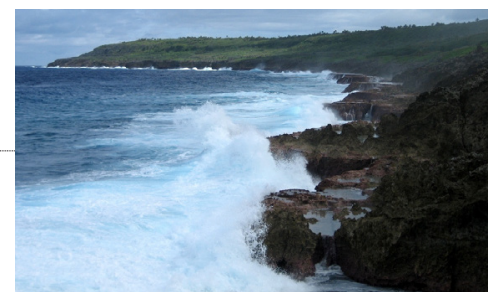




\subsubsection{Current Demographic}

Niue currently has a population of 1,700 (Statistics Niue, 2018) with the population making marginal increases contrary to predictions by many of a dying nation. The island has a very young population with the majority within the age bracket. On the tail end, there is also a growing elderly population. After high school age, there is a clear decline in population reflecting high migration of young people looking for educational and better employment opportunities in New Zealand. There are more females than males in the early and later stage of the age group categories. There are more than 20,000 Niuean's living overseas and this large outflow over the years is a result of Niue's free association with New Zealand.

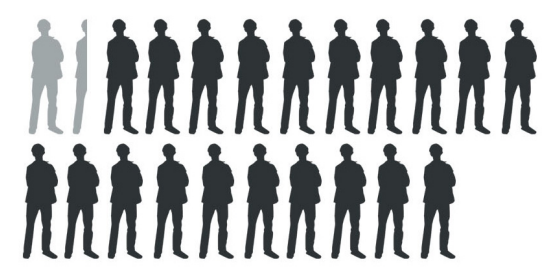

Niue vs Niueans Overseas (current population)

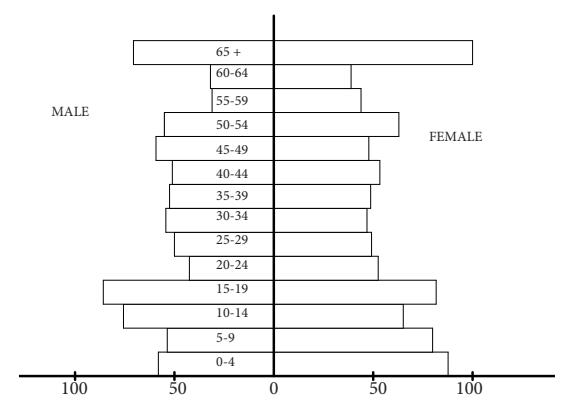

Current status of Niueans living in Niue 

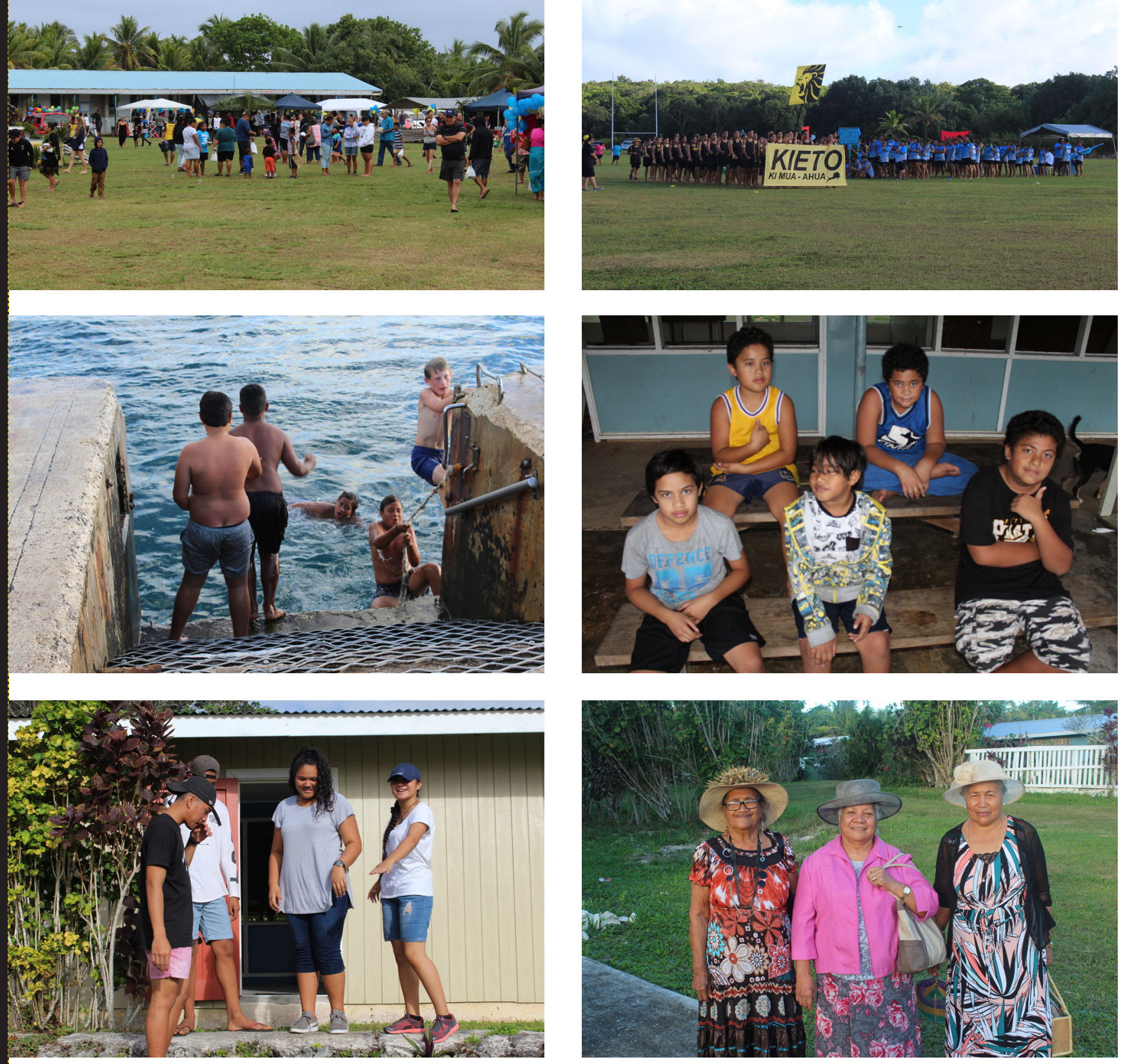

Figure 49. Show day in Alofi South*

Figure 50. Niue high school sports day*

Figure 51. Kids swimming at the Alofi wharf*

Figure 52. Kids hanging around Tuatea after schoo/*

Figure 53. Students who are interested in studying architecture*

Figure 54. Elders (matua fifine) gathering outside after church* 


\subsubsection{Political}

Following a request from Niue's King Tongia Niue became a British protectorate in 1900. However, in 1901 Niue was ceded to the New Zealand government where it was administered together with the Cook Islands. The country achieved the political status of self-government in free association with New Zealand in 1974. Under the special constitutional arrangement between the two countries, Niue is a Realm country of New Zealand alongside Tokelau and the Cook Islands, its people hold New Zealand citizenship, and NZ is responsible for providing Niue with financial and technical assistance at a level needed for the country to function (Chapman, 1982). The Niue government adopts a Westminster Parliamentary system compromising of the executive arm and Legislative. There are 20 members of parliament making up the legislature: 13 are elected from the village constituents, and seven as common roll members. Parliamentary election takes place every three years. 


\subsubsection{Economy}

The island's economy is predominantly public service driven funded from budgetary assistance from NZ- the majority of the workforce works as public servants. Other bilateral partners, including regional and multilateral agencies also make a valuable contribution to the island's development. Although small, the private sector plays a vital role in the country's development. The country's main sources of revenue are Tourism and limited exports of taro, and vanilla and fees earned from foreign nations fishing within the island's EEZ. Niue's GDP is approximately 20,541 (2006 figures) and GDP per capita is $\$ 12,158$ (Statistics Niue, 2018). The island and its people rely heavily on imports; in fact, the country's balance of payment is heavily in favour of its main trade partner, New Zealand. The island is connected to the rest of the world via a twice-weekly flight from Auckland and also a cargo ship that services the island on a monthly basis. 


\subsubsection{Climatic}

Niue's climate is tropical and has two distinct seasons - a warm wet season from November to April and a cooler dry season from May to October. (science, 2011)

Niue's average temperature throughout the year is $25^{\circ} \mathrm{C}$ with the hottest month being February with an average of $27^{\circ} \mathrm{C}$ and the coldest month being July with average temperatures of $23^{\circ} \mathrm{C}$. The wettest month is usually January with a rainfall average of $183.6 \mathrm{~mm}$ average, the annual rainfall per year is $1138.3 \mathrm{~mm}$.

The windiest month being December with an average of $16 \mathrm{~km} / \mathrm{h}$.(science, 2011)

Climate change

Niues temperatures will continue to increase, with more hot days, changing rainfall patterns, more extreme rainfall days, less frequent but more intense tropical cyclones, sea level will continue to rise and ocean acidification will continue. (science, 2011)
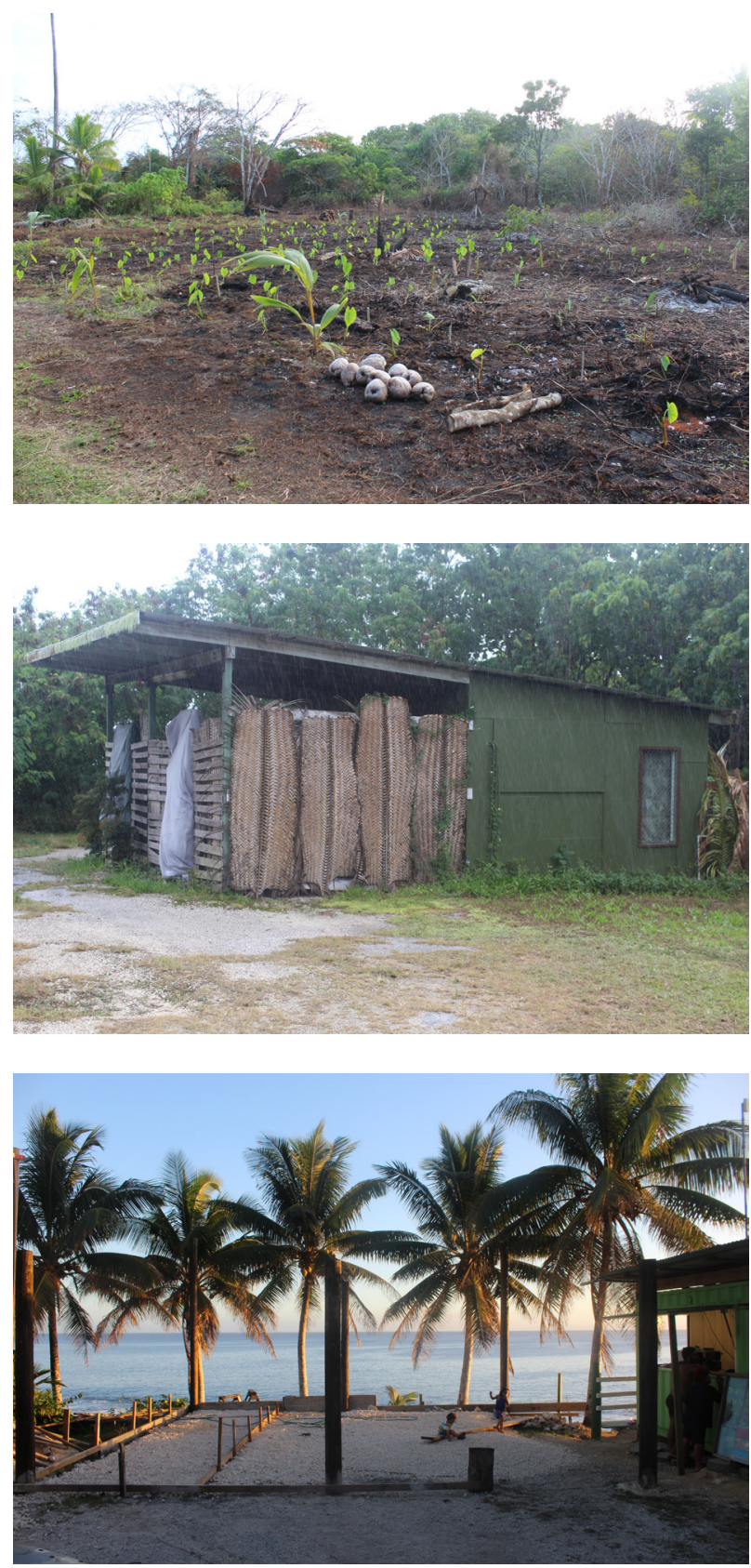


\subsubsection{Cyclone Season}

Niues cyclone season falls between the months of November to March which means that on average Niue is $60 \%$ cyclone free annually.

According to the history over the last century of cyclones that have passed or hit Niue, it is more likely to be hit by Category 1-4 Cyclone every 1 in 10 years and a Category 5 Cyclone to hit Niue, 1 in 50 years. (Barker, 2000)
Cyclone season

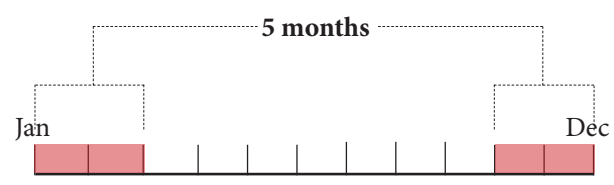

$60 \%$ of the year is cyclone free.

\section{Catergory 1-4 Cyclones}

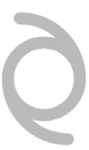

Yearly

\section{Catergory 5 Cyclones}




\subsubsection{Infrastructure}

\section{Building \& Construction}

Building and construction activity on the island is managed and supervised by staff from the Building Division of the Ministry of Infrastructure under the National Building Code. Building, Electrical, and plumbing work for private residential properties is undertaken by the private sector. Large infrastructure projects are outsourced to overseas companies with private sector also subcontracted to provide services.

\section{Water supply}

There are two main source of water for Niue, Surface water and groundwater. The main source of freshwater in Niue is groundwater in the form of a freshwater lens of approximately $200 \mathrm{sq}$. Km (the area of Niue island (259 sq. km) less a $1 \mathrm{~km}$ strip around the coastline (50-60 sq. km), located some 34 - $55 \mathrm{~m}$ below ground level.

\section{Water usage}

The current use of water is broken down into three main users, $80 \%$ for domestic use, $15 \%$ for agricultural use and $5 \%$ for commercial and industrial use (Niue infrastructure plan: Water and wastewater, 2016)

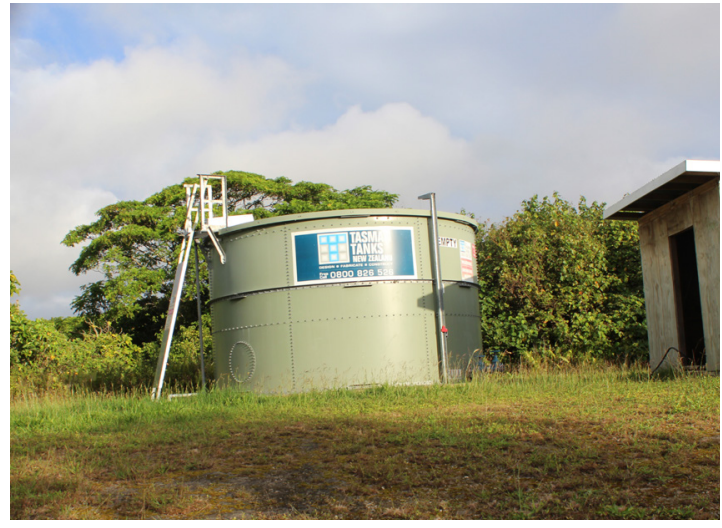

\section{RE D A C T E D}

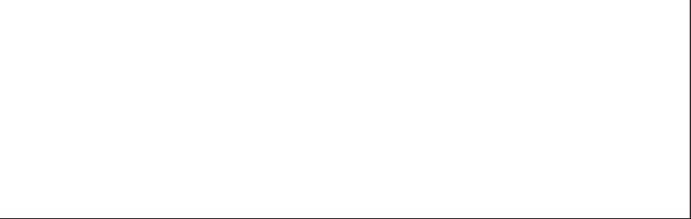




\section{Existing energy production}

Niue existing energy balance: $99 \%$ is imported, $1 \%$ is Produced locally (Niue Strategic Energy Road Map 2015-2025, 2015). Only 1\% of the energy production is sourced locally through solar power and biomass.

\section{Energy consumption}

Niue's total energy consumption shows that Transport 71\%, Residential, community and social services $11 \%$, Commercial $10 \%$, Industry \& Government 7\%, Agriculture, forestry and fishing 1\%. (Niue Strategic Energy Road Map 2015-2025, 2015)

\section{Energy road map}

Niues Target: $\mathbf{8 0 \%}$ renewable energy generation

by 2025. (Niue Strategic Energy Road Map 2015-

2025, 2015)
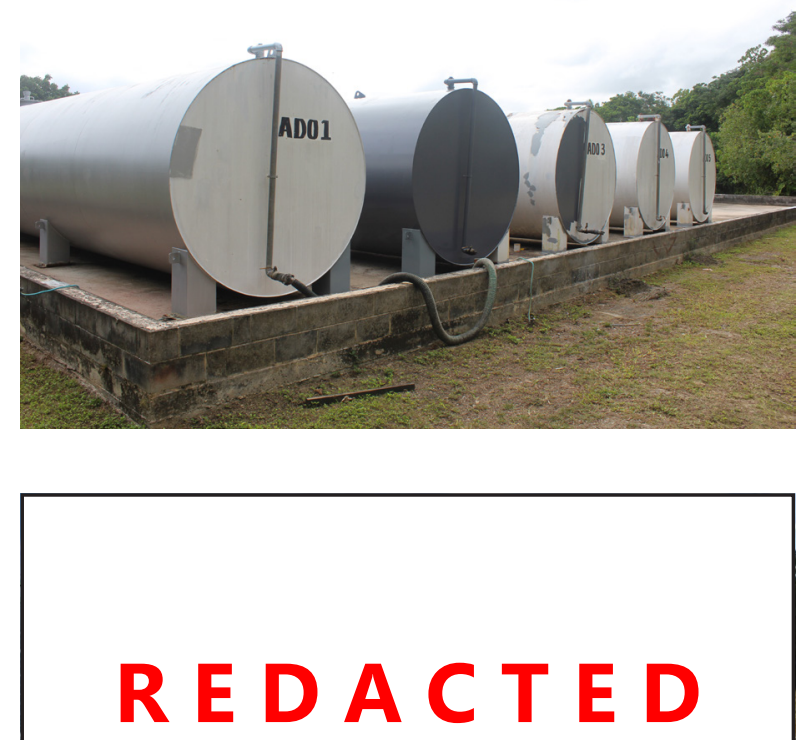


\subsection{History of Disasters}

Niue has had a long ongoing history with natural disasters. Lying in a Cyclone Belt, the island is very sensitive to Tropical cyclones where it has been hit with over 20 Cyclones in the last 100 years. The most vulnerable area is usually the North West coastal side of the island. Over the years, Niue has also been hit with over eight major droughts that has affected the island's agriculture, and people's livelihood and way of living. Niue's location makes it susceptible to earthquakes and tsunami. The island is situated along a relatively quiet seismic area but is surrounded by the Pacific "ring of fire," an extremely active seismic area capable of generating large earthquakes and, in some cases, major tsunami. (Barker, 2000) 


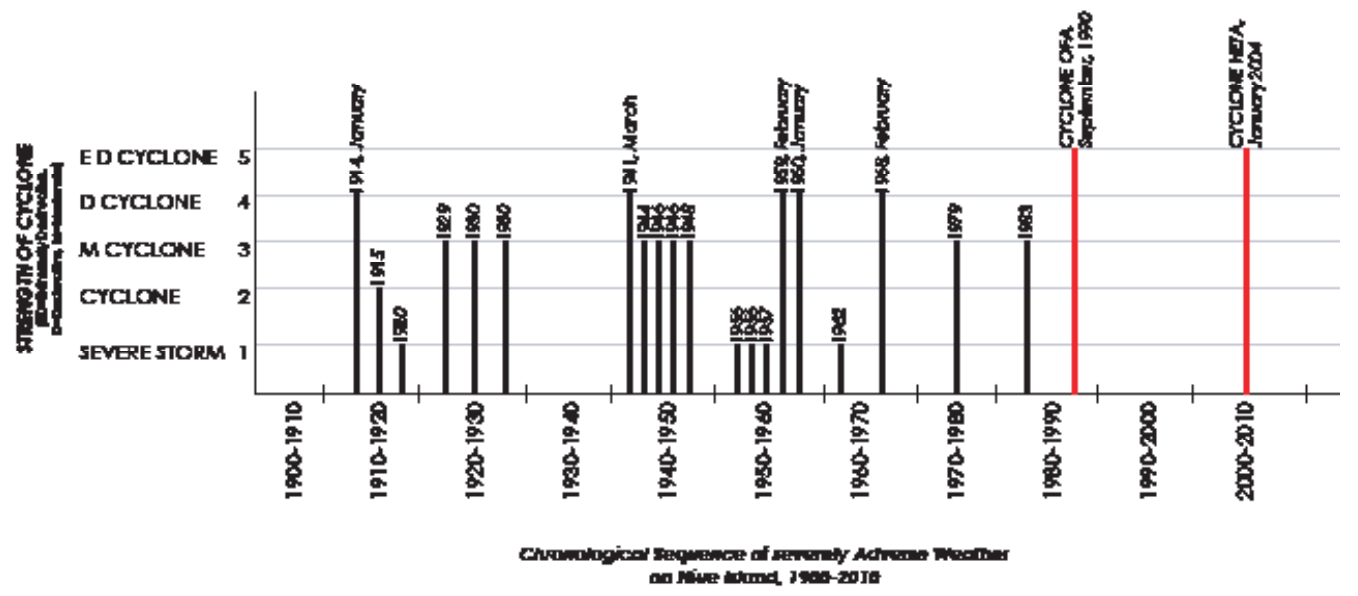

History of Cyclones on Niue

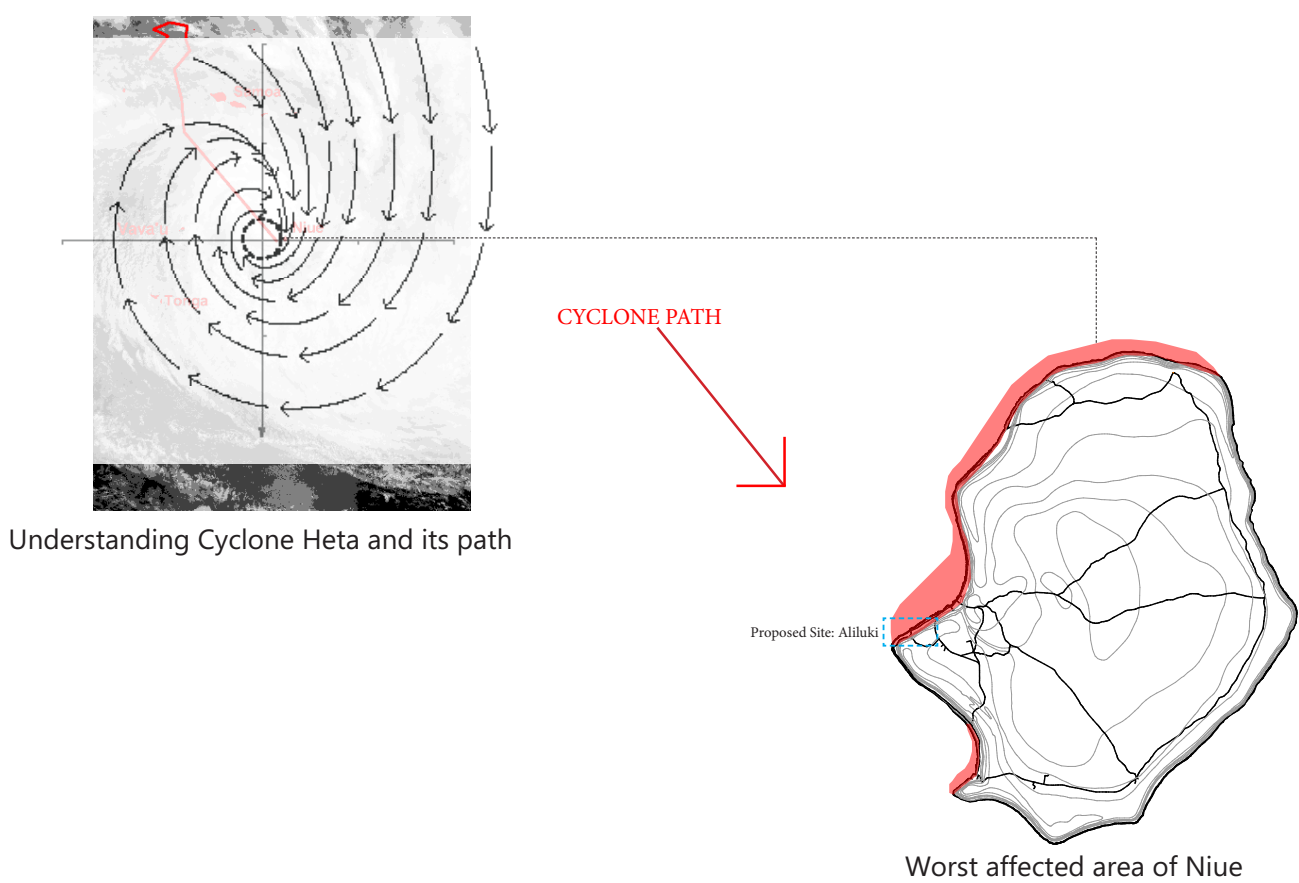




\subsection{Impacts of Cyclones on The Island}

Tropical Cyclones have significant socio economic and environmental impacts on Niuean society and economy. It has in part contributed to the island's declining population over the years. Cyclones impacts on the natural environment, wildlife, and also food production, food security and people's livelihoods. Following Cyclones that have hit Niue in the past, it has affected production of crops grown for exports such as copra, banana, and vanilla. According to historical accounts (Chapman, 1982), Niue was blooming as a country in agricultural food production for export and also the population growth before two cyclones in 1959-1960 hit Niue in consecutive years which caused widespread damage affecting food production and the population. Following period of natural disasters, is a jump in migration as people leave to seek refuge and safe haven in New Zealand. This also occurred in 1990 when Cyclone Ofa a Category 5 hit Niue and cyclone Heta in 2004, which led to Niue's lowest population in the history of the island. 

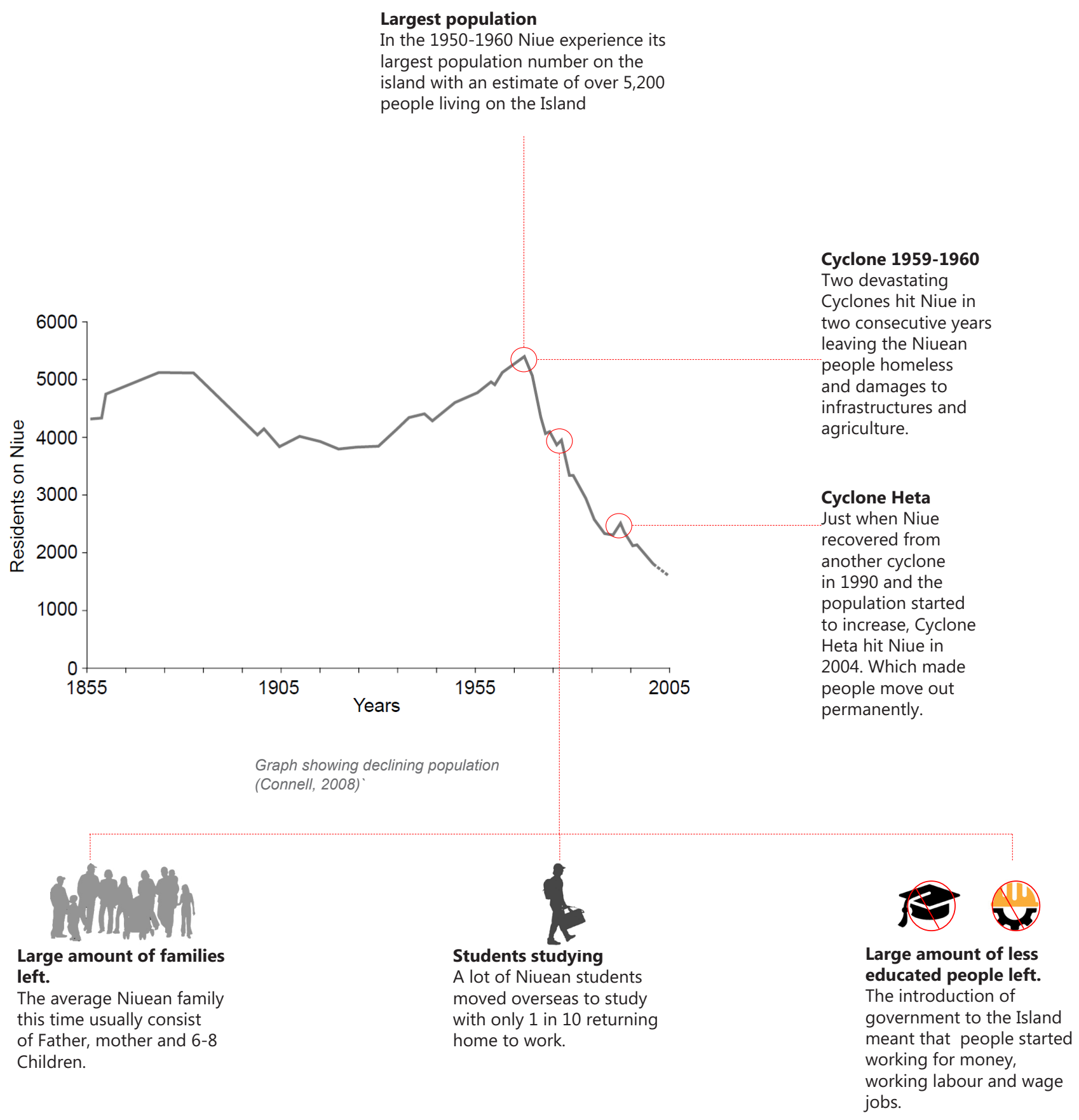


\subsection{Cyclone Heta and Its Destruction.}

On January 5, 2004. Cyclone Heta a category five, and one of the strongest cyclones ever caused peak wind gusts of $296 \mathrm{kms} / \mathrm{hour}$, and waves in excess of 50 meters in height destroying most of the coastal side of the island with wave surges causing widespread damage to infrastructure and the environment. Two precious lives were taken, and many locals experienced a residual level of trauma. Forty-three houses were destroyed, and a further 20 have had to be abandoned with a total estimate net loss of $\$ 4$ million NZD. The direct cost to the private sector, arising through lost buildings and equipment was $\$ 5$ million NZD and the overall direct loss was estimated NZ\$25.7 million (Government of Niue, 2005). The worst affected area was the coastal side of the island with majority of the villages demolished by the wave surges with the worst affected area being the South side of Alofi, Aliluki. 

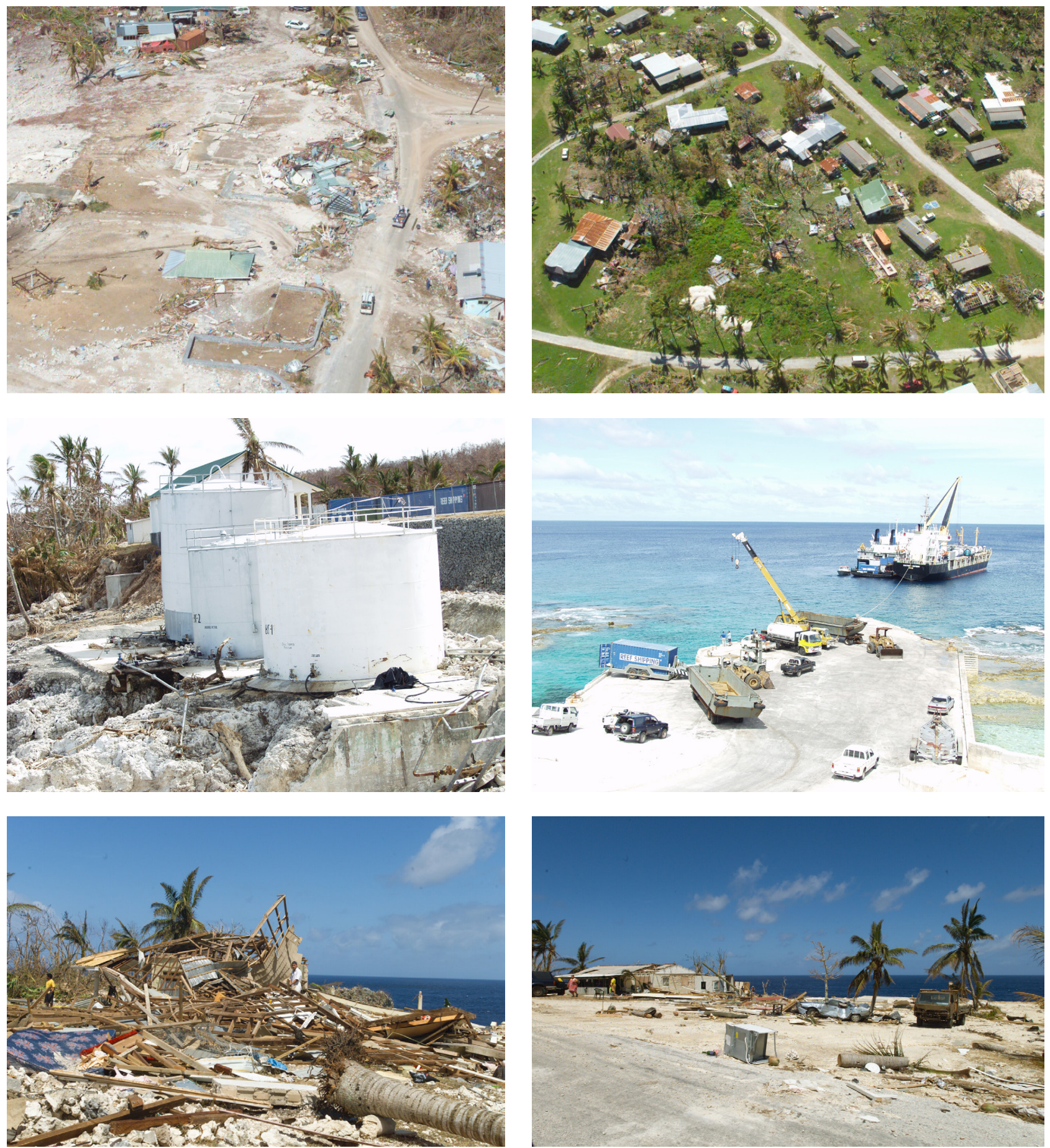

Figure 68. Aerial shot of Coastal area after Cyclone Heta Figure 69. Aerial shot of Inland village after Cyclone Heta Figure 70. Damaged petrol tanks after Cyclone Heta Figure 71. Boat arriving at Alofi wharf

Figure 72. Full destruction of a house in Alofi

Figure 73. Tropical destruction 


\subsection{Aligning with The Governments Vision}

\section{Preserve and document the local traditions and practices}

A strong aspect of the Niue government strategic plan is to ensure that the Taoga Niue, culture and values are preserved and protected (National Strategic Plan, 2016)

\section{Resilience}

Environment and climate change: Climate change and natural hazards. A safe resilient Niue to impacts and challenges of climate change, (Niue Strategic plan 2016-2018, 2016).

\section{A sustainable future}

OVERALL VISION: Access to modern energy services, affordability of energy, energy efficiency and productivity, and environmental sustainability, (Niue Strategic Energy Road Map 2015-2025, 2015)

Target: $80 \%$ renewable energy generation by 2025, (Niue Strategic Energy Road Map 20152025, 2015).

\section{Improve socio-economic of Niue}

Enhance investment in people to improve skills and create local workforce. Create more paid jobs and more opportunities for establishing and growing businesses. 


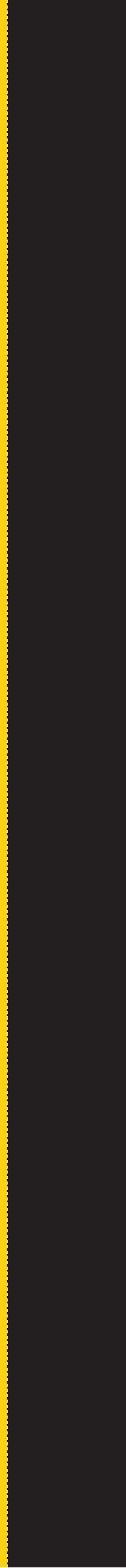


5. Site analysis 
Ty

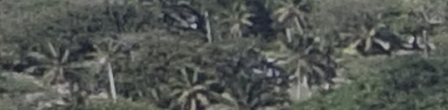

3.

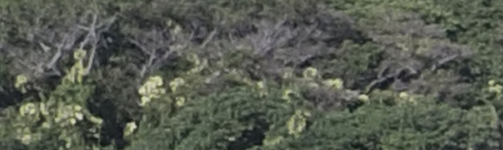

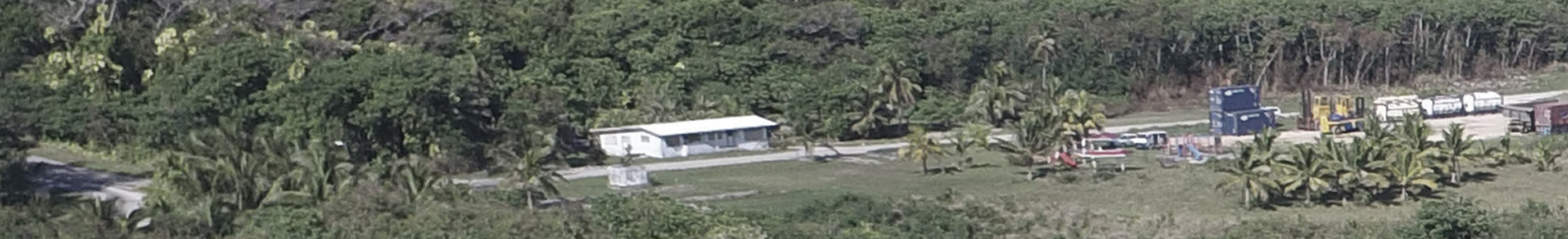

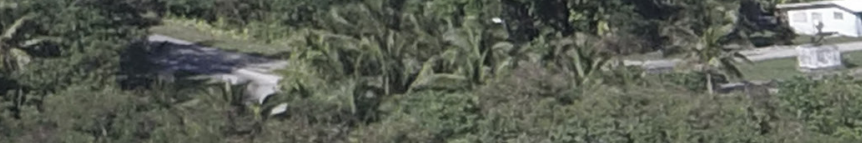

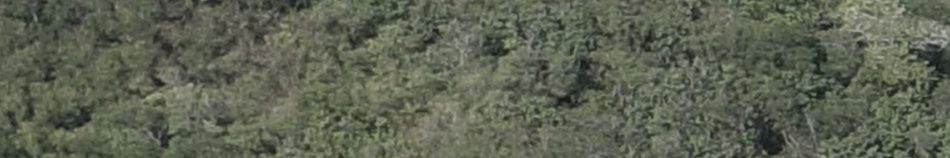

$$
\text { arisitis }
$$

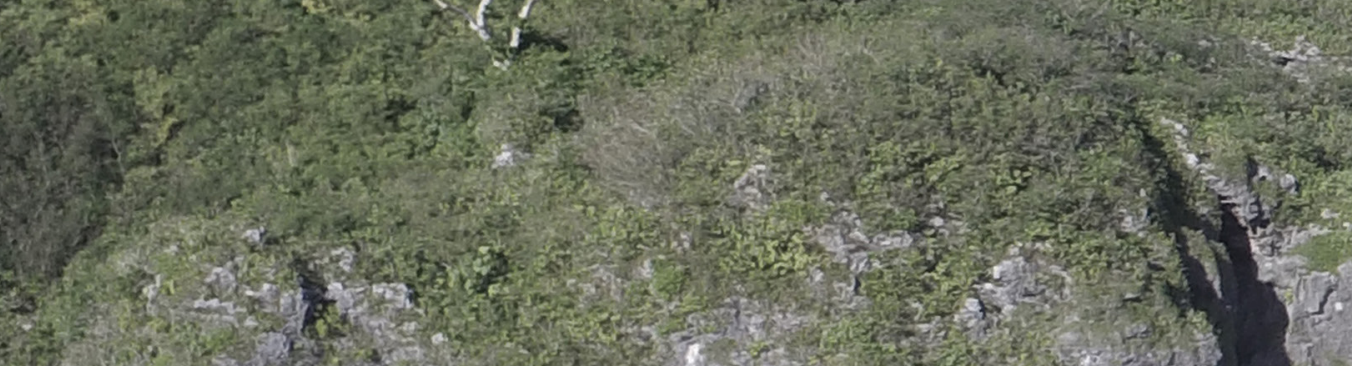

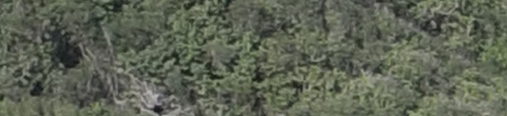

4.

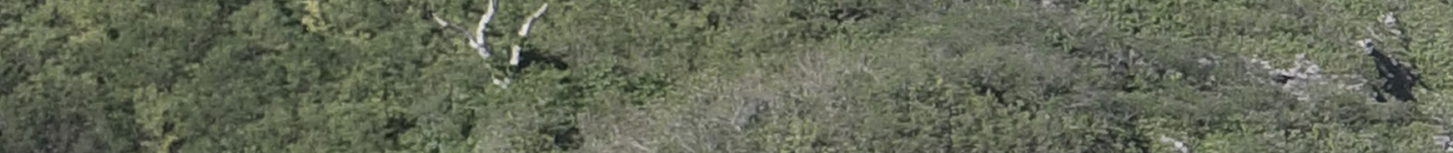

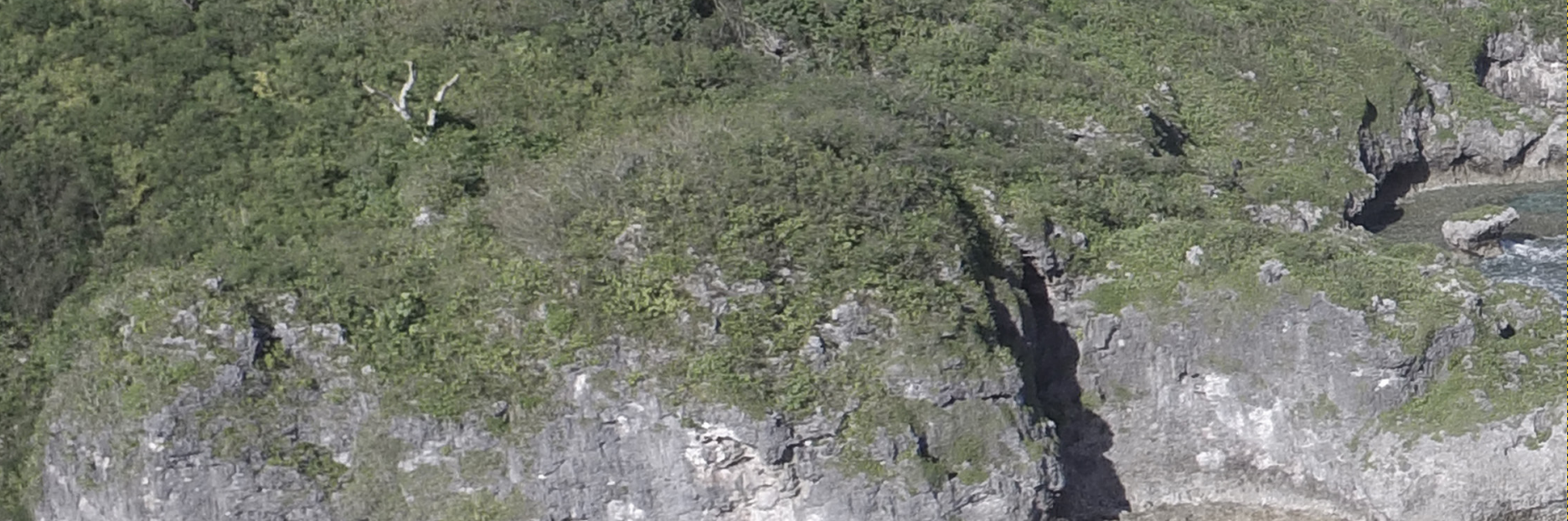

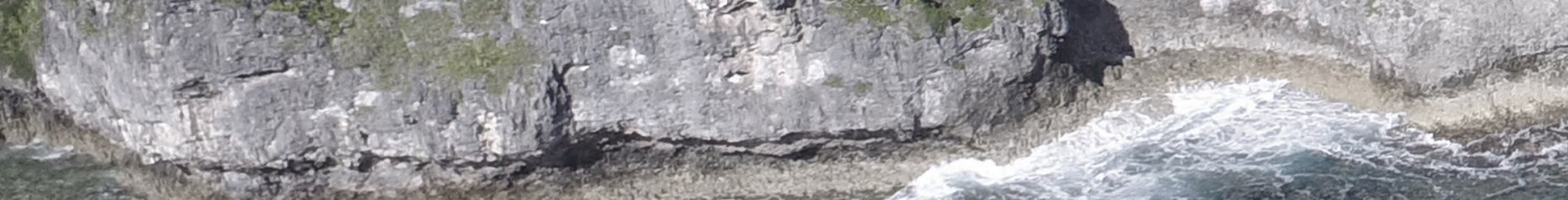
C.

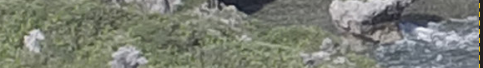

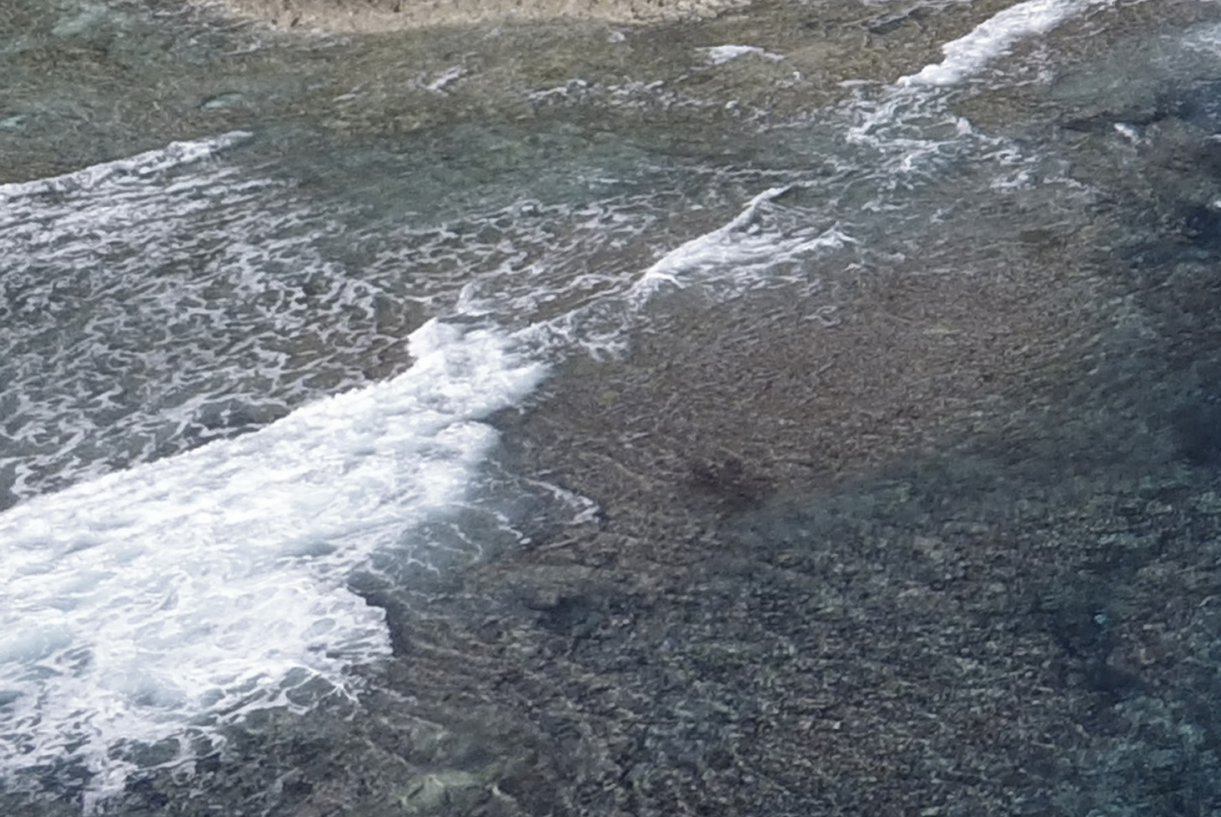



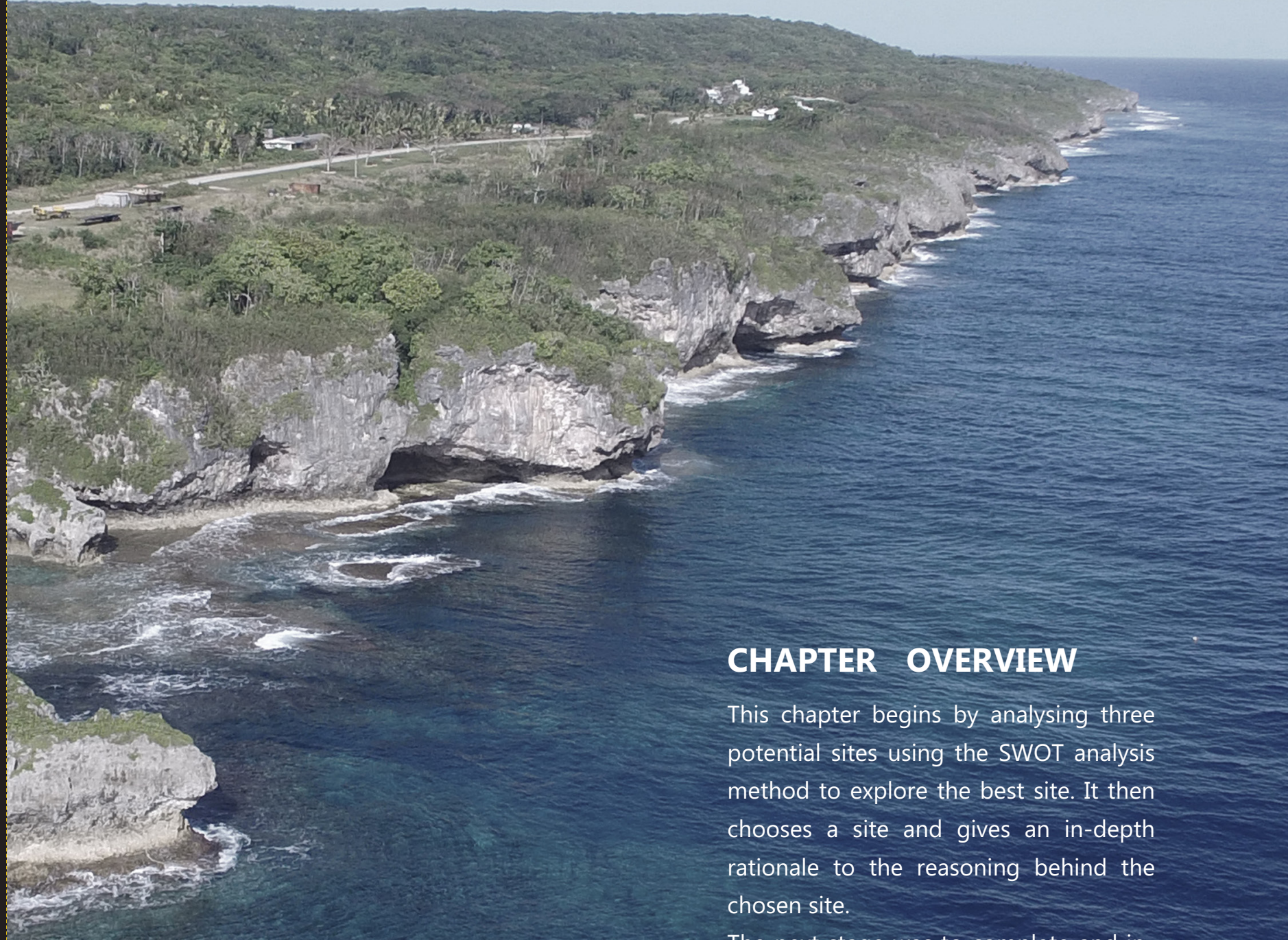

\section{CHAPTER OVERVIEW}

This chapter begins by analysing three potential sites using the SWOT analysis method to explore the best site. It then chooses a site and gives an in-depth rationale to the reasoning behind the chosen site.

The next stage was to complete and indepth disaster analysis to understand how and why the destruction of the site was increased and worse than previous cyclones.

The last stage was the study of its current site interms of the site amenities, connections, existing services, natural environment, site constraints and site opportunities. 
SITE ONE: Aliluki, Alofi South

\title{
6.1 Potential sites
}

\author{
SITE TWO: Fonuakula, Alofi
}

\author{
SITE THREE: Tamakautoga
}




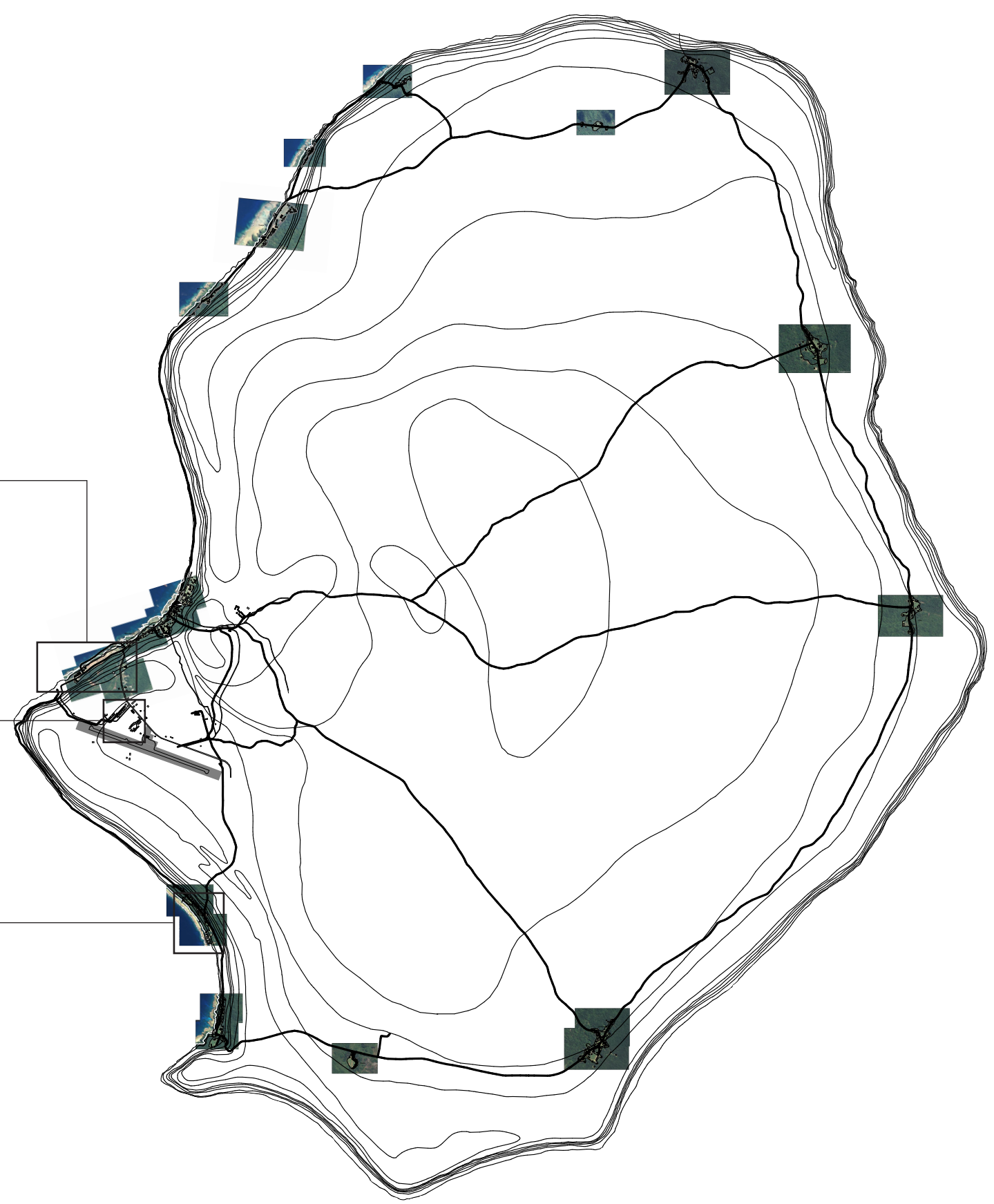




\section{SITE ONE: ALILUKI, ALOFI SOUTH}

\section{Strength}

The history of the site is rich in culture and identity. Its located in the capital of Alofi.

Already existing infrastructure to build around.

Coastal positioning is in prime location.

Its located next to the airport. The area is a gateway to the island.

\section{Weakness}

Its located in the most fragile area of the Island to cyclones.

The full destruction of the site will take a lot of convincing to rebuild.

Land ownership is mixed between crown land and private family land.

Its treatment as a services area for the greater capital.

\section{Opportunities}

Great opportunity to re-develop the area and create a new identity for the place.

An opportunity to make the site more resilient and safe during a cyclone.

To enhance the historical significance of the site.

Coastal edge could be developed as a landscape feature walkway.

To create a memorial landscape design.

It's the first meeting point for the tourist. Enhancing the site will enhance the experience of the tourist.

\section{Threats}

Its very fragile and sensitive to future disasters.

Government treating it as a back of house area which would stop any redevelopment on the area.

Any development may be stopped by the local community as it might not be aligned with their values.

Any redevelopment may be destroyed by tsunami waves.

\section{SITE TWO: FONUAKULA, ALOFI}

\section{Strength}

Its located up on the upper terrace which is completely safe from tsunami waves.

The government has moved and plans to move all infrastructure up to this area.

The area can support large scale developments.

It is located right next to the airport, golf course and new government infrastructures.

\section{Weakness}

There is a disconnection with the coastal area.

The area is too congested with new developments. The new area also loses connection with the cultural aspect and a sense of place as it may become to modern and westernise for the standard of Niue.

\section{Opportunities}

With the move of the infrastructures up to the upper terrace, the redevelopment can be moved up and add value to the master planning of the new area.

To develop a safer architecture that only has to deal with cyclonic winds.

There is an opportunity to build and work around the airport.

\section{Threats}

The plan of moving the capital up to the area may cause severe damage to the natural environment, resources and wildlife.

The area may become too westernised and loses its unique Niuean identity.

New developments will exhaust the natural resources and capacity of energy sources. 


\section{SITE THREE: TAMAKAUTOGA}

\section{Strength}

The site is totally hidden to the full force of the cyclone because of its location and placement in relative to the direction of the cyclone.

It is the next village that the tourist will see.

New tourist development in the village.

Scenic resort, Niues only hotel is located in Tamakautoga.

It's on the coastal side with great views and a beautiful sunset view.

\section{Weakness}

Public infrastructure is limited in the area.

It's not located in the capital.

Not enough resources in the area to have a large scale development.

\section{Opportunities}

Due to its location, its deemed to be the safest area for any development.

Tourism facilities are invested more in this area. More opportunities to develop tourism infrastructure.

There is an opportunity to have a brand new development where the architecture and design iteration can be tested.

\section{Threats}

Any large scale redevelopment may not be accepted by the local community.

Although its a safe area and usually safe from tsunami, future cyclones may cause Tsunami damage on the area.

Development may damage the fragile wildlife and agriculture of the area.

New developments, may drain the natural resources in the area. 


\section{Rationale}

\section{History of site}

Aliluki was known as the social and cultural hub of Niue. It was a place where the locals and the tourist would gather in celebration of Niues culture. The Huanaki cultural center (the only one in Niue) drew all the different villages to perform and sing during big function, festival and annual events. Huanaki cultural center was the heart of the area, bringing joy and a sense of togetherness for the Niuean people. Complimented by this was the only museum that Niue had which was located in the same facilities. This stored rare Niuean ancient artifacts, rare documentation and the history of Niue.

The area also had Niues national hospital, new Amanau apartments, several local businesses and Niue hotel.

The identity of the area was not only a social meeting point but a vast contrast of a more new developed village compared to the rest of the other villages. The value and the significance of this place was vital for the Niuean people.

\section{Re development of the site}

After the destruction of Cyclone Heta, few attempts were made to re-develop the site. There were initiatives by the local village council to turn the area into a park, there was also study done by the Manukau city council on providing an in depth analysis of different options of redeveloping the site and also a study to see if it was viable to re-build on the site or to move to higher ground. Currently there has also been attempts to revitalize the area through adding new program, new landscape design to enhance the site but in terms of the bigger development, the site still remains a stagnant land overgrown with grass and treated as the services area to the main capital. 


\section{Existing services and infrastructure}

The existing services to Aliluki and the areas around it are in good condition and have not sustained as much damage as the infrastructure did. Aliluki has sufficient capacity to carry out a re-development of the site.

\section{Water}

Water in Aliluki is supplied through a water tank on the top terrace that is gravity fed to the existing site. There is sufficient capacity to support redevelopment in the site, however its important to note that any large scale development must look at alternative ways of collecting water as it might exhaust the water supply currently.

\section{Sewage}

Sewage is usually disposed via individual septic tanks which means that it is not a problem. The only issue is the potential impact of any new large scale development may cause contamination to the main water supply. All actions must be made to locate septic tanks away from water bores.

\section{Power}

There is sufficient electricity to support new developments on site. The majority of the existing power network is underground and didn't sustain much damage from the cyclone. There are a few overhead lines which in future developments need to be transferred underground to avoid damage during a cyclone.

\section{Telecommunication}

There is a distribution network available that can provide sufficient capacity for the area. There are also plans to install fibre optic which will hugely support any future redevelopment on site.

\section{A sense of place}

The study and information gathered from the community engagement highlighted one thing that this site has. The coast.

The coast is such a vital part of the identity of the Niuean people who live on the coastal side. There is much reliance from the people of the coast as there is the coast to the people. It is part of the genetic makeup of Niueans. To get the ability to wake up to the sound of waves, to hear the whales communicate to each other, to smell the ocean breeze, to see the sun set on the horizon and to walk down the local sea track to go for a swim, speaks volume of the deeper connection the people have with the water. As well as that, people who live on the coast rely heavily on the sea for food sustenance, the ability to go out fishing on canoes and to gather seafood on the reef. These connections will all be lost if there was a need to relocate the whole village to the higher terraces.

The stagnant and lack of development on Aliluki is also a key aspect on why it is important to redevelop the site. The need to rebuild and redevelop the site will bring a sense of justice and closure for the people of Niue. The development will not only be a physical entity on site but it will symbolise how resilient Niuean people are. A stance to respect those who have lost and experienced hardship during the cyclone, a way of mourning the loss and give respect to the power of mother nature, to rebuild the relationship the people had with the site but most importantly to give respect to the two precious lives lost during the cyclone. 


\section{RE D A C T E D}

Image of before Cyclone Heta 


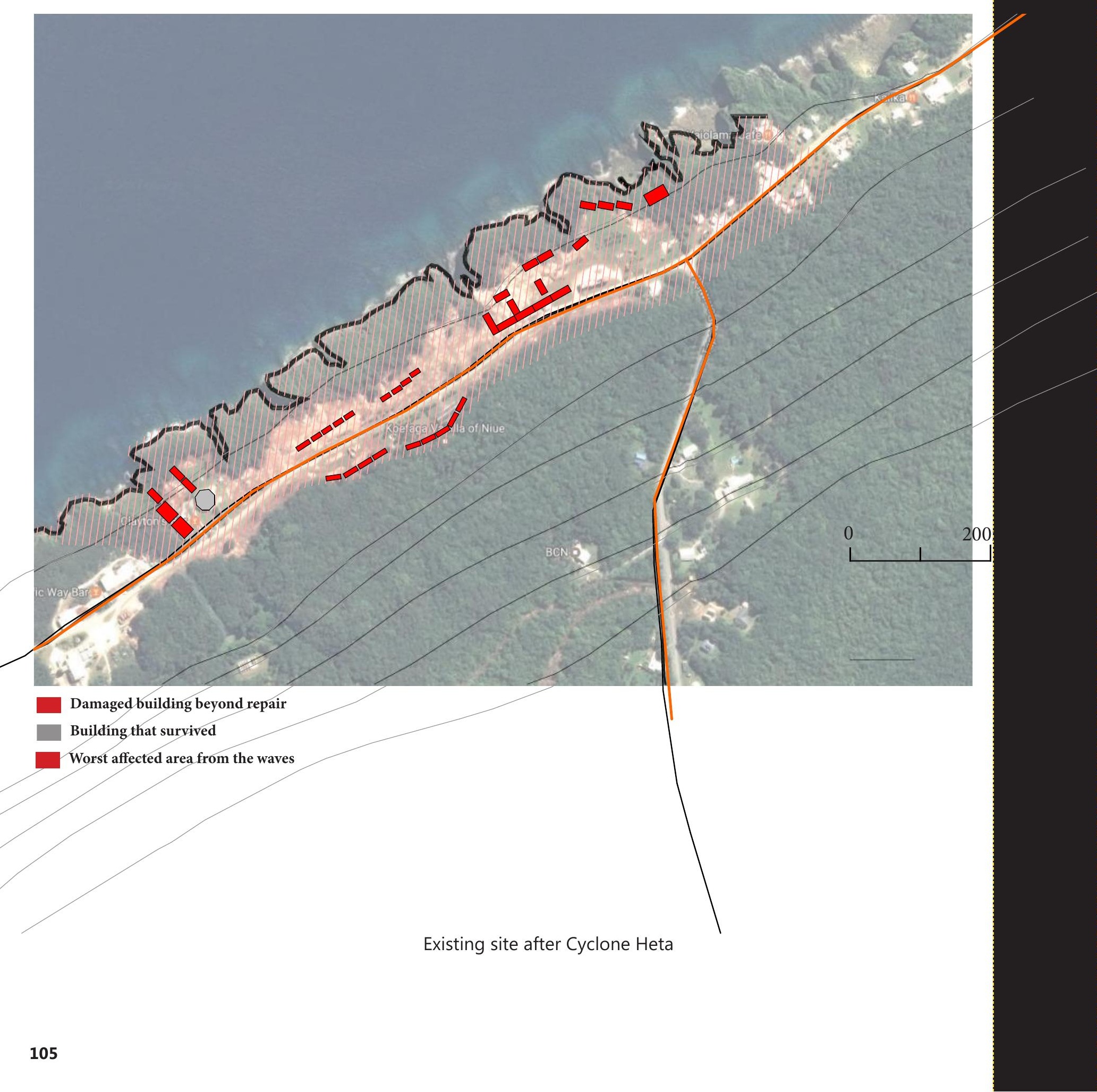




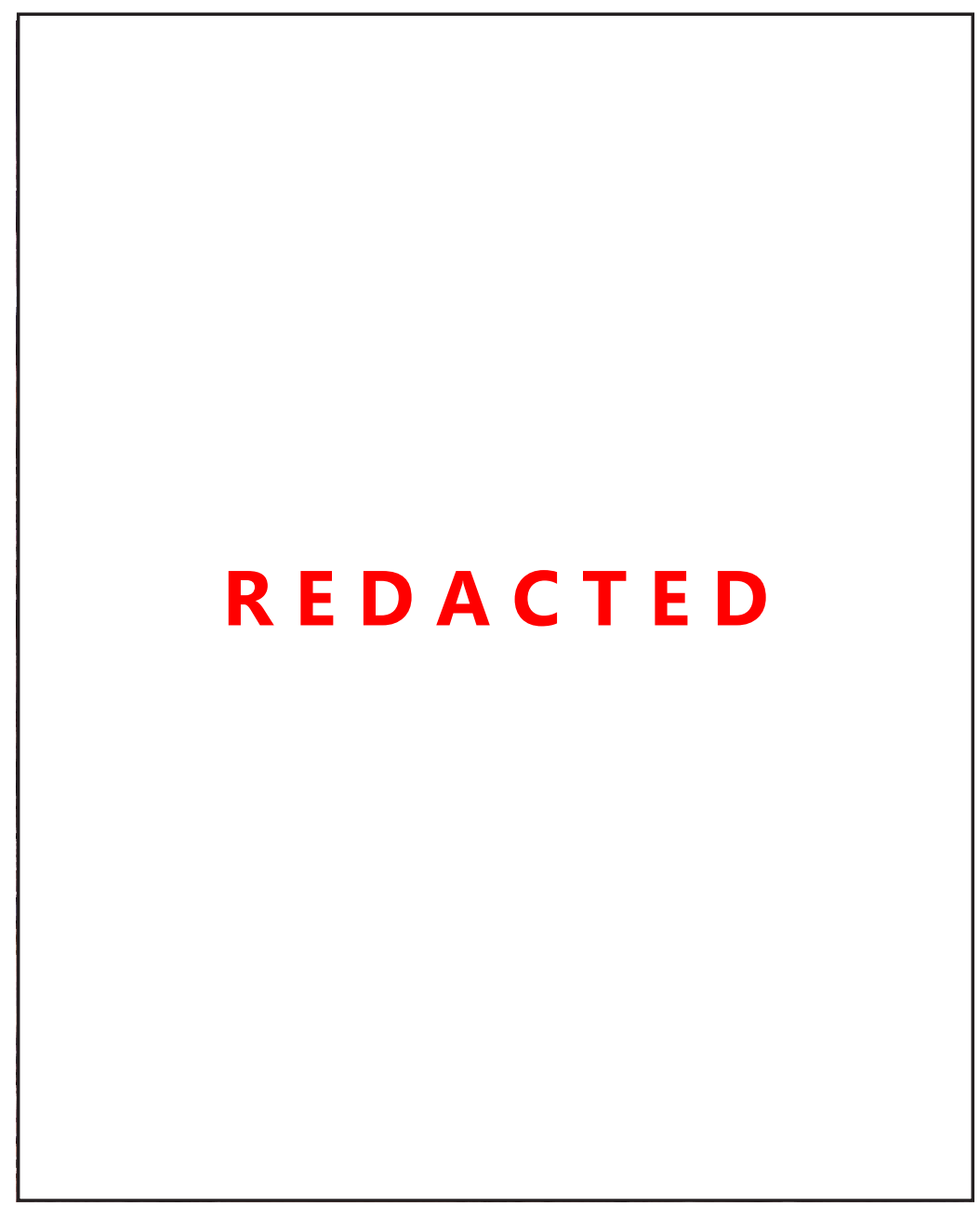

Image of Aliluki after Cyclone Heta 


\subsection{Disaster analysis}

This section explores an in-depth analysis to how and why the waves reached heights of 50 meters and 200 meters inland. It draws from literature and studies on causes of the Storm surge destroying the coast of Niue, more so Aliluki.

Through site analysis and interviews with key informants, it also explores the areas that were most vulnerable to high storm surges. This was defined by the extent of the damage on the existing infrastructures and from personal experience of Cyclone Heta.

Understanding these key factors and key learnings from Cyclone Heta will enable a more resilient and robust solution in the redevelopment of the site. 

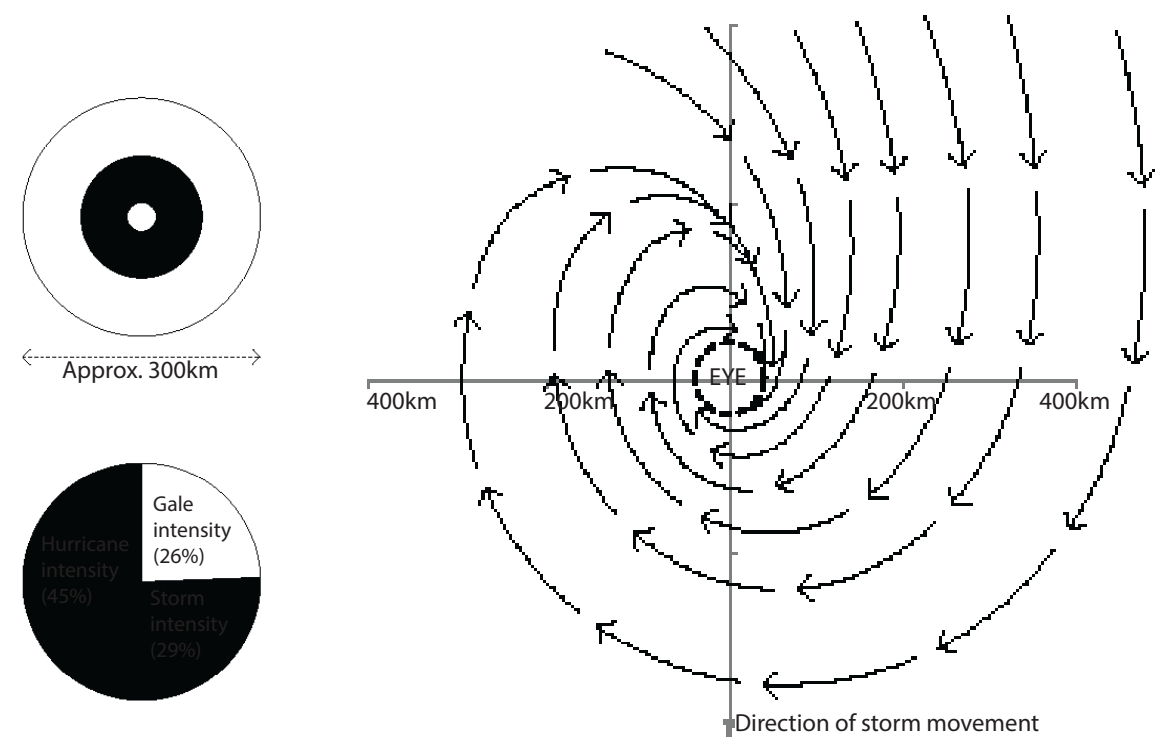

\section{Cyclone characteristic}

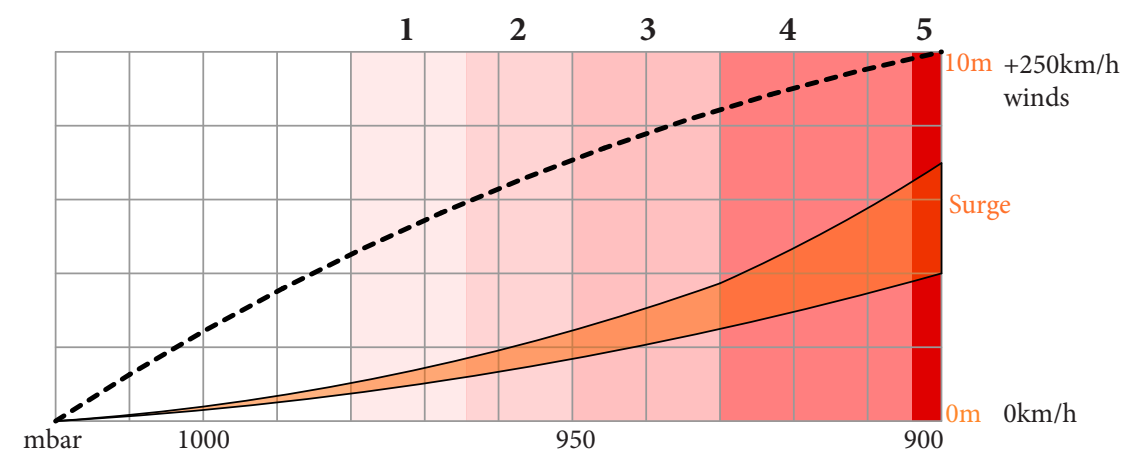

\section{Saffir-Sampson Scale}

$\begin{array}{ccccl}\text { Cat. } & \text { Wind }(\mathbf{k m} / \mathbf{h}) & \text { Pressure (mbar) } & \text { Surge }(\mathbf{m}) & \text { Potential damage } \\ \mathbf{1} & 152 & +964 & 1.2-1.5 & \text { Trees, Shrubbery, mobile homes } \\ \mathbf{2} & 176 & +950 & 1.6-2.4 & \text { Roofs, mobile homes } \\ \mathbf{3} & 208 & +930 & 2.7-3.6 & \text { Trees stripped, building damaged } \\ \mathbf{4} & 248 & +905 & 3.9-5.4 & \text { extreme: flooding, major damage } \\ \mathbf{5} & +250 & -905 & +5.4 & \text { catastrophic: houses blown away }\end{array}$

Figure 81. A study of cyclones characteristic

\section{Cyclone Catergories}

Figure 82. Graph showing relationship between Cyclone strength and

storm surge

Figure 83. Graph highlighting damages per Cyclone category* 


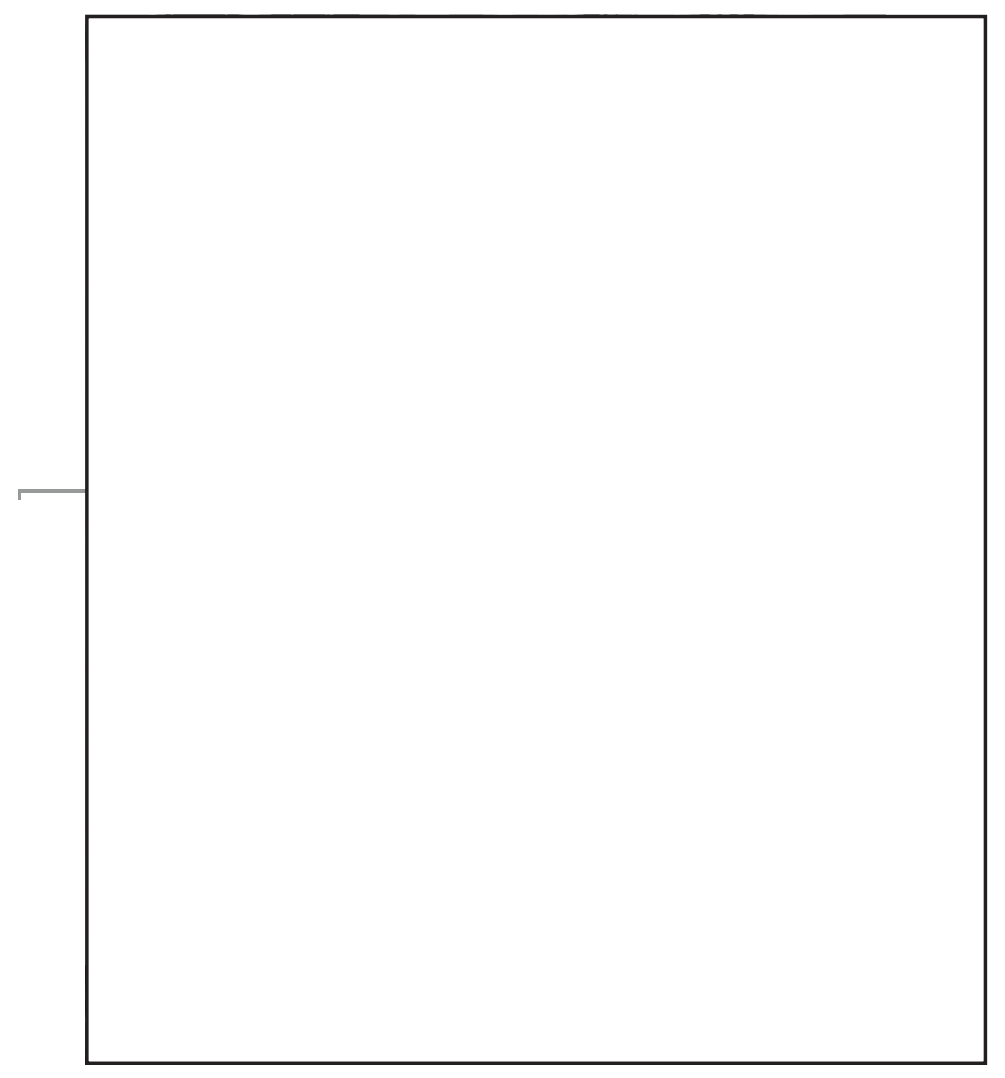

Understanding Cyclone Heta and its path 


\section{CAUSES OF TSUNAMI WAVES}

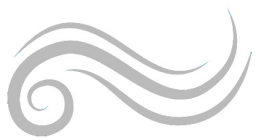

$320 \mathrm{~km} / \mathrm{h}$ Violent Winds

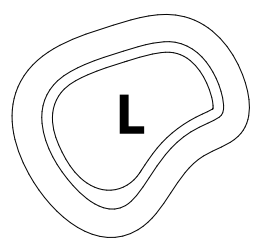

Low Atmospheric pressure

High Tide \& 10m waves

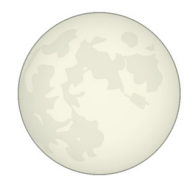

Full moon

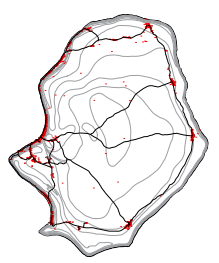

Niues Terrain
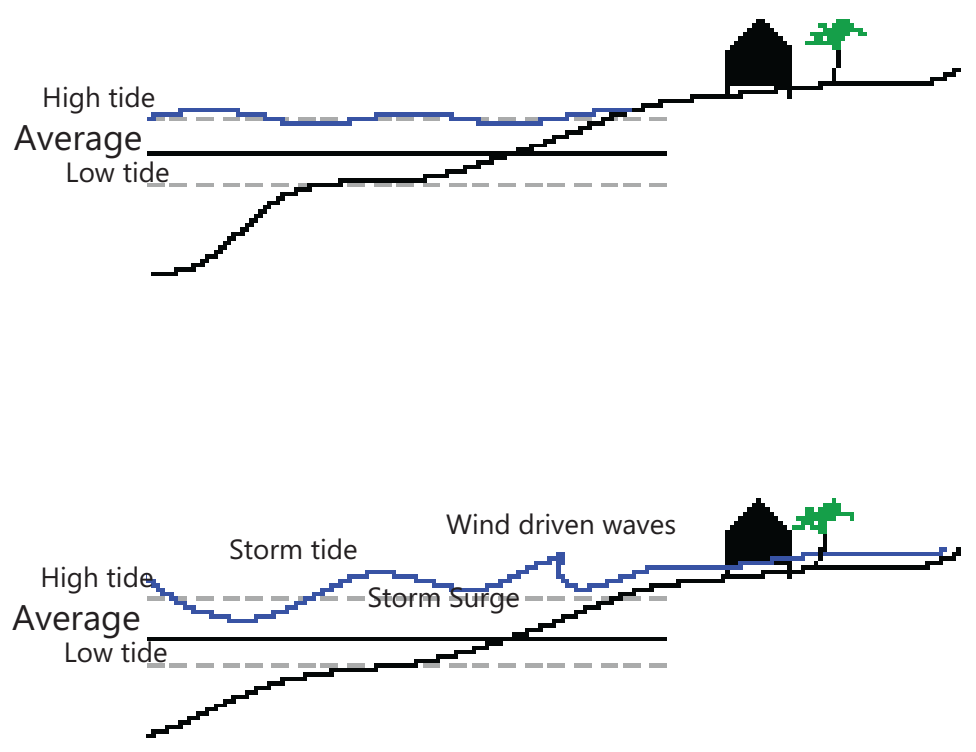

Other low lying atolls

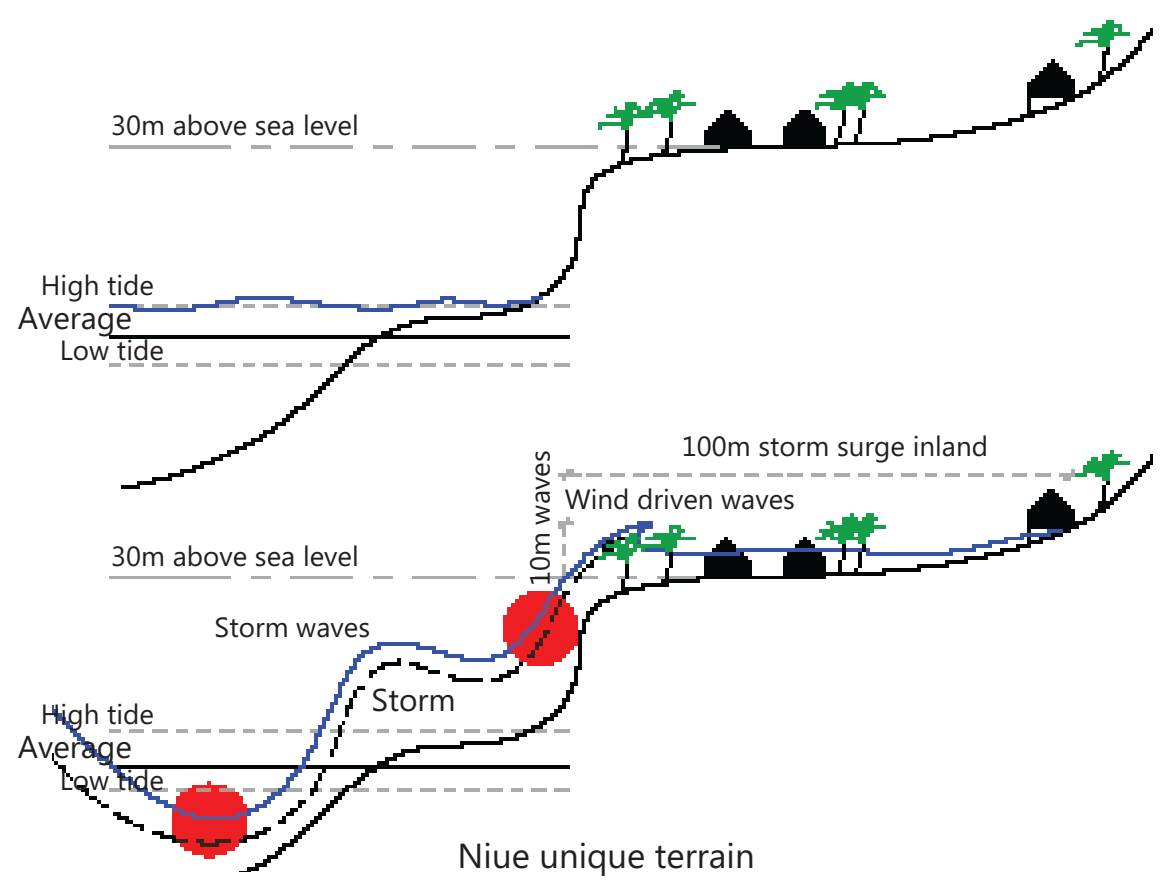

Figure 84. Collage of the path of Cyclone Heta* (Left)

Figure 85. Study showing the different causes of Tsunami waves* (Top)

Figure 86. A Study showing the difference between Niues terrain and other low-

lying Islands ${ }^{*}$ (Top right) 


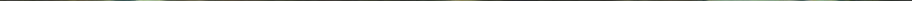




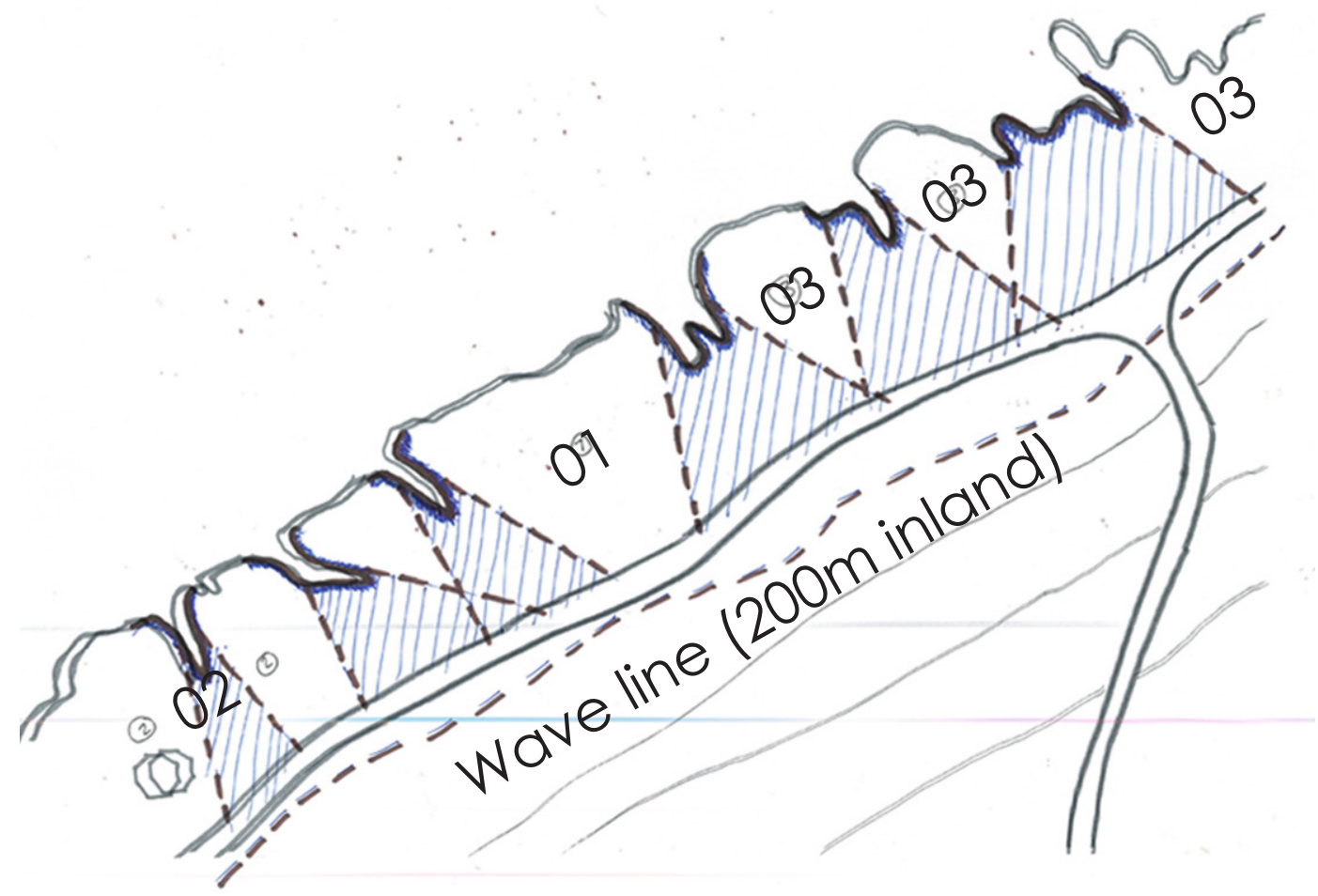

HIGH RISK AREAS 


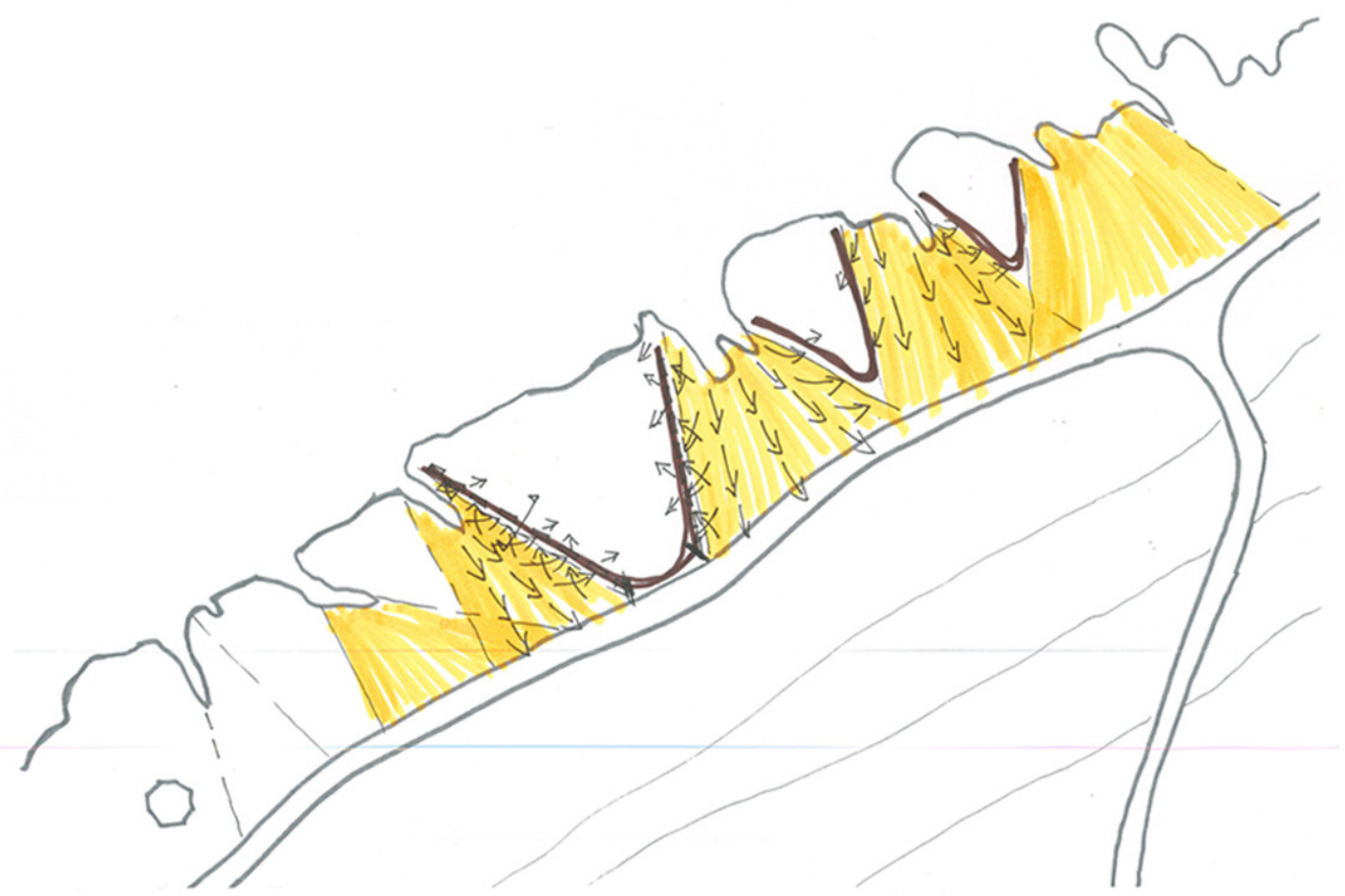

THE DIRECTION OF WAVES 
6.4 Existing site 


\section{Site ammenities}

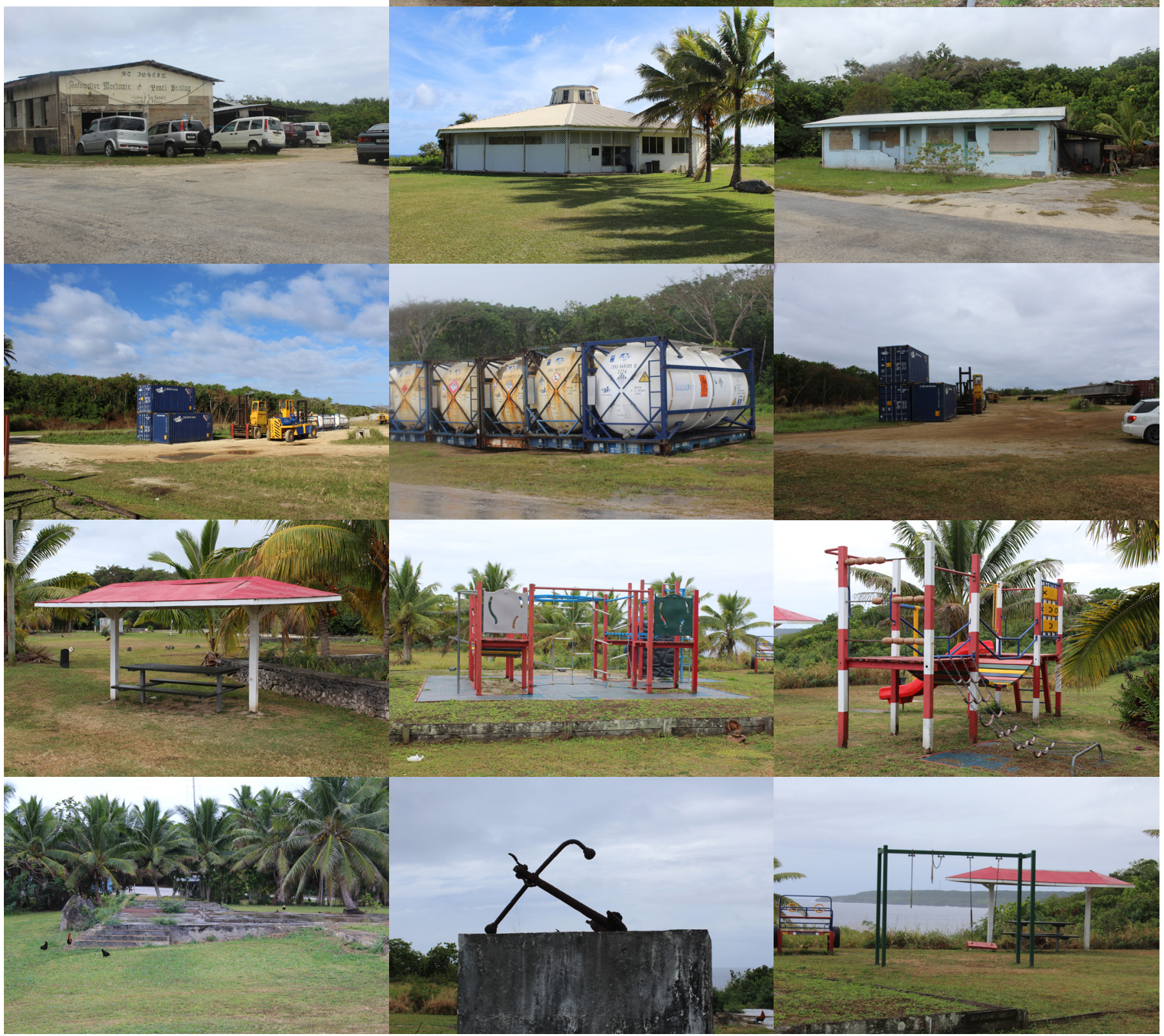

Figure 91. Collage of existing infrastructure in Aliluki (top) 
Existing ammenities

a Residential

Government

Shops

Private businesses

Government

Community spaces

Churches

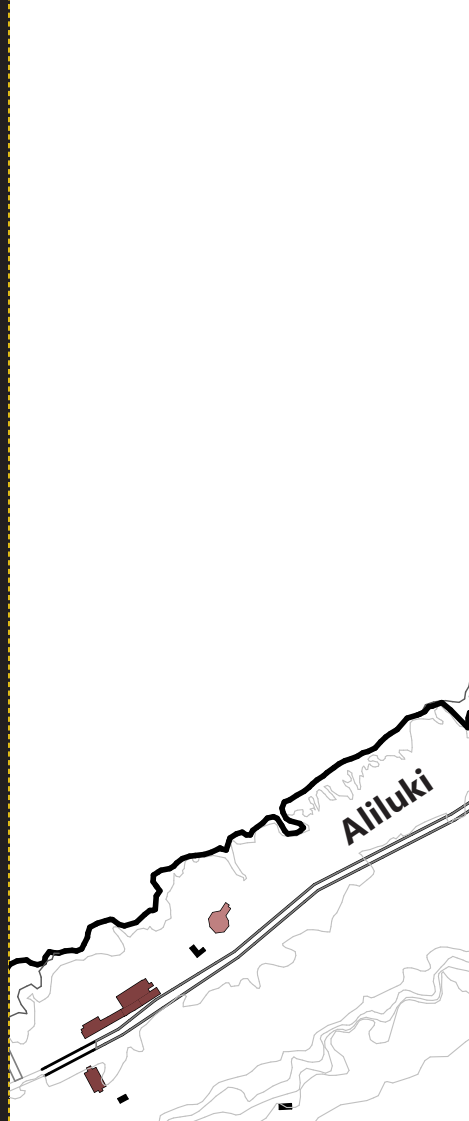




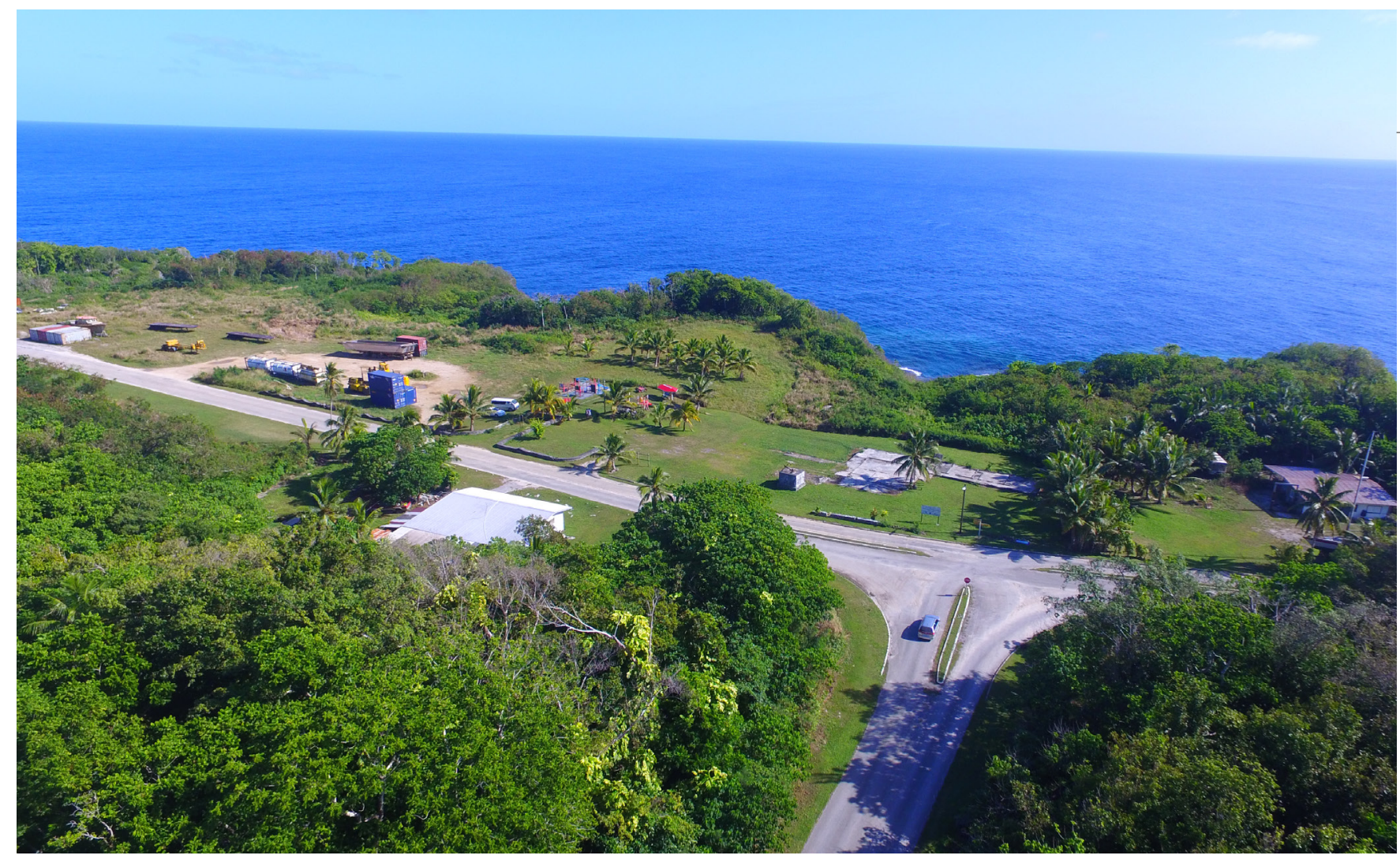

Critical connection junction

Figure 93. Drone image of junction between Aliluki, to airport and Alofi North 


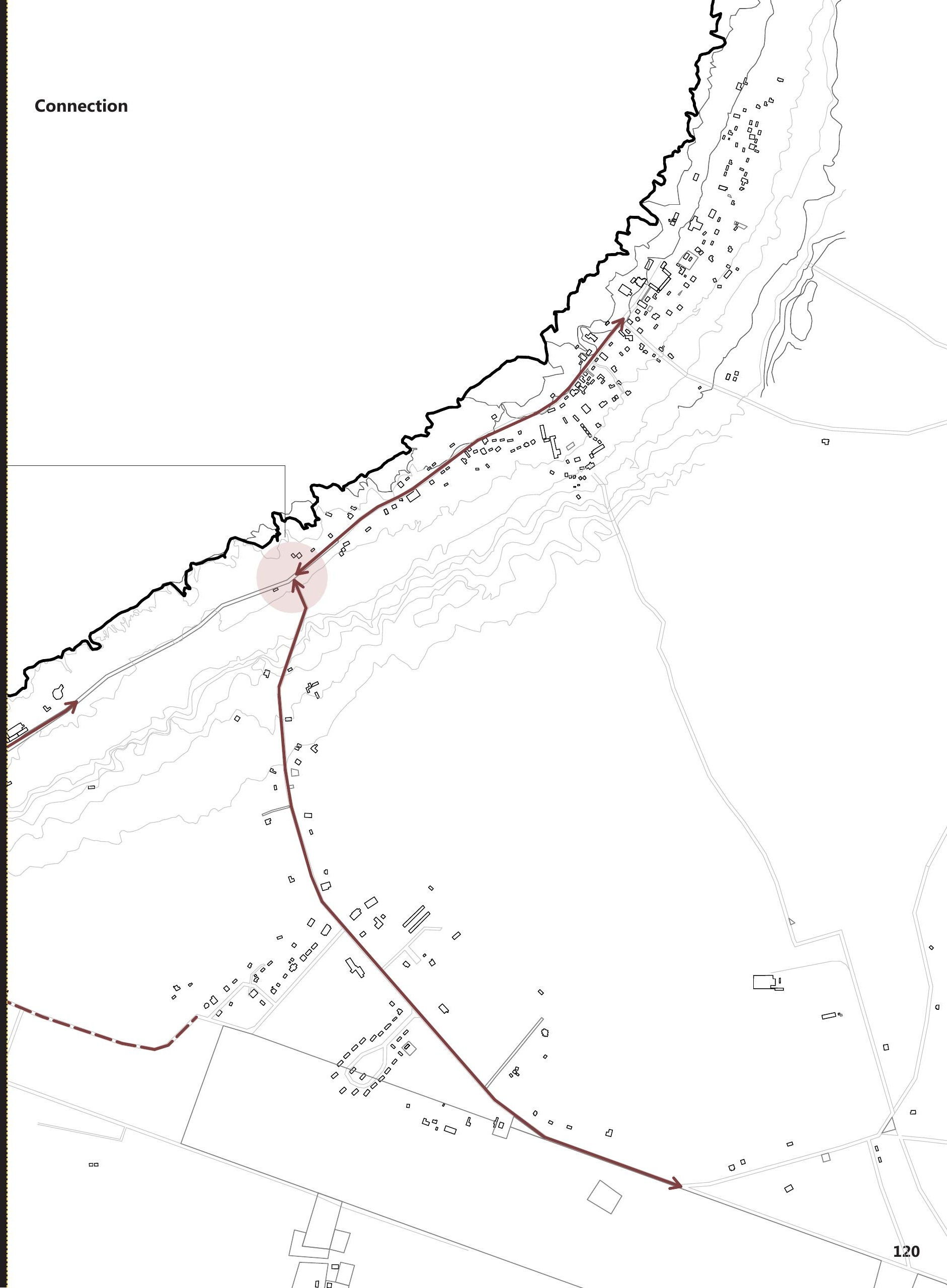




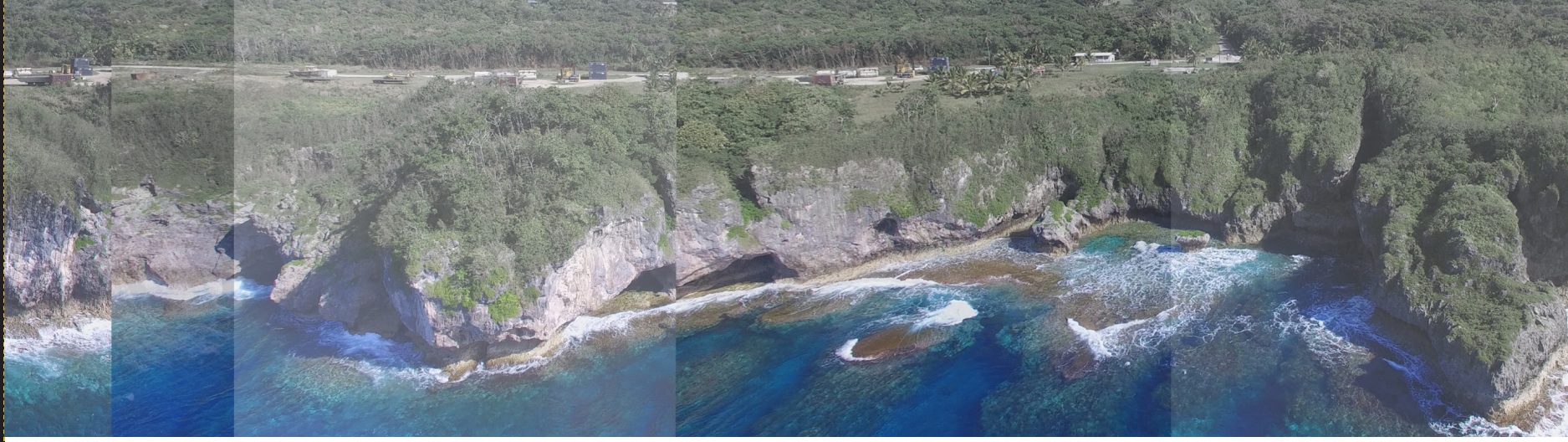




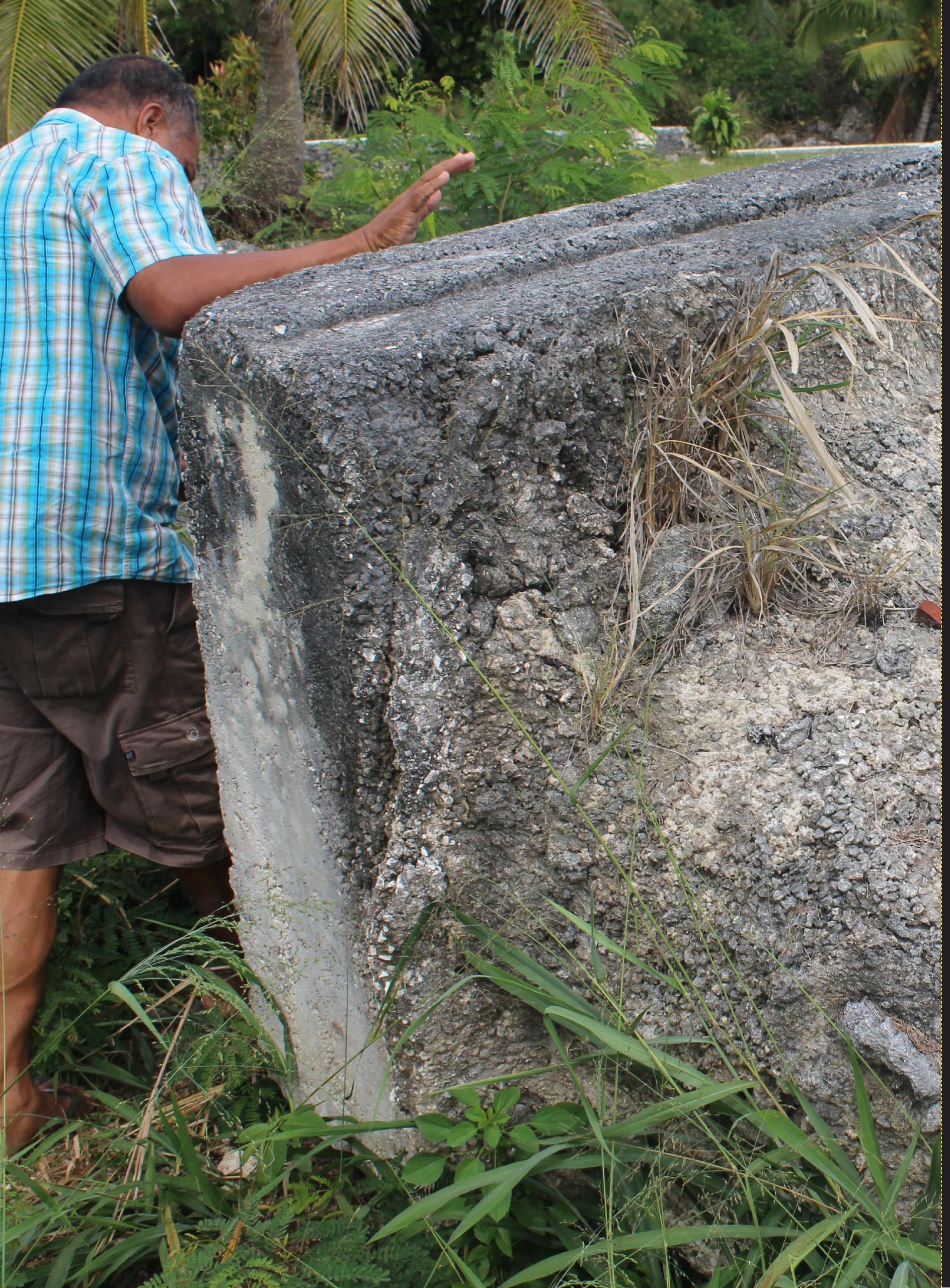




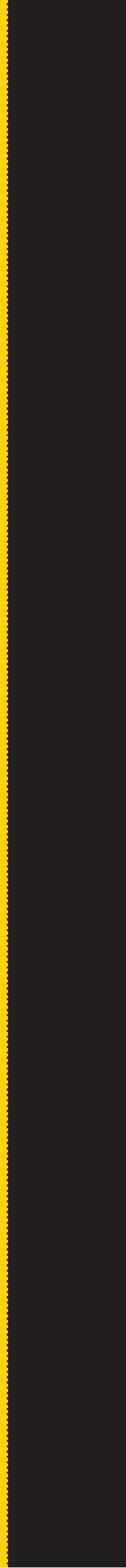


6. Community Engagment 


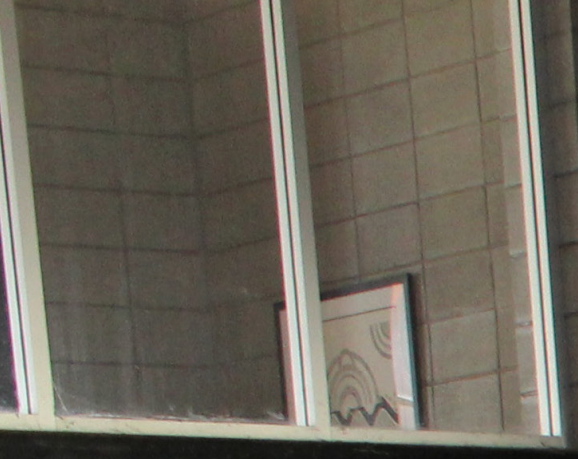

II.

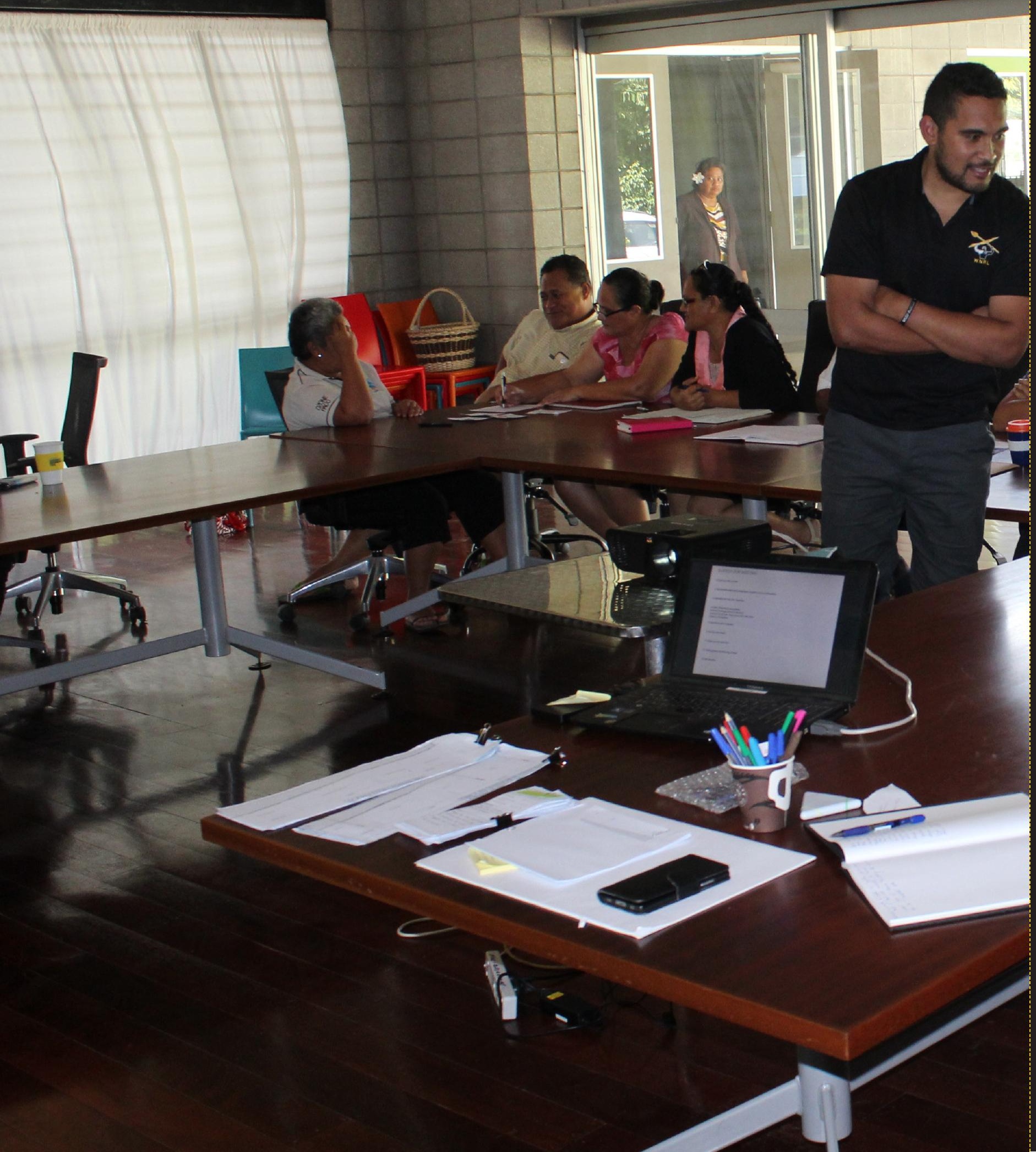




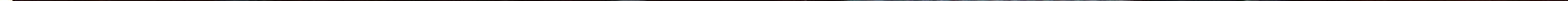




\subsection{Questionnaires}

The questionnaires aimed to identify the issue of Niue's declining population. As shown in previous research, the biggest decline in population occurs when high school students leave for education and better economic prospects. The aim is to identify the reasons why they leave and to understand ways whereby they can be encouraged to remain in Niue. Niue after high school.

It also addresses the issue of why people return to stay in Niue and what brought them back. The final aim of the questionnaires was to validate and gain an understanding on how important it is to live on the coast, especially given the understanding that the coast, particularly the sea/water is an integral part to the daily lives of those living in the coastal communities. 
1) Would you stay after high school?

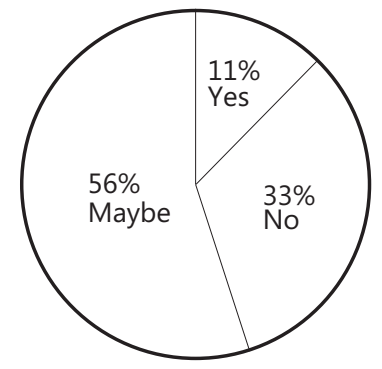

2) Reason for staying/leaving.

\section{Staying:}

Look after family

Work experience

Leaving:

Pursue studies

Experience the world
3) Incentives to

stay in Niue

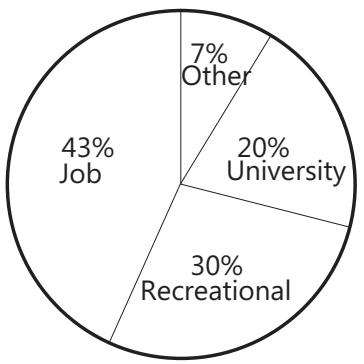

4) Best thing about Niue

Freedom, family, friends, free things, Culture, Paradise, Parties, swimming, people, very safe and its home.

\section{Sample group B (Employees)}

1) Staying in Niue for more then 3 years?

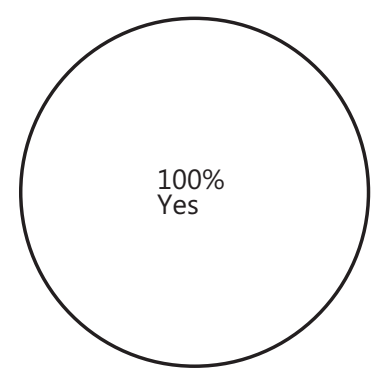

2) What made you return?

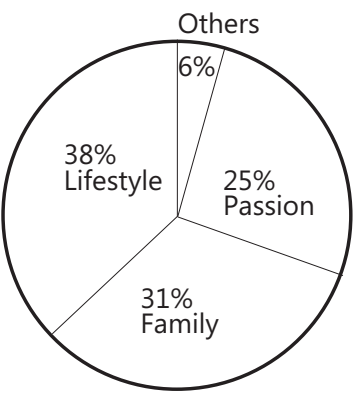

3) Development suggestions for Niue

Youth opportunities. More students returning. Increase capacity (Education, skilled work force, strong infrastructure system/ Transparency).
4) Best thing about Niue

Freedom

Easy lifestyle

Community life

Climate

Culture and traditions

Free sources

\section{Sample group C (Coastal communities)}

1) Most important aspect of living on the coast?

Calming sounds of the sea and waves.

Fishing and seafood is a vital part of the make-up of coastal people. Access to water \& swimming.

Fresh air, improves heath and well being.

It's a privilege to have million-dollar view of the ocean, hear the waves each day.

Calm scenery that the blue ocean provides.
2) Would you move inland if a cyclone hit Niue again?

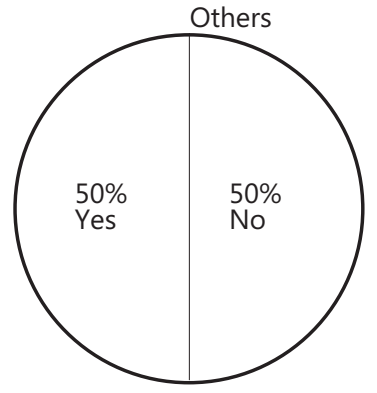

3) Give reason why? Why not?

\section{Move:}

Don't want to challenge the power of nature. Experience the high waves.

Govt has legislated to move.

\section{Staying:}

Its faith and trust in God for this protection.

A personal connection with the water.
4) Best thing about Niue

Sense of place. Belonging, ownership of land, culture, identity. Safety for children. Freedom. Free resources. Paradise. Weather: tropical climate. 


\subsection{Participatory design}

\section{Resilience}

The first step of the participatory design was to provide the participants with design strategies that will ensure minimising wave damage on site and safeguard people from future cyclones.

The main threats were identified as:

- The waves

- Cyclonic winds.

The focus group chosen were the government departments (expertise on the field) and the Alofi village council. The vast experience of the Head of Department on the research topic was important and the experience of the Village council on Aliluki were important in influencing the best design option for Aliluki.

Each group were asked to measure each design strategies based on the design guidelines below and to identity if it works or doesn't work.

\section{Design guidelines}

- Minimise wave damage

- Cost efficient

- Sustainable

- Allow people to stay on the coast

- Safe

The results of the design workshop was recorded and as shown in the next page. 

SEA
COAST

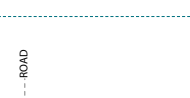

EXISTING APARTMENTS
HILL

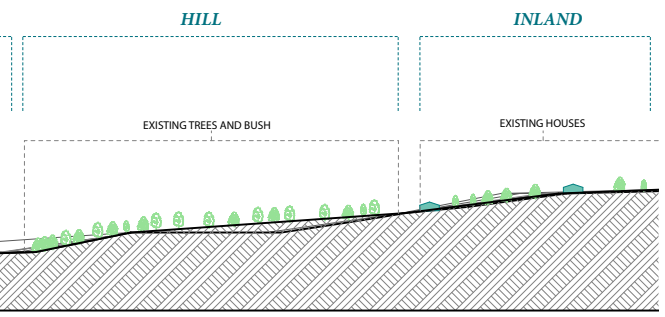

\section{DESIGN STRATEGY 01: NATURAL BARRIER}
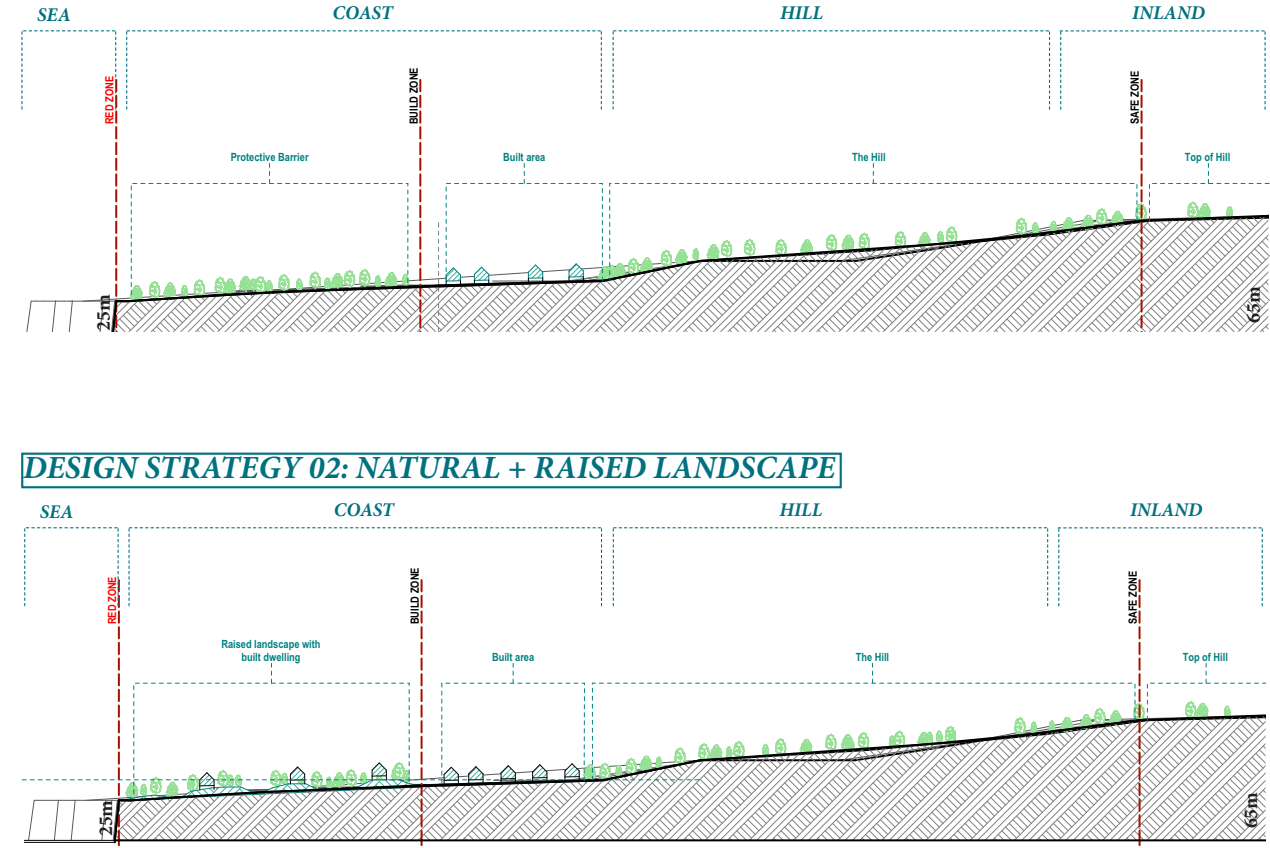

\section{DESIGN STRATEGY 03: RAISED PLATFORM}

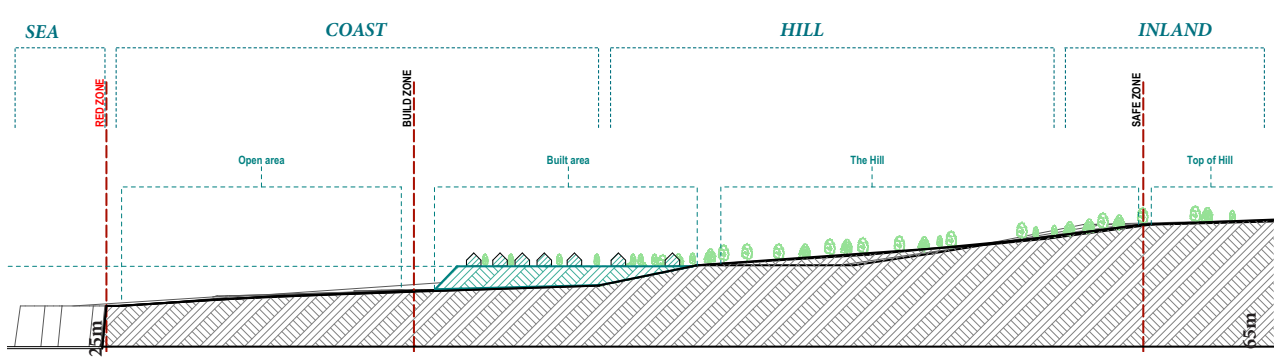

DESIGN STRATEGY 04:BUILDING ON A HILL 


\section{Design Strategy One: Natural Barrier}

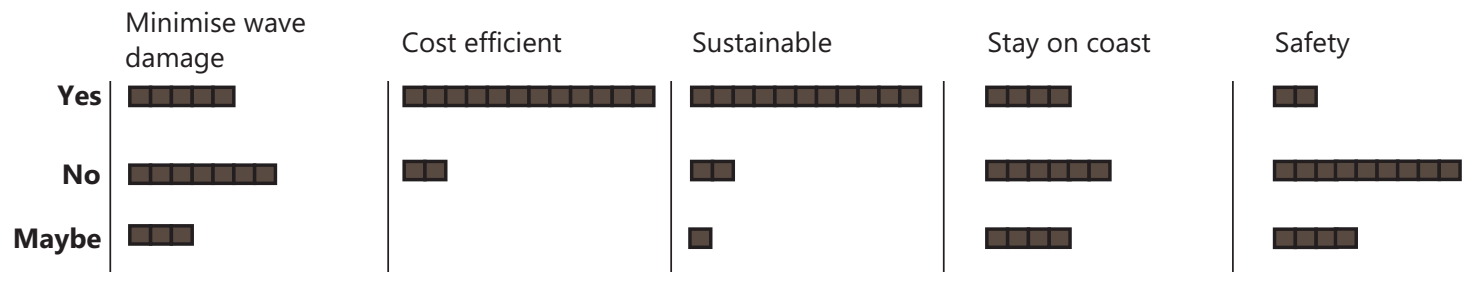

\section{Comments:}

- Based on coastal trees and species, attract birds and restore bird life.

- Safety will depend on cyclone category.

- Tree will block the road and access ways.

- Different wave directions.

- Risky for people's safety.

\section{Ideas:}

- Futu, Pao, Gate, Fetau, Tamanu, Kalaka, Tuna.

- Design needs to take into consideration local conditions, Plants and soil need to look into retaining walls.

- Hardy soil structures. Rock phase.

- Blend the local environment with the available technology to determine the most appropriate methods of mitigation.

\section{Design Strategy Two: Natural Barrier + Raised Landscape}

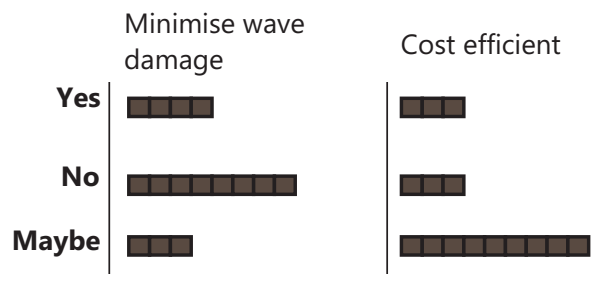

Comments:

- Trees will cause more damage, too close to houses

- Costing, tenure of land.

- Combination with other structure, landscape may help.

- Wave buffer needs plants that are resistant to salt water damage.

- Not recommended, at own risk.

- The engineering of any raised landscape must be of type approved to provide the landscape needed for resilience.
Sustainable

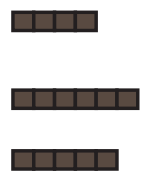

Stay on coast

Safety

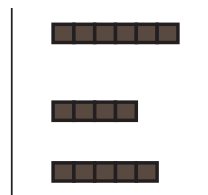

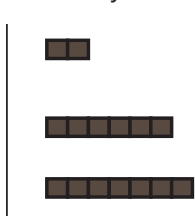

Ideas:

- No trees, no houses.

- Walking, heritage park.

Recognize historical site

- Ensure its done properly.

- Not suitable for building houses.

- Soil structure is secured before it can be raised.

- Resting area is a great idea.

- Can be built on the raised landscape. 
Design Strategy Three: Raised Platform

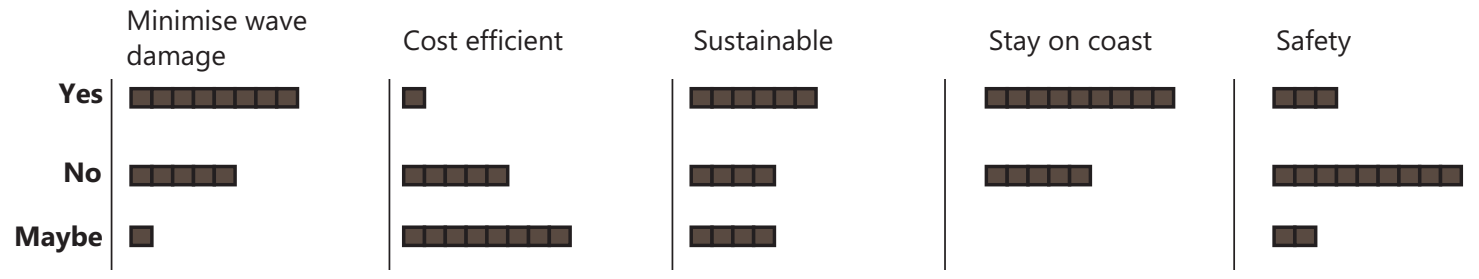

\section{Comments:}

- Cost to high.

- Not enough natural resources, land disputes, delays in project.

- Damage to historic sites.

- Possible compromise with the view \& need for protection.

- Planting the trees and raised platform $1+3$.

- Ensure that there is no erosion.

\section{Ideas:}

- Depending on the robustness of the raised platform. It may become hazardous as a result of waves.

- Pilot concept first.

- Use other options or precast structure.

- Build a concrete retaining wall in front of raised platform.

- Incorporate historic sites, blend with the natural environment.

\section{Design Strategy Four: The Hill}

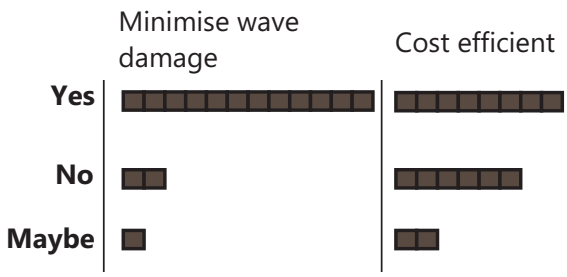

\section{Comments:}

- Development of area is costly, damage to wildlife.

- Safety from wave damage but exposed to wind damage.

- Too much open space, no buffer.

- Access maybe a challenge.

- Land disputes.

- Lost of identity on the coastal area.

- Encroachment into private family land.
Sustainable

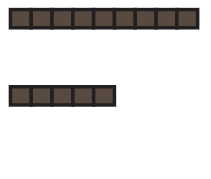

Stay on coast

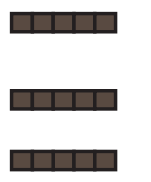

Safety

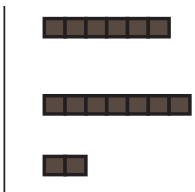

\section{Ideas:}

- Engineered design houses that can withstand high winds.

- Park and rec area in the open area.

- Historical sites enhanced.

- Safety from wave damage.

- Good for accommodation.

- Mobile houses like containers move during cyclone season.

- Worth investing in a house. 

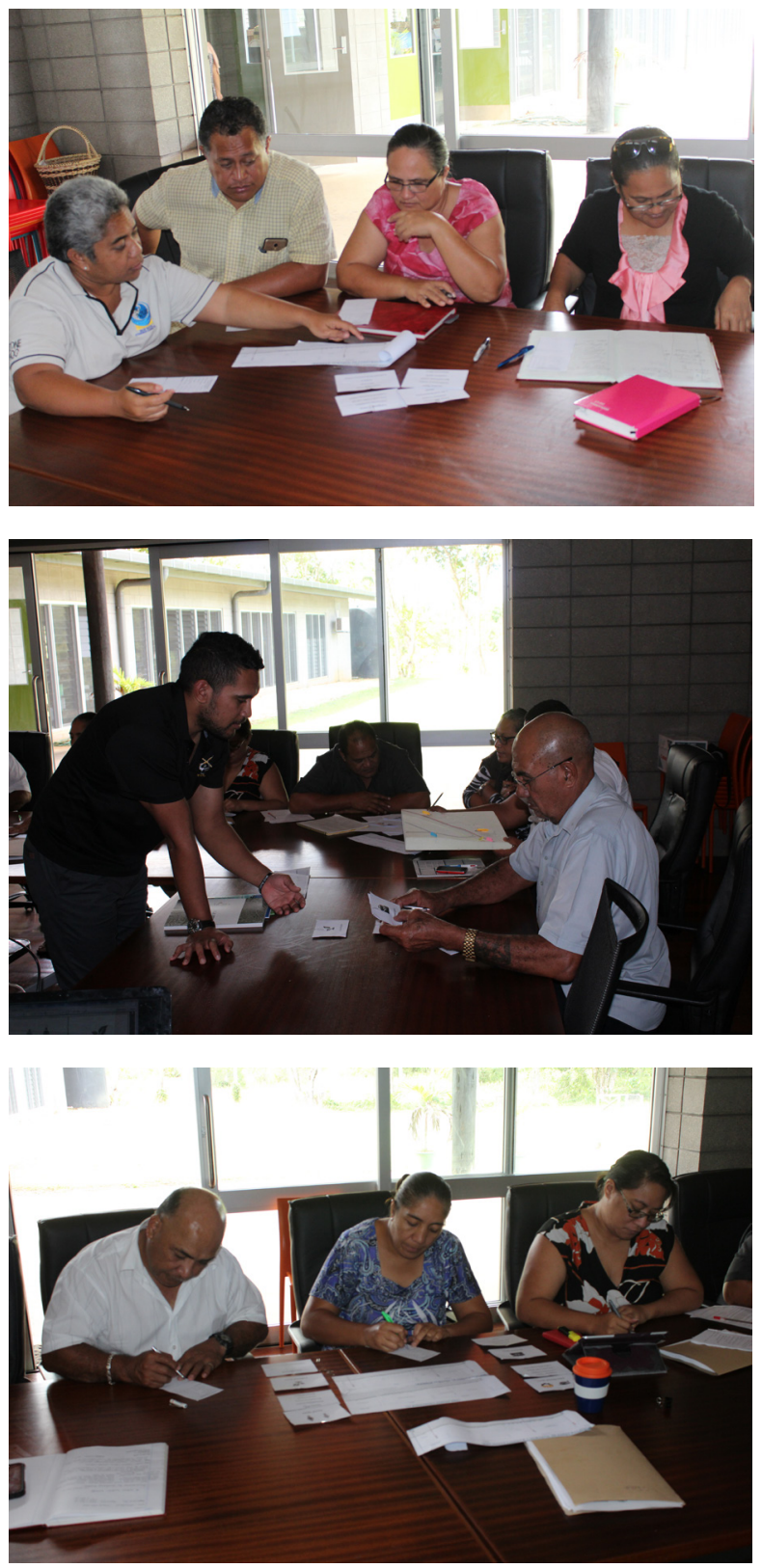

\section{Key Concerns}

- Tamakautoga is the best site according to the studies. Ideal type of house considering the environment, especially the coastal side.

- Is it worth building on the coastal side (Business wise), High risk?

- How do you compromise, safety, looking at views if we have trees?

- Consider different paths of cyclones, standards for the investments must meet cyclone red zone area, consider the purpose of building and needs, the requirements, businesses or home?

- Design criterias, building codes, ensure that design meets the building codes standards.

- No discussion with the people when building the Govt building, no public confrontations or forum, no connection with people.

- Frequency of cyclones, environmental factors. Natural disaster: no legislation to red zone, build at your own risk, liability is on the people.

- Trees and rocks may act as hindrance and add to destruction of cyclone.

- Does your plan include costing?

- Historic reserves, Pa maka, need to retain heritage and cultural center.

- Migration patterns and inappropriate renewable energy sources. 

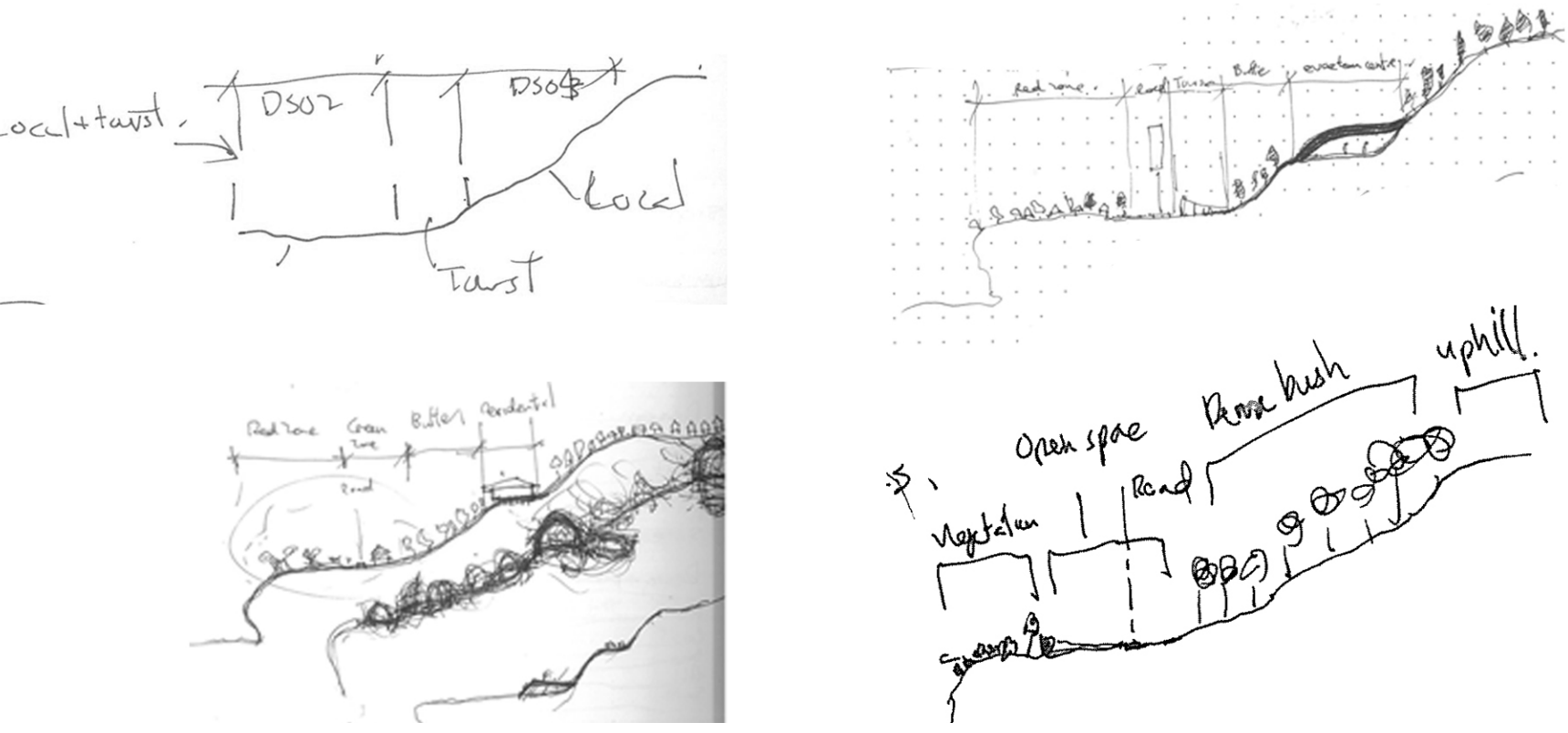


\subsubsection{Identity}

The next stage of the redevelopment of Aliluki was to define a new identity for the site.

Three focus groups were chosen to undertake this design exercise, the government, the Alofi South village council and the high school students. They were chosen because of their knowledge of the site, community involvement and to get a more fun and exciting perspective on the possibilities that could go on site.

Program cards were used to get a general understanding of what the best redevelopment plan is. Ranking from the most important to the least important and giving the reasoning why.

A site model was also CNC routed to give participants a deeper understanding of the different zones and how a resilient solution must also work with a new identity of the site.

The results are recorded, summarised and will be used to inform the later design.
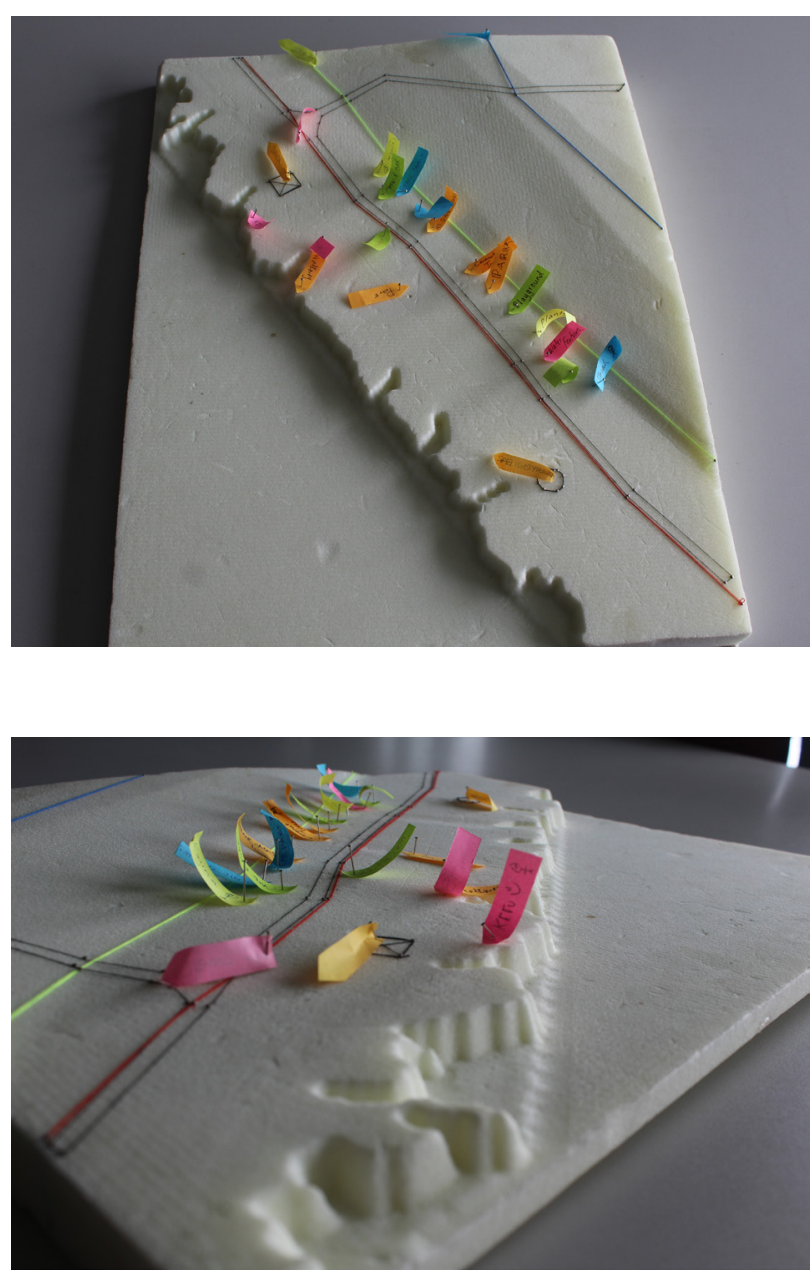

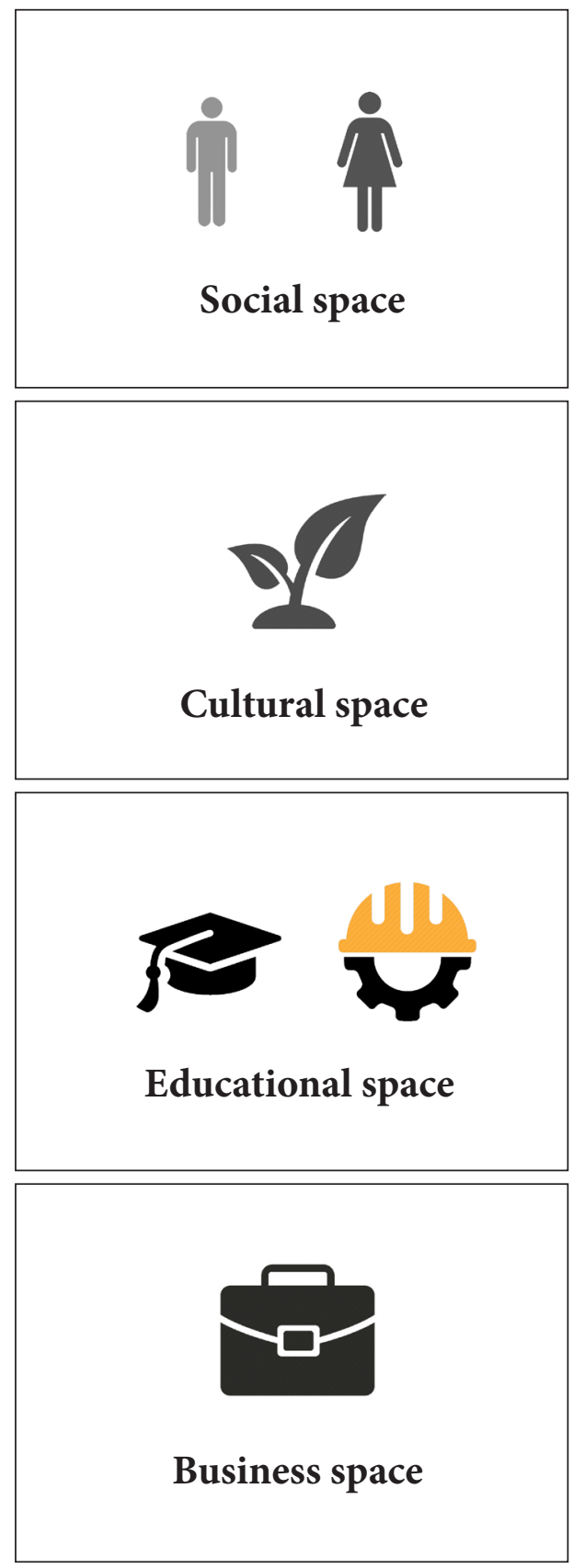

\begin{tabular}{|c|}
\hline Market Place \\
Performance centre \\
Recreational centre \\
Outdoor park \\
Memorial Place
\end{tabular}

\section{Cultural Centre}

Museum

Gallery

Cultural Performance centre

\section{Language Centre}

University Facilities

Arts and Crafts school

Cultural learning centre

Local Businesses

Tourism Centre

Cafe and Restaurants

Shops 


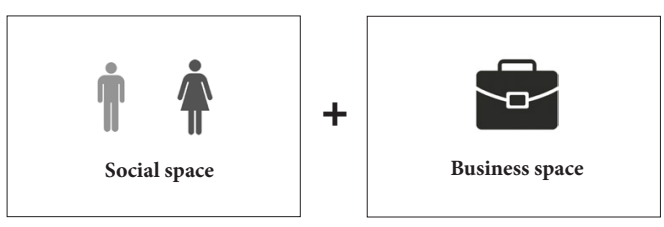

\section{Rationale:}

It would be cost effective, sustainable and inclusive of many areas. It will also be dynamic and allow for movement between different features. Pop up business, integrated spaces for socializing.

Compliment the Huanaki performance area and history of place. Open area for the community and visitors. Create recreational facilities to promote healthy living and promote and generate more business and trades.

\section{Alofi South village council response}

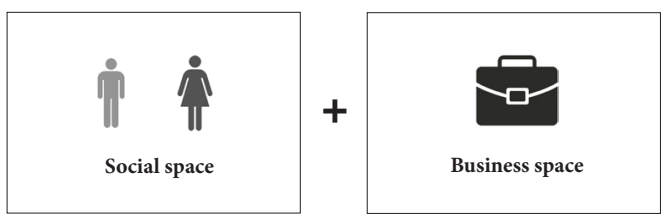

\section{Rationale:}

Alofi South are envisioning the redevelopment of Aliluki to be a vibrant living community. Where the traditions and culture are complimented with the new contemporary and way of living for the Niuean communities.

A Museum or a memorial that shows how strong the cyclone was. Either through a new building or the integration of design into the landscape is one of the main things that the community wanted. To highlight and allow people and visitors to appreciate the power and the full force of the cyclone. 


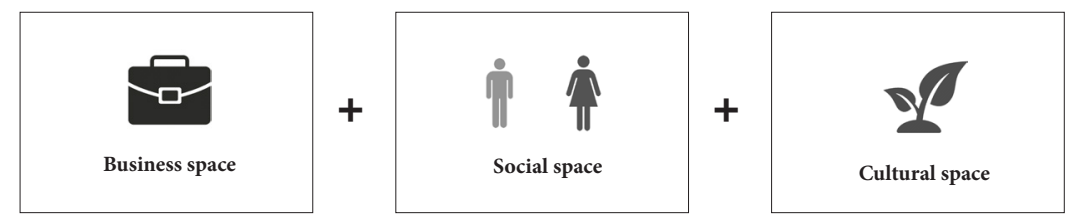

\section{Rationale:}

Culture is not so important to them because they learn culture at home. It is good for the tourist. But the good selling point of the students is through businesses where they can work and earn money, socialize through these different centers, immerse themselves in the culture which therefore becomes the education space that is require of them.

\section{Program suggestions (Red zone):}

- $\quad$ Outdoor park (Proper park): Flying fox, camping space, playground, running tracks, outdoor gym, biking track, sculpture park.

- Swimming pools.

- Fish market.

- Outdoor movie theatre.

- Community garden.

- Coastline walk.

- Outdoor arcade with an outdoor vibe.

- Recreational center.
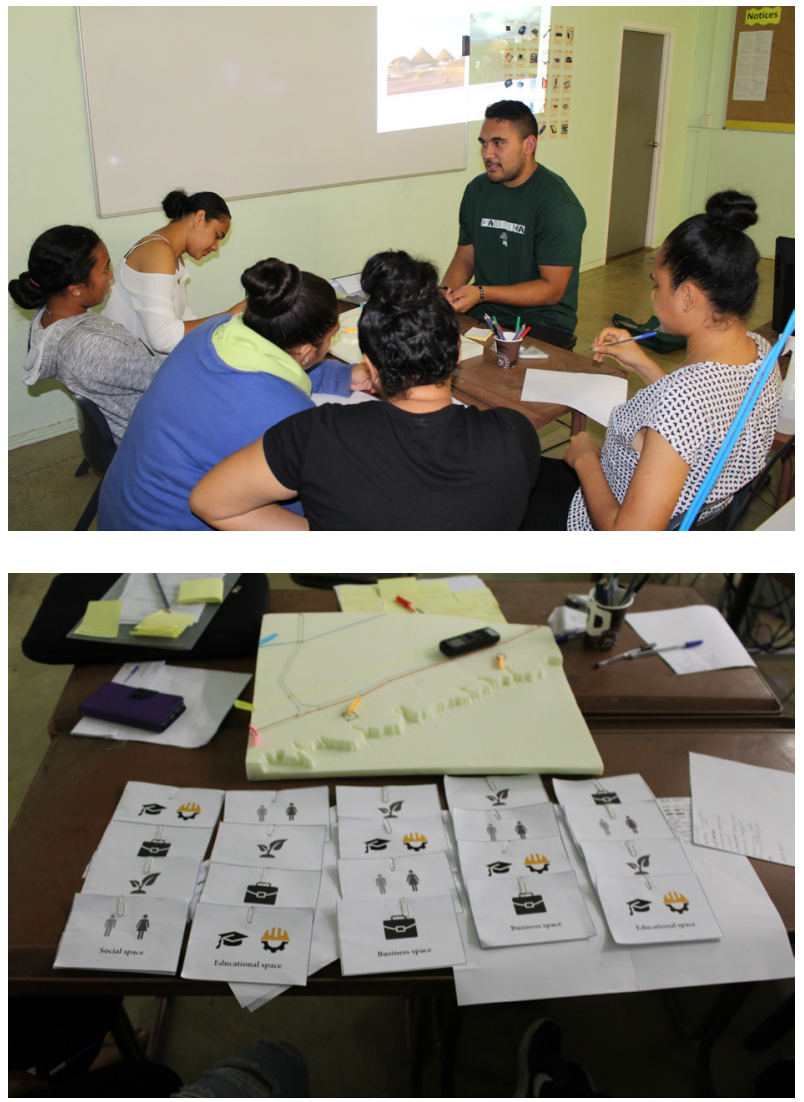


\subsection{Oral Tradition, The Study of The Vernacular.}

Historically, Niuean traditions of passing down knowledge is predominately done orally through songs, chants, and stories from generation to generation. Due to the lack of study and documentation of local traditions and knowledge to do with Niuean building traditions and architecture, this section aims to explore this knowledge through the same method of word of mouth through interviewing respected elders within the community.

For this research, participants were chosen based on their wealth of knowledge on the topic, their understanding of the history and tradition of Niue, and their position as respected elders within their villages and the Niuean community.

The primary aims of the interviews were to identify traditional building techniques and methods that were used by locals historically, to better withstand cyclones. The interviews conducted however provide more in-depth knowledge by the participants on Niue's built environment this research only covers this information very briefly. A separate work will involve the detail documentation of the participants' narratives, outside this study

The results of the interviews are summarised and documented through images and general knowledge information. 

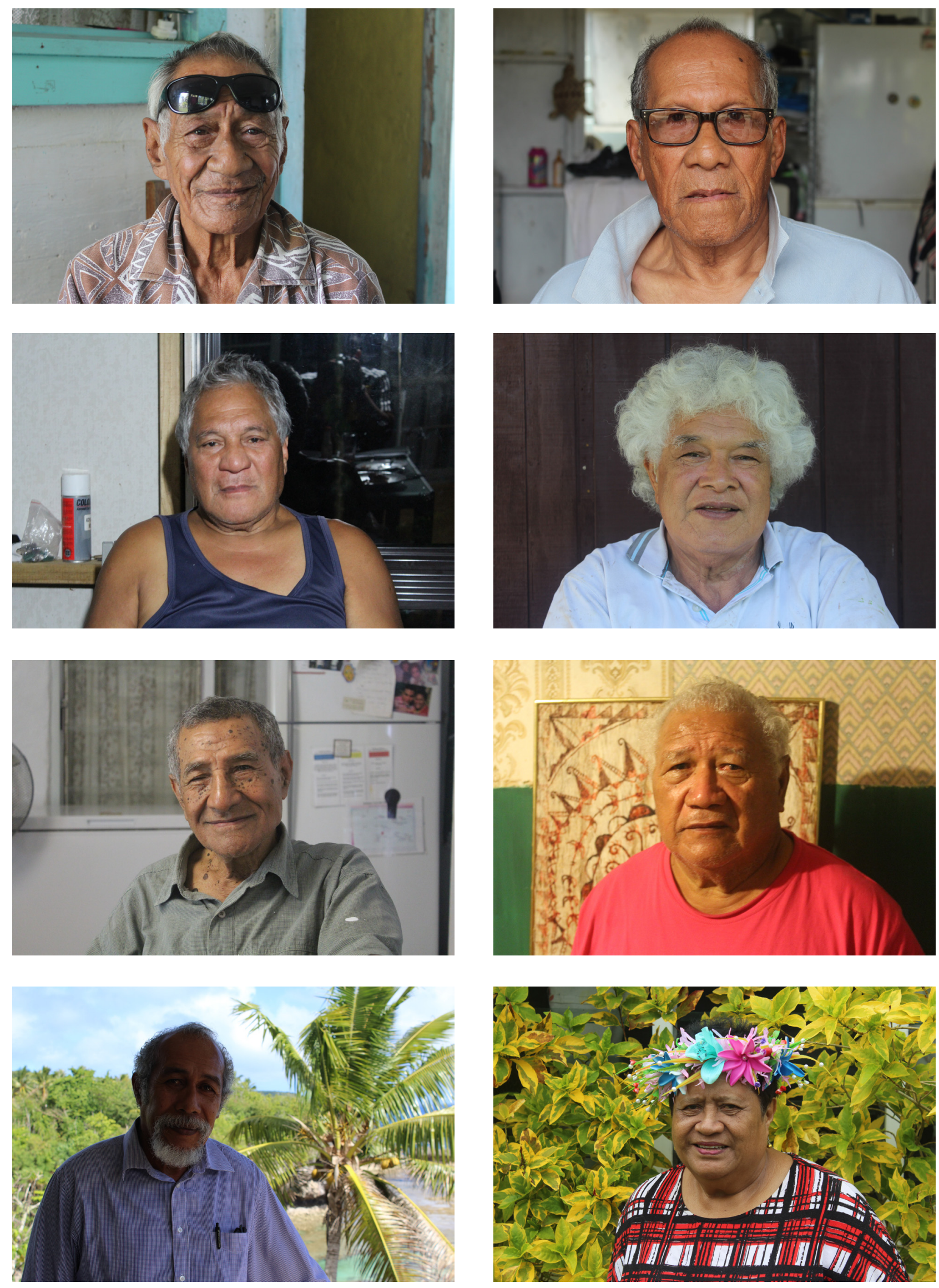


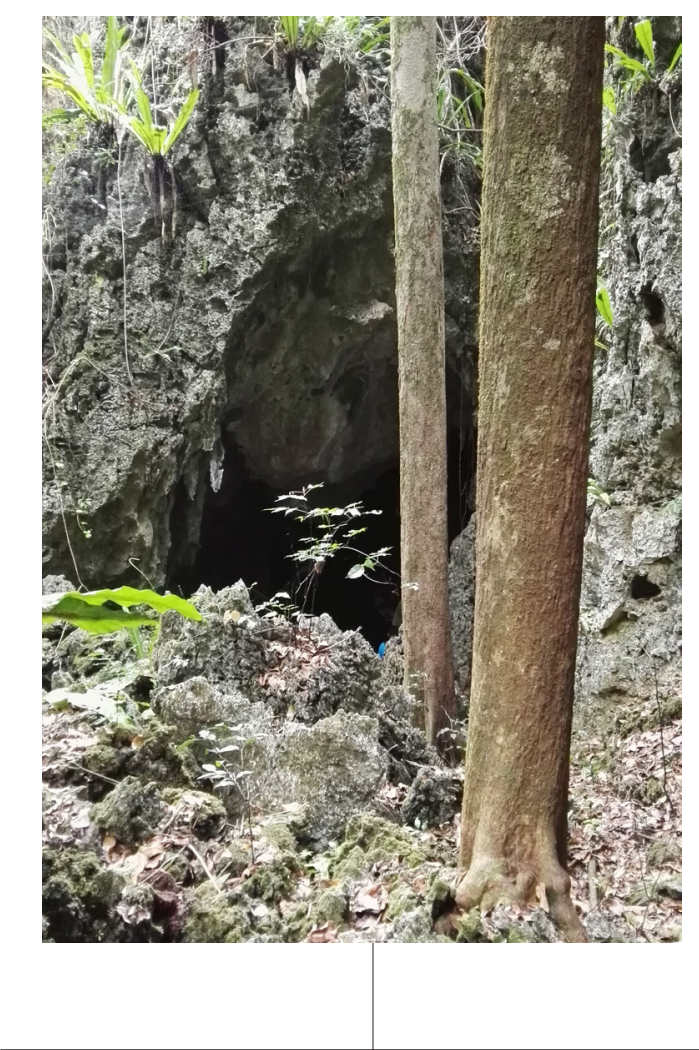

Figure 112. Family cave used for shelter during Cyclone

\section{1) Caves/Ana}

Use: During the first settlements of Niueans, majority if not all used the caves as their shelter, home and safety from cyclones, and their enemies. The use of the caves varied depending on the size of the cave. It was used as shelter from warfare (Taue), a gathering place for the people to cool down, wash clothes, gather water and socialize, and mainly as a home for each family.

Form and construction: This was the unique and natural terrain of Niue, providing the Island with an abundant of caves all around the Island. Caves range from different sizes and also had different use.
Pre Christianity
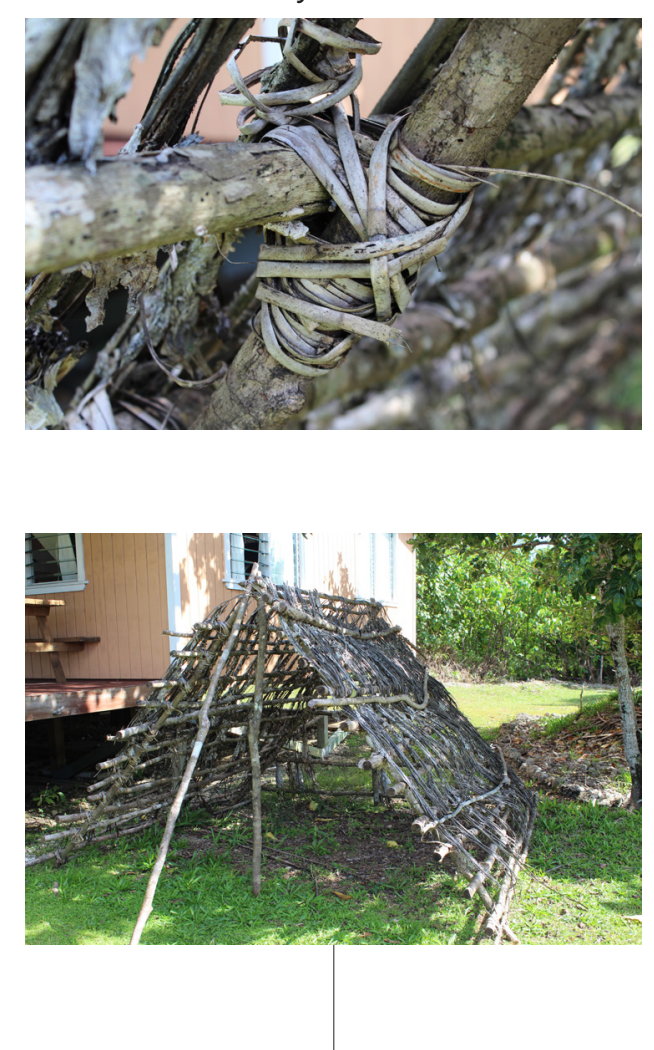

Taoga Niue Musuem*

\section{2) Fale Luku}

Use: The fale luku was used predominately as a temporary shelter for families while they worked in the fields and forest. It was also used by the warriors as a temporary shelter during warfare.

Form and construction: The form of the fale luku was of a triangle shape where timber pole is placed on the outside and lean in to the ridge in the middle. It was tied with mahi va or ovava roots and covered with Luku leaves as a shelter. 


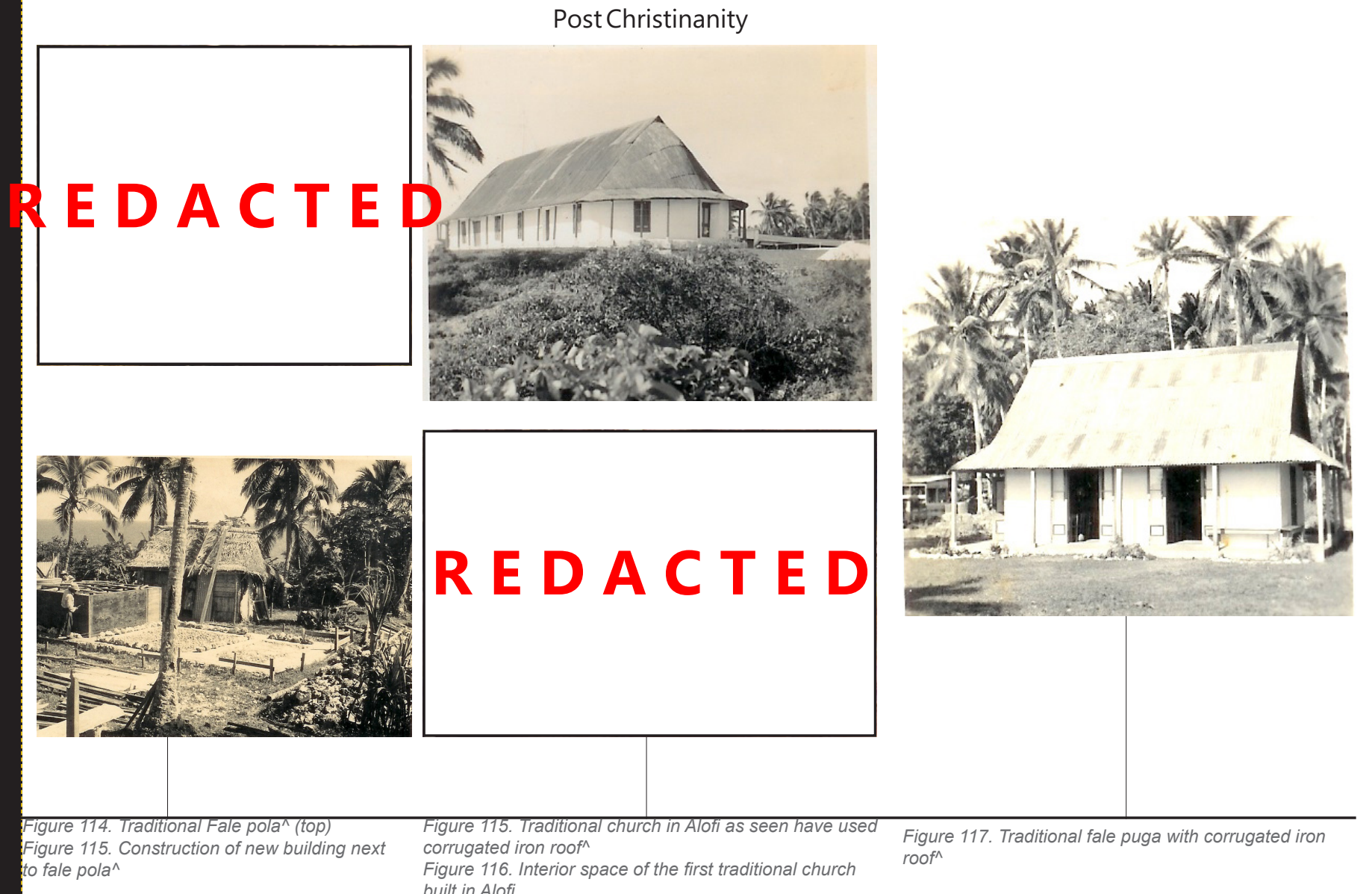

\section{3) Fale Pola}

Use: The fale pola was the first ever recorded shelter that was used as a home or permanent dwelling for the Niuean people. The fale pola was mainly used for sleeping, meetings and storage.

Form and construction: It was a simple house that took a simple rectangle form with a triangle roof. It was constructed out of Kafika (native hard wood) as the main structure with the dried coconut leaves used as the cladding for the house. The structure of the house was tied together by mahi va or coconut woven husks and the foundation usually consisted of fine aggregate as the foundation with woven mats on top.

\section{4) Fale Tapu}

Use: The introduction of christianity brought the concept of church to Niue. The church was used as a place of gathering for the villagers to worship and give thanks to God to whom they believed.

Form and construction: The form of the first church took similar shape to that of a traditional Samoan fale. It had a steep but oval roof with white washed walls. The main external structure was constructed out of limestone rock and internal structure out of $v$ to support the long span roof. All tied together by woven coconut husk. It was covered by sugar cane leaves or dried coconut leaves.

\section{4) Fale Puga}

Use: The fale puga was a development from the traditional fale pola. It had the same use and function, but it was designed and constructed to be more durable.

Form and construction: It took the same form as the fale pola. The external structure was constructed out of Kafika poles that was woven together by smaller Kafika strands (Fitifiti) and plastered with limestone to create an external wall. The roof structure constructed out of Kafika and covered with dried coconut leaves or corrugated roof. All connections were either tied together or nailed. 
枏1

ine
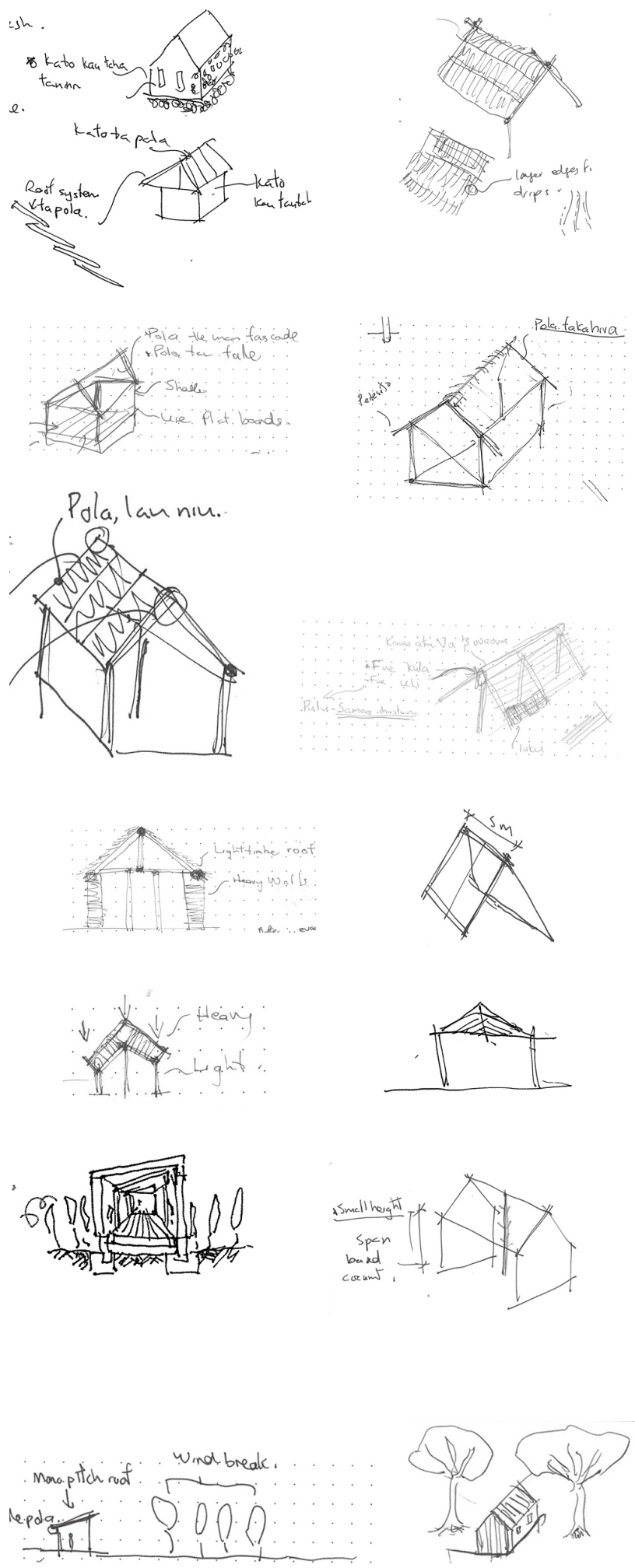
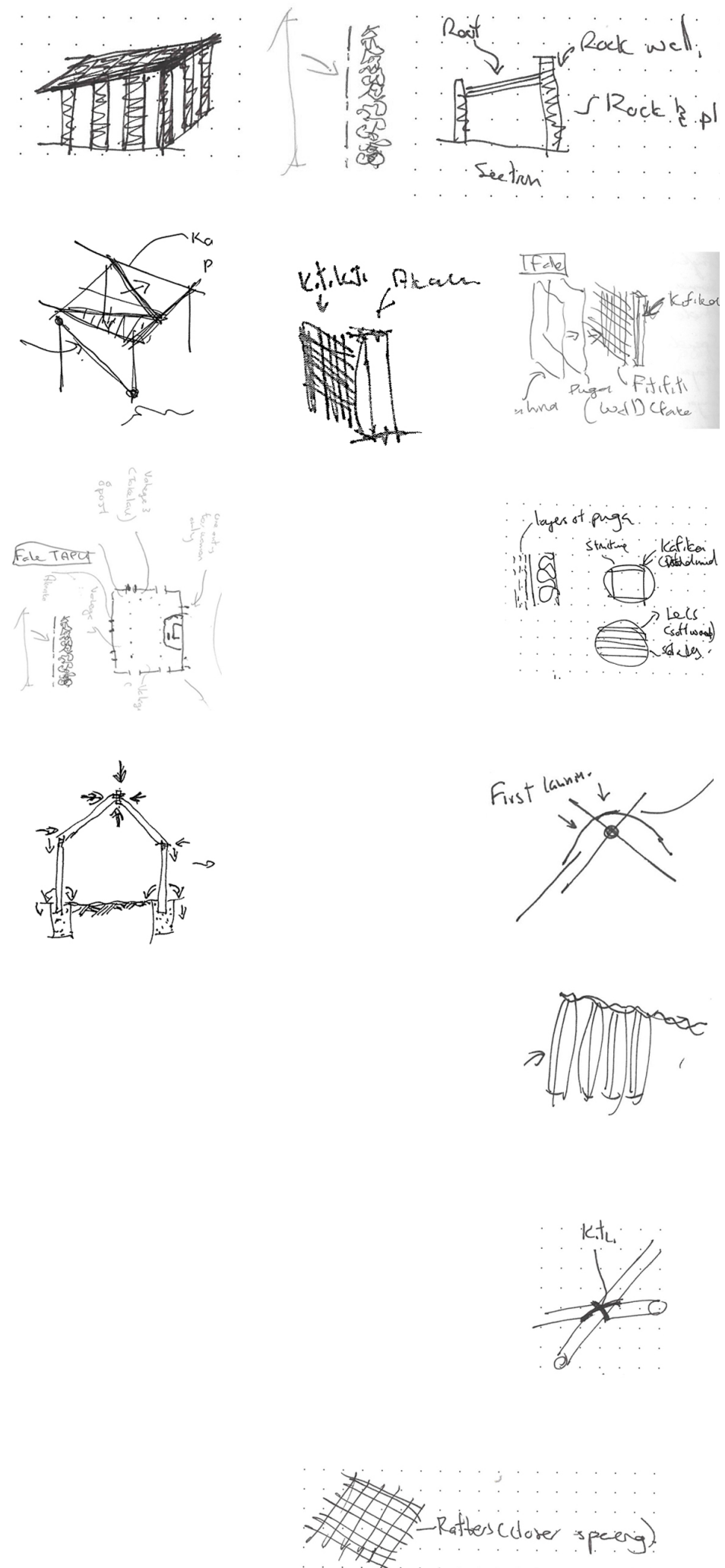


\section{Traditional Building Techniques to Withstand Cyclones}

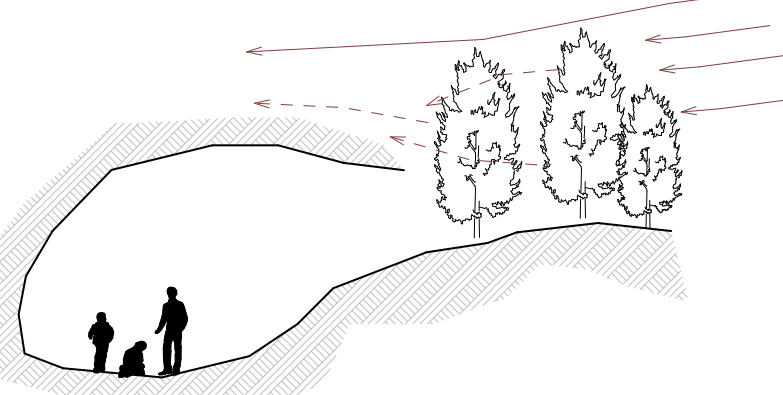

Ana (Caves) were the main source of protection during cyclones

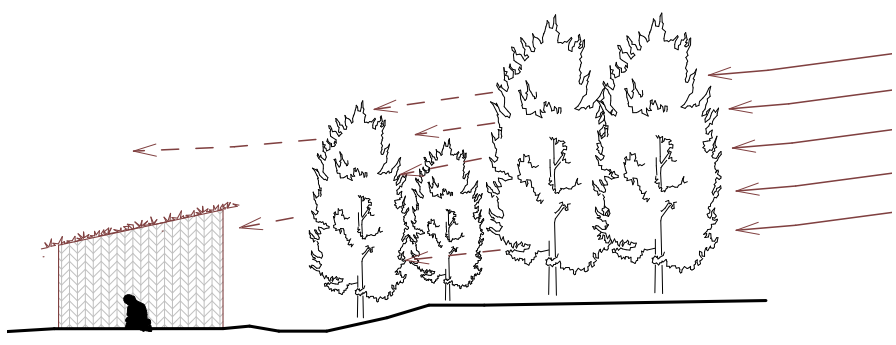

Fale pola (Hut) were build around big trees for protection during cyclones

Predominantly, caves were the safest and most protected form of natural shelters for the Niuean people as mentioned by all the matuas. As more time and investment were spent on the Fale polas, simple techniques were identified and used to protect the houses from the cyclonic winds. These are shown by the diagrams on the next page. Although simple, it can be seen that these techniques are underlying principles for cyclone resistant principles that are used today.

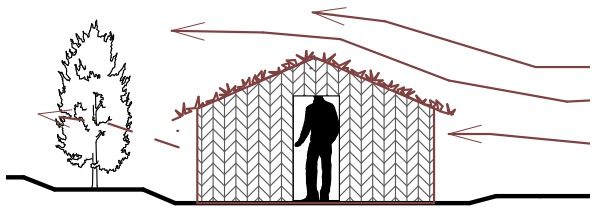

Fale Luku or Fale pola were built really low to allow the wind to blow over it. It also had small openings so less wind could enter the hut

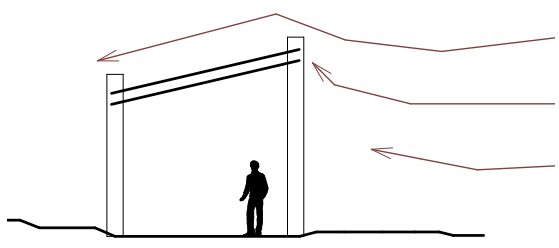

Rock walls were built with the roof built in between these walls to protect the roof from uplift

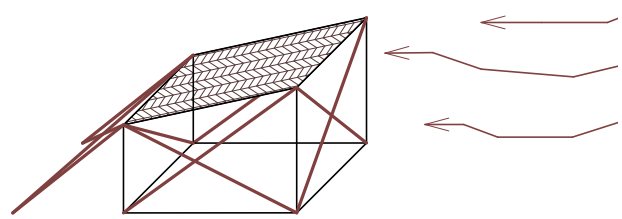

Fale pola (Hut) had extra bracing added on to it, both on the interior and exterior during cyclone season 


\section{Chapter Summary}

Involving the community in the design process of the research was really successful and helped the author have a better understanding of the Niuean culture, the community's perspective, key issues that need to be addressed and most importantly the importance of documenting traditional knowledge to do with local building and vernacular Niue traditions.

In addressing the two components of the design research, the site and the architecture, data collection, participatory design and interviews all helped the author to generate concepts that reflect the community needs and culture in the next stage of this research. 


\section{Key Learnings}

\section{Questionnaires}

- Majority of the students show that they are willing to stay provided that there are more opportunities available.

- Increase in the capacity such as jobs, education, training programs and recreational facilities are needed.

- There is a strong sense of place and identity for the communities living on the coast.

\section{Design strategies}

- A more natural and ecological approach is needed.

- With any solution, there needs to be serious consideration to the surrounding natural environment.

- Land ownership is a key issue for any redevelopment of Aliluki.

\section{Program cards}

- A social and business space is required for the redevelopment of Aliluki as stated by the government and the Alofi South village council.

- More social and recreational programs are needed.

\section{Verncular architecture}

- Caves were the main source of shelter during cyclone seasons.

- Historically traditional church building withstood cyclones but was demolished due to new christianity beliefs.

- Ovava tree acted as a emergency shelter for some of the coastal community during Cyclone Heta. 


\section{0}

-

[.

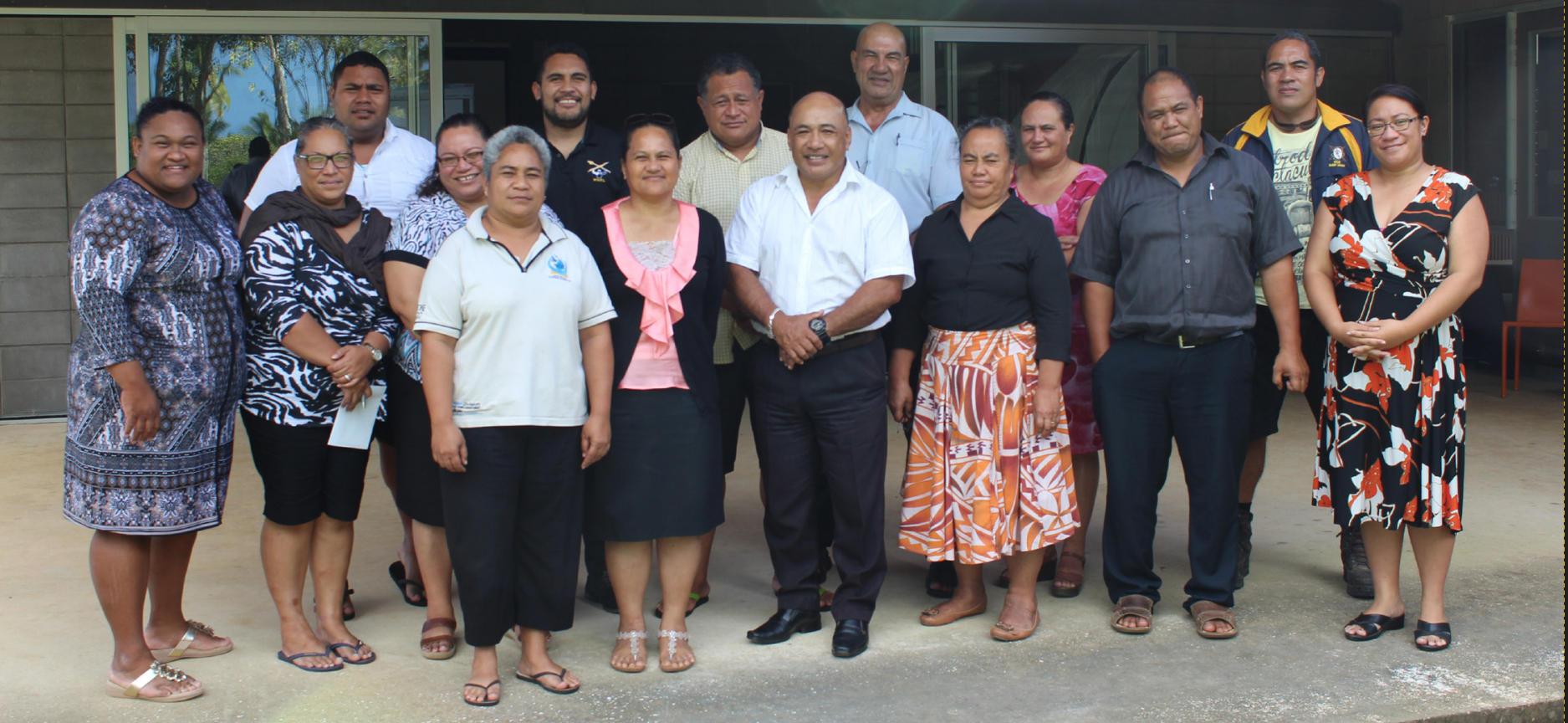




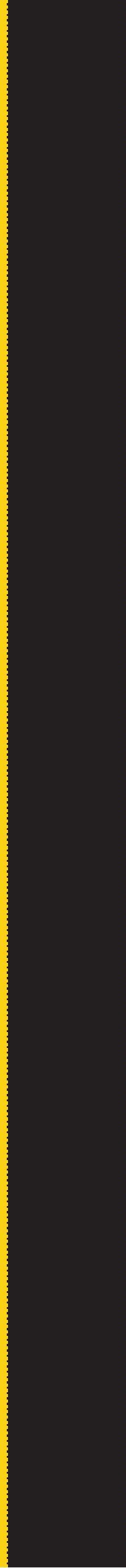




\section{The Process}




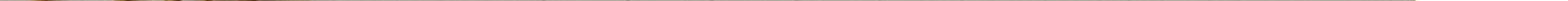




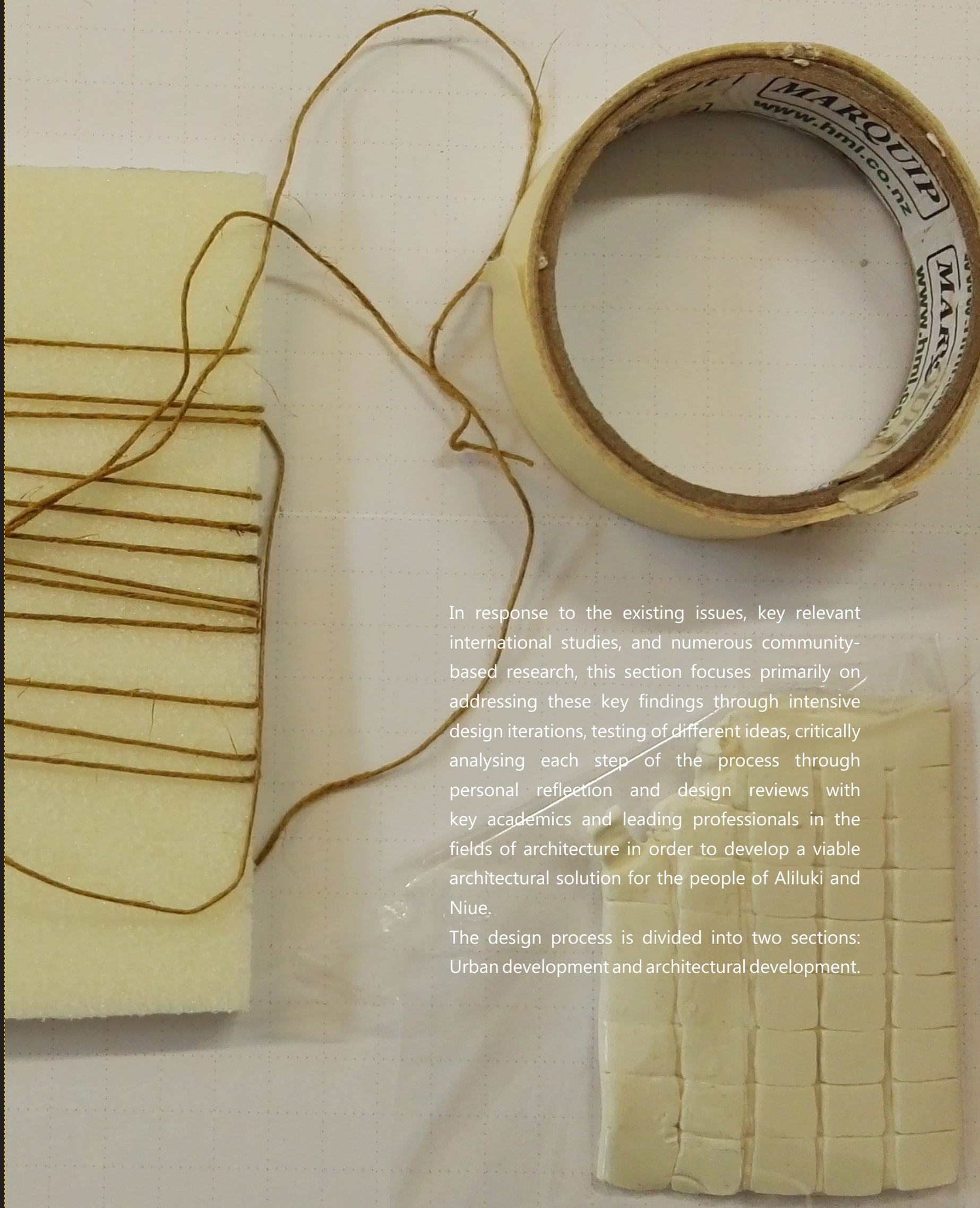




\subsection{Urban Conceptual Design}

The design process starts by looking at redeveloping Aliluki with a primary aim to develop a viable architectural solution that increasing the resilience and sustainability of Aliluki to future disasters and contributes to the economic prosperity of the community through increased opportunity.

The first initial conceptual iterations is in direct response to the literature, case studies and early site investigation. Lessons from Cyclone Heta shows that the main cause of the destruction of Aliluki were the Tsunami waves and Cyclonic winds. The initial design conversation was how to stop or minimise future tsunami waves from destroying the site again and where to locate a redevelopment that is safe for the local community to rebuild.

Initial thoughts was to have a barrier that can stop the waves reaching inland or dissipate the waves full force and to zone the area by identifying high risk zones, medium risk and low risk for future redevelopment.

The three design concepts begins to address these issues, each concept posing its advantages and disadvantages. 


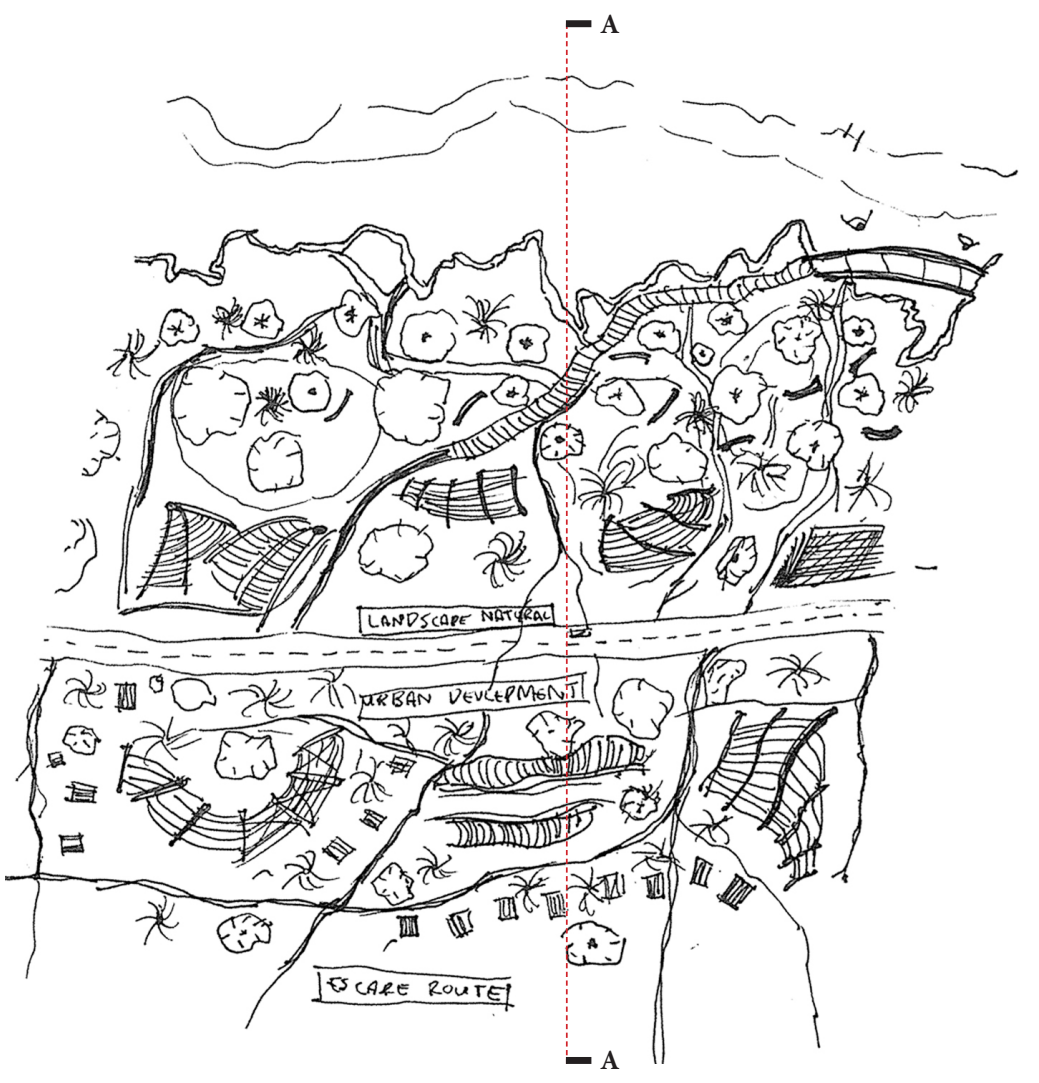

Natural barrier

Architecture

Escape route

Conceptual Site Plan

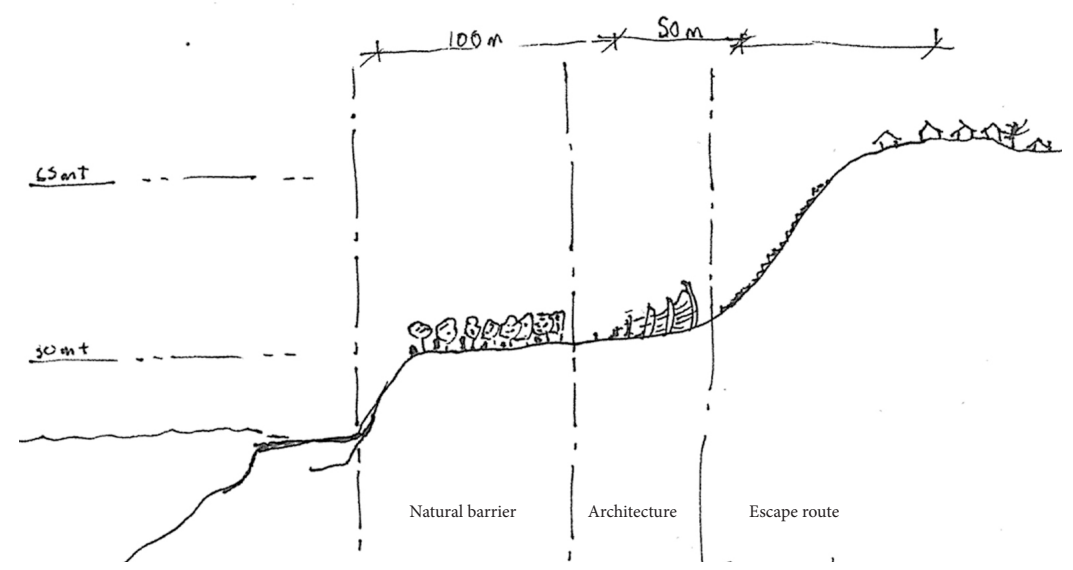

Conceptual Section A-A

\section{NATURAL BARRIER}

Growing and replanting native and coastal trees on the coastal edge to act as a first barrier from the waves and any redevelopment is moved further inland. 

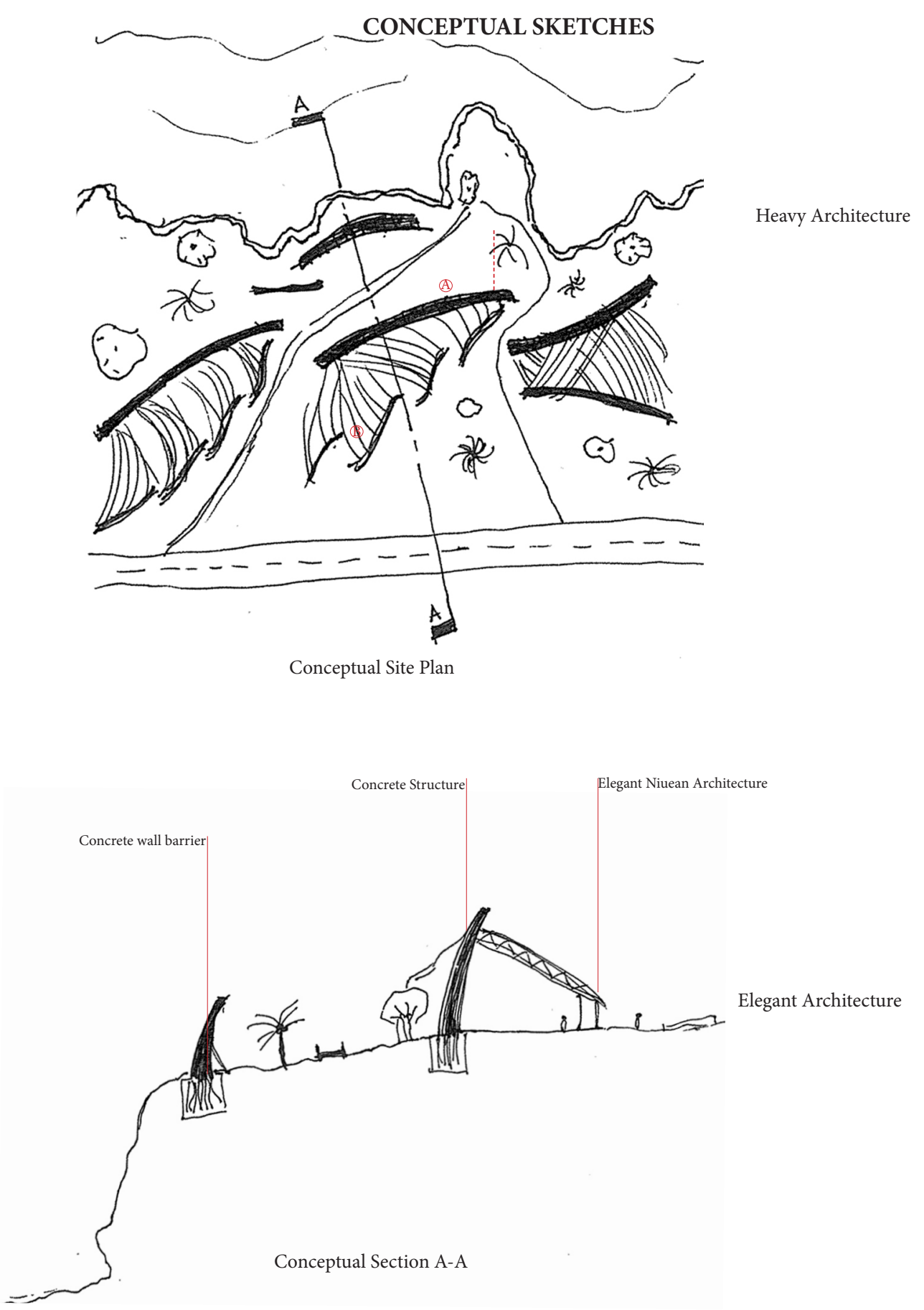

\section{DOMINANT STANCE}

Designing an architecture on the coastal edge which consist of heavy concrete walls facing towards the sea with a light and simple architecture built behind it. 

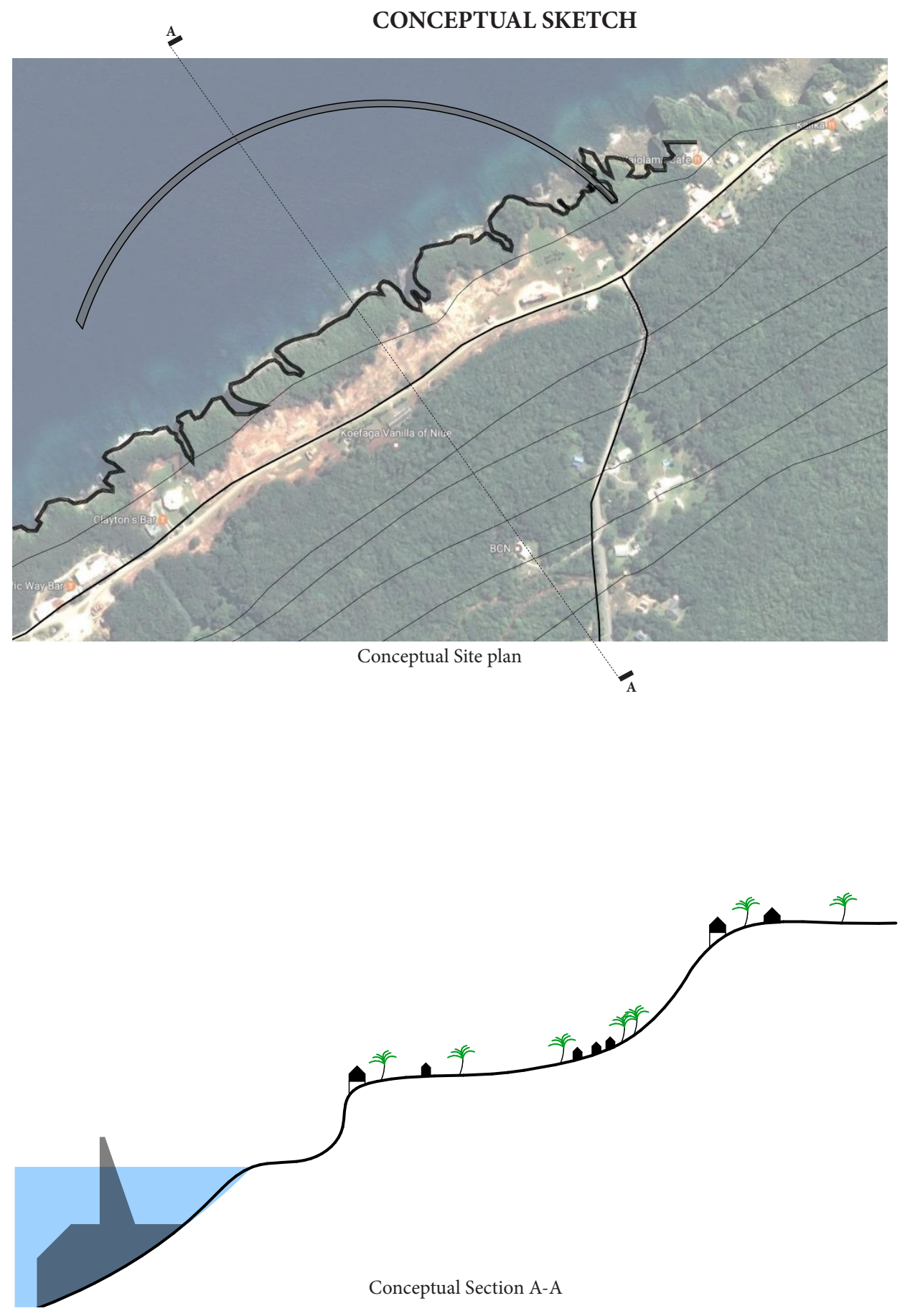

\section{SEA WALL}

Building a sea wall out further at sea to eliminate the build up of waves reaching inland. 


\section{Critical Reflection of Design}

\section{Natural Barrier}

Strength

- This concept resonates with the research issues highlighted in the literature, case studies and site studies.

- Ecological approach is sustainable for the Niuean community.

- Utilising local and natural resources.

- The concept separates the zones well.

Weakness

- Concept is still undeveloped.

- The feasibility of the trees as a barrier is questionable.

- Seperation of the community with the water.

\section{Dominant Stance}

\section{Strength}

- The architectural concept is unique.

- It merges engineering solution with architectural solution.

Weakness

- Hard concrete wall engineering is to complicated and costly to build.

- Feasibility of wall protecting the architecture and people behind it.

\section{Sea Wall}

\section{Strength}

- Conceptually it eliminates the threats of waves.

- It adds connection for the locals to the water.

Weakness

- Sea wall is too expensive to build.

- The sudden drop of the reef makes a sea wall harder to build. 


\section{DESIGN REVIEW ONE FEEDBACK}

\section{Strengths}

- Working with the landscape is the way to go with buildings integrated with it.

- Creating an architecture that is informed by culture will be iconic.

\section{Weakness}

- Unclear clarity on what the research aims to tackle. Urban or architectural.

- Need to identify the the safest area on the Island.

- The landscape solution can only be proven to be resilient after a cyclone.

- A question over the feasibility of the natural barrier.

\section{Suggestions moving forward}

- Urban growth. How would this affect the ecological footprint of the place?

- Is it community resilience or cyclone resilience?

- Start investigating what has resisted cyclones. What systems? What houses? What natural vegetation?

- Look at tourism and how to integrate it into the design.

- Focus the research on providing recommendations formthrm Niuean people based on the development plan. For example, new typology of houses, buildings, production spaces. Give a real and practical proposal to the Niue government.
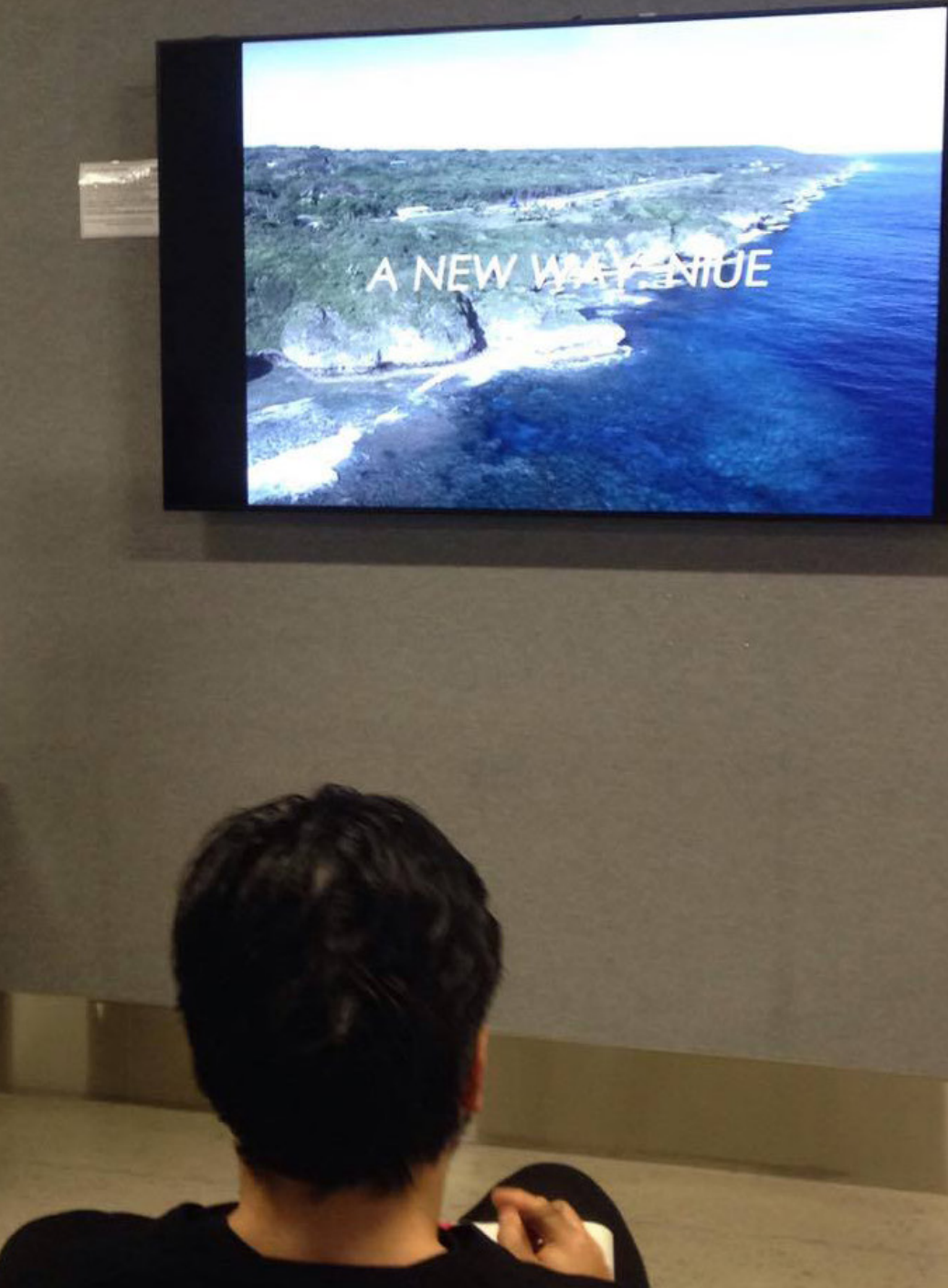


\subsubsection{Urban Developed Design}

The key issues and opportunities raised in the critical reflection were very insightful thus giving this research a clear sense of direction moving forward. Drawing back to the key findings of the literature review and merging the feedback from the design review, methods of data collections during the field study were created to address and explore these issues even further. The field study was a vital part of the research and helped inform all the important key design aspects of the site development moving forward. The list below summarises how the development design was structured. 


\section{Key Issues:}

- Clarity if its Urban or architectural thesis?

- The feasibility of an ecological approach.

- Lack of contextual study.

- Respond also to community resilience.

\section{Key Response:}

- Site specific studies.

- Design workshops.

- Questionnaires.

- Interviews.

- Observations.

\section{Drivers of Design Response.}

- Enhance resilience of Aliluki.

- Revitalizing the site.

\section{Key findings that will influence the master plan}

Design workshop findings

- Based on the participatory design on design strategies, the best option for the redevelopment of the site is combining Design strategy One and Four.

- The program cards revealed that a more social and business orientated space is needed for Aliluki, mainly the coastal area.

- The questionnaires reveals the need for more jobs, more recreational and social programs and the importance of living on the coast.

Site specific studies

- Crevices are the most vulnerable points during storm surge.

- There is a flat upper plateau just before the hill which is good for redevelopment purposes.

Interviews

- Ovava trees protected a lot of the families from the tsunami waves.

- There are plans of redeveloping Aliluki but due to lack of competency, development fell short.

- Red zone area. Government states, build at your own risk. No insurance cover.

\section{Observation}

- Aliluki currently feels very dead and stagnant.

- As a gateway to Niue, Aliluki needs an urgent redevelopment. 
N

$\oplus$ New Coastal Walkway and cycle way with bridges between the coastal edge.

Cantilevered lookout

Main landscape designed design.

Memorial piece

Native and coastal trees to be replanted in the area provided.

Sportsfield

Accomodation for Tourists
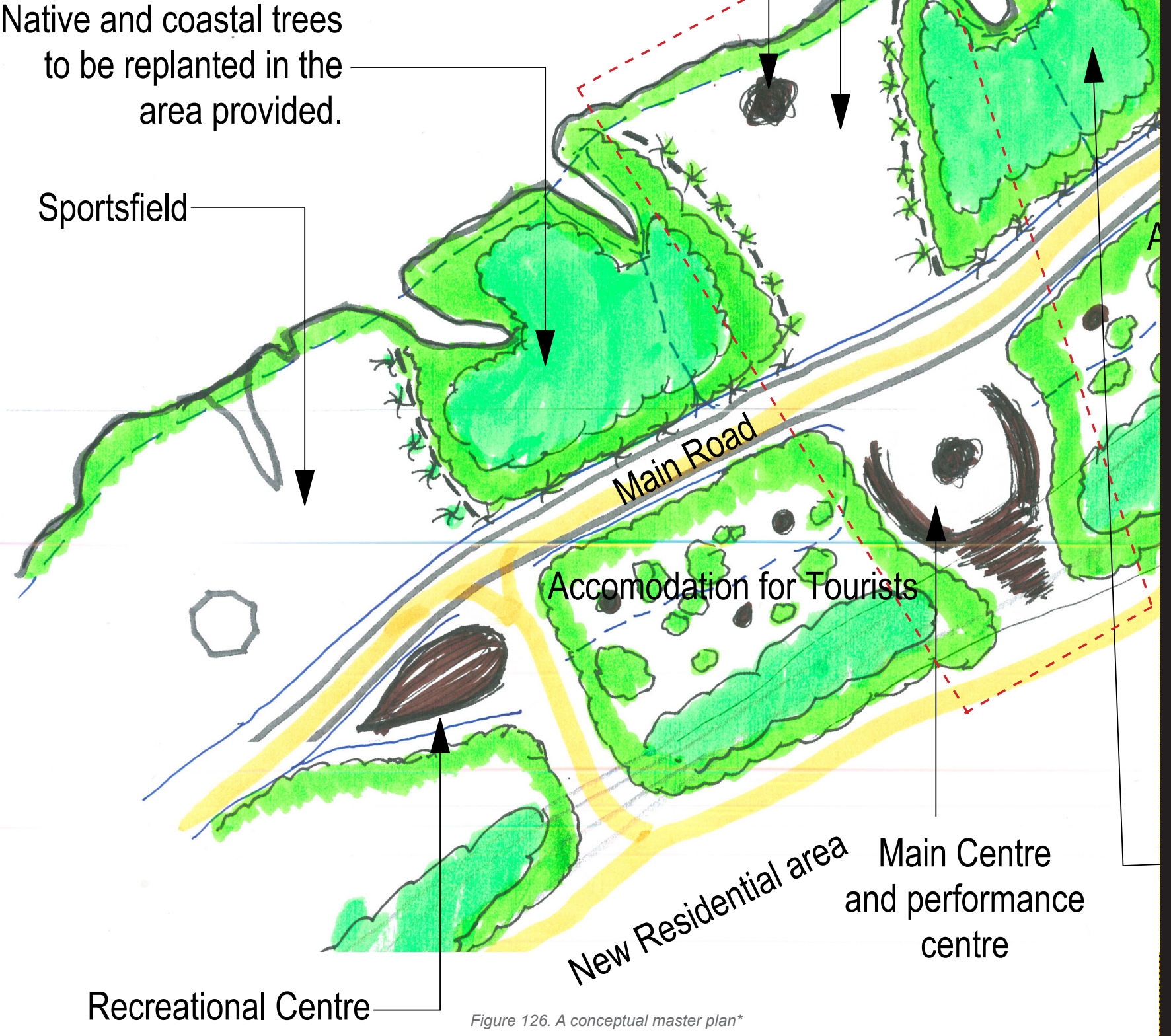


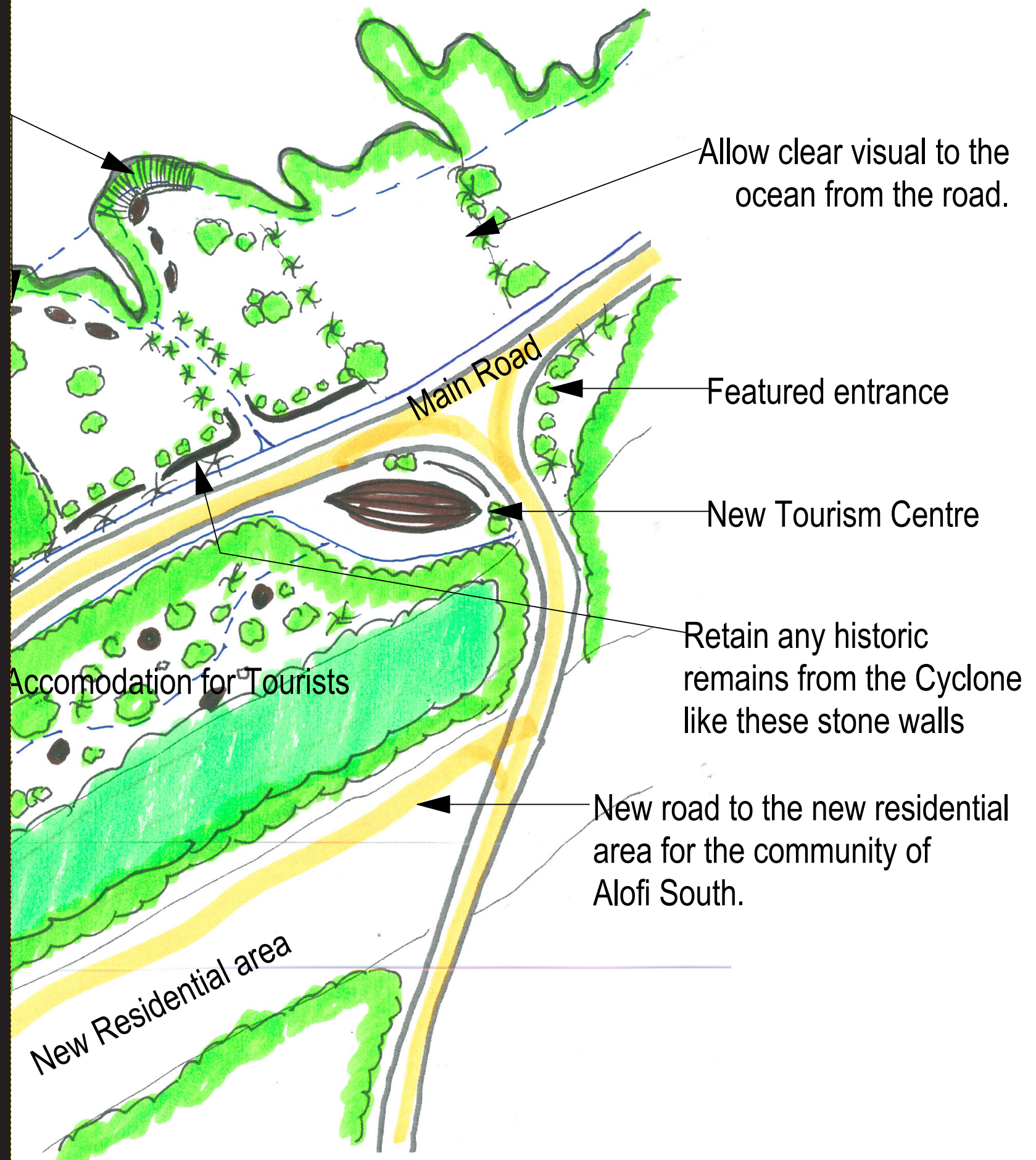

Native and coastal trees

to be replanted in the area provided. 


\section{Key Moves}

01. Zoning the site.

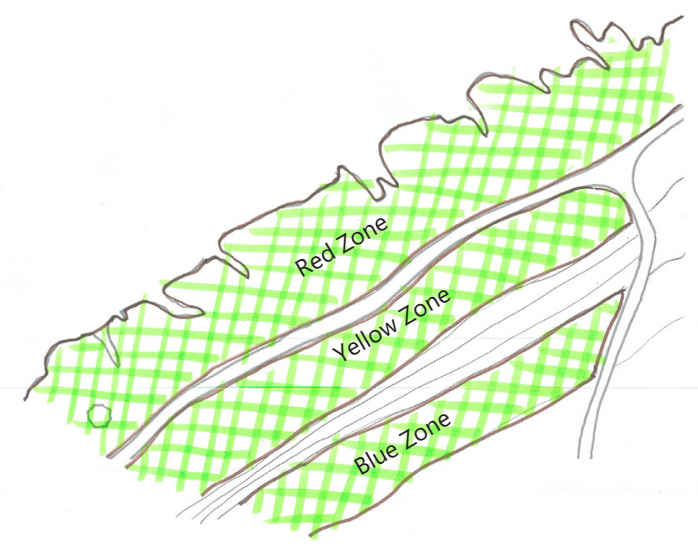

\section{Red Zone}

This zone is for open park areas, walkways and businesses who are looking to utilize the coastal view. Temporary shelters and business can be built on this area.

\section{Yellow Zone}

This zone is for the redevelopment of the area through a new infrastructures and accommodations

\section{Blue Zone}

This zone is specifically for residents still wanting to build close to the coast.

02. Adding a new road

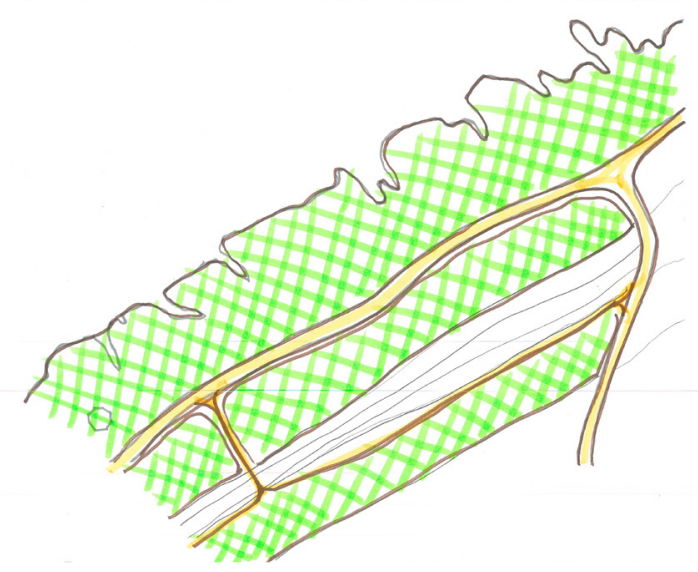

\section{New road}

Adding a new road allows better flow in and out of Aliluki, espeacially during Cyclone season.

03. Creating openings.

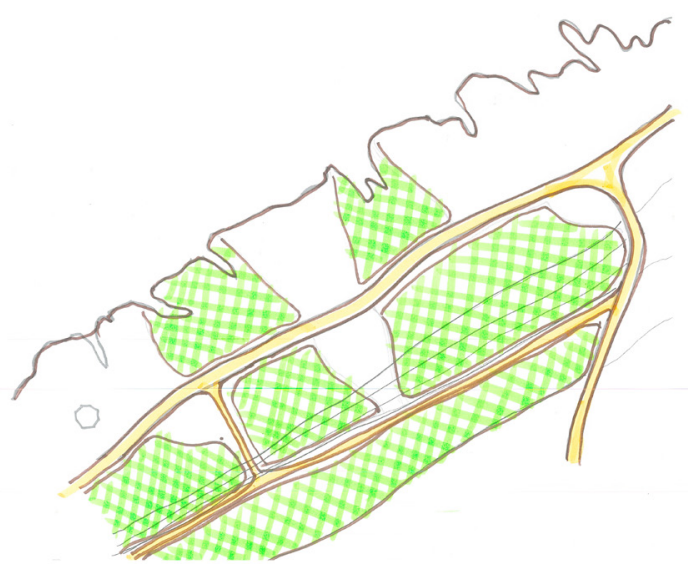

\section{Views}

The identity of the site influences the site geometry. Allowing openings to the sea and natural barrier that protects the site. 


\section{Rationale}

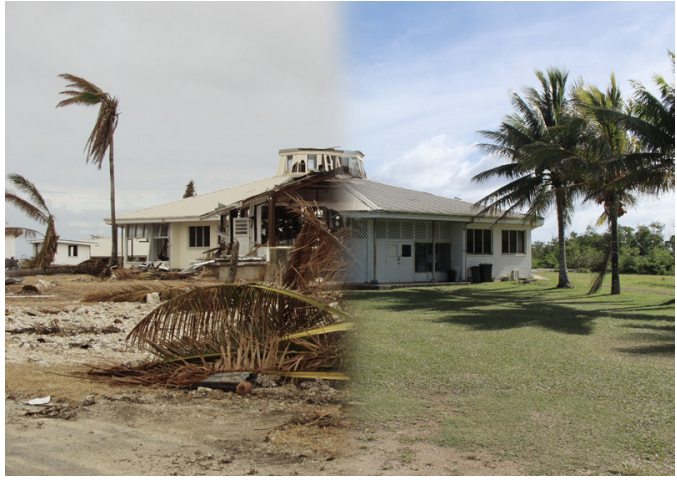

RESILIENCE

01. Natural barrier

02. Rules and regulations

03. Early warning systems.

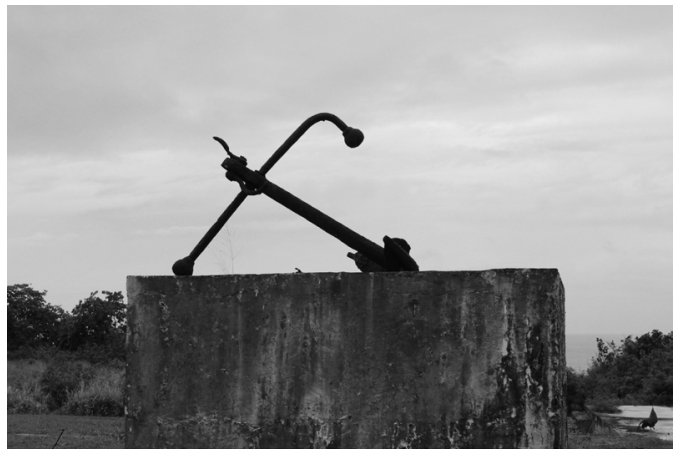

HERITAGE CONSERVATION

01 . Retain heritage infrastructure

02. Retain heritage native trees.

03. Restoration of wildlife.

Figure 128. Image showing Niue Hotel post Heta and now* (top left) Figure 129. A new more social feel, like the image* (top right)

Figure 130. A memorial for the loss in Aliluki* (bottom left)

Figure 131. No order in parking* (bottom right)

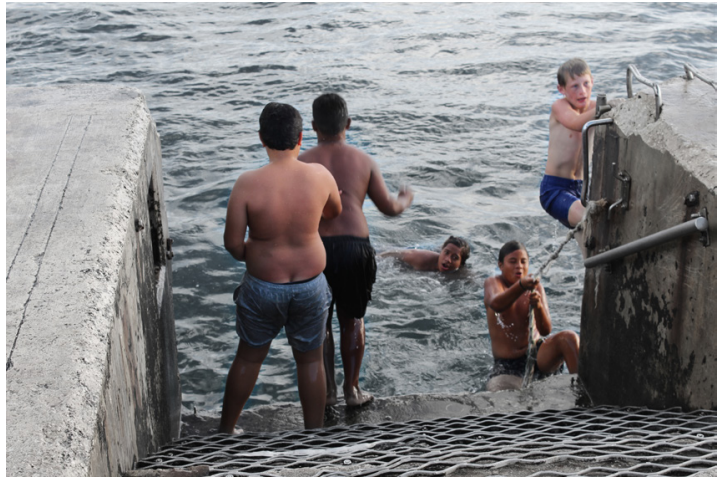

IDENTITY

01. Social + Business space.

02. Resilient stance.

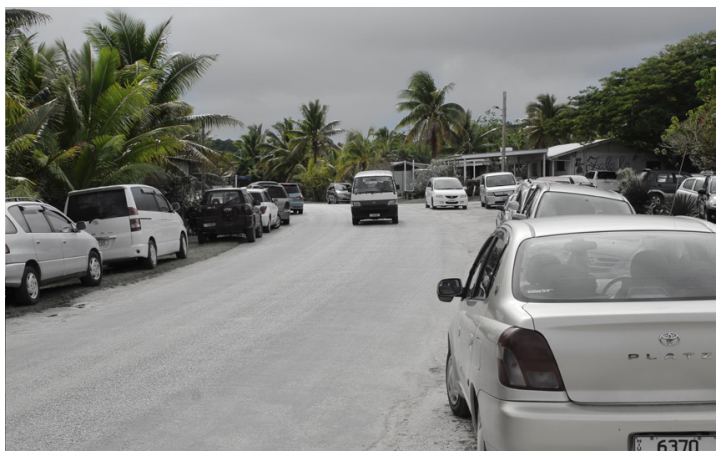

CONNECTION

01 . Road and pedestrian connection.

02. Reconnecting with the water.

03. Visual connection.

04. More escape routes 


\section{Resilience}

\section{NATURAL BARRIER}

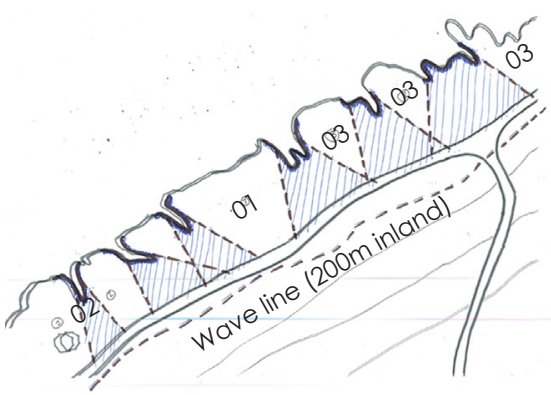

HIGH RISK AREAS

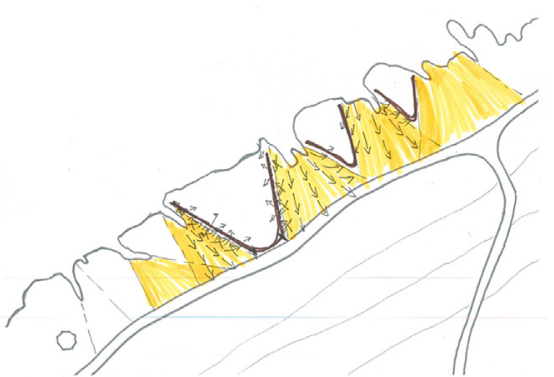

THE DIRECTION OF WAVES

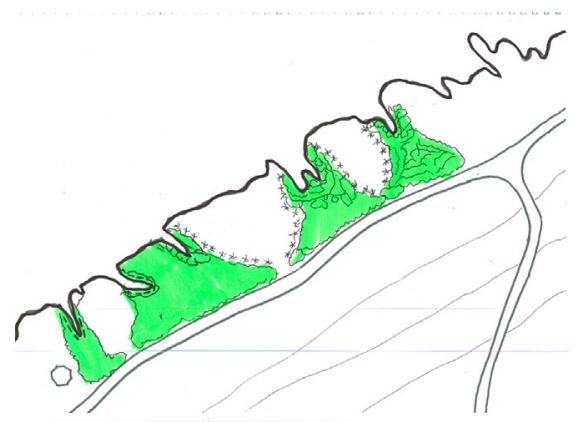

DESIGN RESPONSE

\section{RULES AND REGULATIONS PER ZONES}

\begin{tabular}{|c|c|c|c|}
\hline ARCHITECTURE & RED ZONE & YELLOW ZONE & BLUE ZONE \\
\hline Shelter/Pavilions & - & 口 & [ \\
\hline Residential Dwelling & 口 & 口 & [ \\
\hline Tourist accomdation & 口 & [ & - \\
\hline Buisnesses and shops & 므 & [ & [ \\
\hline Medium Scale & - & 口 & - \\
\hline Commercial Scale & - & 口 & - \\
\hline
\end{tabular}

\section{EARLY WARNING SYSTEMS AND ESCAPE ROUTES}

RED ZONE = Cyclone hitting the island

YELLOW ALERT $=$ Full evacuation to higher grounds

BLUE ALERT $=$ Be on alert 


\section{Identity}

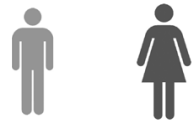

Social space

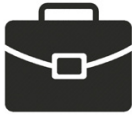

Business space
RED ZONE

Infrastructure Landscape

Pavilions Gym park

Shelters

Accomodation area

Pop up

business

Golf course

Sports field

Cycle ways

Walkways

Vegetation area

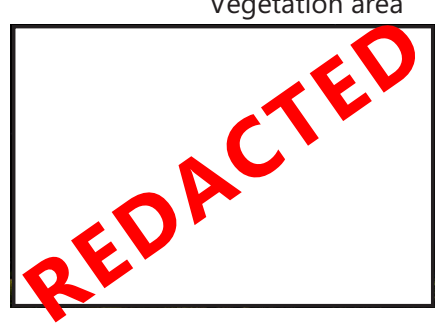

YELLOW ZONE

Infrastructure

Medium size

buildings

Commercial size

buildngs

Tourist accomodation

Pavilions
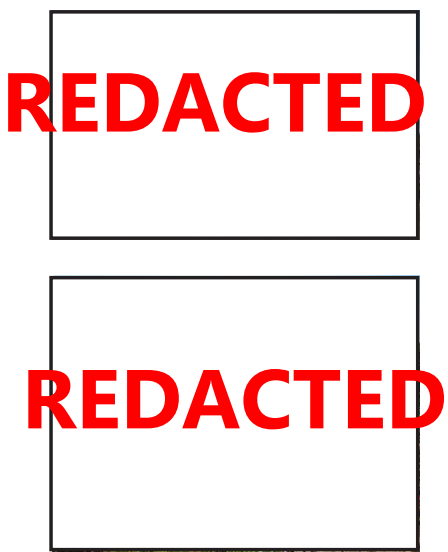

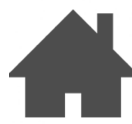

Residential

BLUE ZONE

Residential

Permanent housing

Residential housing

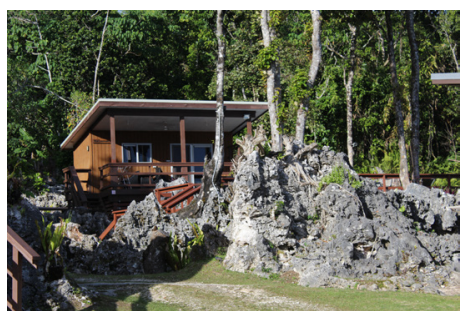




\section{Connection}

STREETSCAPING

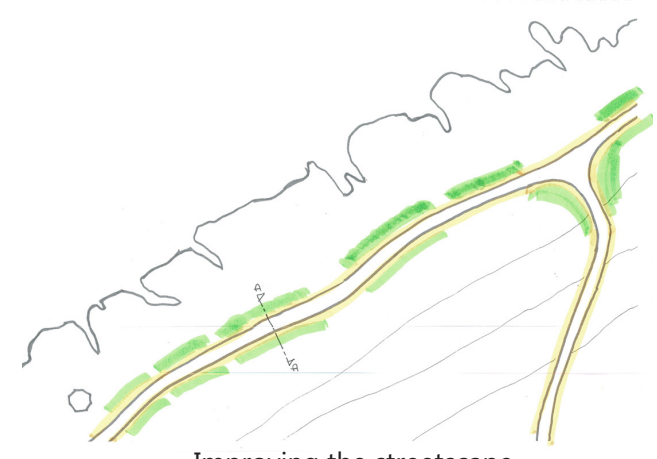

Improving the streetscape of the exisitng roads

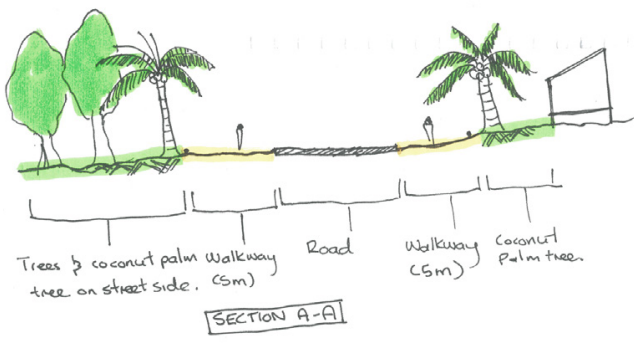

Section of example of design for the road.

\section{CONNECTION TO THE SEA}
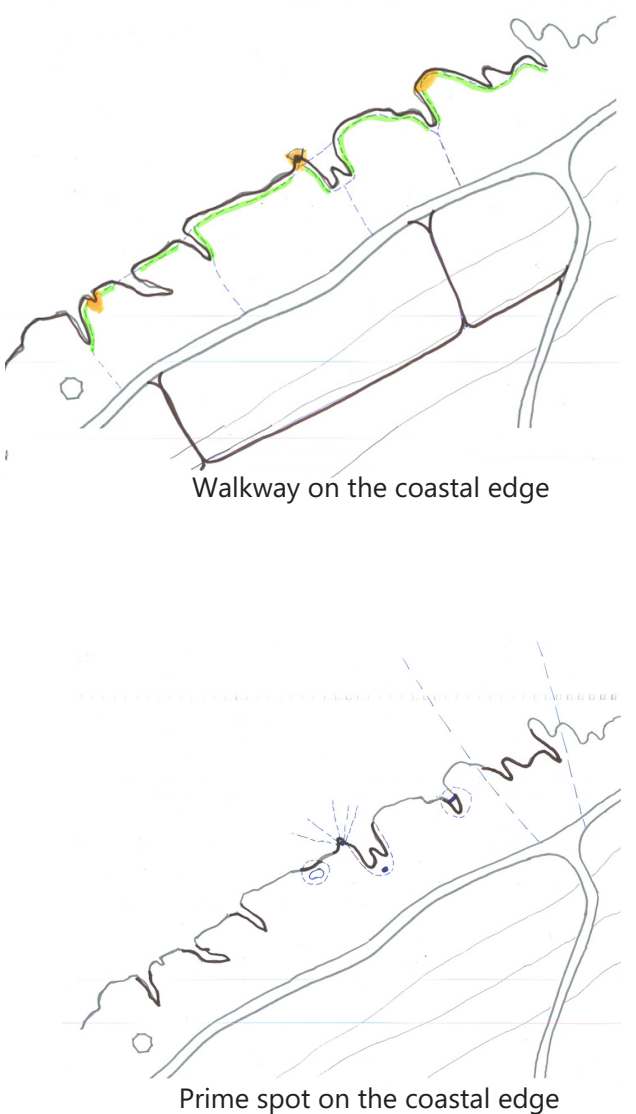

VISUAL CONNECTION

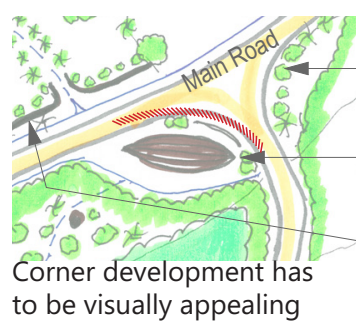

to be visually appealing

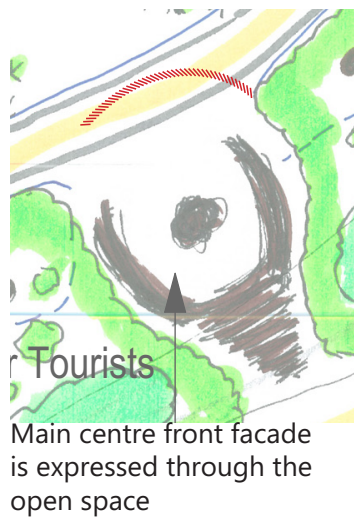

Main road junction design 
HERITAGE INFRASTRUCTURE

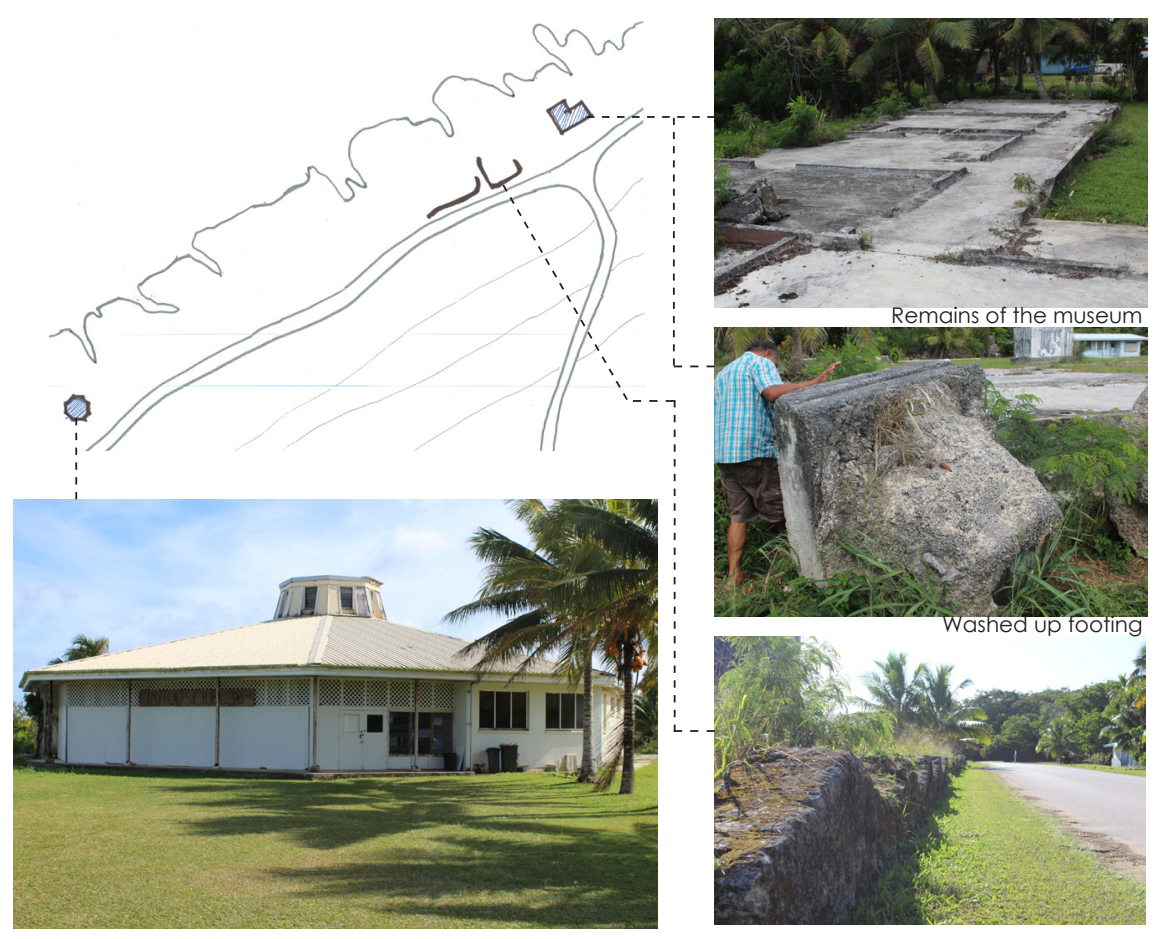

Remains of the Hotel

Remains of rockwalls

HERITAGE TREES

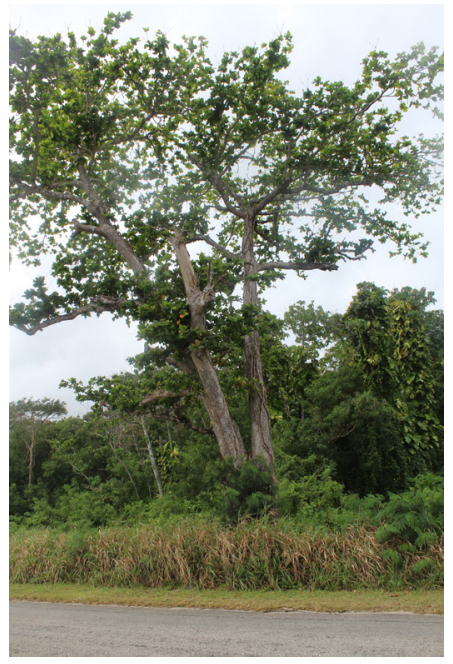

Puka tree

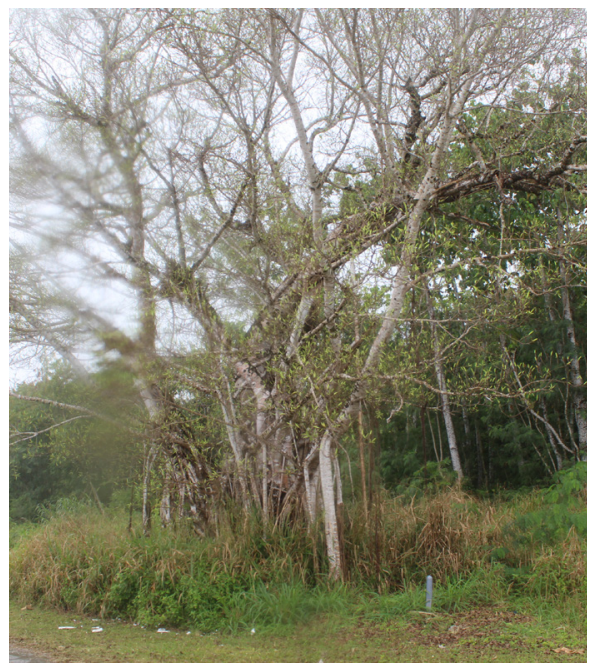

Ovava tree 


\section{Design Review Two Feedback}

\section{Strengths}

- Planting the trees on the sensitive corridors works well but can be backed up with some ecological research and case studies.

- The green infrastructure is very clever and should be the way to go.

\section{Weakness}

- There is a lot of distant to the water.

- Look at plotting system and where the families can rebuild on site. Designing this will give a relationship between the green infrastructure and the people who live there.

- Individual ownership vs government ownership land.

- Design for a better connection to the water. The link to the water is very important.

\section{Suggestions moving forward}

- If resilience is important then think about $60 \%$ of the year when it is cyclone free. Look at sustainable systems such as rainwater collection, renewable energy sources.

- How is generating energy driving the design of proposed buildings and green infrastructure?

- Adapting to the soft adaptation to climate changes such as planting trees as well as the hard ones such as sea walls and building infrastructures. 


\subsection{Architectural Concept Design}

\section{Conceptual design}

The architectural development phase began after the field study research. Although there were early attempts at creating design iterations that reflected early research issues, it was only fitting to begin a design response after the field research. The primary aim being a design method that leads to a contemporary architectural solution informed by the local culture, traditional practices, and contextual situation of Niue. The design iteration process is documented below.

Early design iterations and concepts were in direct response to the field study research. This phase the author began by conceptualising ideas and findings though the medium of sketches and also computer modelling. The list below summarises how the preliminary design was structured. 


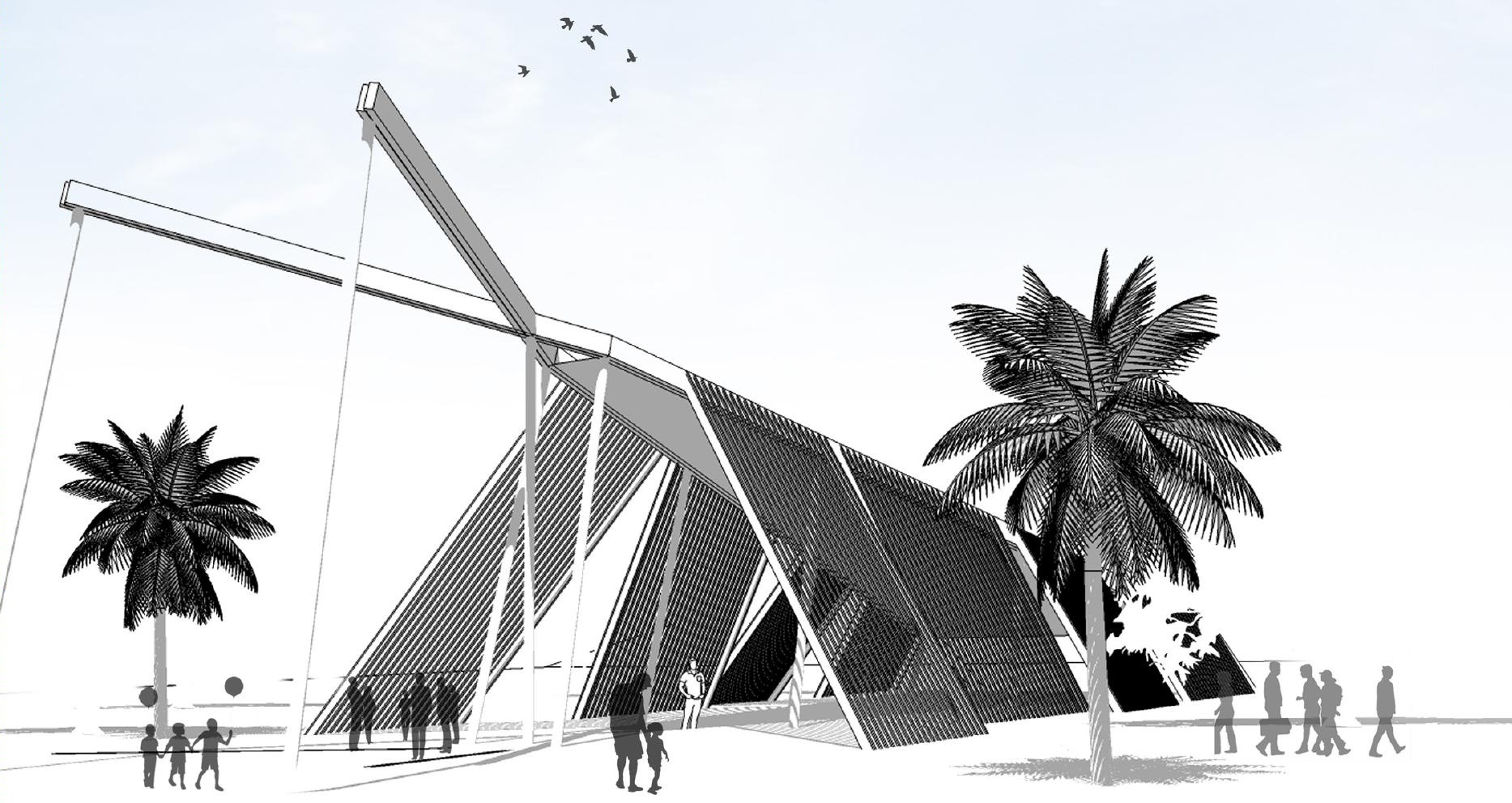

\section{Key issues:}

- Lack of architectural identity.

- Lack of the understanding of the vernacular architecture.

\section{Key response:}

- Interviews with elders.

- Early design sketches.

- Design excersise with students.

- Site observation.

Drivers of design response.

- Culturally driven design.

- Locally inspired architecture.

\section{Public scale}

Figure 140. Concept design of a branch of the proposed 
Design Process One

Student attempts at form
Design Process Two

Cave narrative
Sketches
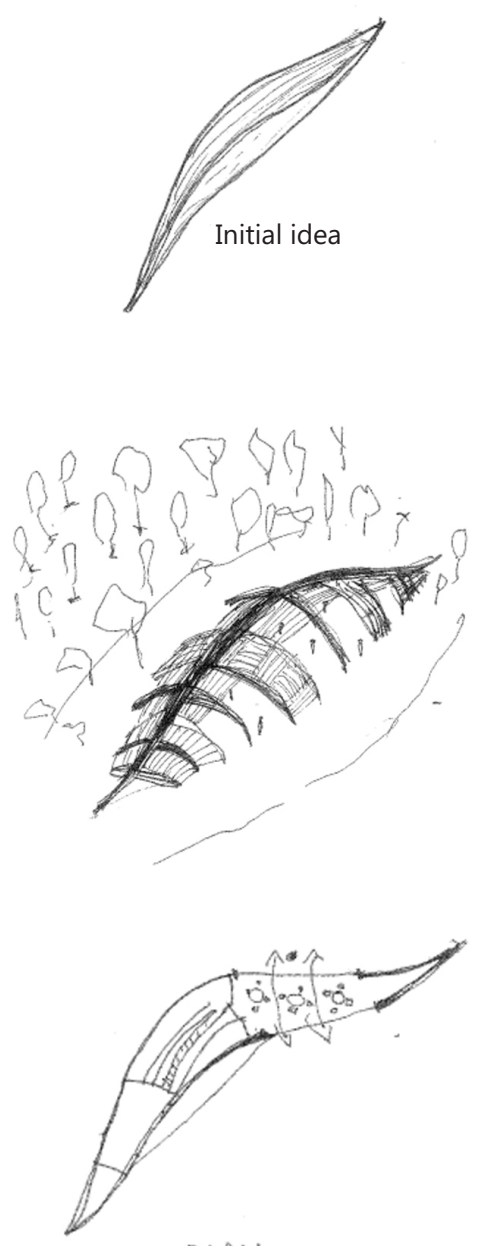

PLAN

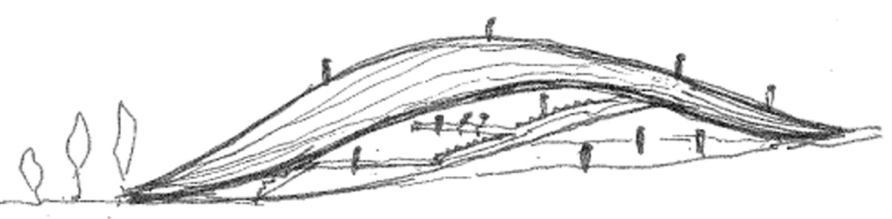

Pavillion that is influenced by the coconut tree
Sketches

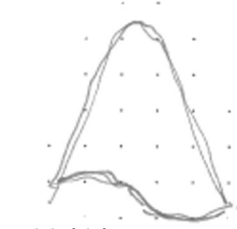

Initial idea
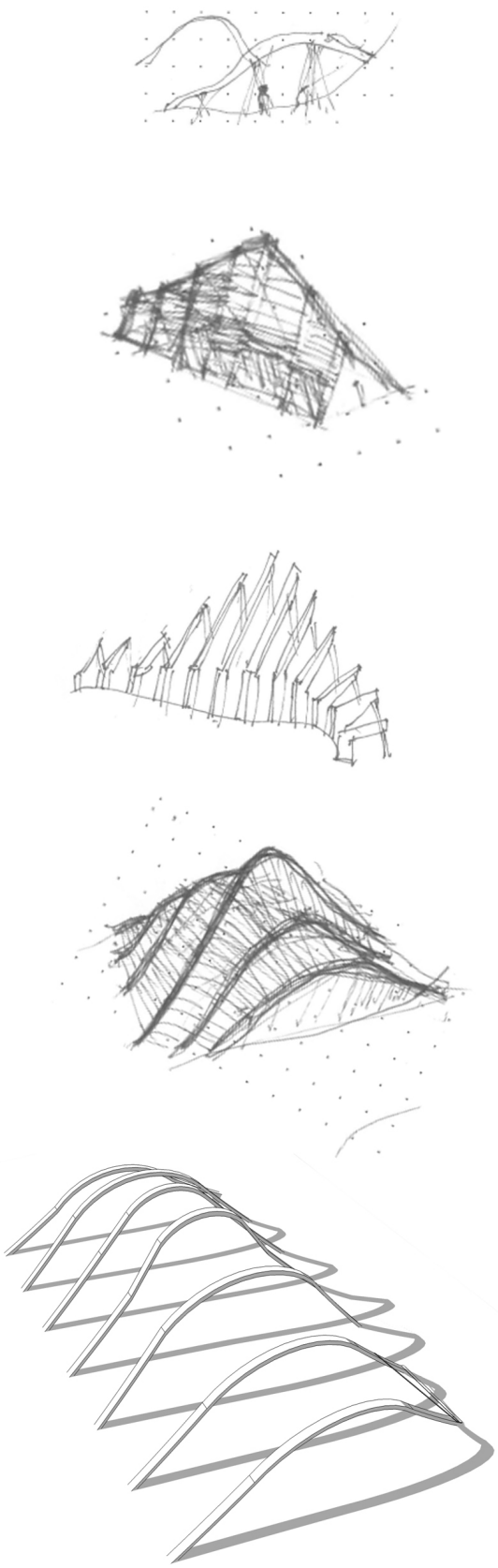

Model 
Design Process Three

Influenced by the village
Design Process Four

Ovava tree, a safe haven
Sketches

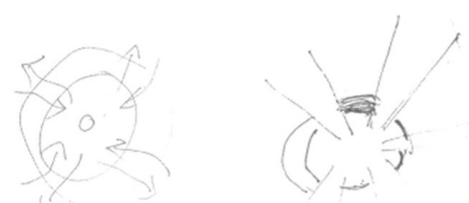

Initial idea
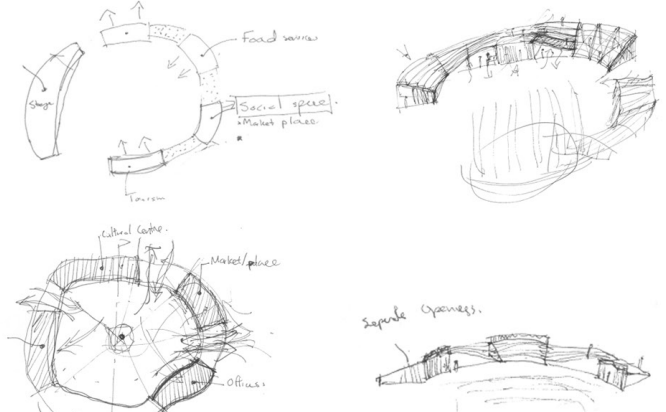

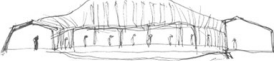
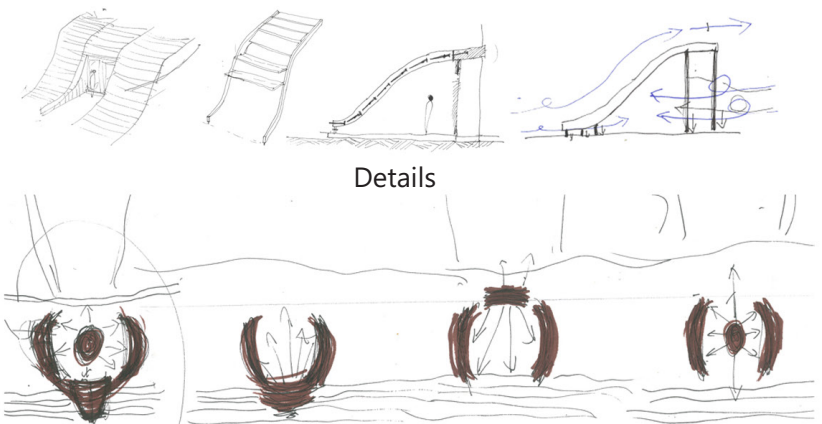

Relationship to site
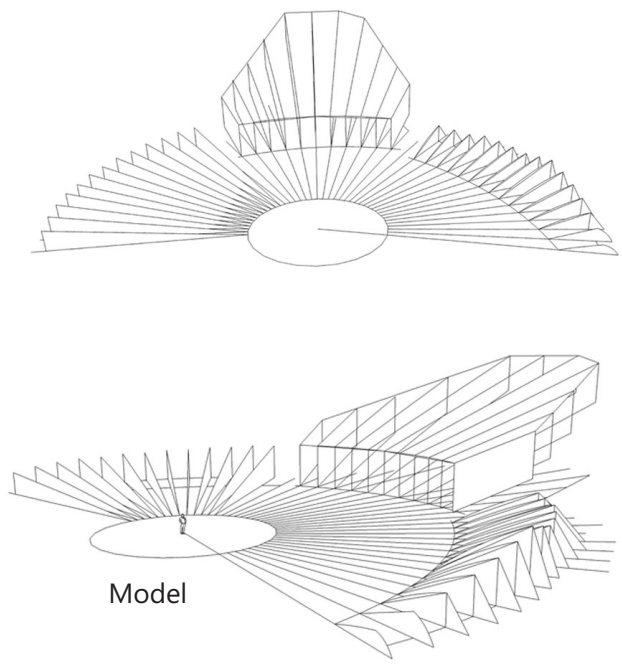

Sketches
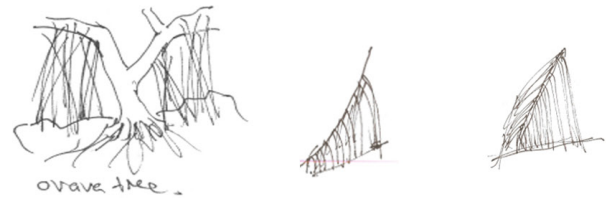

Initial idea
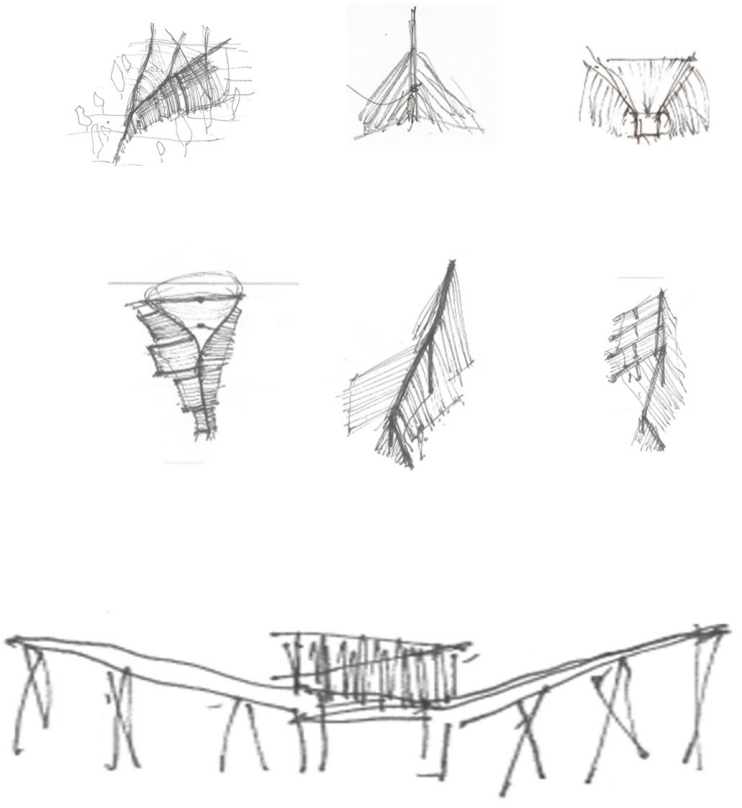

Model
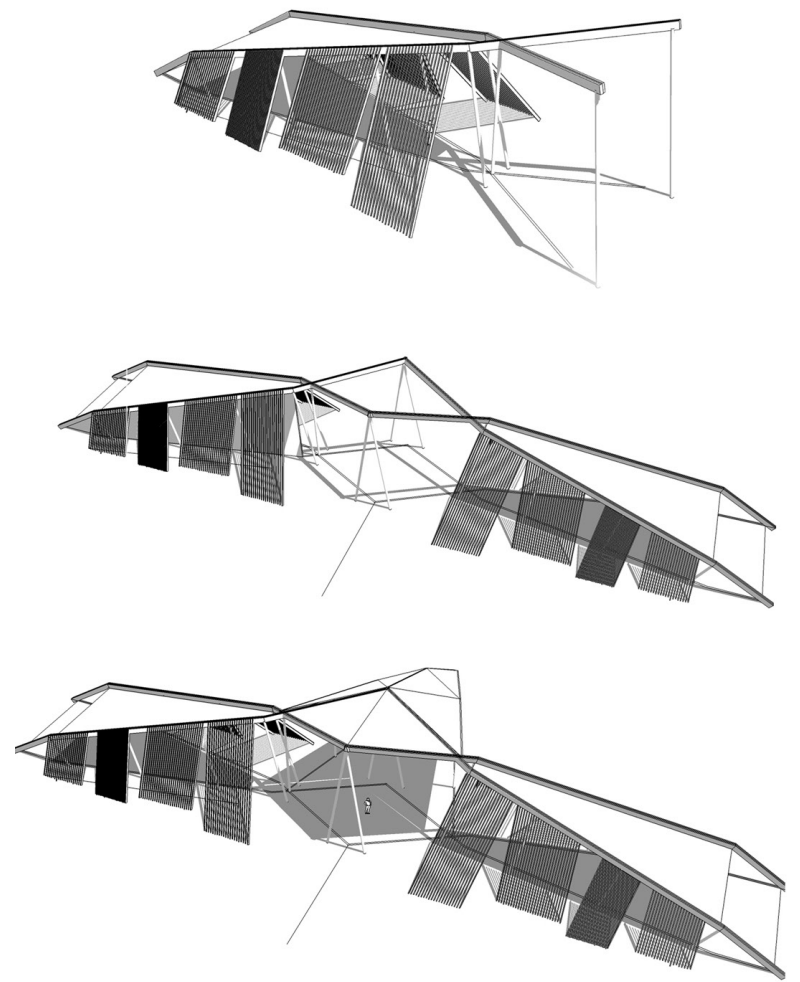


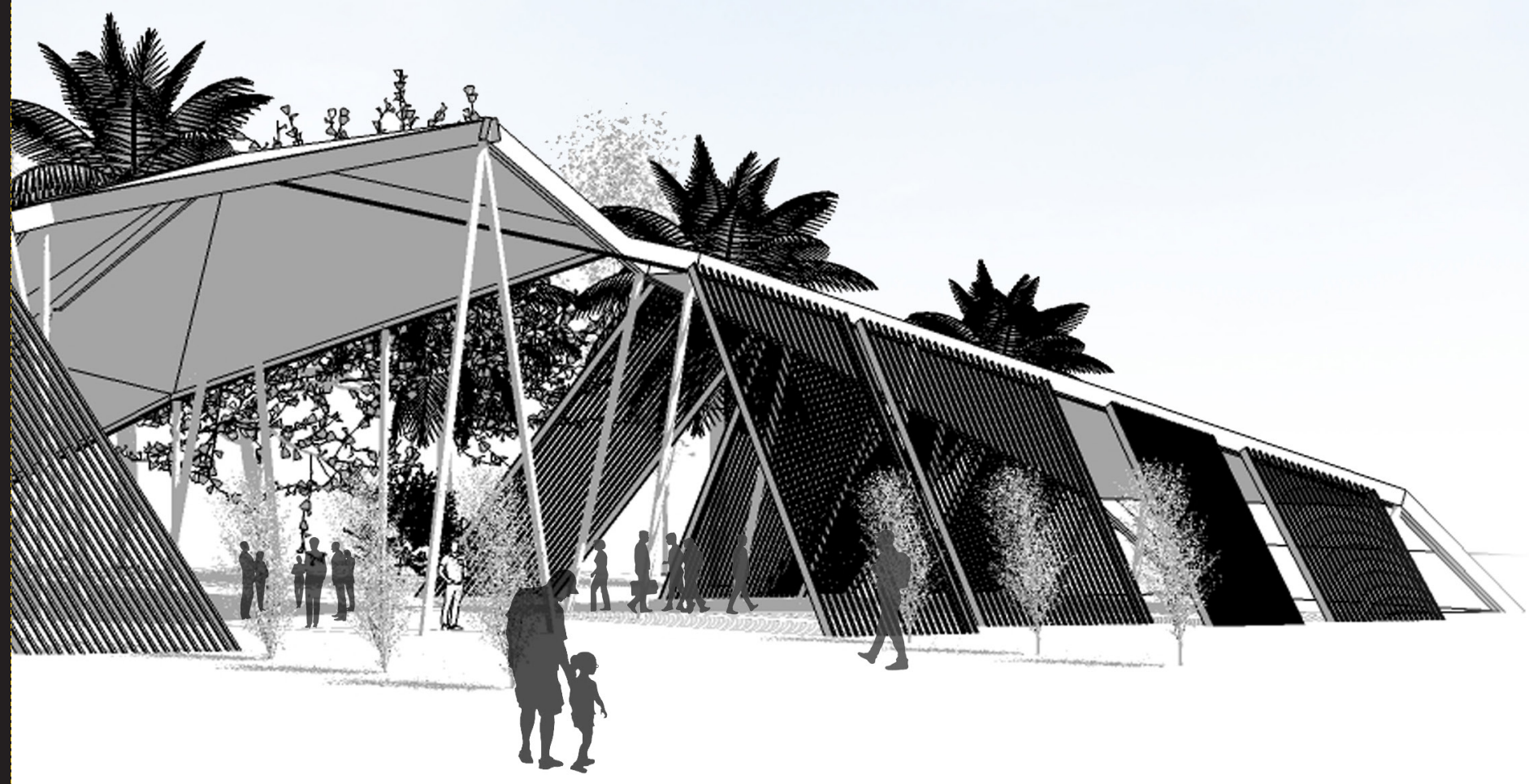




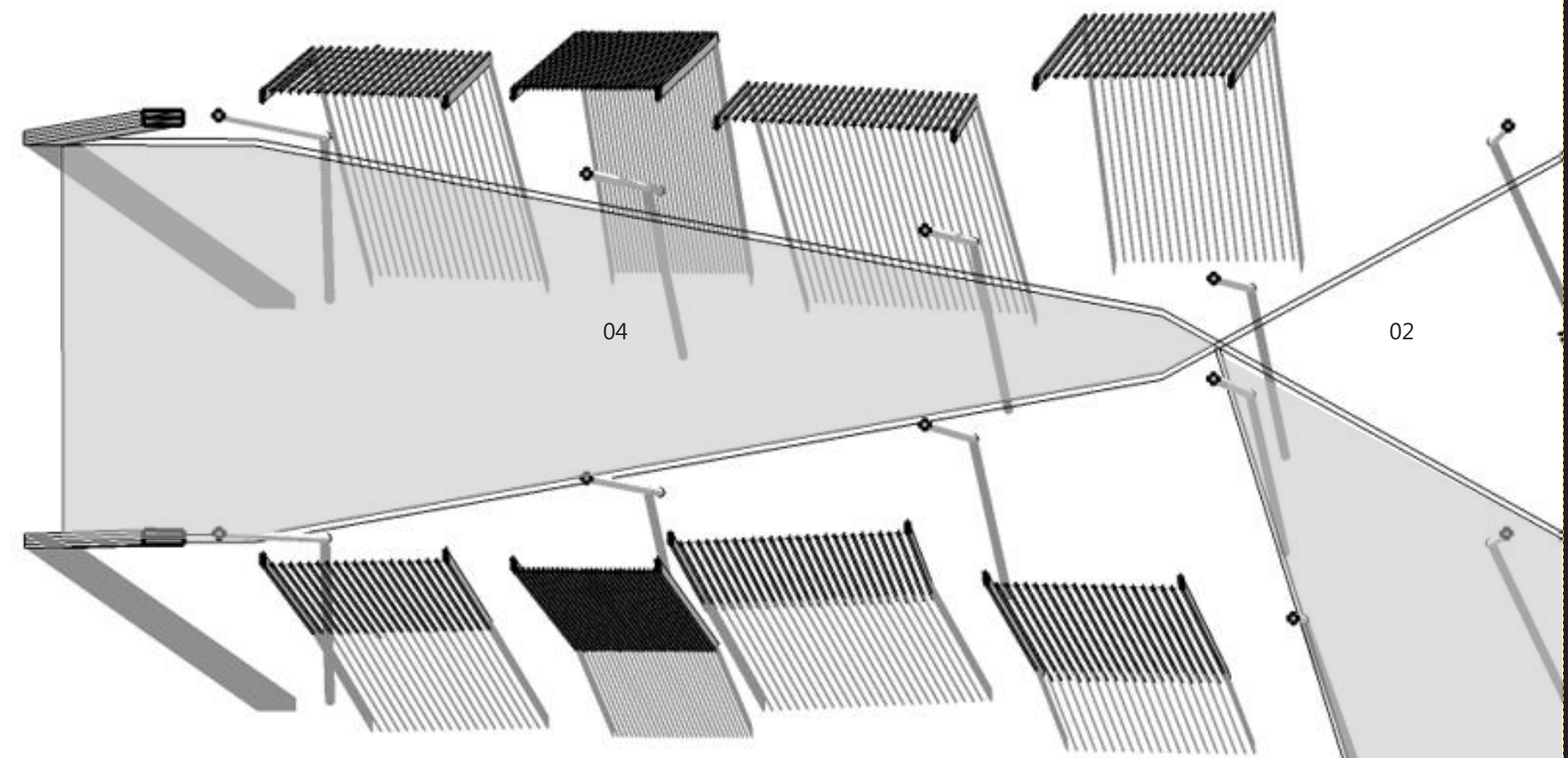

\section{PLAN}

Legend

01. Main entrance

02. Grand foyer

03. Open shelter foyer

04. Office and shops

05. Function room/market place

Figure 143. Final conceptual design plan* 


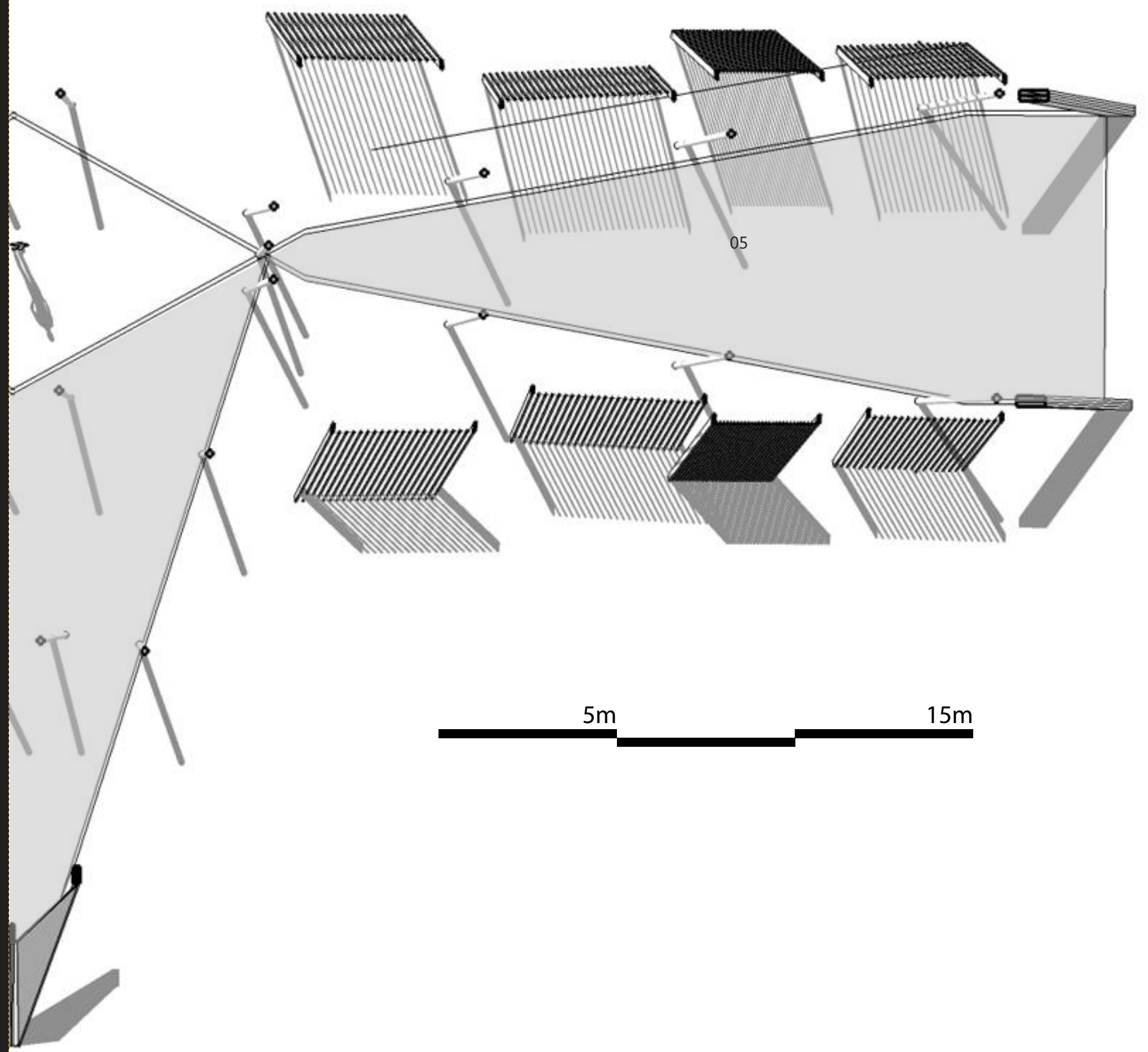




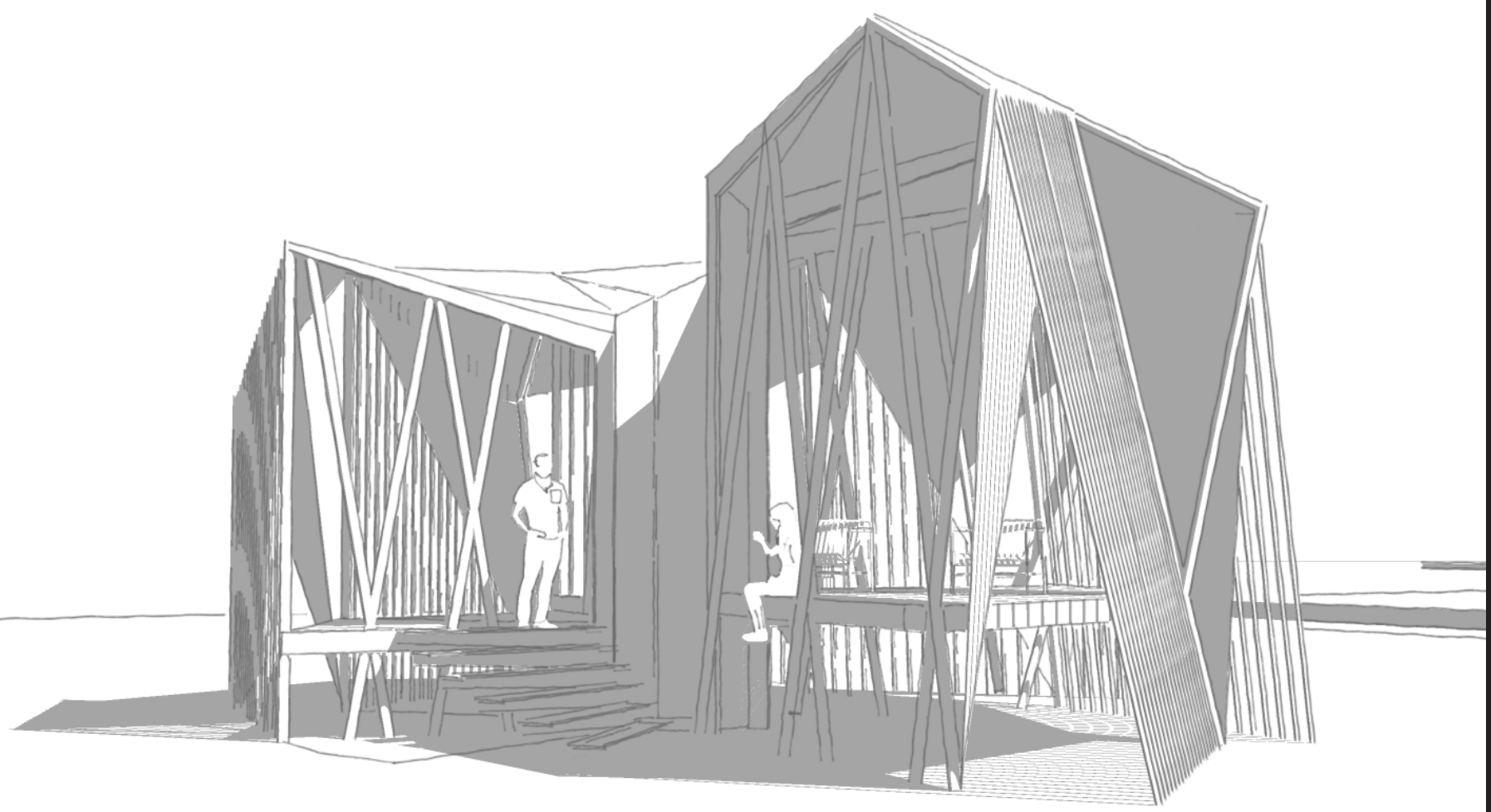

Domestic scale

Figure 144.Conceptual design of a tourist house proposal* 
Design Process One

Using an organic form

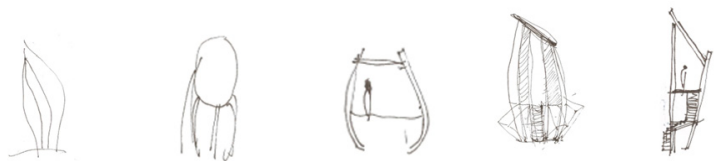

Sketches

Design Process Two

Using the coconut seed
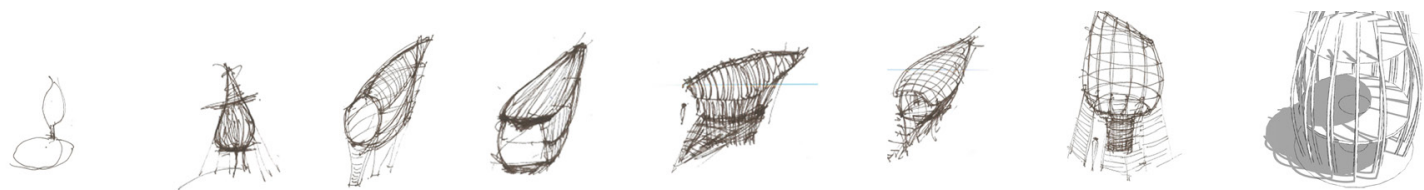

Model

Sketches

\section{Design Process Three}

Using the Ovava tree
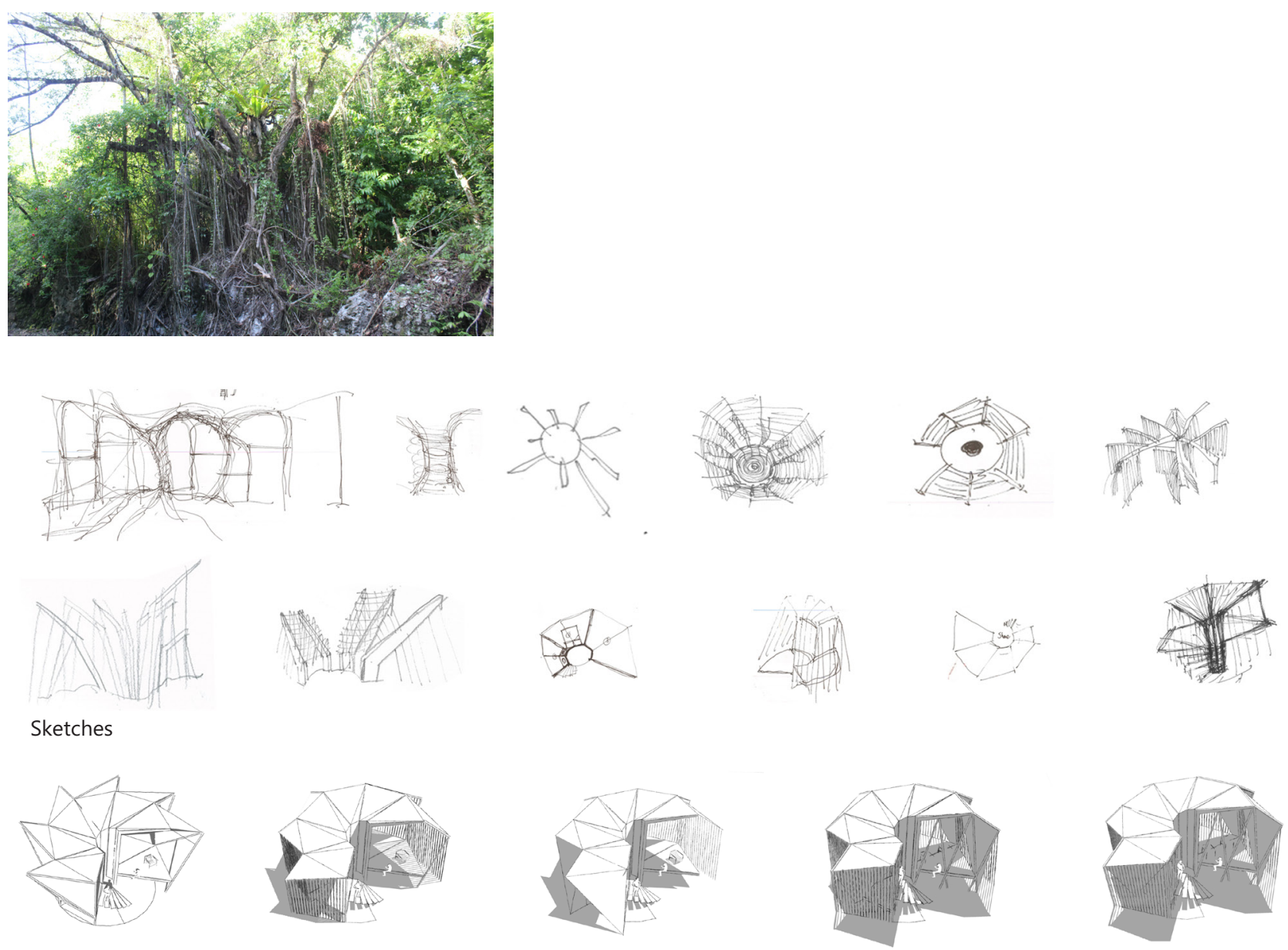

Model 

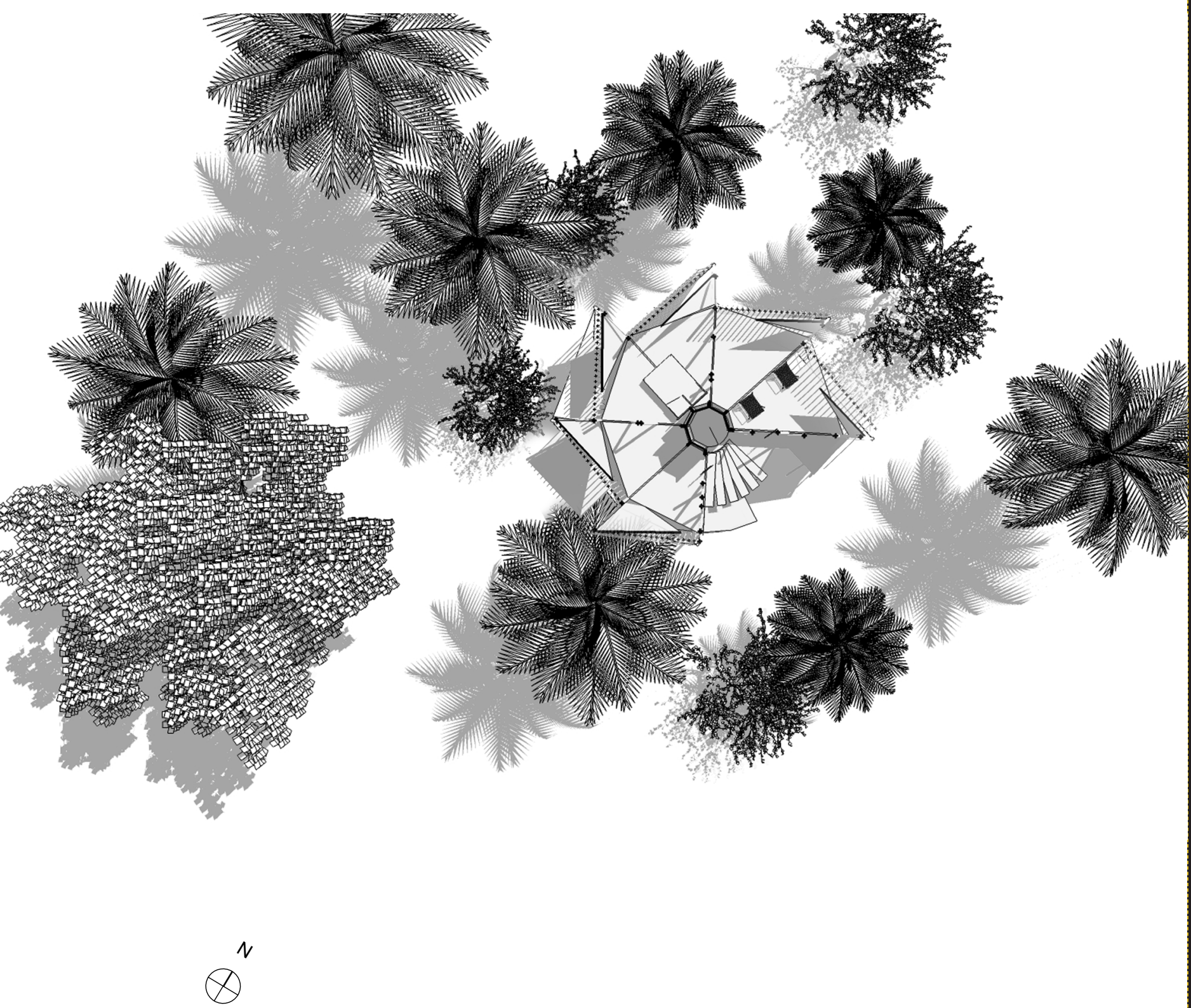

Site Plan (NTS) 


\section{Critical Reflection of Design}

\section{Strength}

- Design process reflects the local context of Niue

- The formal and tectonic of the design is strong.

- The concept arrives with a unique solution in its formal context.

\section{Weaknesses}

- Design does not consider cyclone resistant techniques.

- Concept focuses on the use of manufactured timber for the design.

- Further development and design investigation. 


\section{Design Review Two Feedback}

\section{Suggestions moving foward.}

- Architecturally it's fascinating. How can you play on this idea of vertical connection between land and sea? Usually we think of horizontal connection.

- Where are they going to go when there is a cyclone?

- More development on the idea of the Ovava tree, definitely looking at materiality and how it reflects the cultural identity and how it enhances the idea. Especially if the vernacular is lost or replaced. Really pushed the idea across. 


\subsubsection{Developed Design}

After critical reflection of the preliminary design, it was important to revaluate the positioning and stance of the design process when it comes to generating concepts and ideas. A critique from the literature highlights the importance of understanding the local context in generating a well-suited design outcome to a place. The author felt that his methods of generating concepts in the preliminary stages were foreign and out of context in the case of Niue. It was important for the author in all methods of the research, mostly importantly the design process to be fully submerged in the traditional methods of creating and designing through hands on making. This phase of the design also took a step back to draw from all aspects of the research that are highly relevant in the developed design process. The list below summarises the structure of this section. 


\section{Key Issues}

- Western methods of creating concepts through software modelling.

- Concept design is weak to cyclones.

- Lacking the development of the Ovava tree idea.

- Vernacular architecture is lacking.

\section{Key Response}

- Use the Ovava tree as the driver for the design.

- Utilize traditional methods of creating through physical modelling.

- Introduce Bamboo as a potential building material.

- Focus on a cyclone proof design.

- Draw from case study of vernacular architecture in the pacific.

- Use the key findings from the interviews with the elders as driver for design.

\section{Drivers for design}

- Ovava inspired architecture.

- Cyclone resistant structure.

- Traditional method of creating.

- Traditional methods of construction. 


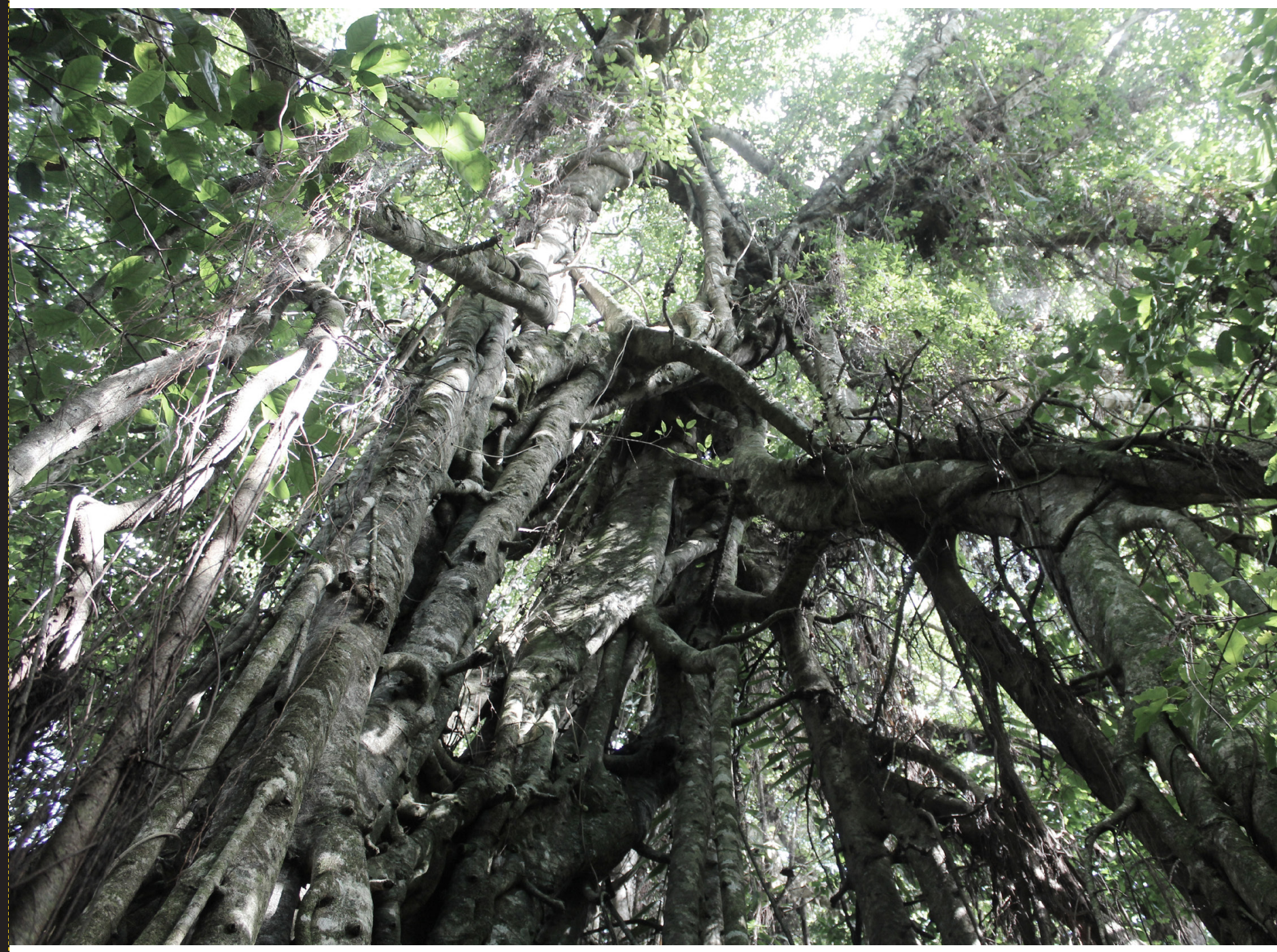




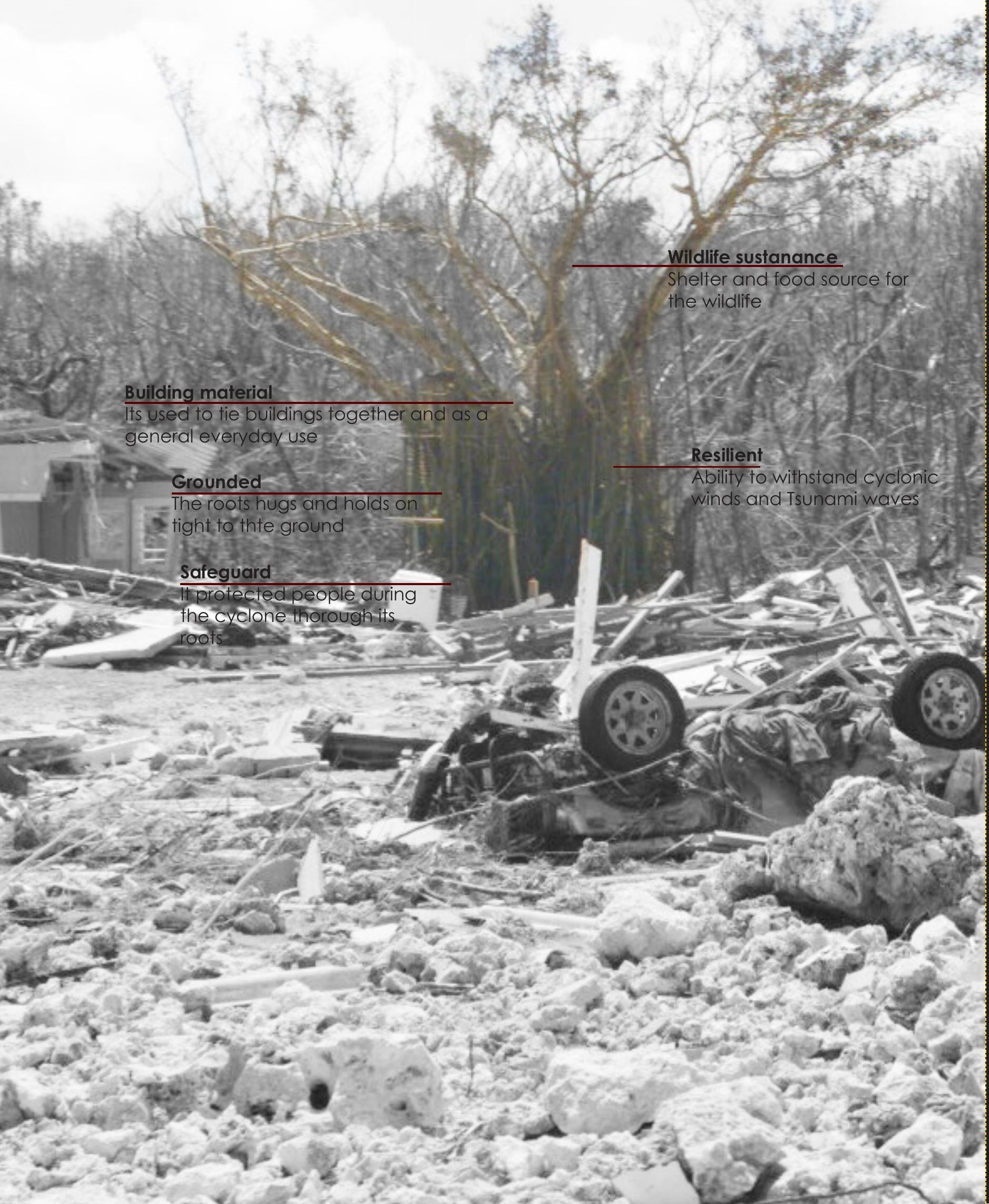




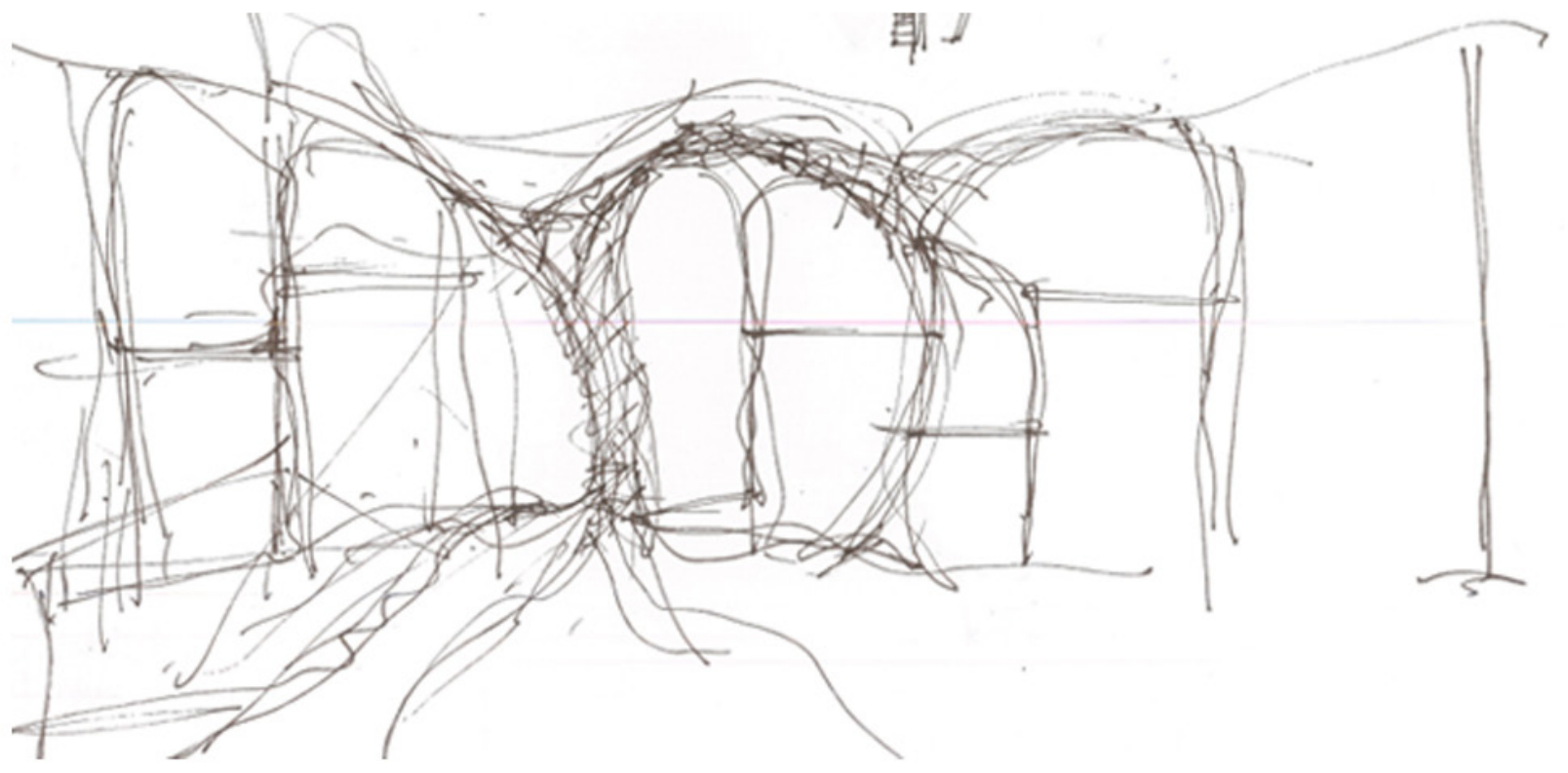




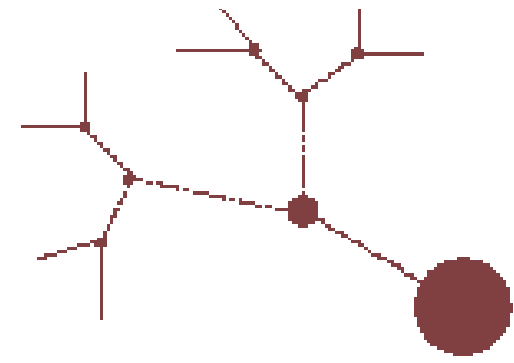

Ability to ground itself before growing further

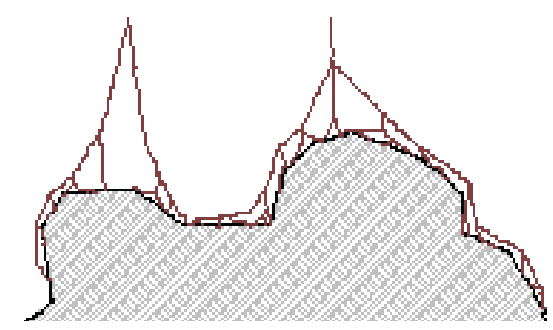

Roots system anchors the tree to the ground

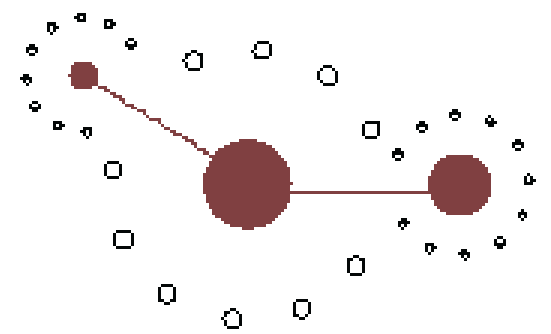

Structure of tree simplified.

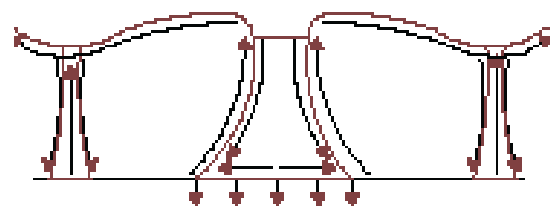

Cantilevered column with tie downs as it exntends

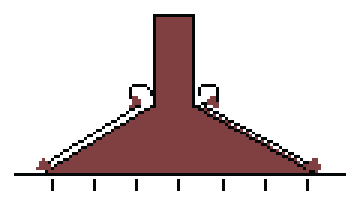

Foundation spreads out which anchors tree both horizontal and lateral loads 

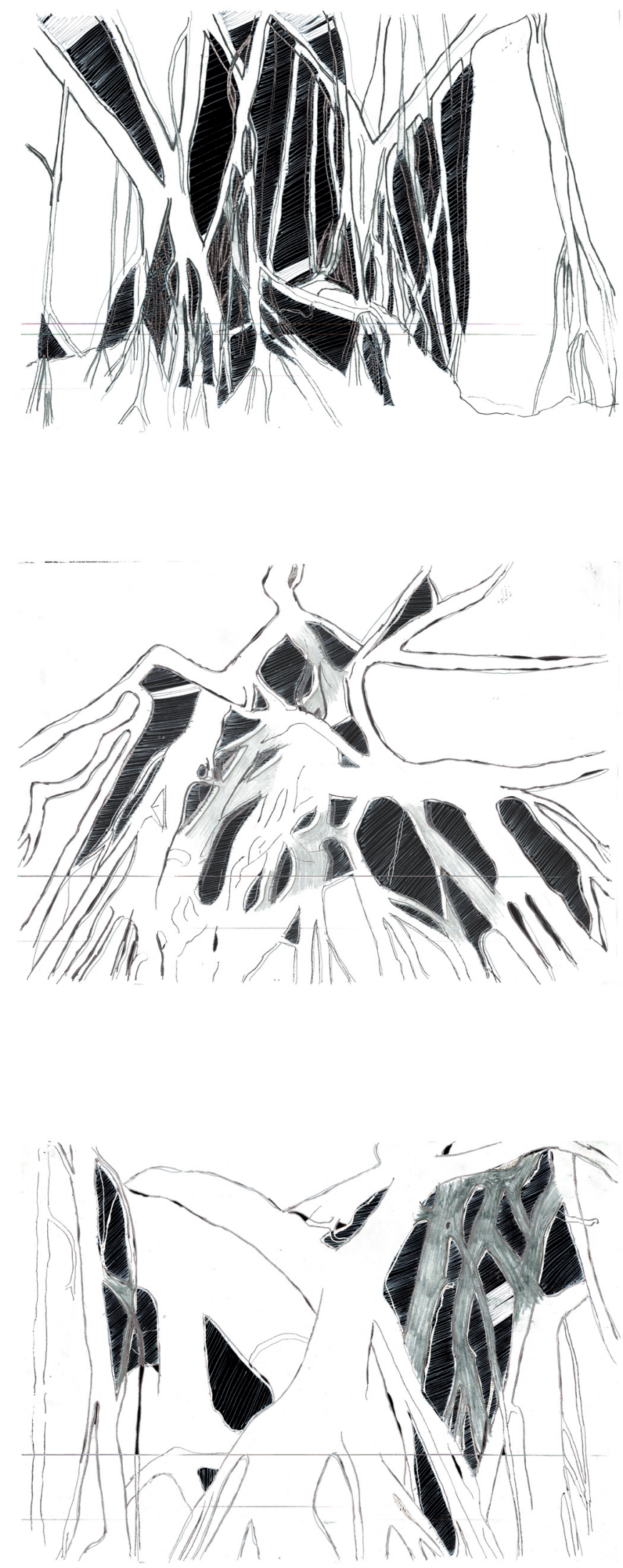

Figure 152. Early sketch explorations of the spaces between the root network* 


\section{RE D A C T E D}

\section{RE D A C T E D}

RE D A C T E D

\section{Flexibility}

Ability to create unique shapes

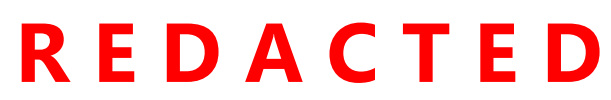

Vernacular Architecture

Ability to create unique shapes 


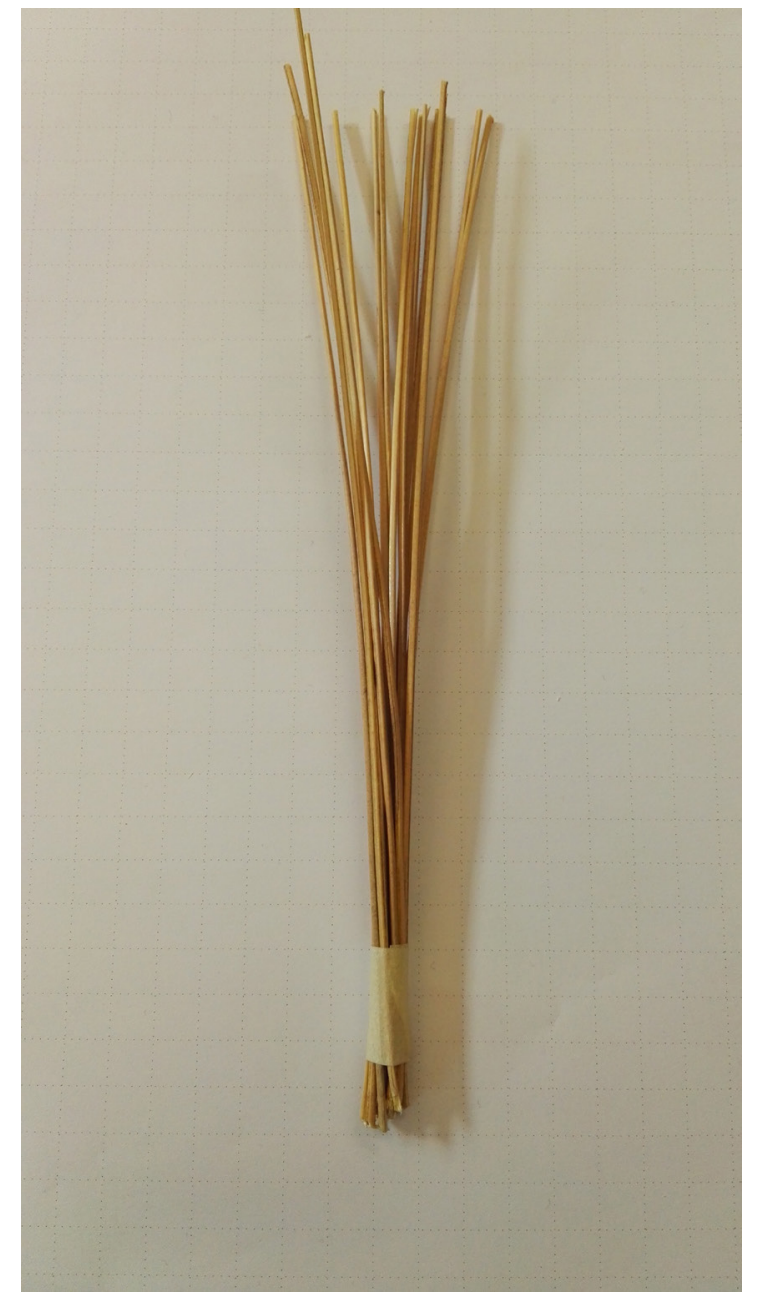

Kaniu strands

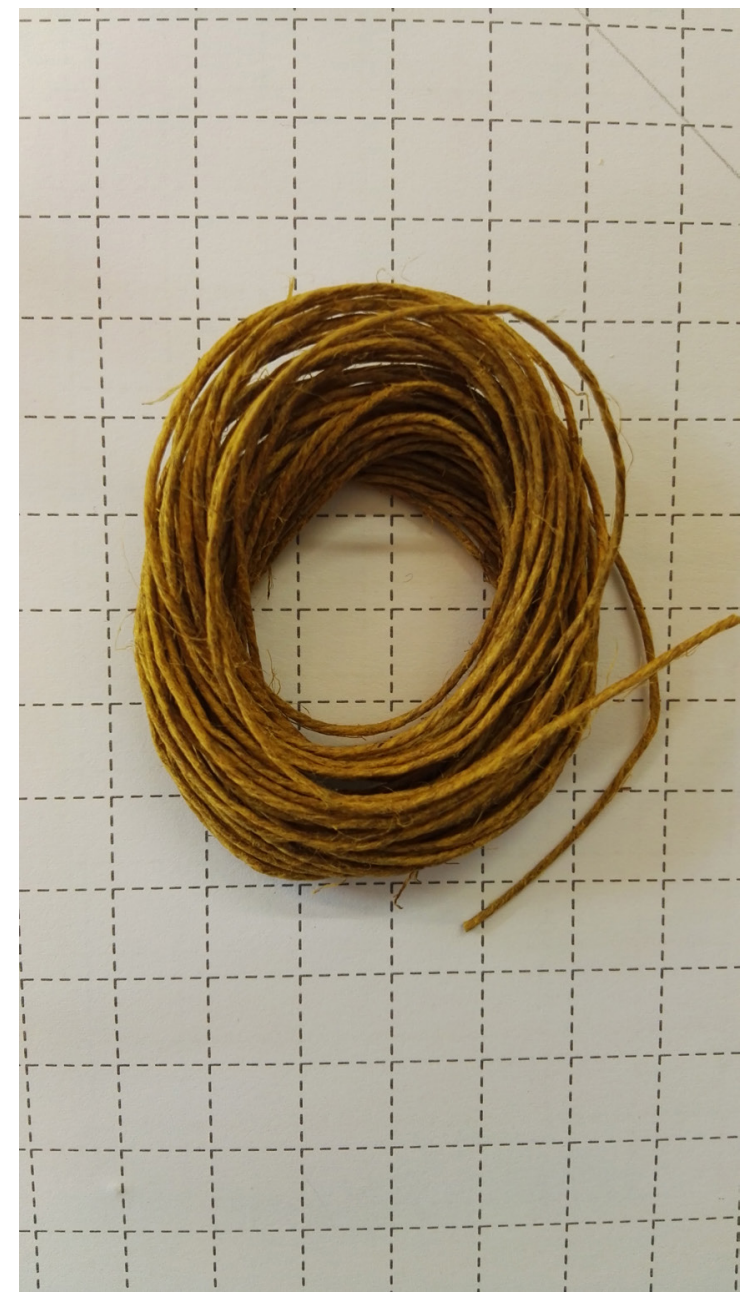

Flax rope. 


\section{Material Testing}
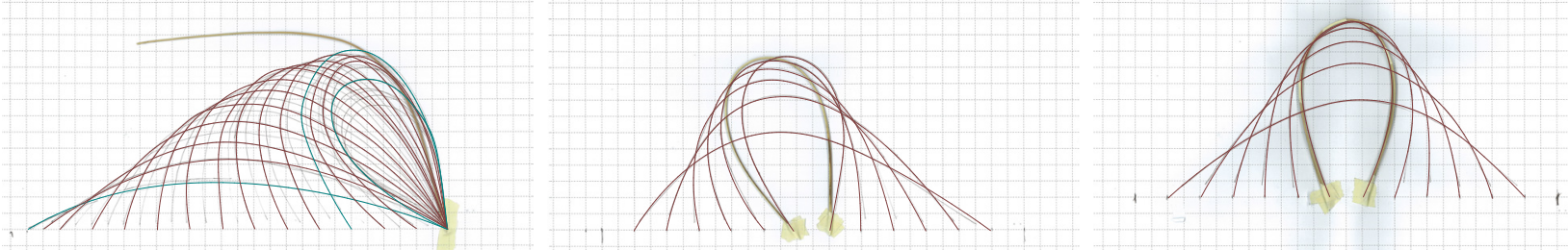

\section{Form Making}
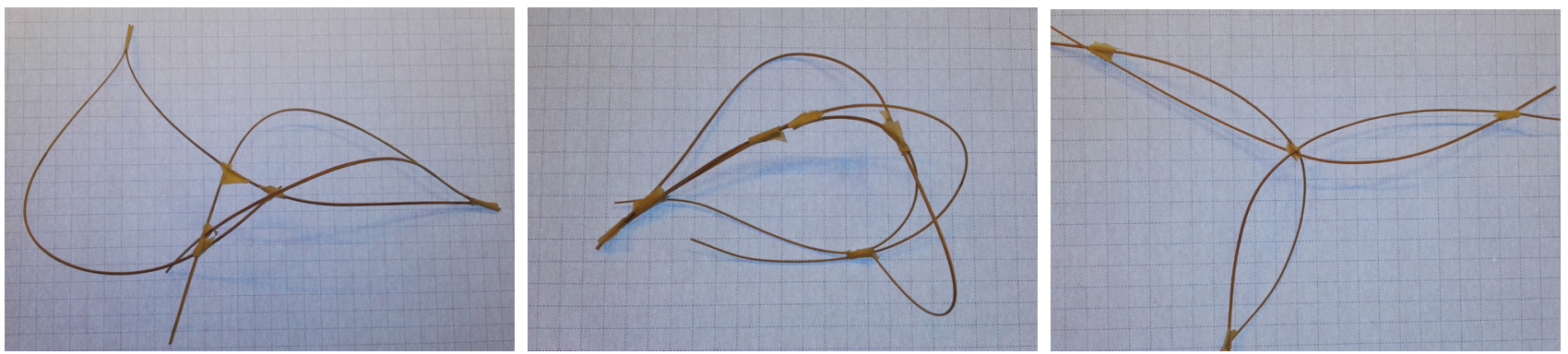

\section{Form Making II}
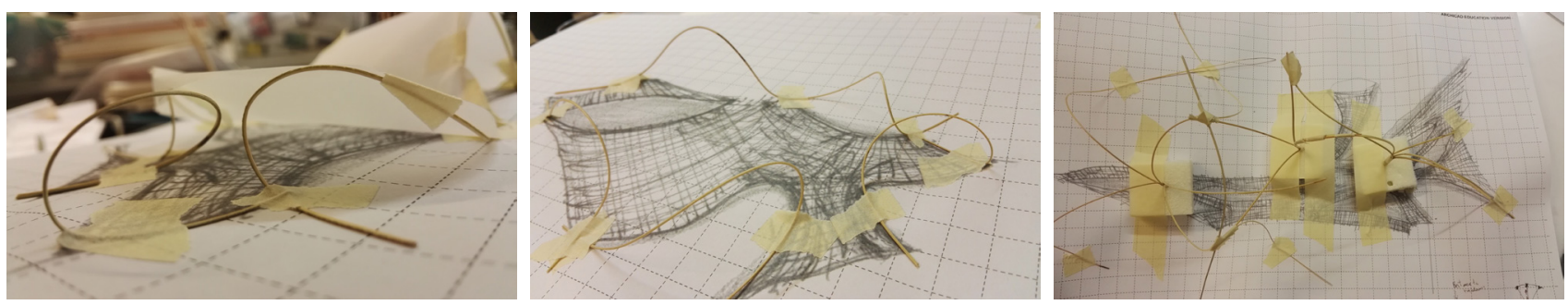

Figure 159. Testing the material properties of Bamboo through the Kaniu stick (top) Figure 160. Testing material through form making*

Figure 161. The process of modelling with the design framework of the Ovava tree* 

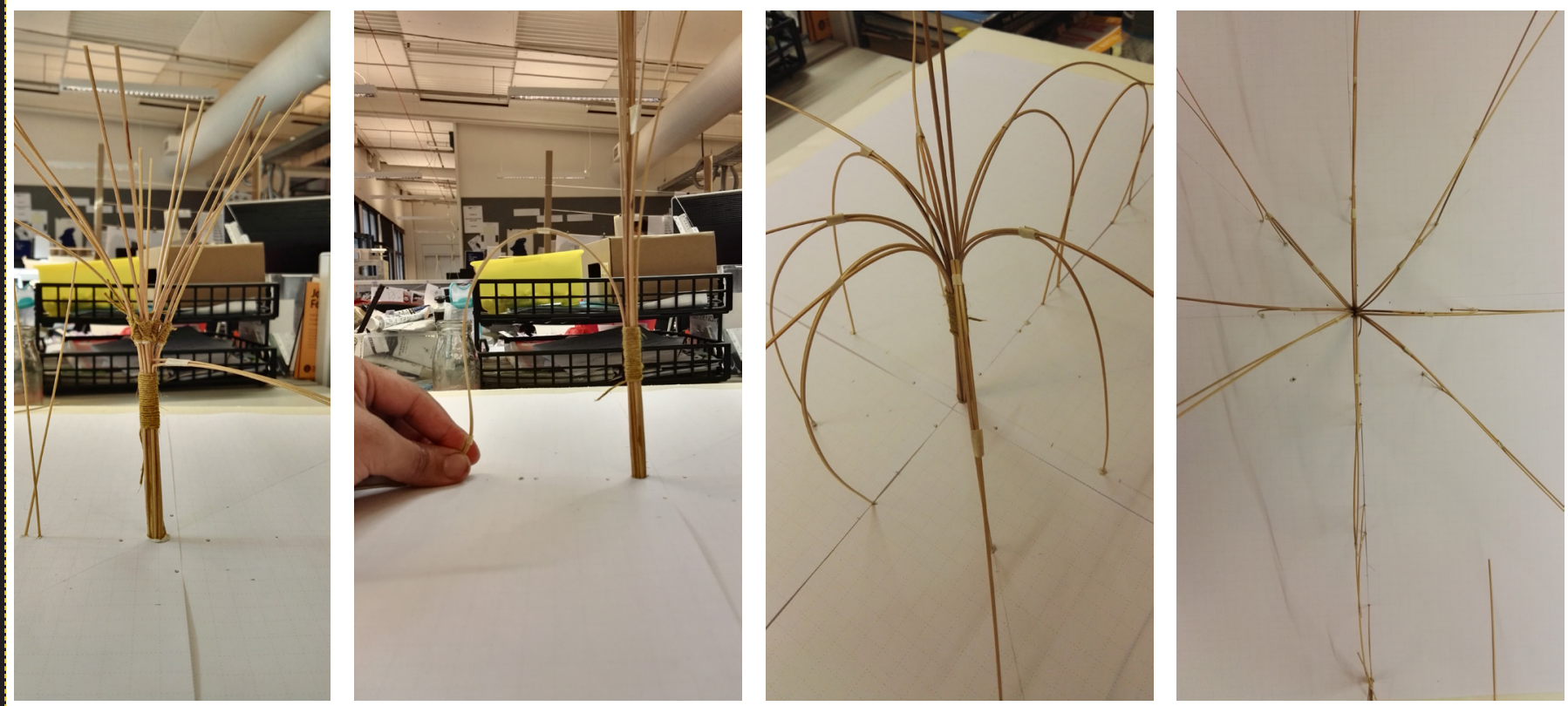

01. Central core

Foundation of central core with 8 supporting members.
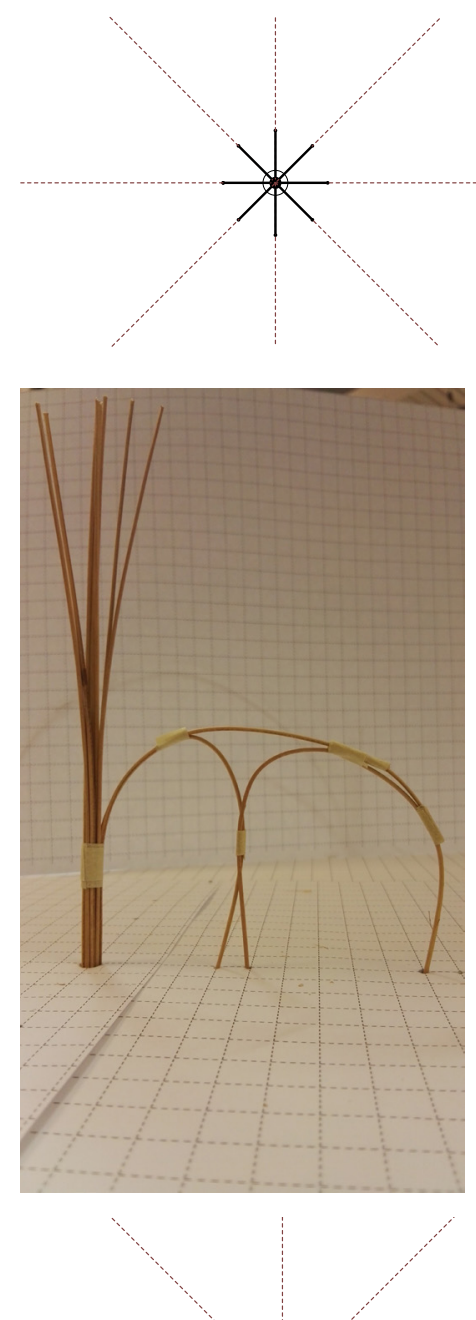

03. Roots reinforced 8 pillars are horizontally braced

\section{Roots planted}

Structure from core is reinforced by the 8 pillars

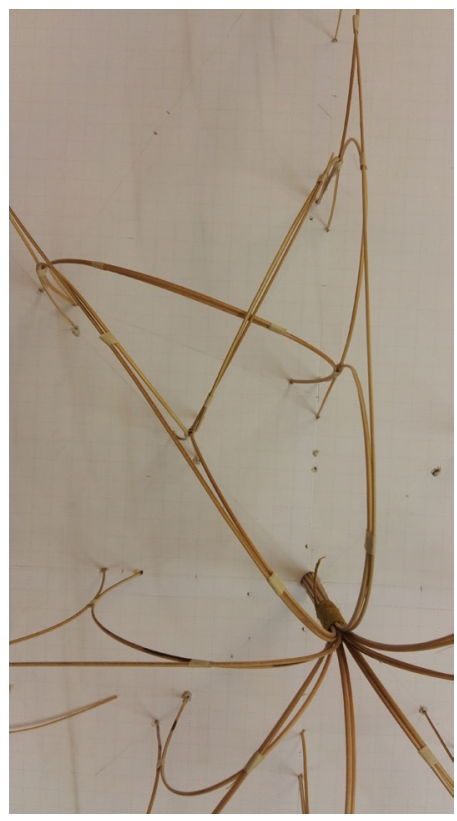

04. Branches are grounded

From the Pillars, branches extended out and grounded at the same time 

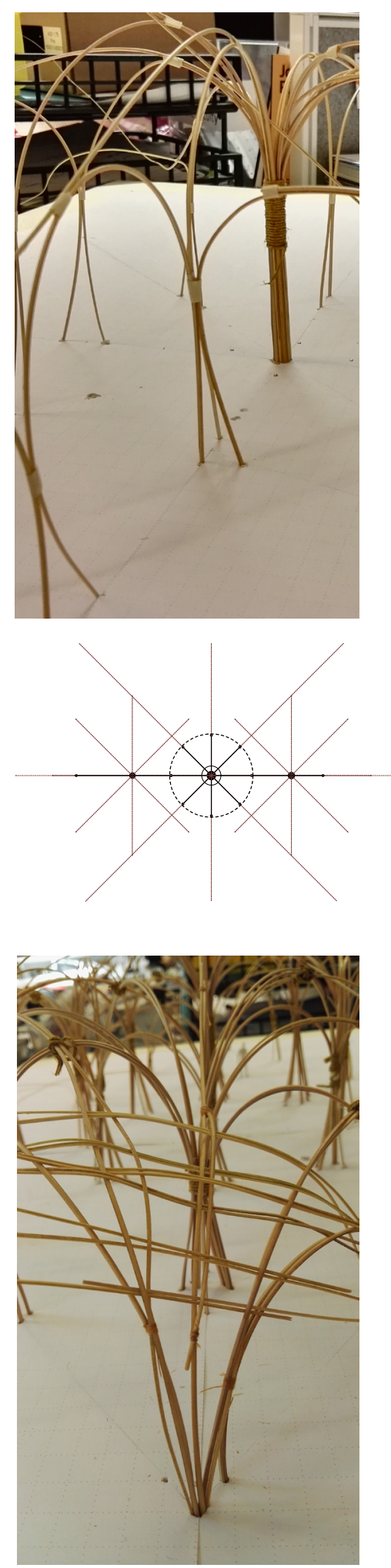

\section{New roots}

\section{grounded}

Newroots

grounded on both

sides

\section{New roots grow}

New roots are grounded from both the central and secondary core.
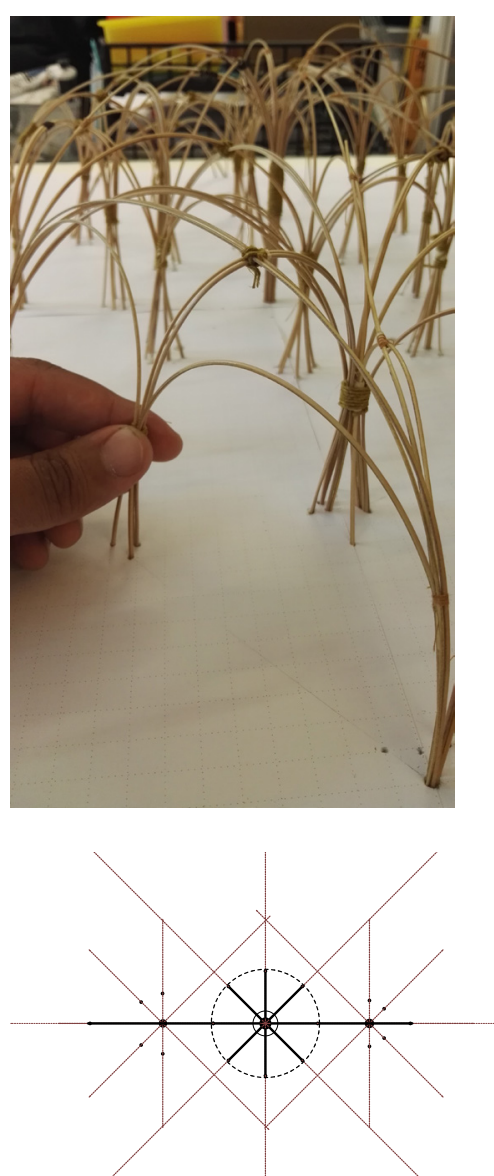

06. Roots

expands around secondary core Roots extend out around core to add rigidity
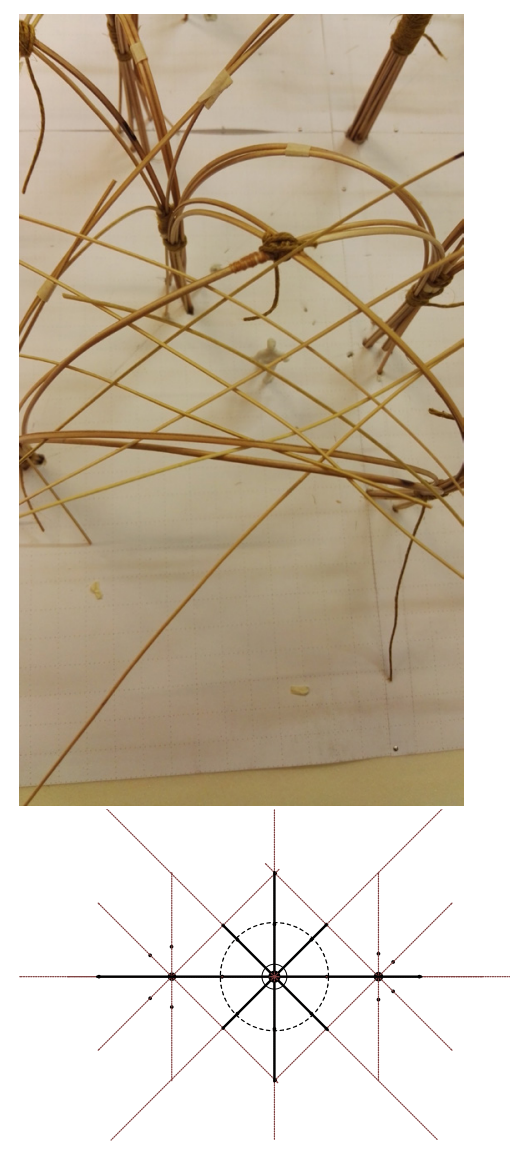

08. Branches extends further The more its grounded, the more it grows 


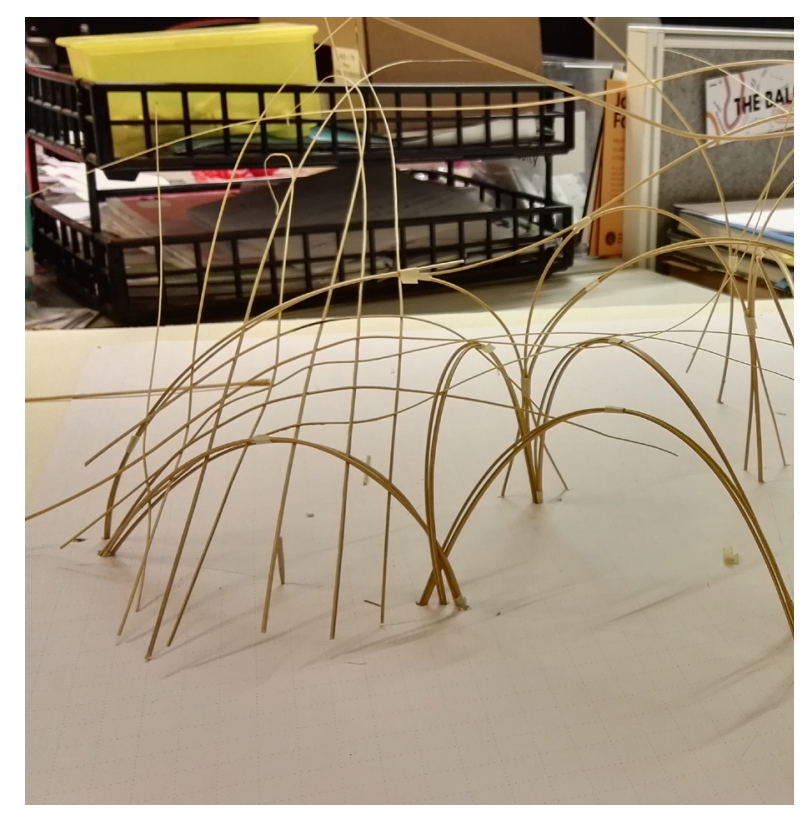

09. Branches are merging

Branches grows

back to the central core
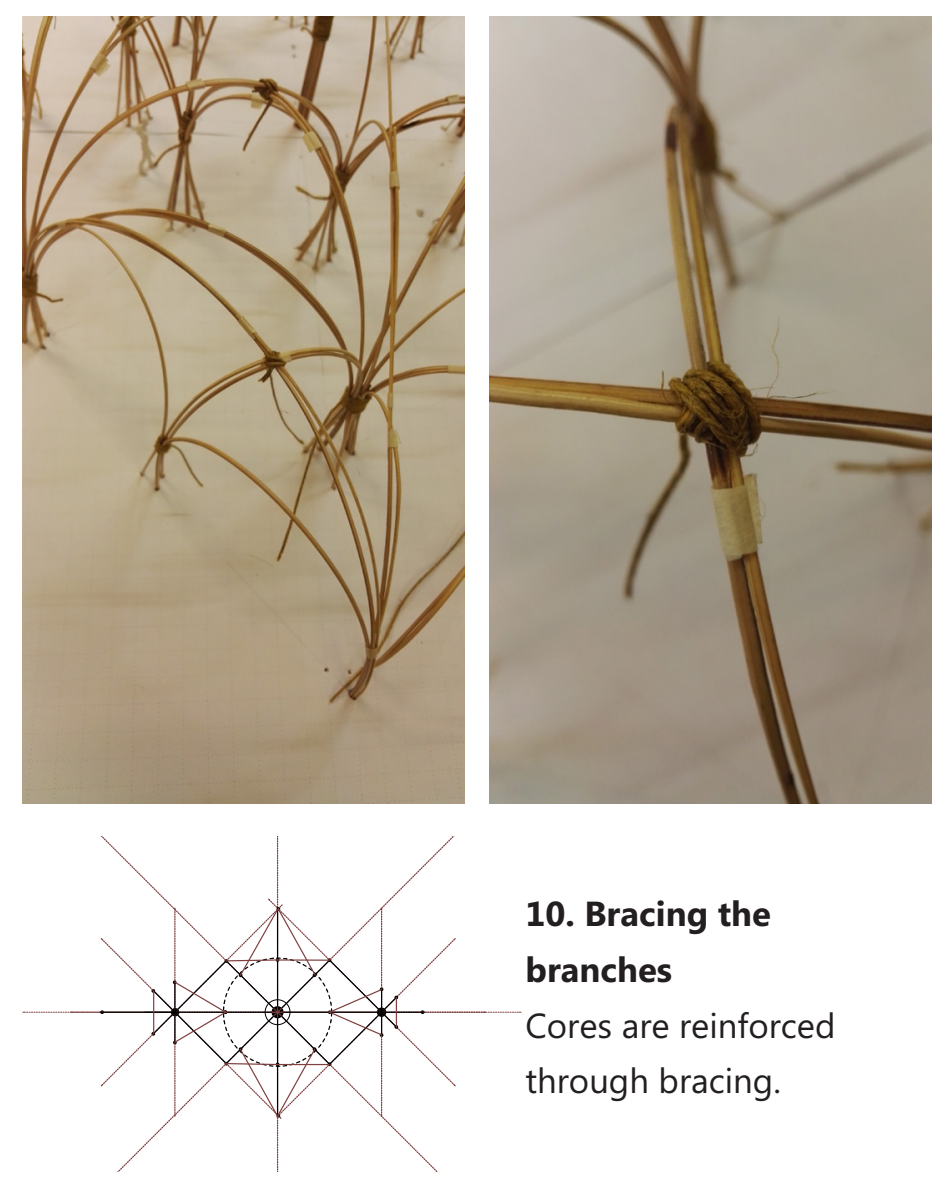

10. Bracing the branches

Cores are reinforced through bracing.
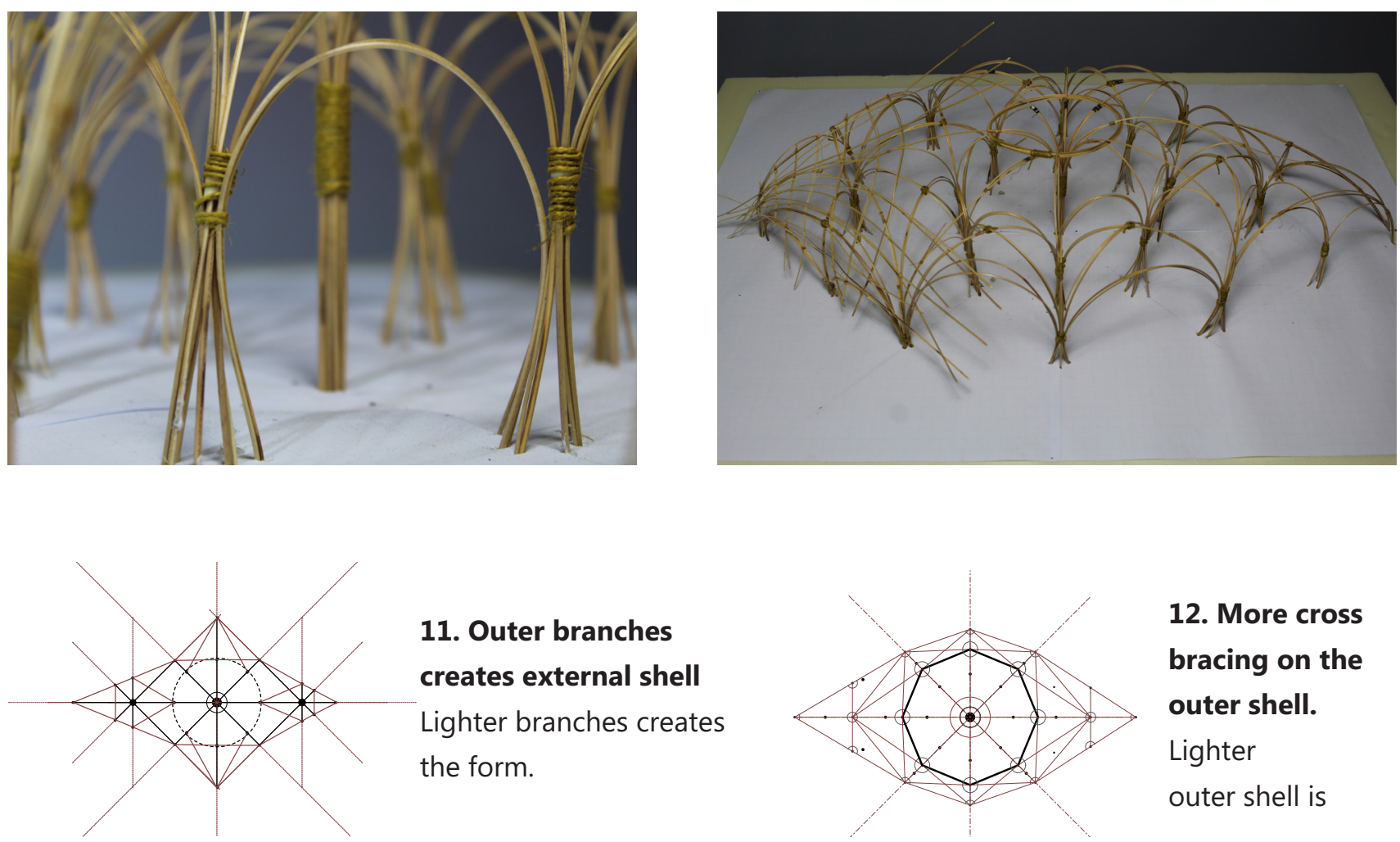

11. Outer branches creates external shell Lighter branches creates the form.

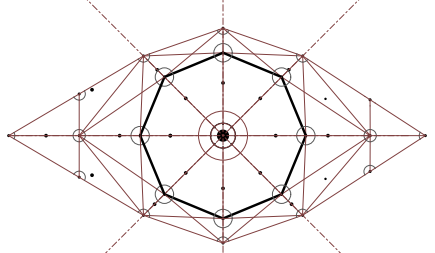

12. More cross bracing on the outer shell. Lighter outer shell is 
01. Central core

Foundation of central core with 8 supporting members

\section{Roots planted} Structure from core is reinforced by the 8 pillars

\section{Roots reinforced} 8 pillars are horizontally braced

\section{Branches are grounded} From the Pillars, branches extended out and grounded at the same time

\section{New roots grounded} New roots grounded on both sides

\section{Roots expands around} secondary core

Roots extend out around core to add rigidity

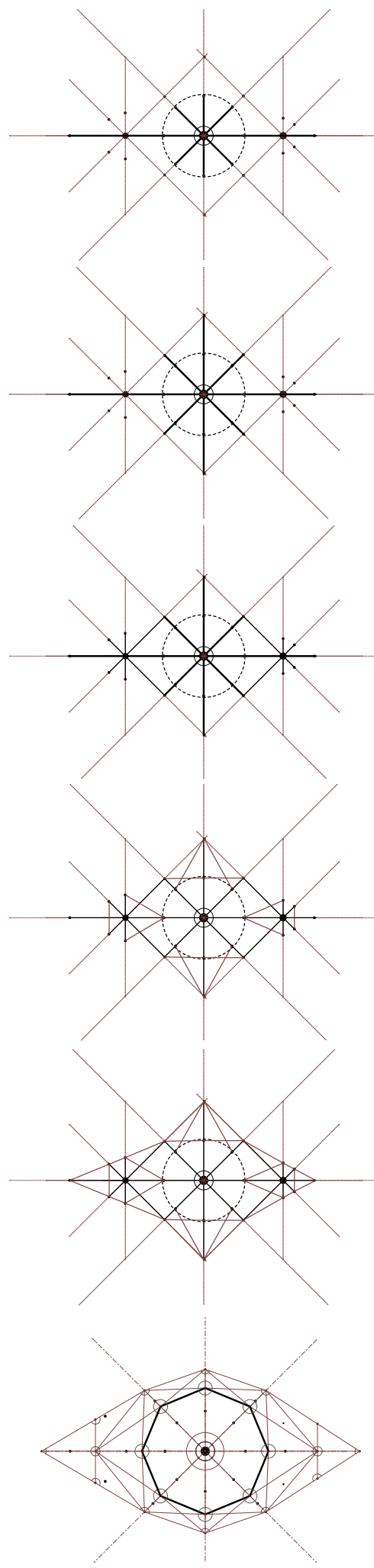

07. New roots grow New roots are grounded from both the central and secondary core

\section{Branches extends} further

The more its grounded, the more it grows

\section{Branches are} merging

Branches grows back to the central core

10. Bracing the branches Cores are reinforced through bracing

\section{Outer branches} creates external shel Lighter branches creates the form

12. More cross bracing on the outer shell Lighter outer shell is reinforced

\section{Design framework}



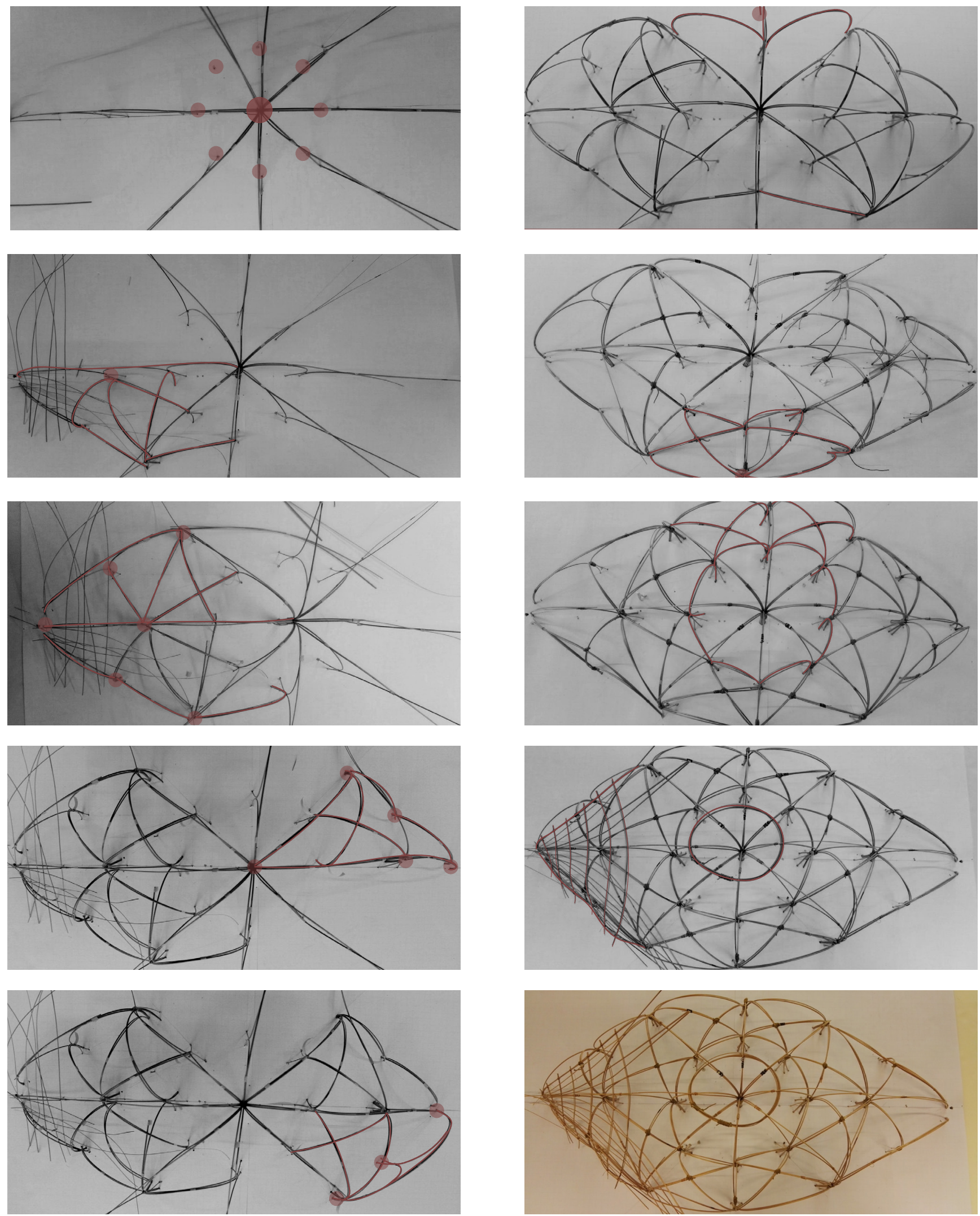

Model following design framework.

Figure 163. Physical model following framework through trial and error* 

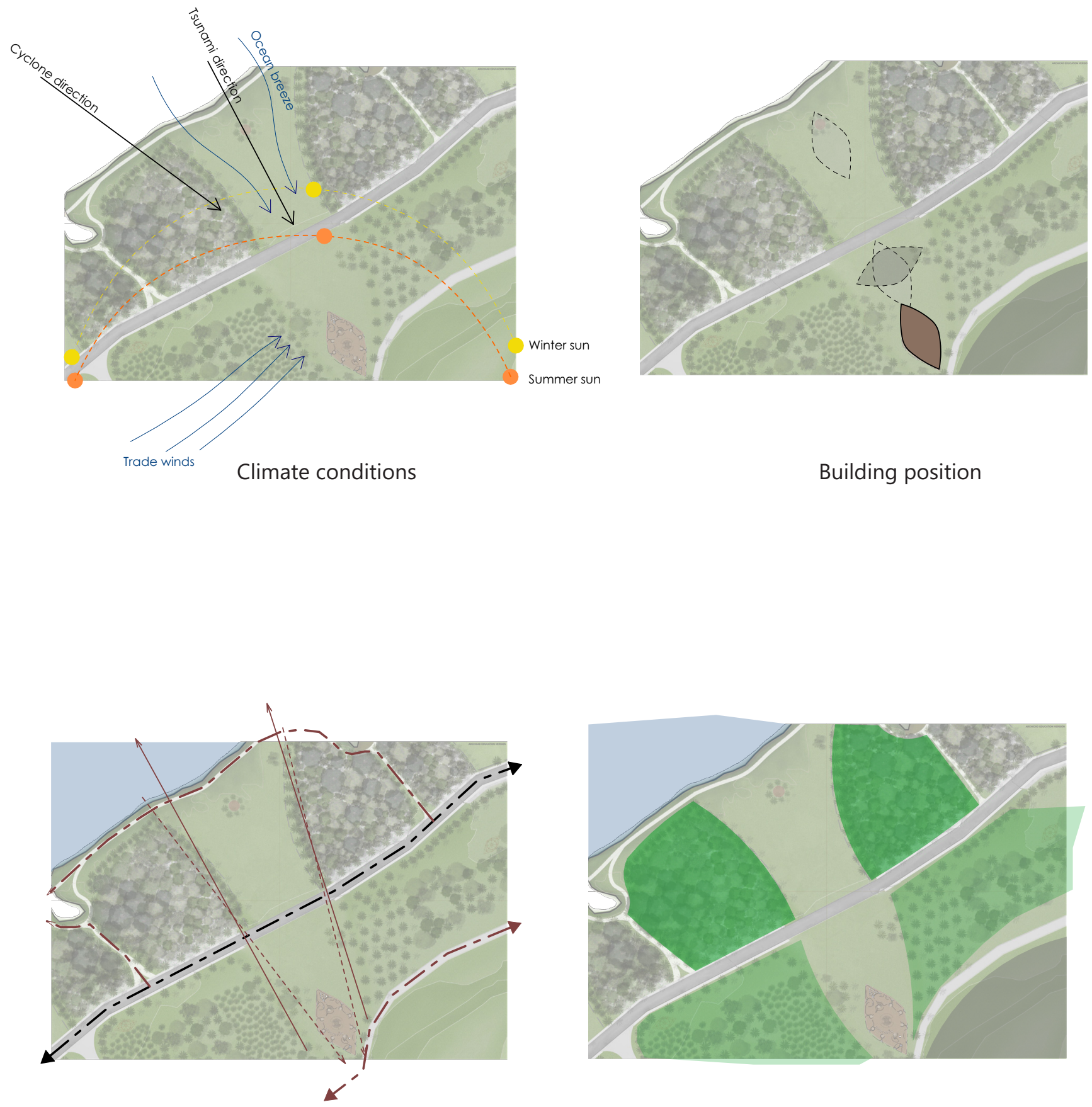

Connection

Natural environment

Site conditions. 
$\oplus$
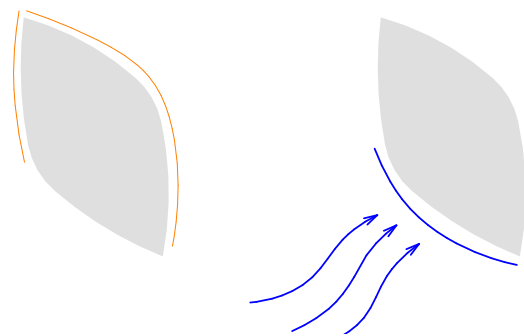

Trading winds

Form response-Day to Day

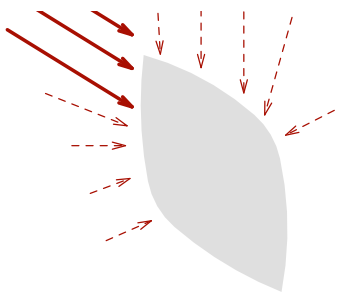

Cyclone direction

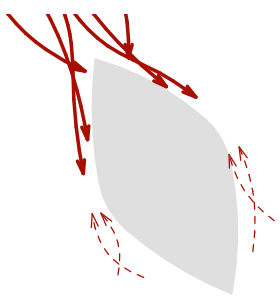

Wave direction
Ocean winds
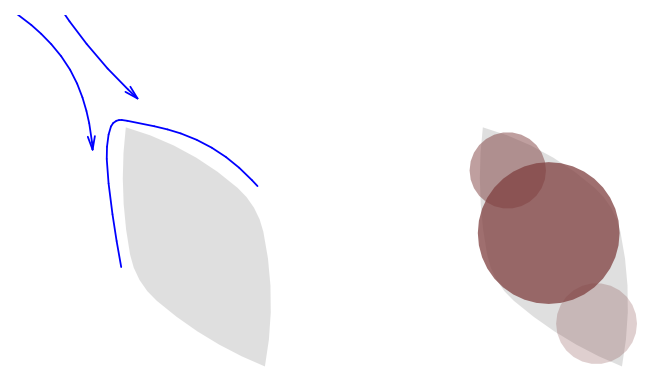

Spatial hireachy

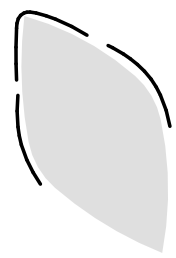

Sensitive areas

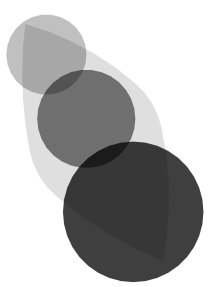

Spatial hireachy

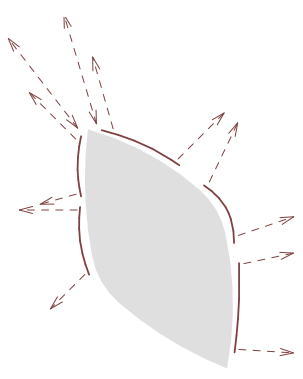

Wider connection

Form response-Disaster

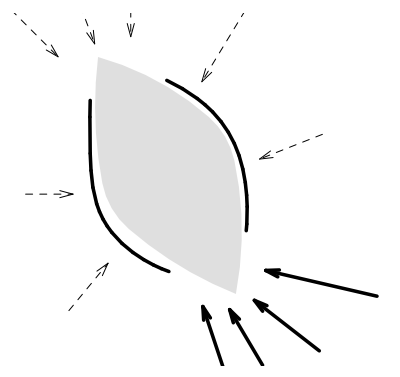

Wider connection to site

\section{Form response to site.}




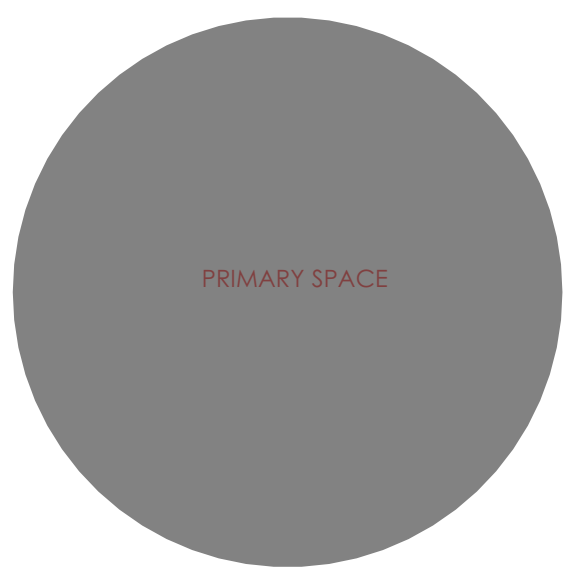

SECONDARY SPACE

\section{MINOR SPACE}

Spatial arrangement

\section{Program hierarchy.}

Figure 166. Spatial arrangement based on the Ovava tree framework of central core being 

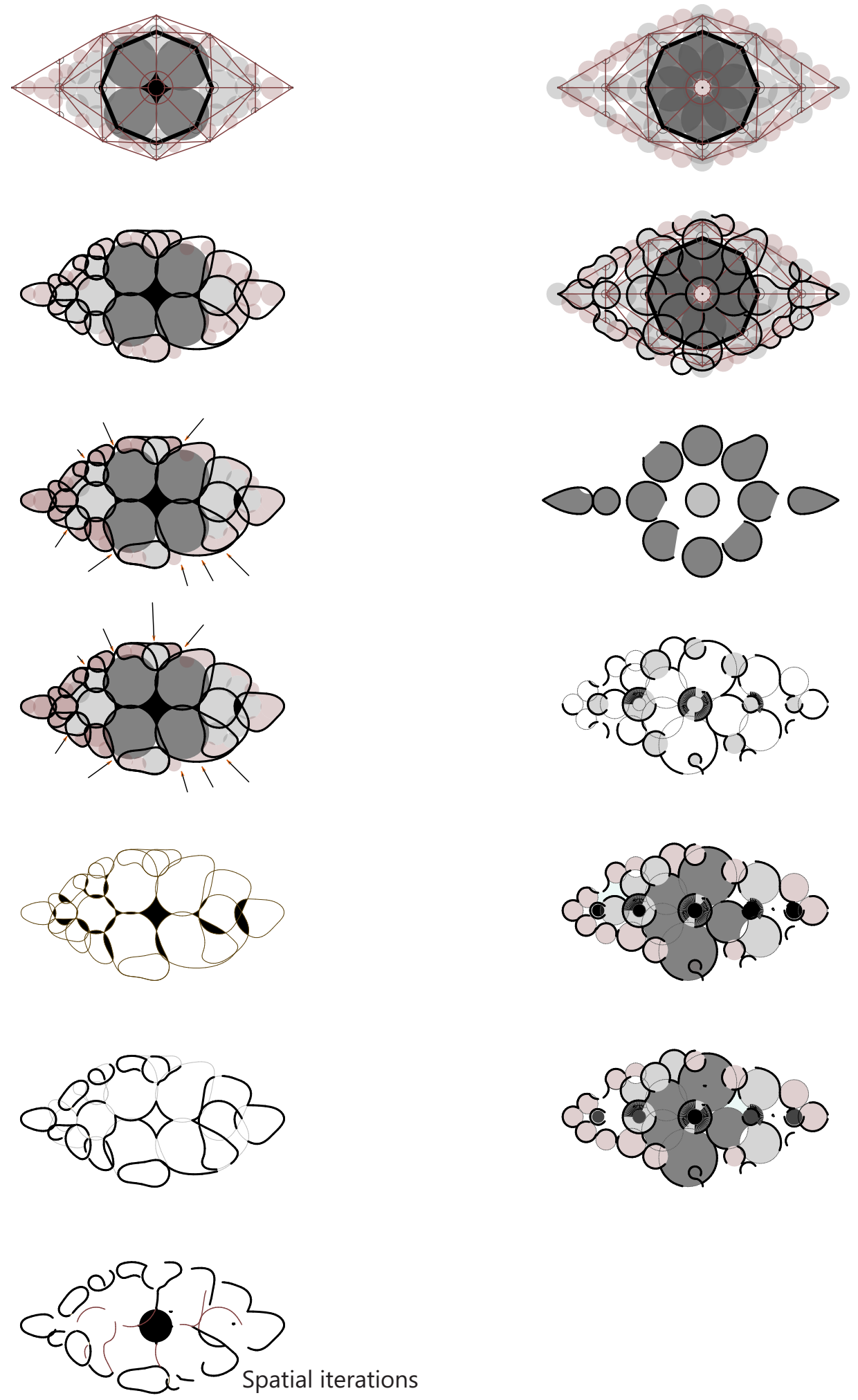

Program spatial iterations.

Figure 167. Testing of this spatial arrangement on form. Protecting the middle with smaller minor spaces on the outer shell* 


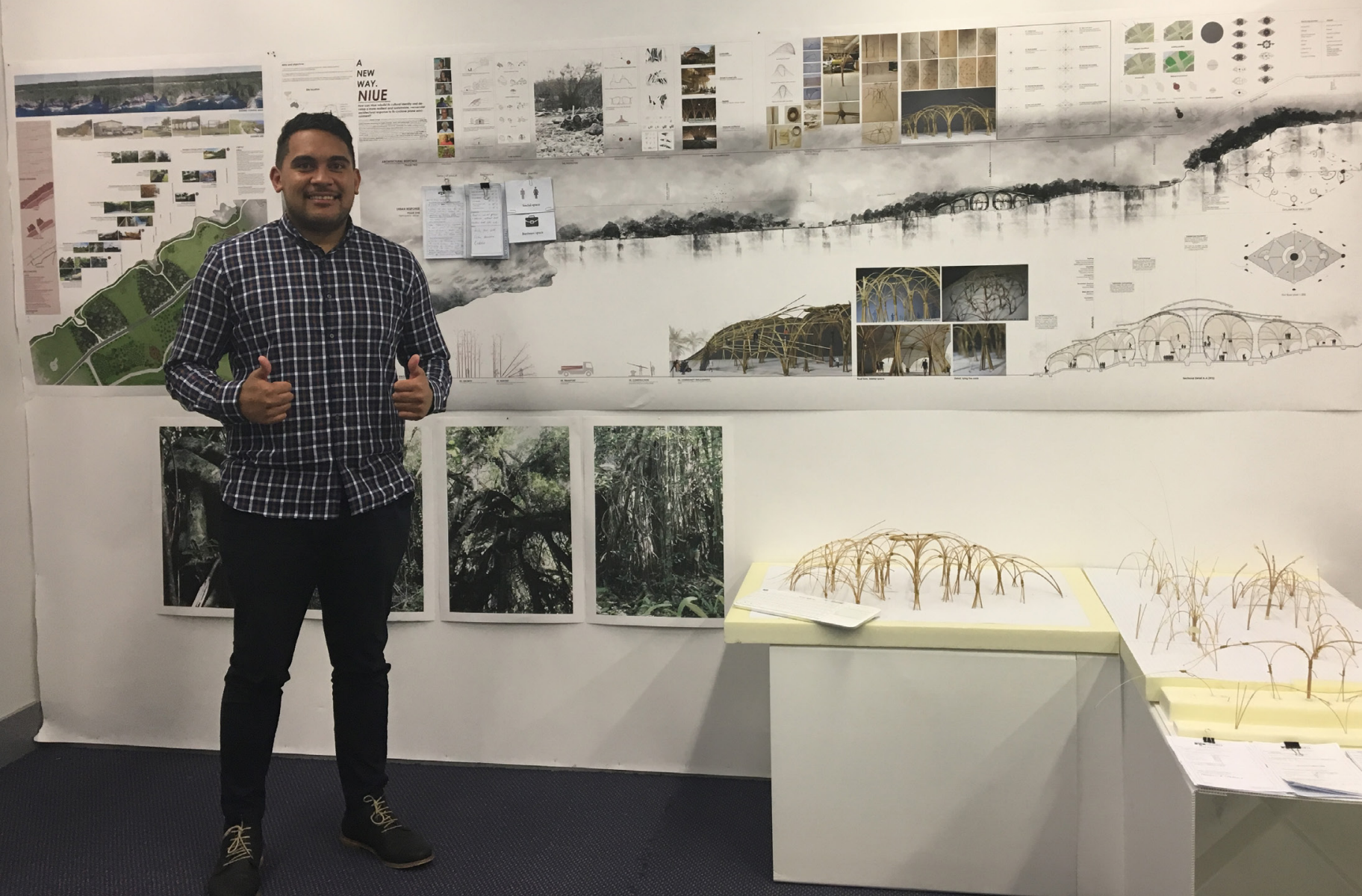




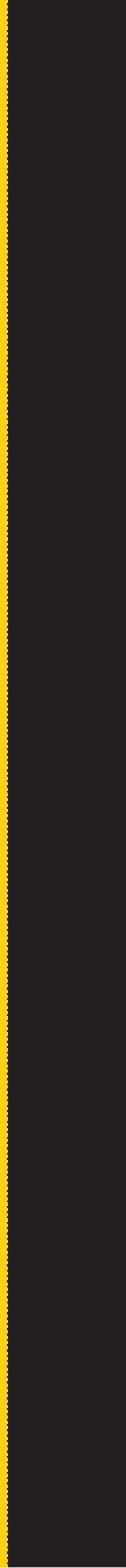


8. Final Design 



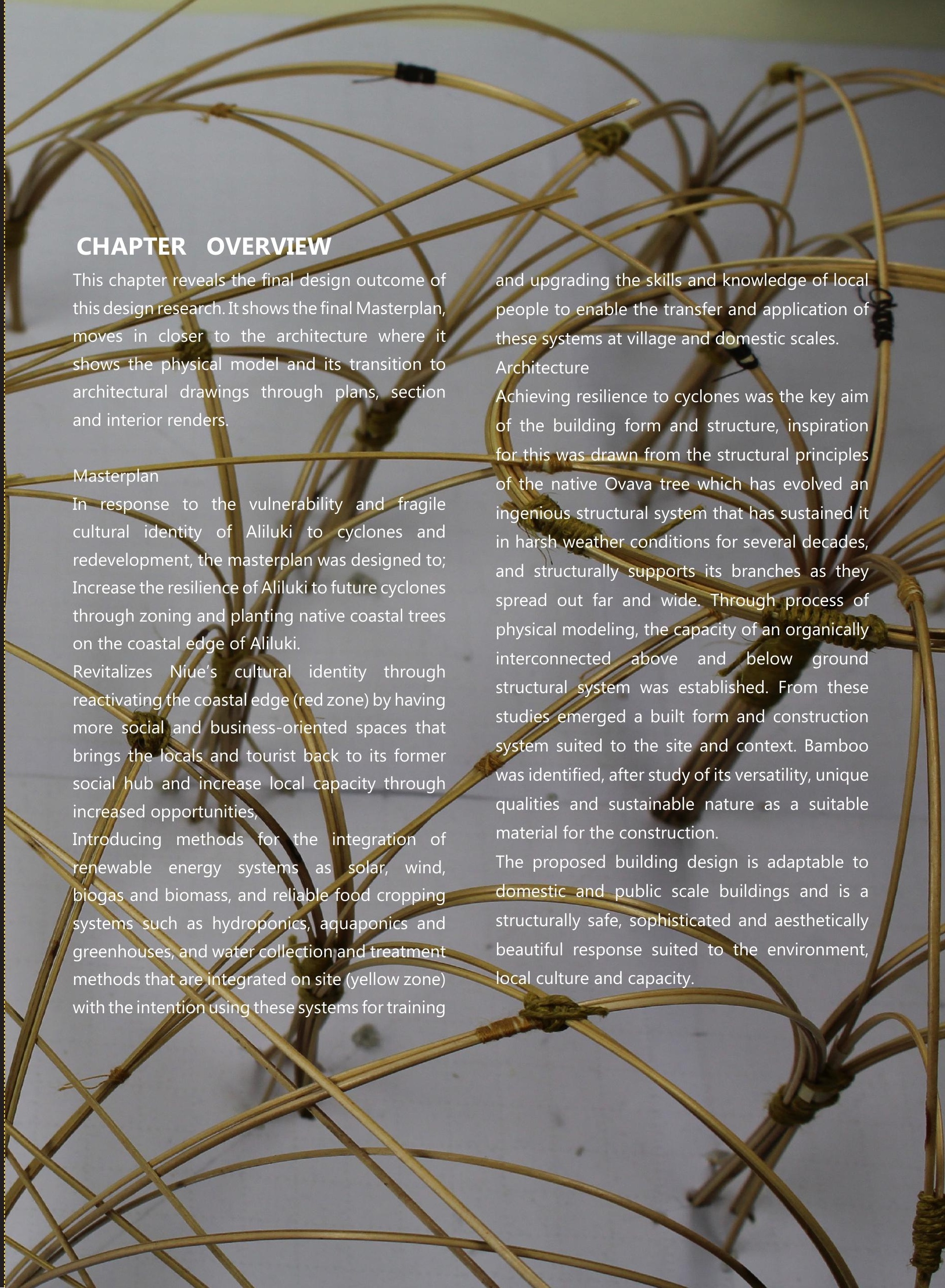




\section{MASTERPLAN}

Red zone-Social \& Business space

R.01. Clear open view of coastal area

R.02. Existing rock walls/Pa maka

R.03. Open green space for show days and local festivals

R.04. Replanting of native coastal trees and plants

R.05. Memorial park

R.06. Walkways through the forest

R.07. Sports field/Outdoor park

R.08. Existing Claytons bar

\section{Yellow zone-Architectural/Sustainable systems}

Y.01. Proposed redevelopment of businesses

Y.02. Proposed cluster of houses

Y.03. Hydroponic research centre accommodation

Y.04. Proposed greenhouse cluster

Y.05. Re-plantation of coconut trees

Y.06. PROPOSED EVACUATION CENTRE

Y.07. Bamboo plantation for evacuation centre

Y.08. Proposed tourist accommodation

\section{Blue zone-Residential/Maaga foou}

B.01. New proposed area for the local residents B.02. Proposed area for renewable energy system

B.03. Solar panel area

N

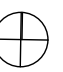




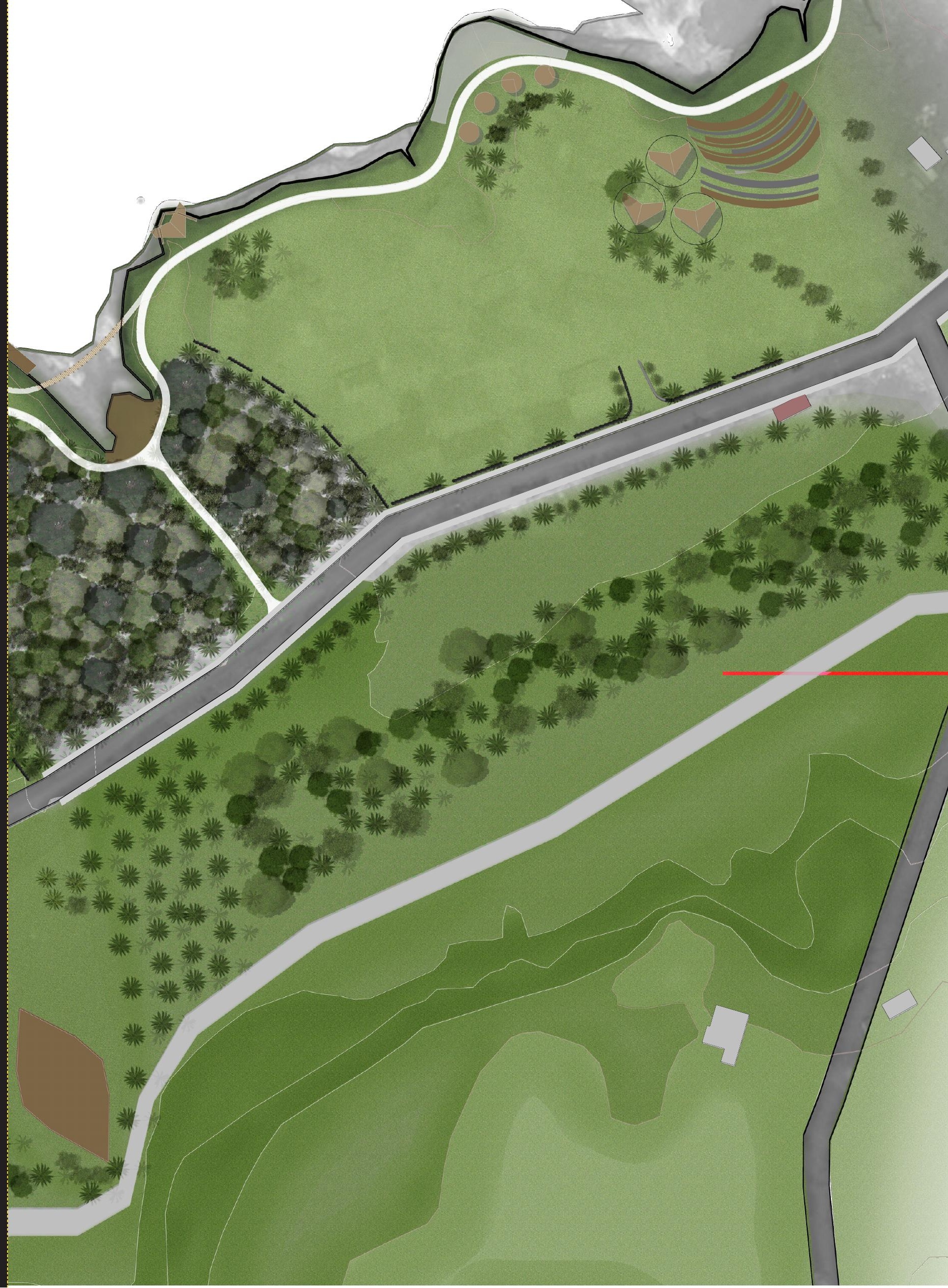



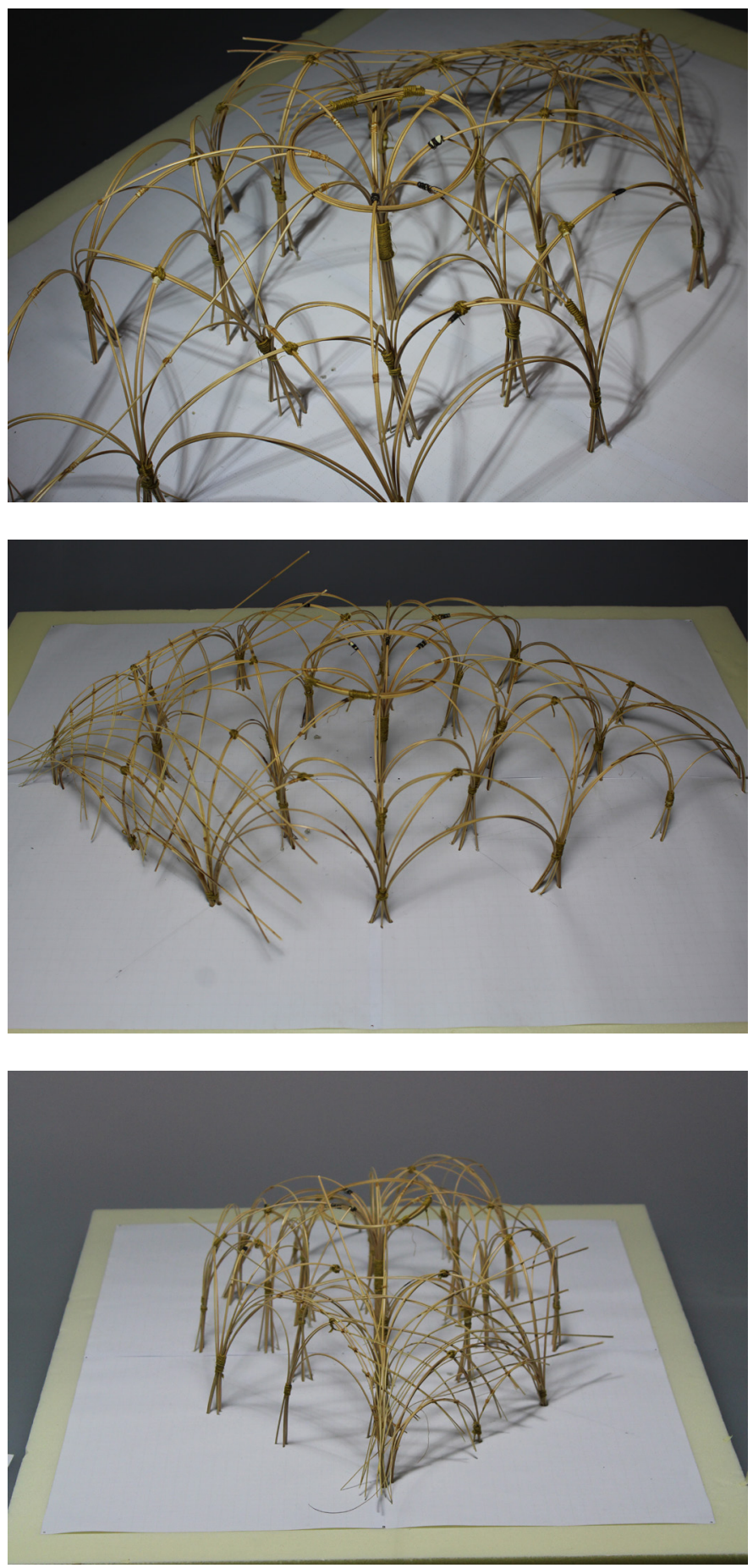

Figure 171. Exterior shell of the model is interlinked with the central and secondary core* 

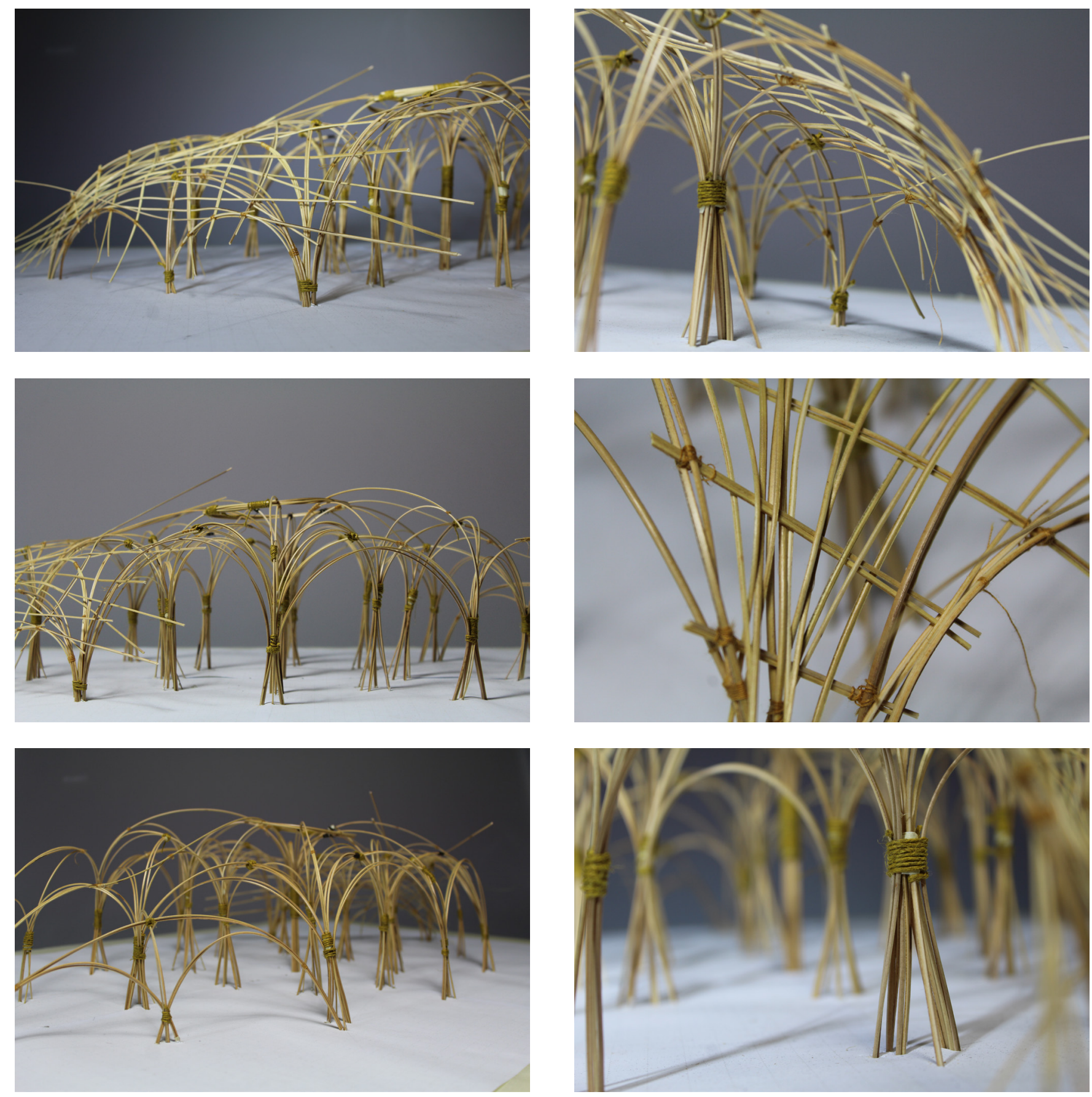

Figure 172. The arching entry points provide structural rigidity to the form*

Figure 173. Interior structure and roof weaved on to the external skeleton structure* 
4

$\otimes$

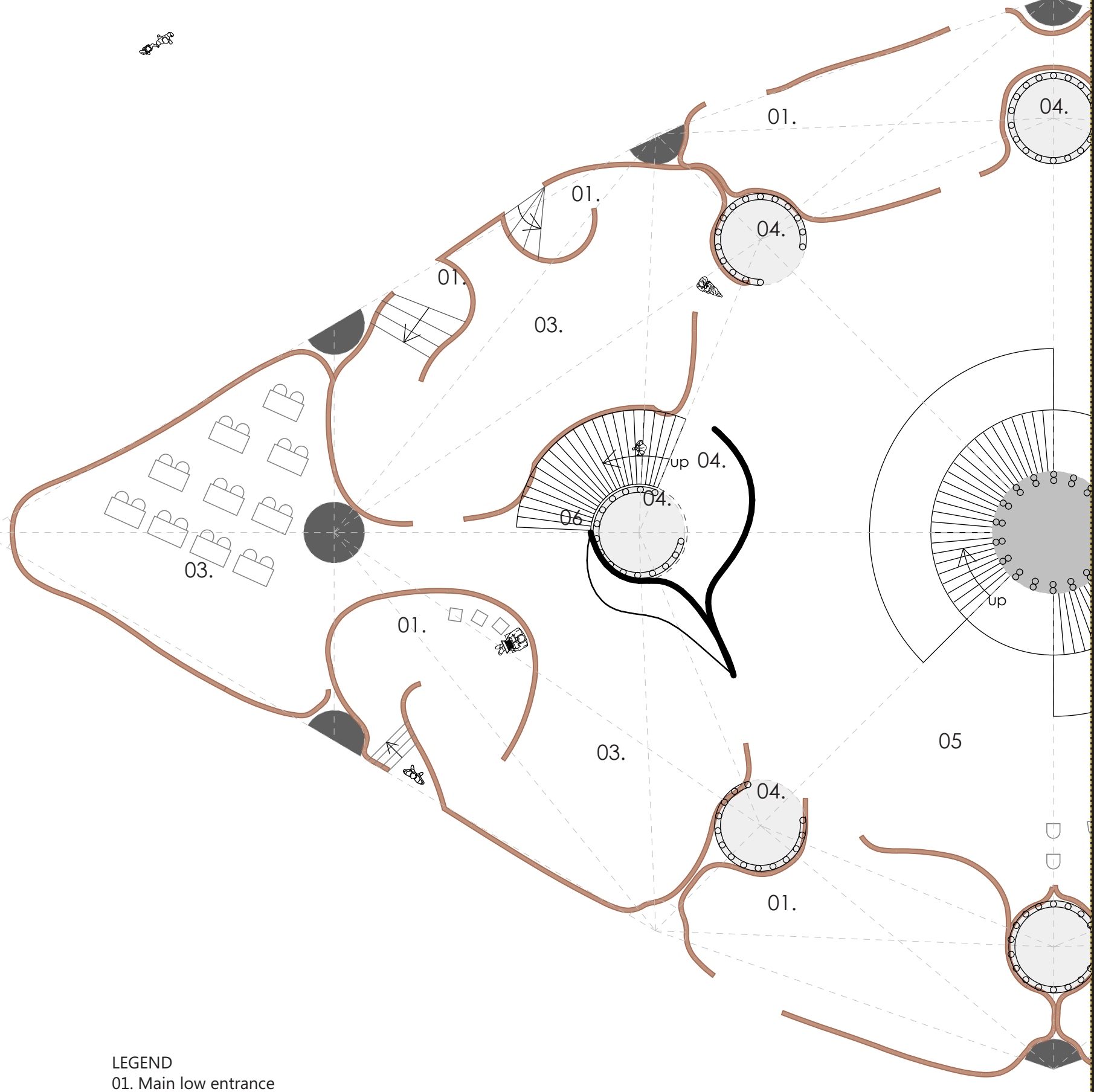

Dain low entrance

02 . Secondary entrance

03. Shelter, meeting rooms, exhibitions,

Classrooms, Toilets, kitchen

04. Storage, display area

05. Market place, performance area,

Cultural activities, Protected shelter

06. Stairs

07. Disaster office operational room

08.Educational,medical, protected shelter 
02.

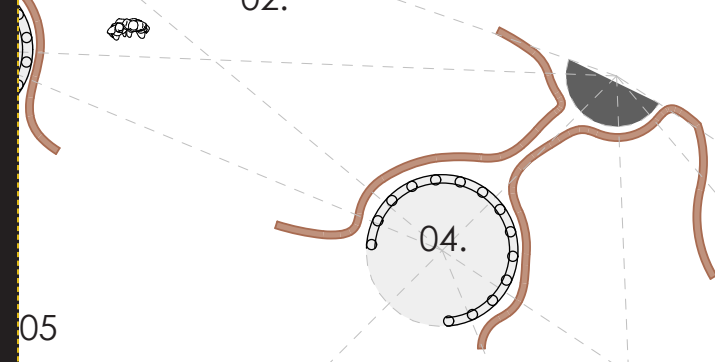

02.

03.
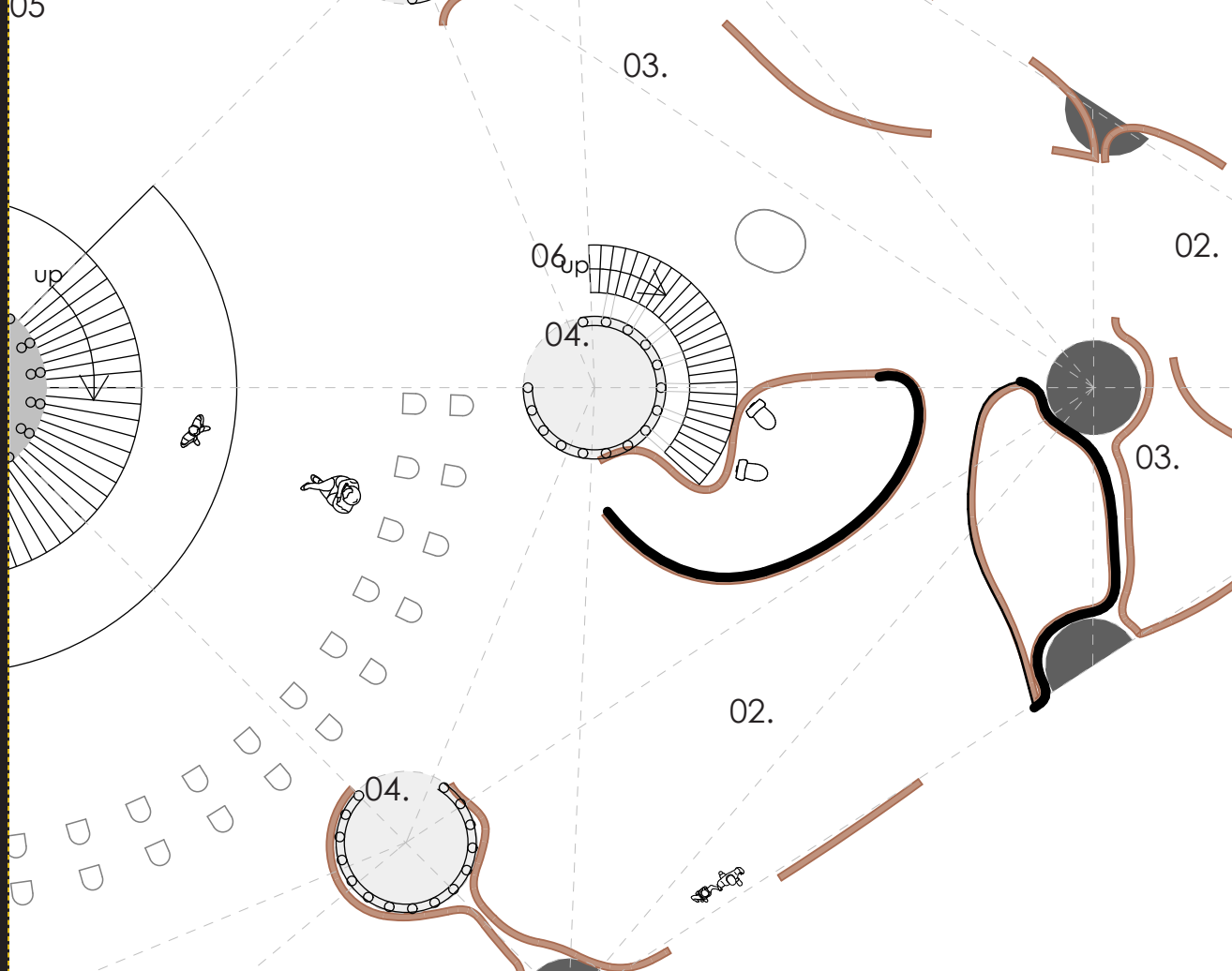

02.

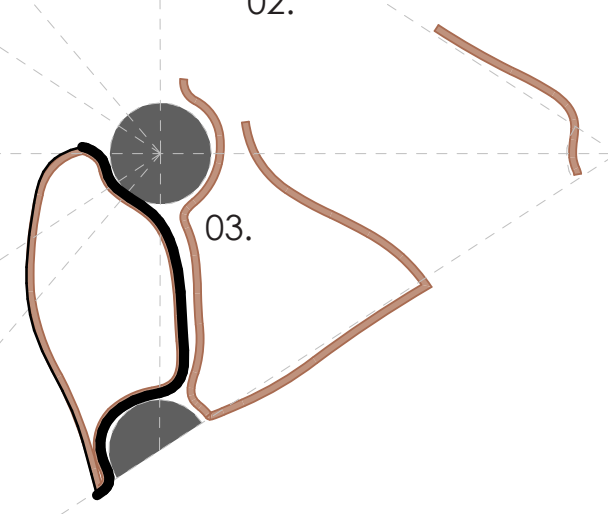

02.

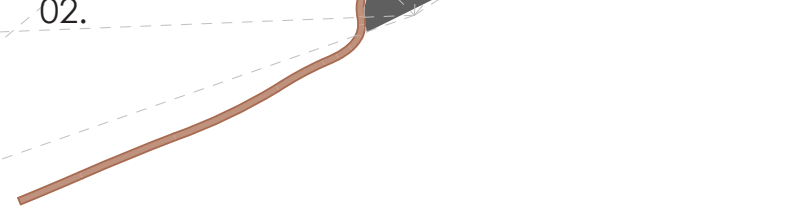




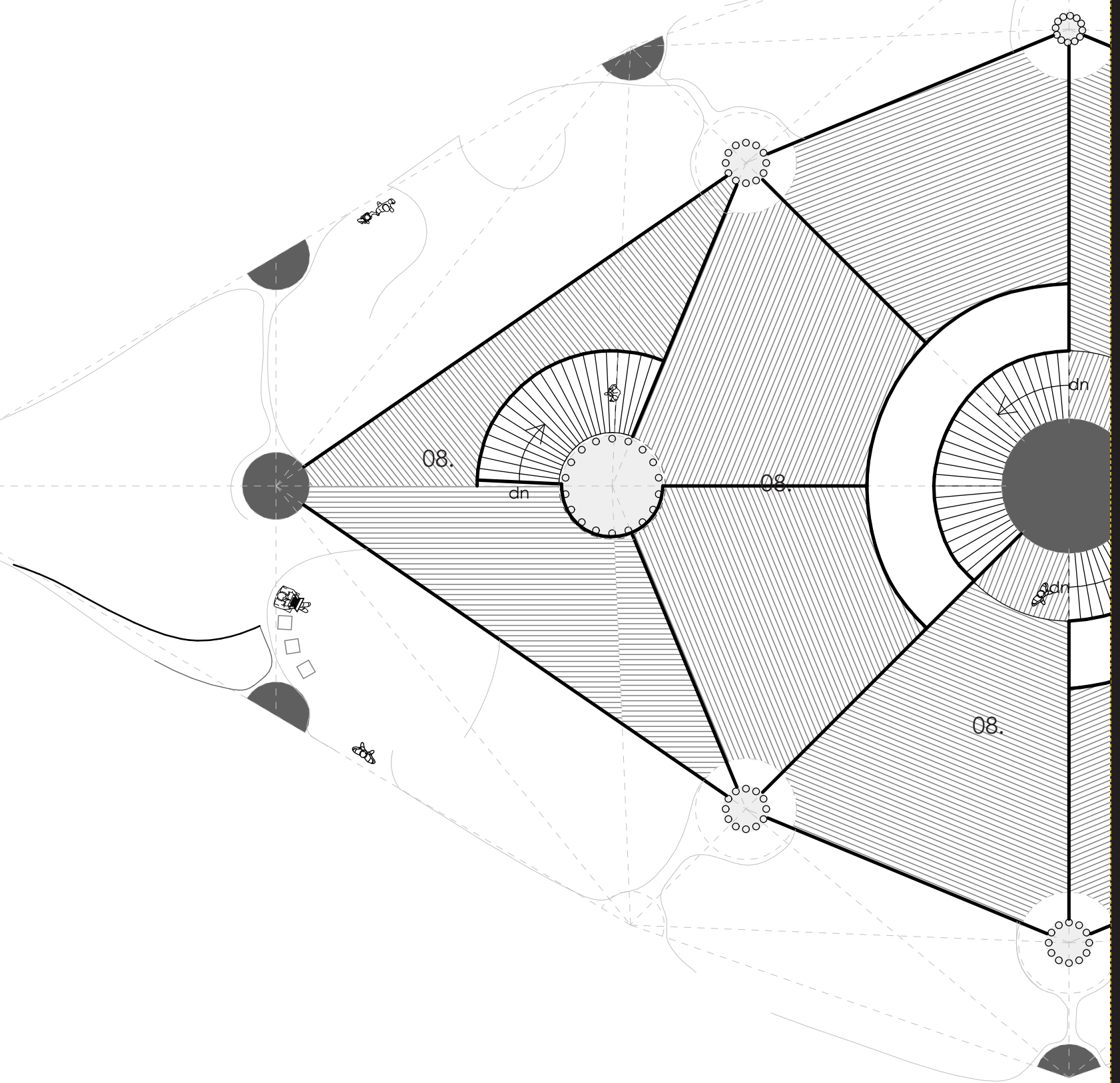

LEGEND

01. Main low entrance

02. Secondary entrance

03 . Shelter, meeting rooms, exhibitions,

classrooms, Toilets, kitchen

04 . Storage, display area

05. Market place, performance area,

cultural activities, Protected shelter

06. Stairs

07. Disaster office operational room

08.Educational,medical, protected shelter 


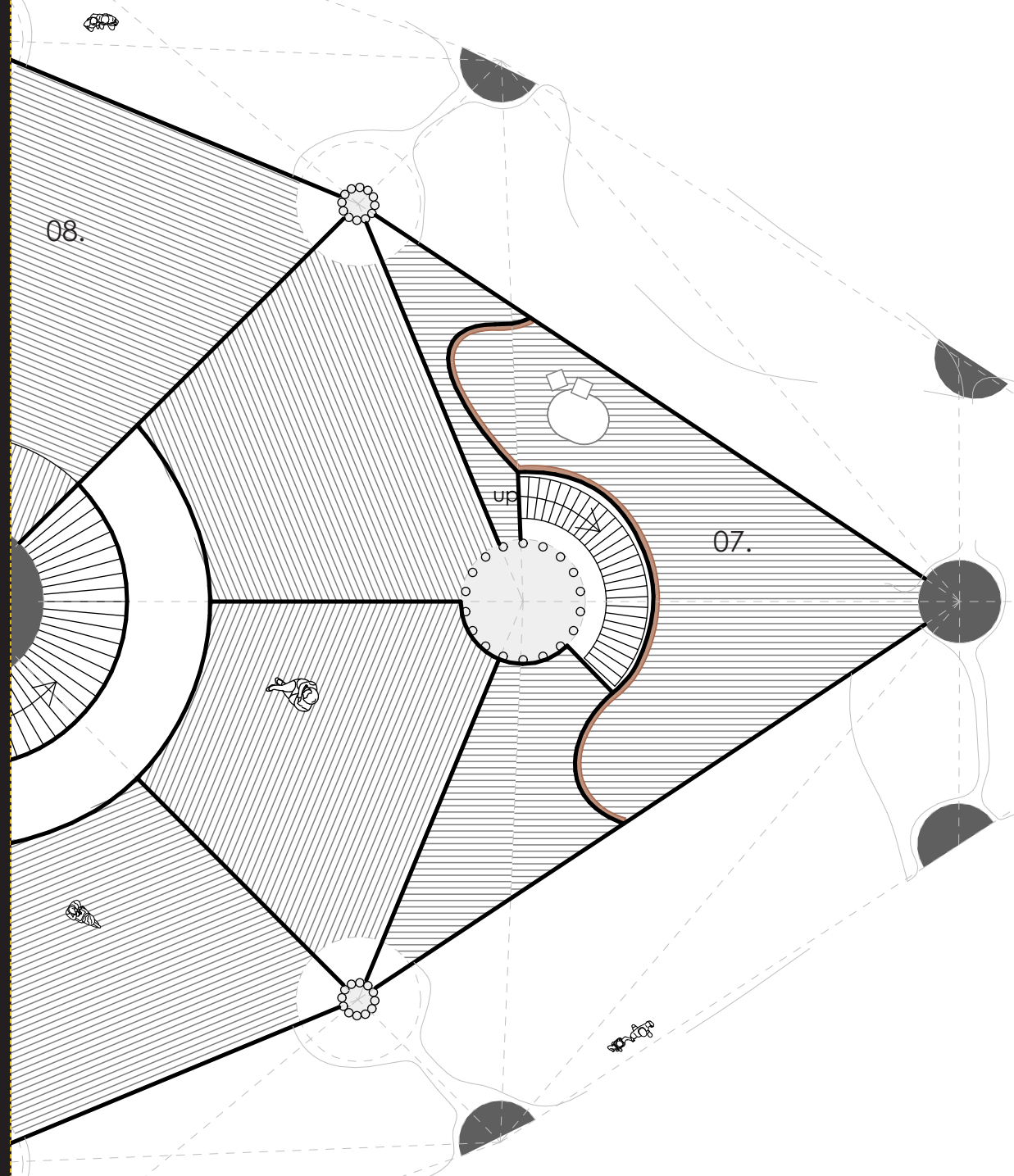

Figure 162. First floor plan, is more formal and rigid to add extra lateral support for building* 


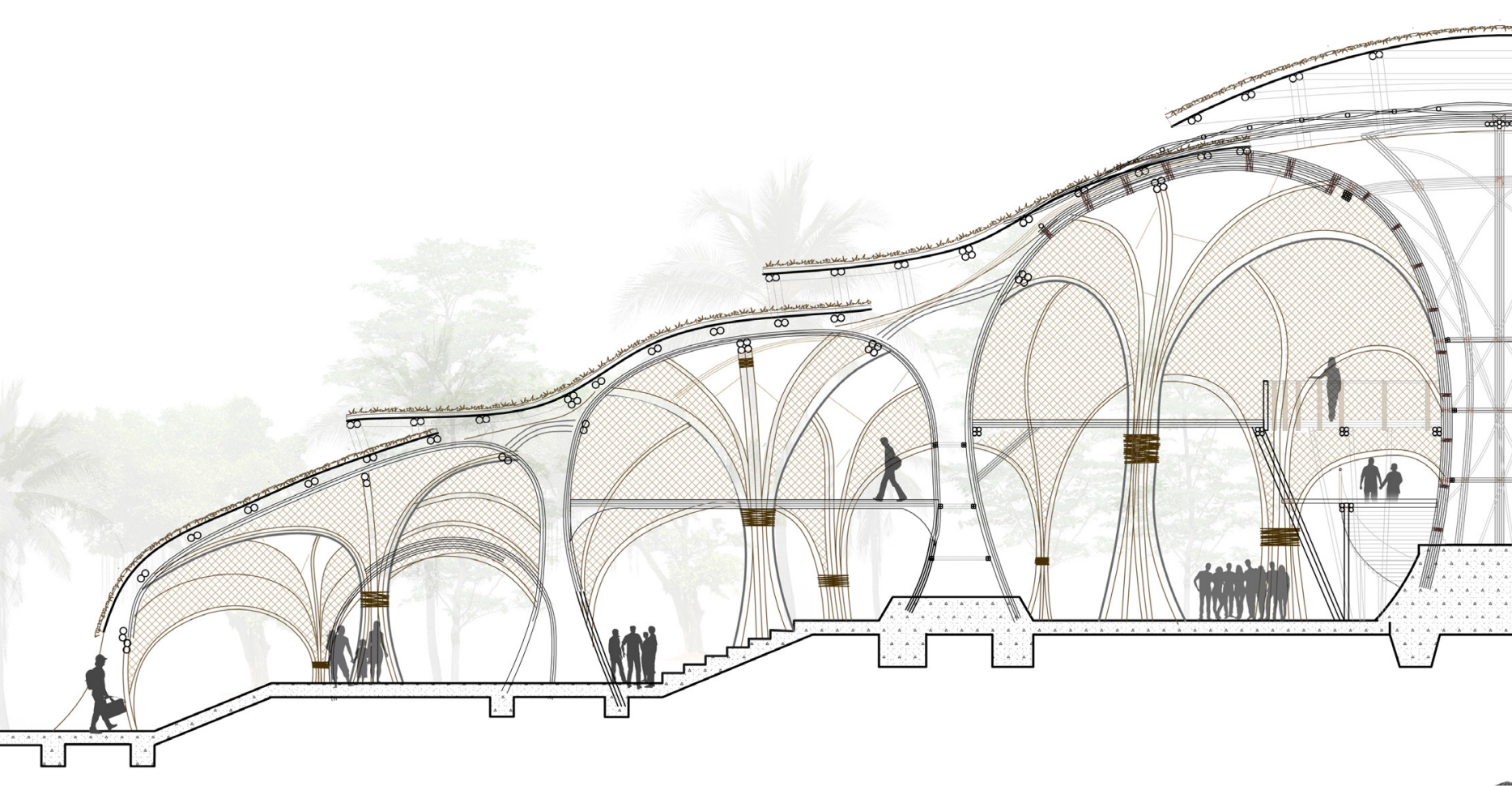




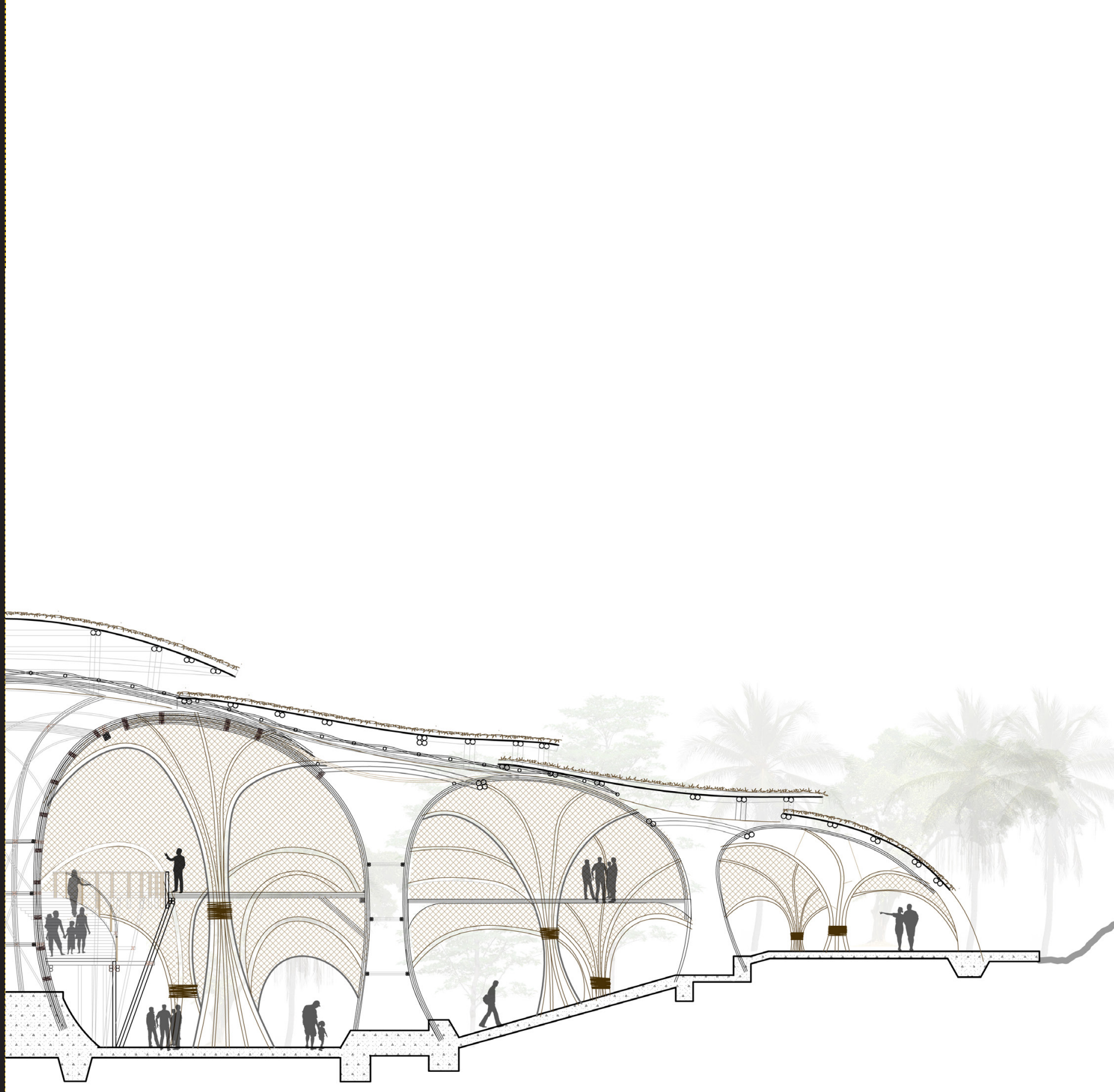




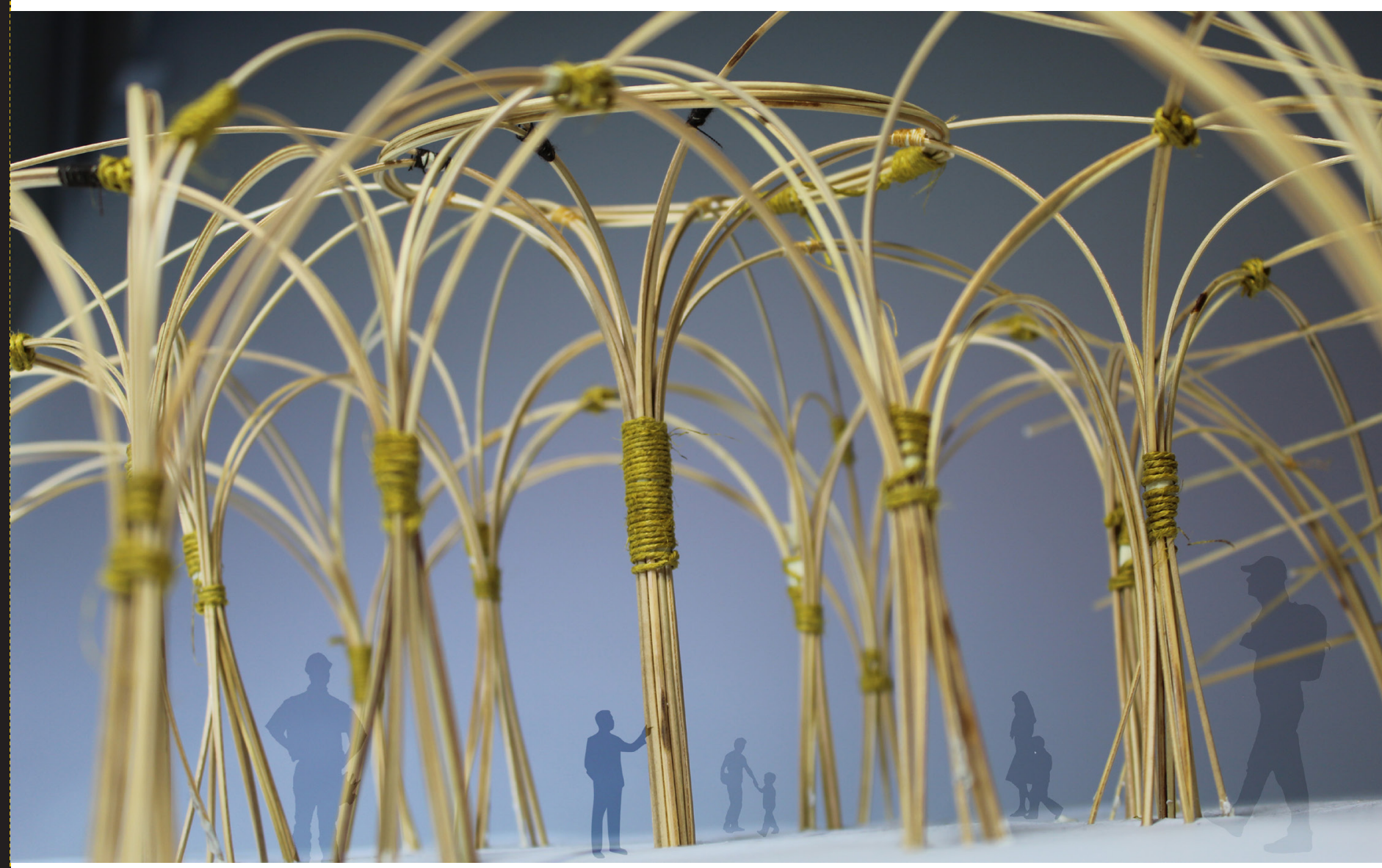

Figure 177. Interior space showing the large cave like space, with exposed weaving structure* (left)

Figure 178. Interior render beginning to show the large generous 


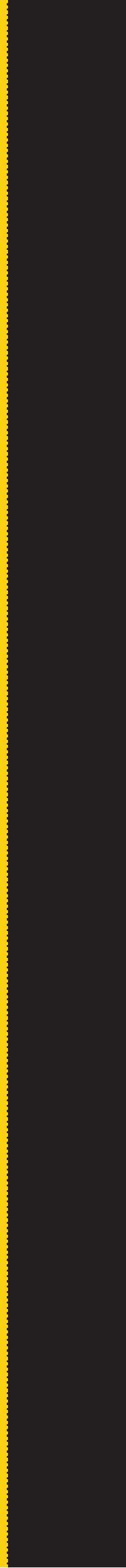


9. Design Discussion 



\section{CHAPTER OVERVIEW}

The final chapter of the design research looks at explaining the design and how it reflects the current research aims and objectives, how it addresses the existing issues and how it responds to the voice of the community. It begins by discussing the master plan and how it responds to future cyclones, how the space is used on a daily basis and how the solution benefits the local community and tourists. The architecture is discussed based on its building form, building positioning and structural capabilities to resist cyclones. Sustainability issues are discussed and explored, material choice is discussed based on local readily made materials.

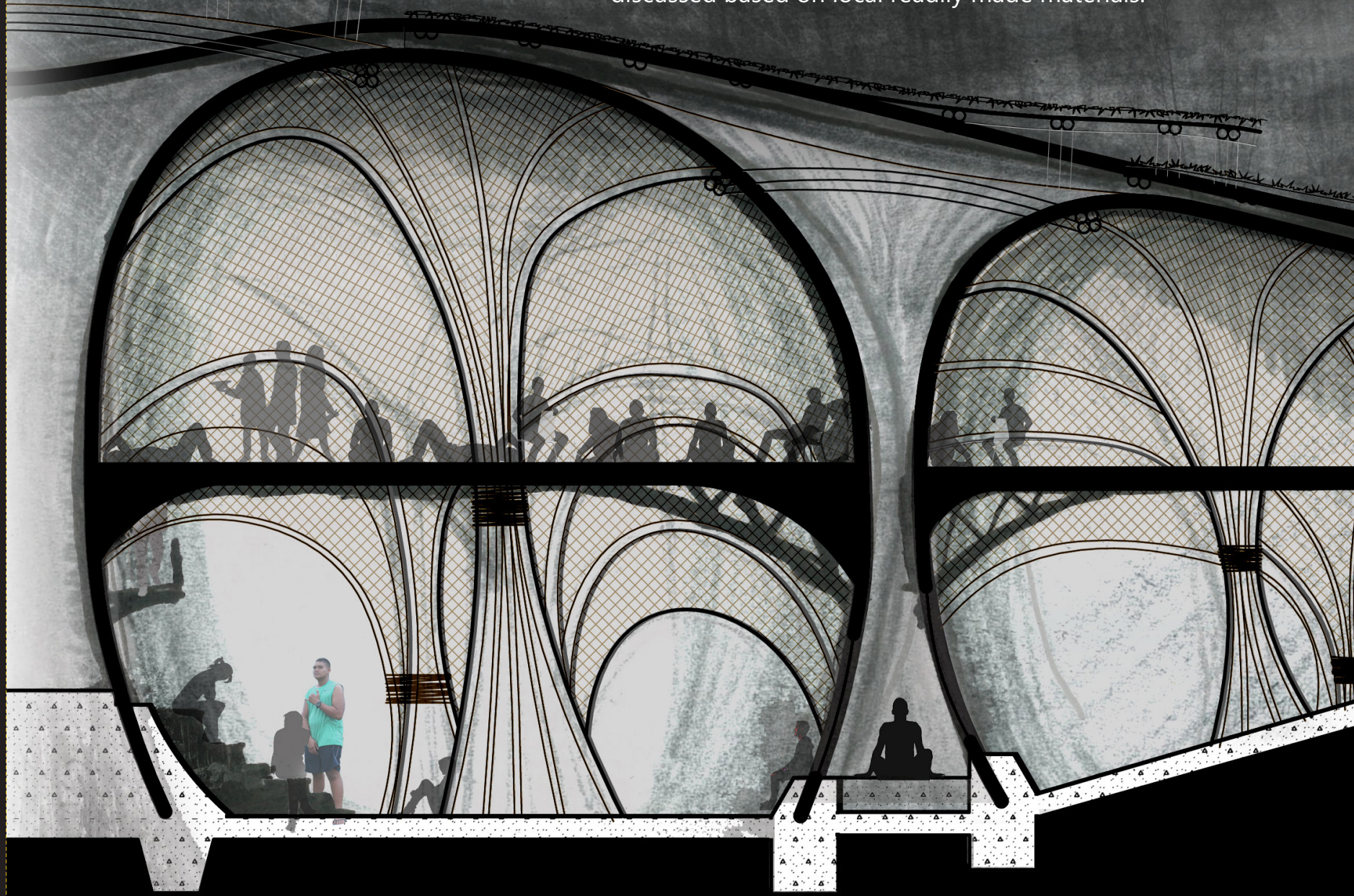


9.1 Masterplan discussion 
Develop a viable architectural solution that increasing the resilience and sustainability of Aliluki to future disasters and contributes to the economic prosperity of the community through increased opportunity. 


\subsubsection{DISASTER SCENARIO}

Pre disaster

The masterplan plan is divided into three main zones: red, yellow, and blue, which are determined by the level of safety the community has from potential tsunami waves. The red being high risk zone, yellow medium risk and blue low risk zone. Before a cyclone, early warning systems that are currently being practice and used efficiently by the Niuean community will be employed. This gives the residents who are living on the blue zone ample time to prepare their homes for the strong cyclonic winds and the rest of the community to take shelter in the Evacuation centre.

The new roads design are placed with the primary aim to ensure a quick and easy escape route for the local community to higher grounds in an event of cyclone.

\section{During disaster.}

The key to increasing the resilience of Aliluki was to eliminate or minimise one of its biggest threats, the tsunami waves. Eliminating this threat allows infrastructures, new developments and the locals to deal directly with only cyclonic wind forces which can be dealt with. The local community can take shelter in their own homes as there are strict requirements for any dwelling to be cyclone proof or;

Take shelter in the Evacuation center. 


\section{Post-disaster.}

As community resilience is a measure of how the community can bounce back after a natural disaster, the masterplan provides emergency water, food, and power through the integration of these system on site, located on the yellow zone which aims to sustain the local community during the initial post disaster period. The redevelopment is designed to be the focal point of the Niuean community, acting as the beacon of light during and post disaster.

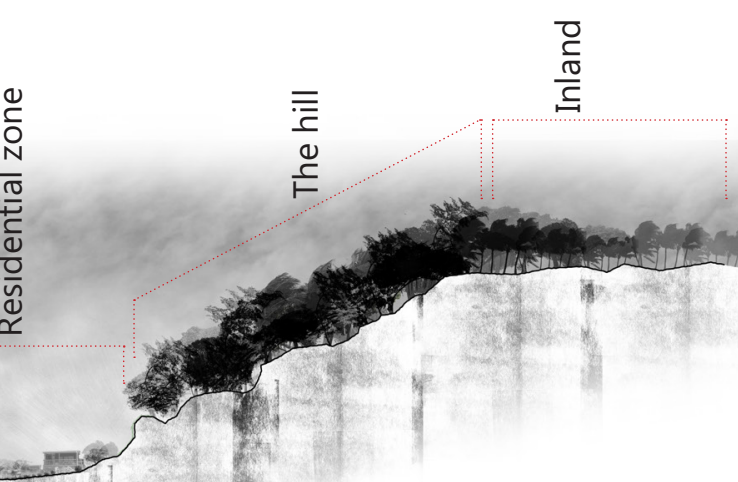




\subsubsection{DAY TO DAY SCENARIO}

For about $60 \%$ of the year, Niue is cyclone

free. The importance of the masterplan in addressing cultural and social issues is important. The findings from the community highlighted the urgent need for developments of new businesses to increase local capacity through entrepreneurial opportunities and more social and recreational programs on site. These are crucial in attracting the Niuean community and tourist which enhance the sharing and celebration of the cultural identity of the Niuean people. 
A social hub.

The red zone has been designed to reconnect people to the water and revitalise Aliluki as a social hub for Niue. It is designed with the key principles of identity, heritage conservation, and connection.

Landscape architecture:

Walkway

A rugged coastal walkway is designed to follow the coastal edge line of Aliluki where it is fully integrated into the rugged and sharp limestone formation. Simple swing bridges that float across the crevices, which goes through the forest back to the main road. The main aim of this walkway is to encourage active and pedestrian thoroughfare through the site and the coastal edge.

A memorial for Huanaki cultural center.

An outdoor integrated landscape seating/ performance area is designed to enrich the heritage conservation of Aliluki and to encourage social and cultural interaction with the site.

\section{Lookout points}

The main look out point is strategically placed to enhance the experience of pedestrians flowing through the walkway. The location of the lookout is the focal point where the best view of the ocean can be seen through.

Landscape designed park.
The area where the cultural center is located is designed as a memorial for the two precious lives lost during Cyclone Heta. As a narrative, the cultural center is a symbol of the mum who is looking out for his son (Memorial sculpture) and vice versa. The clear opening, that expands out to the water, a constant reminder of the power of nature with the rock walls complimenting the view looking outwards.

Open park.

The open park designed for local social functions such as show days, local festivals and to keep a clear visual of the water.

Outdoor sports park.

The outdoor sports park located on the east corner is designed for locals to fully integrate with the site by allowing the flow of pedestrian and movement beyond the cultural center. Through site observations, vehicle movement predominately moves from west to east.

\section{Temporary/light architecture.}

\section{Shelters.}

Light construction and low cost shelters made out of bamboo are scattered around the site to dissipate pedestrian congestions and congregation on one certain area.

Pop up businesses. 


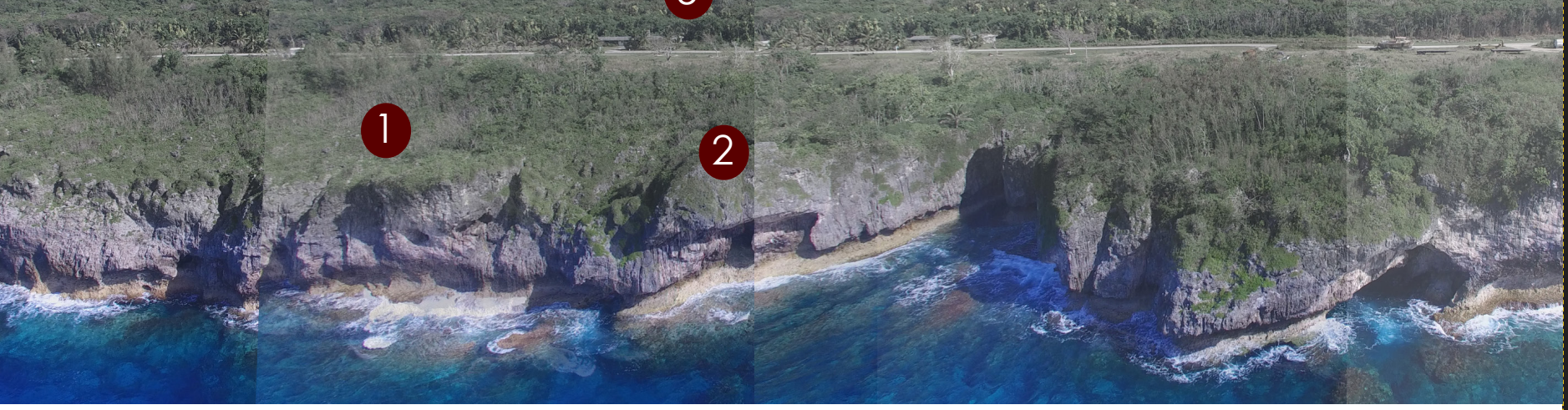

2
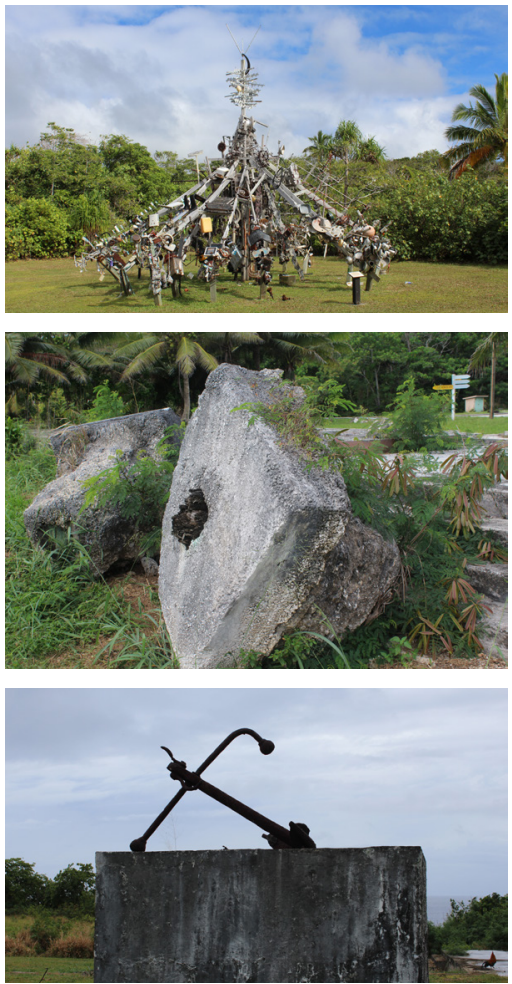

\section{Memorial piece}

a. An anchor is placed as a

memorial on site

b. Foundation piles swept up to

the cultural centre

c. Art sculpture at Liku
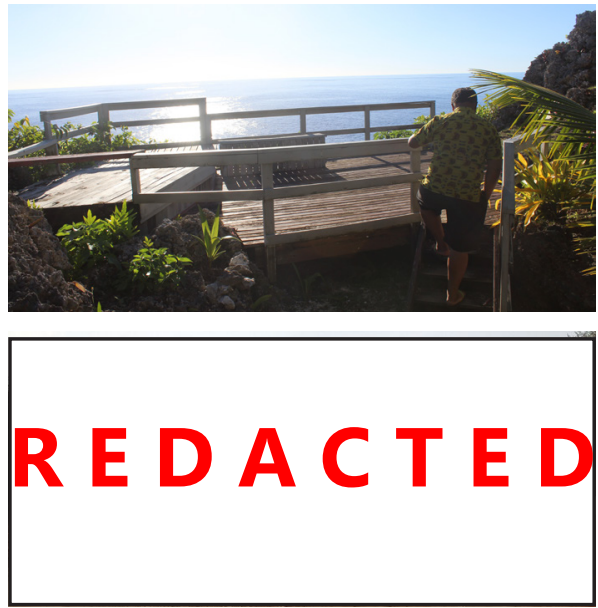

Lookout platform

A. Precedent Sweep observation

b. Lookout point in Makefu, Anana motel

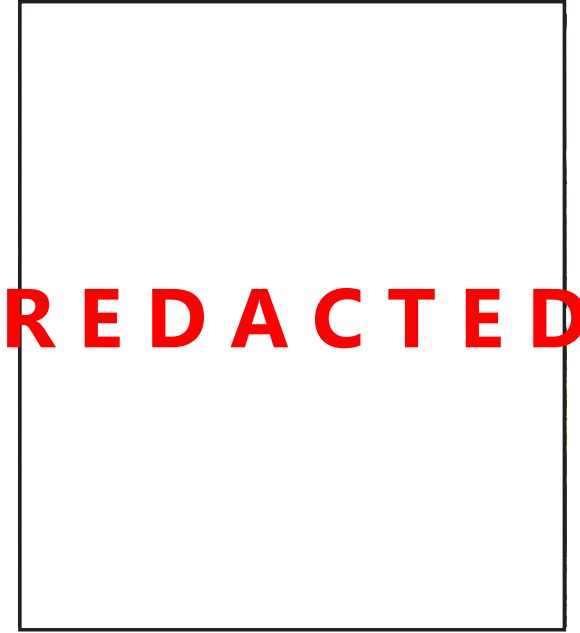

Precedent-Carrick-a-Rede-Rope-Bridge Using a light rope bridge across the cliff enhances the experience of the coastal walk. 

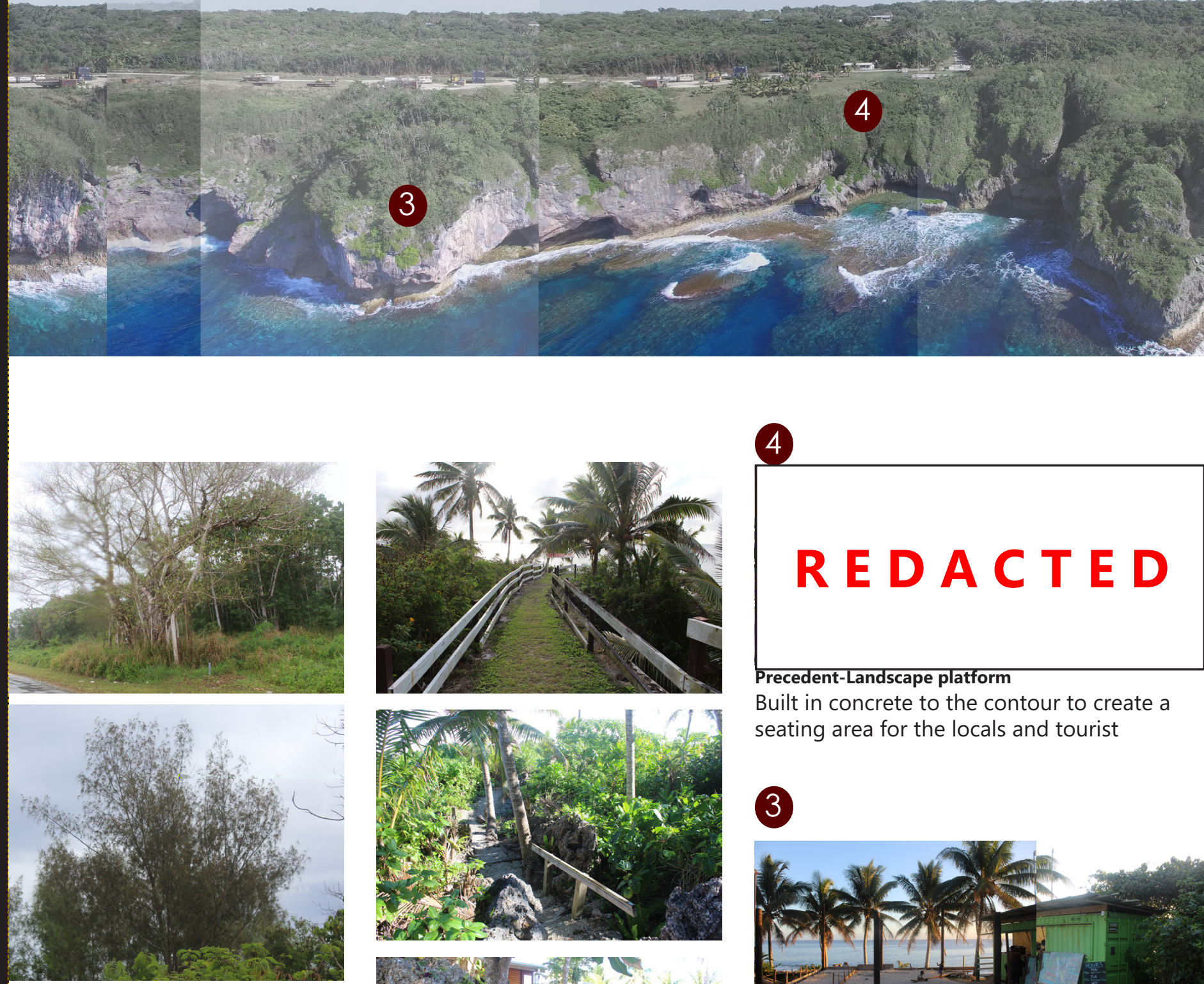

(4)

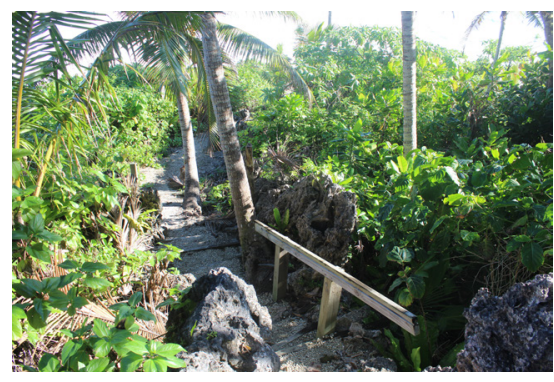

Precedent-Landscape platform

Built in concrete to the contour to create a seating area for the locals and tourist
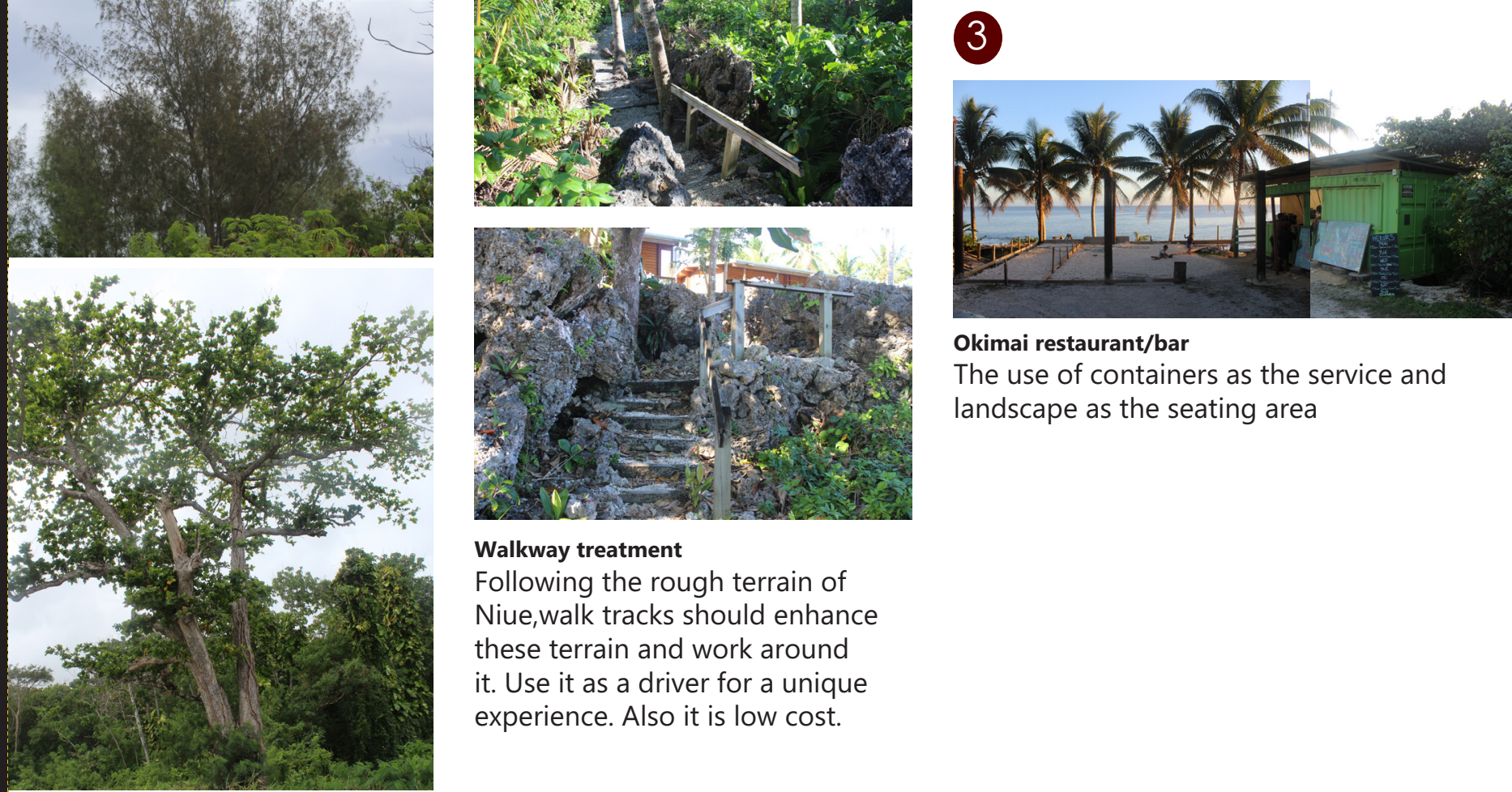

\section{Okimai restaurant/bar}

The use of containers as the service and landscape as the seating area

\section{Walkway treatment}

Following the rough terrain of Niue, walk tracks should enhance these terrain and work around it. Use it as a driver for a unique experience. Also it is low cost.

\section{Native coastal trees}

Such trees as

Futu, Pao, Gate, Fetau, Tamanu, Kalaka 

architectural solution informed by the local culture, traditional practices, and contextual situation. 


\subsubsection{Cyclone resistant structure}

\section{Building position}

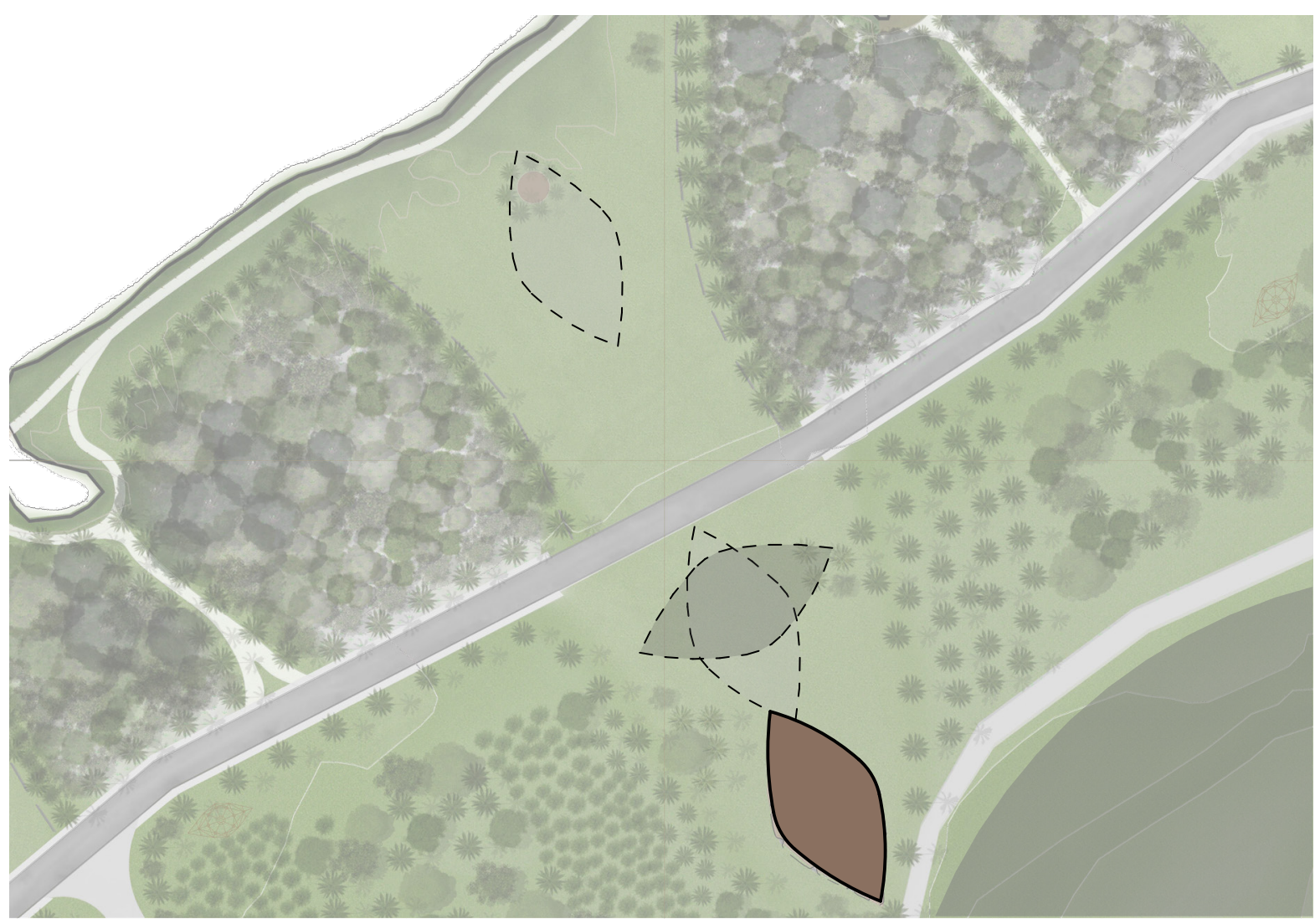

Detailed site studies revealed the multiple hazards that needed to be considered and potential solutions. From these it was established the safest location for the building complex would be further inland on the site and on higher ground. The gradual rise and depressions on the land would allow the building forms and foundations to wrap around and hug the hard limestone terrain and form protective cave like spaces. 


\section{Building Form}

Inspired by the tree, the form begins to take shape from the inside out. The gradual rise and depressions on the land would allow the building forms and foundations to wrap around and hug the hard limestone terrain and form protective cavelike spaces. It starts off with really low outer edges, gradually curving up towards the central core space and back down. It is a fluid and organic form that fits in well with the context of the site. The form of the building allows the wind to deflect and to flow around, and on top of the building. Like the wing of an aeroplane, the form aims to maximise wind deflection which will minimise cyclonic wind damage to the building. 


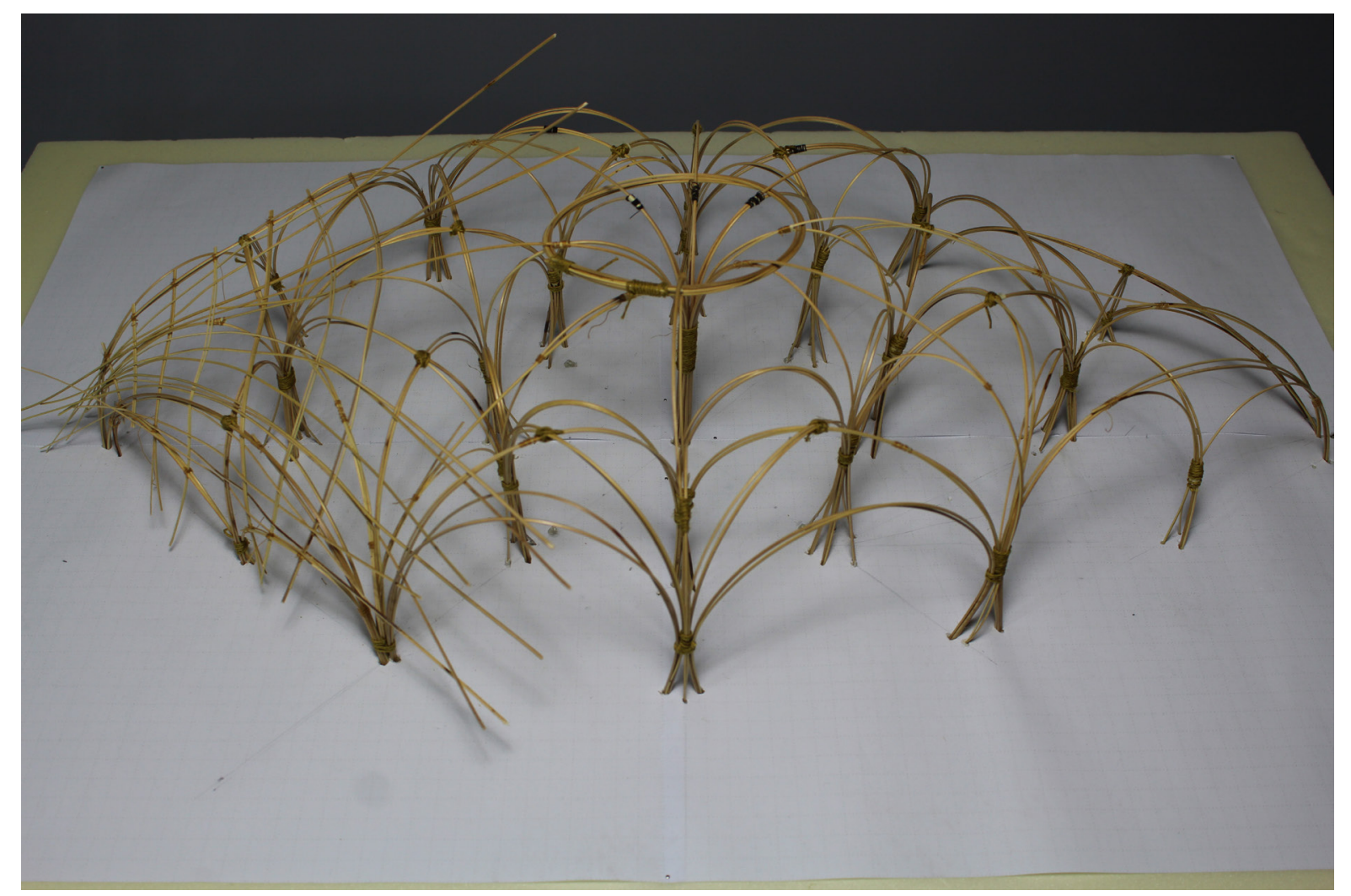




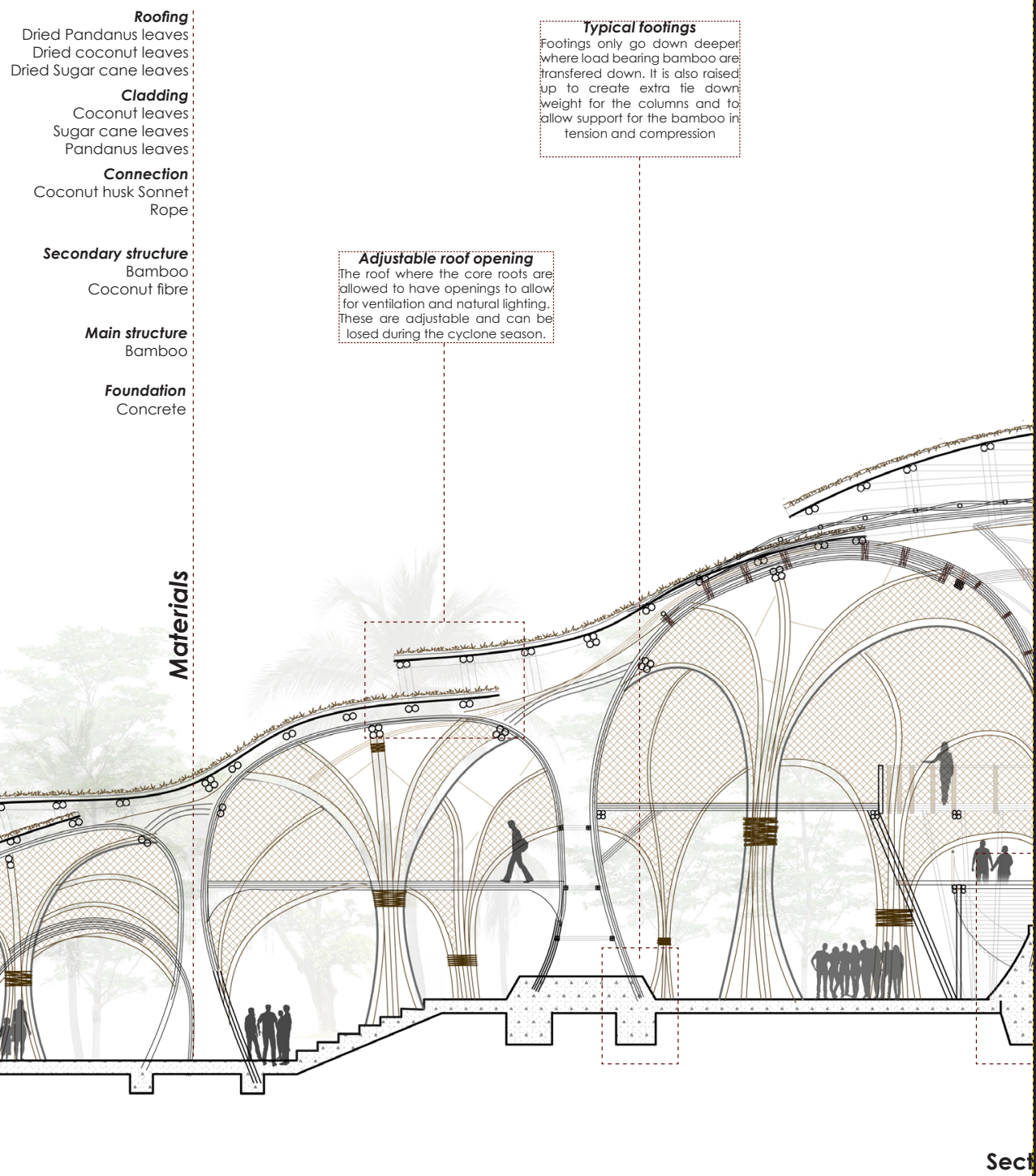


nfral core foundation

rete foundation is raisec

e instead of going down

stone rock.
.

acts as durability for the

moisture and termites

\section{Structural System}

The whole overall structural system was design to mimic the structural principles of the Ovava tree. From the design framework created, the structure begins from the central core, working its way outwards. The central core has the most generous space and is designed to be the most structurally safe area, similarly to that of the Ovava tree. Several secondary core trunks are designed to complement and enhance the structural stability of the central core.

ional Detail A-A (NTS) 


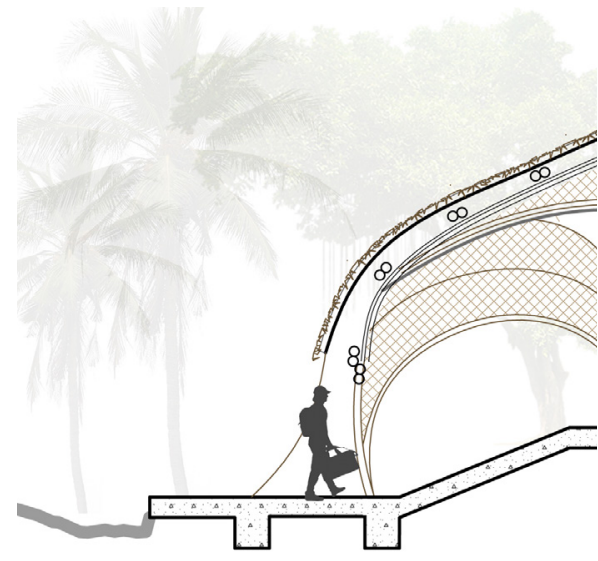

Figure 185 Close up of entry points towards the building.

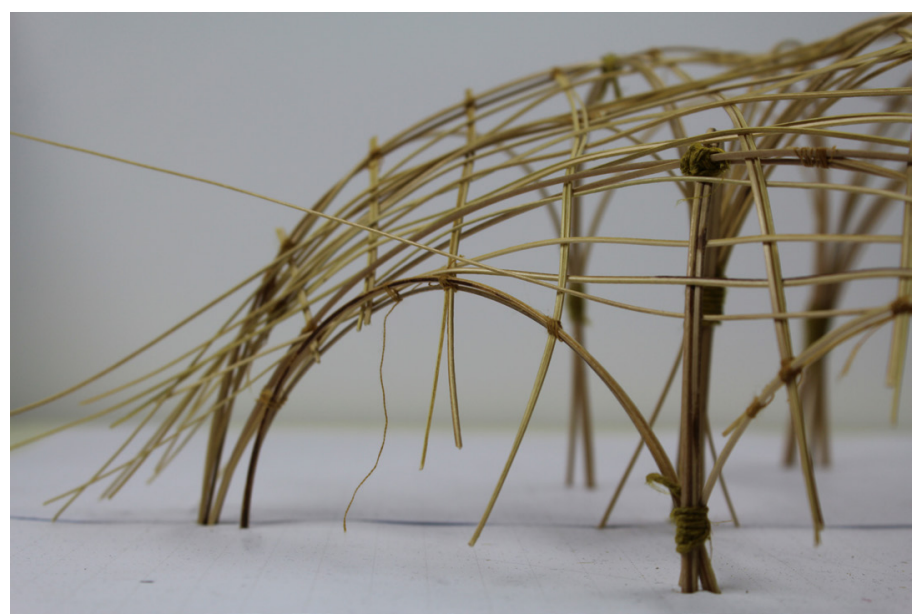

Figure 186. Model expressing same principles*

\section{Low entry points}

Low entry points with step down entrance spaces, strategically located in response to the terrain and raised foundations, minimizes heavy and turbulent winds from forcing uplifting the curvilinear sub structure.

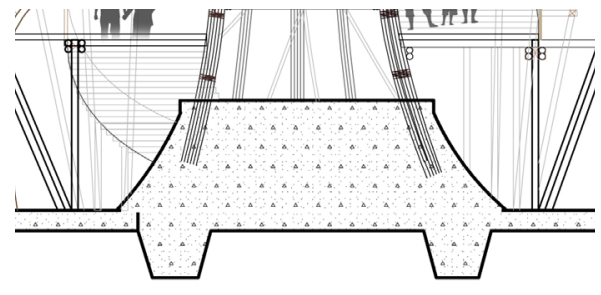

Figure 187. Main concrete foundation to central core*

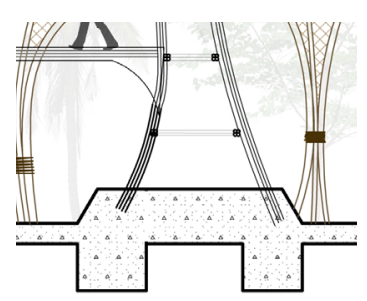

Figure 188. Smaller concrete foundation for secondary core*

\section{Foundations}

A system of raised concrete foundation piles, designed similar to the ground root network of the Ovava tree, protects the bamboo and anchors the substructure to the ground. Formed as a circular maze these cave like foundations are also a protective vertical barrier to tsunami waves that may reach the building. 


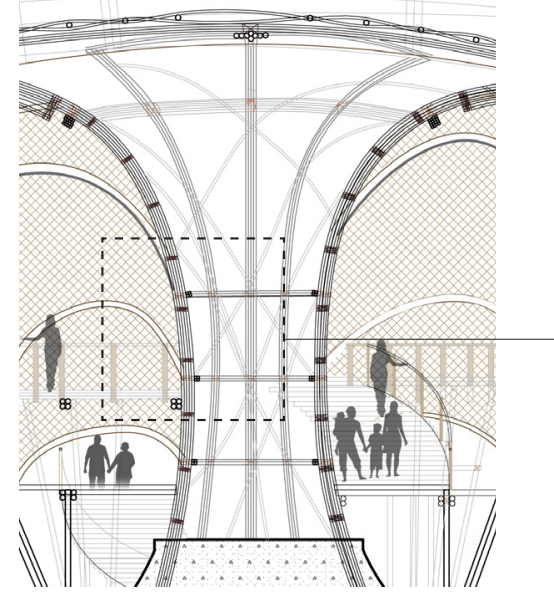

Figure 189. Main central core*

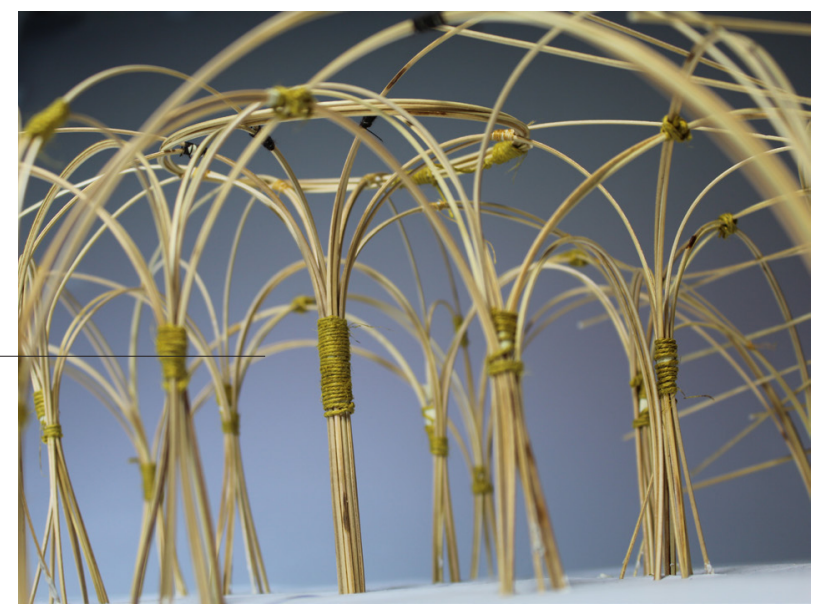

Figure 190. Expressing same principles*

\section{Structural core system}

A large central and several secondary structural cores were designed to acts in a manner similar to the central trunk and supportive above ground root networks of the Ovava tree. This system supports the building both laterally and vertically when cyclonic forces are applied.

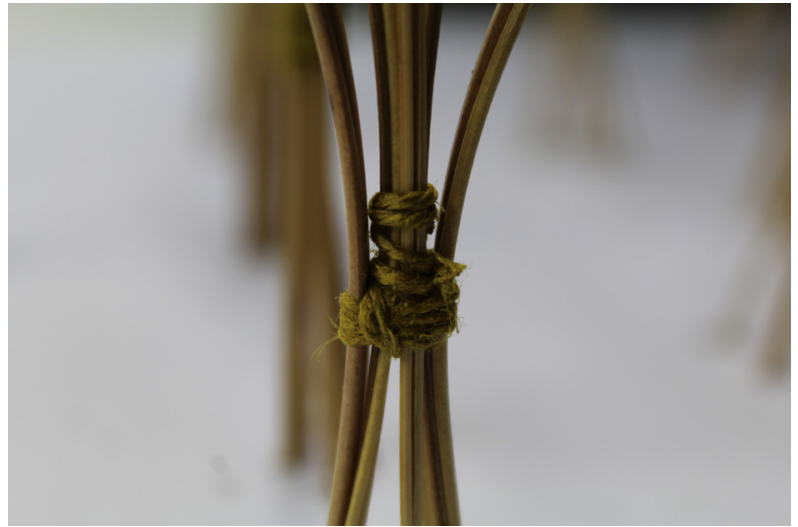

Figure 191. Traditional tying technique to be used*

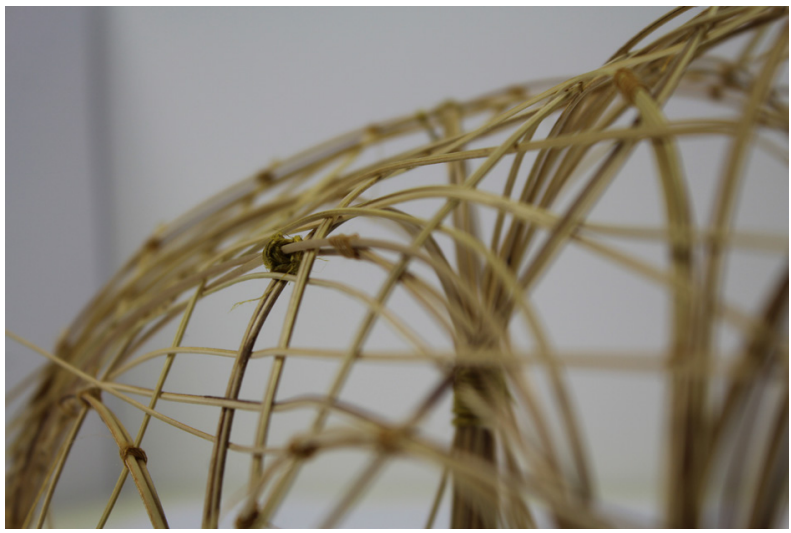

Figure 192. Bracing connection before roof weaved* $^{*}$

\section{Connections}

Traditional tying and lashing techniques were tested for securing these forms and shapes in a manner that allows the building to flex and move within acceptable limits in cyclonic conditions. 


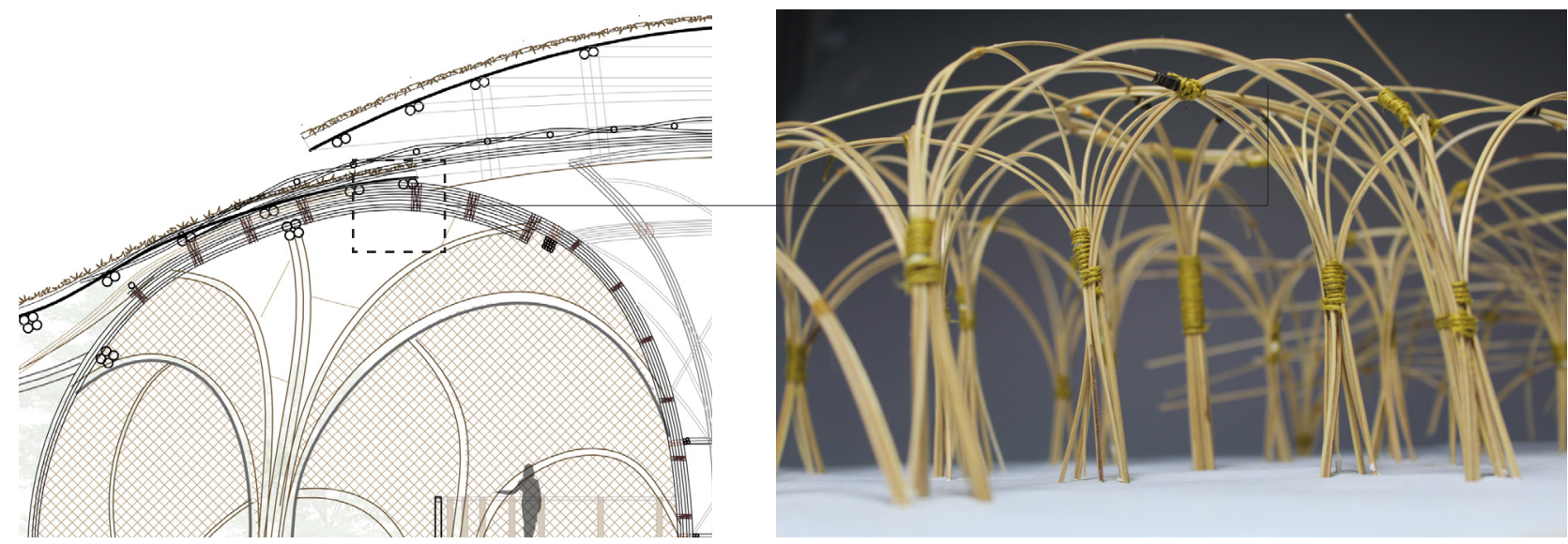

Figure 193. Expressing construction detail

\section{Structural wall system}

Bamboo was identified, after study of its versatility, unique qualities and sustainable nature as a suitable material for the construction.The structural capabilities of bamboo can be maximized by combining multiple reeds and by bending it to create curved forms and round shapes that deflecting cyclonic forces.

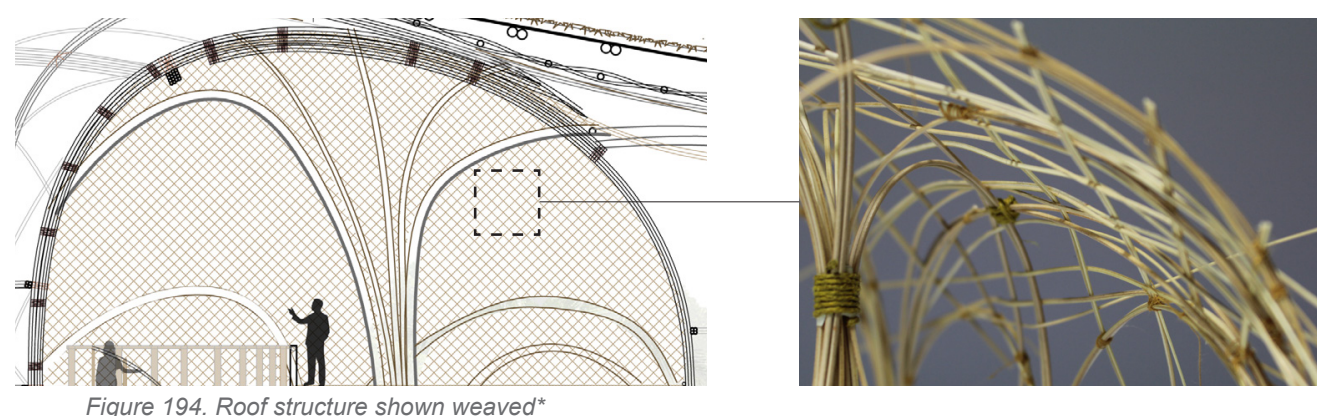

\section{Roof structure}

The roof, a diaphragm system inspired by traditional basket weaving techniques, acts like a lattice brace that links and structurally reinforces the whole building to resist lateral loads. 


\subsubsection{Sustainable Design}

In order to enhance the sustainability factor of this building, it considers passive design principles that minimises the need to use mechanical systems. For tropical country like Niue, natural ventilation, water collection, solar panels and other sustainable and renewable energy have been considered and implemented into the design. 


\section{Natural ventilation}

The building is designed to maximise the use of cross ventilation. As shown, the building positioning on site was placed to maximise the trade winds, and also the ocean winds on site.

The central structural cores and the large cave like space act as a cooling mechanism (just like a cave) but also act a breathing mechanism, allowing cool air to flow through, but also most importantly to circulate hot air though adjustable roof openings.

\section{Water collection}

The lack of rainfall and increase chances of drought calls for the need to find alternative methods of collection water. The big umbrella like roof structure allows the building to collect water efficiently and store through water tanks.

\section{Sustainable renewable energy sources}

Solar panels and other renewable energy systems are located externally on site. Although not shown, the system is designed to sustainably power up the centre servicing the locals who are residing behind the centre. 


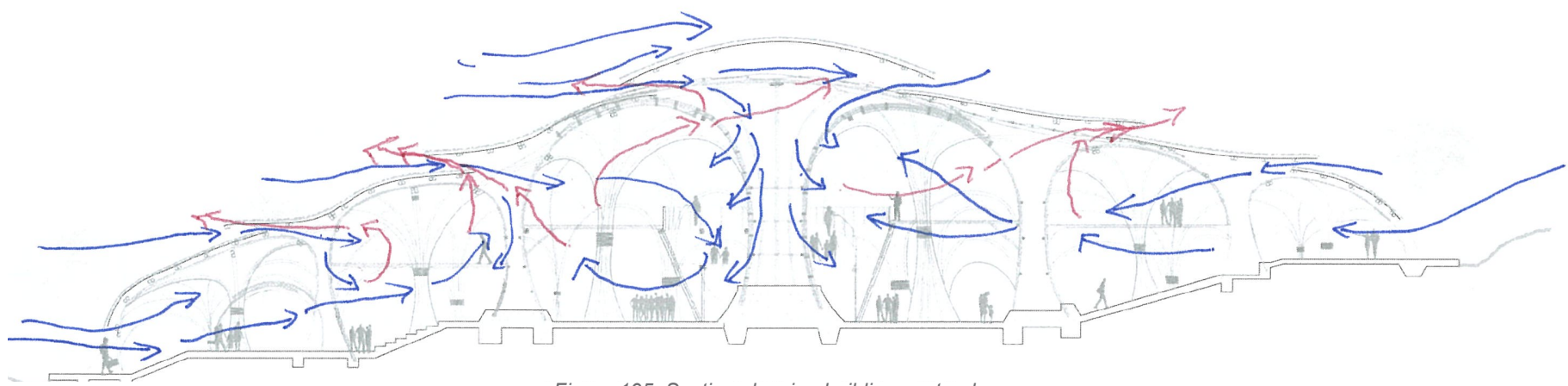

Figure 195. Section showing buildings natural ventilation system.

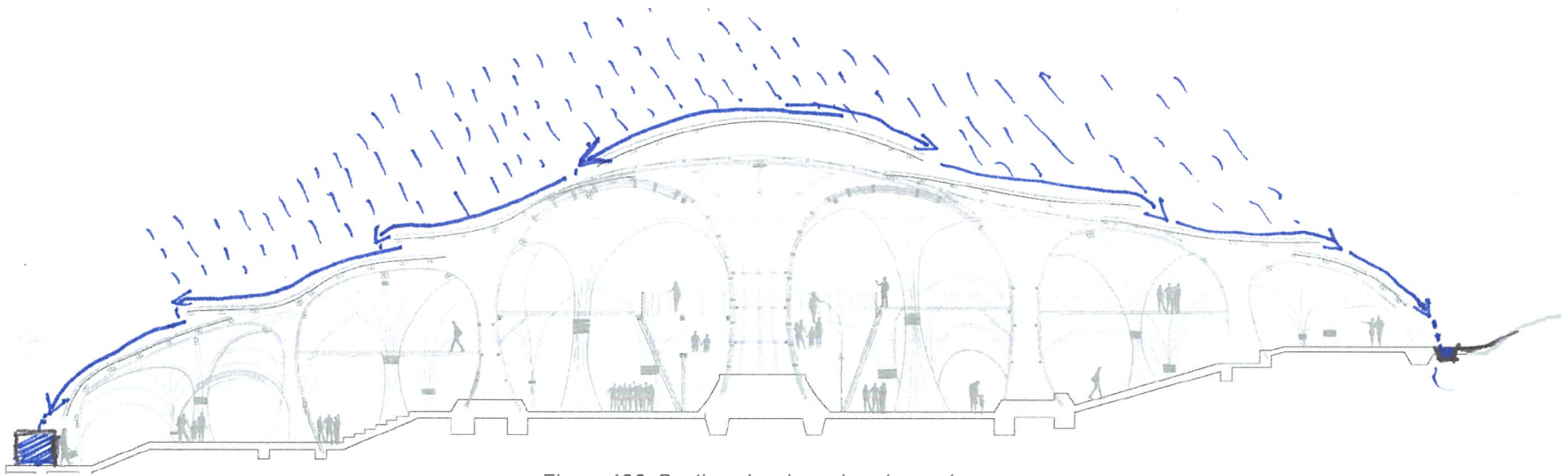

Figure 196. Section showing rainwater system collection* 


\subsubsection{Application of Design}

The design framework that was derived from an intensive analysis of the Ovava tree aims to enable the local community to use it as a framework that can be adapted at both a domestic and public scale. The use of this design framework as a design guideline for future infrastructures that is based primarily around cyclone resistant structures, use of traditional building techniques such as weaving, and tying, and the sustainable methods of growing and harvesting bamboo as shown in this research, will be applicable in the context of Niue and its people. 


\section{Central core}

Foundation of central core with 8 supporting members

\section{Roots planted}

Structure from core is reinforced by the 8 pillars

03. Roots reinforced 8 pillars are horizontally braced

04. Branches are grounded From the Pillars, branches extended out and grounded at the same time

\section{5 . New roots grounded} New roots grounded on both sides

\section{Roots expands around} secondary core

Roots extend out around core to add rigidity

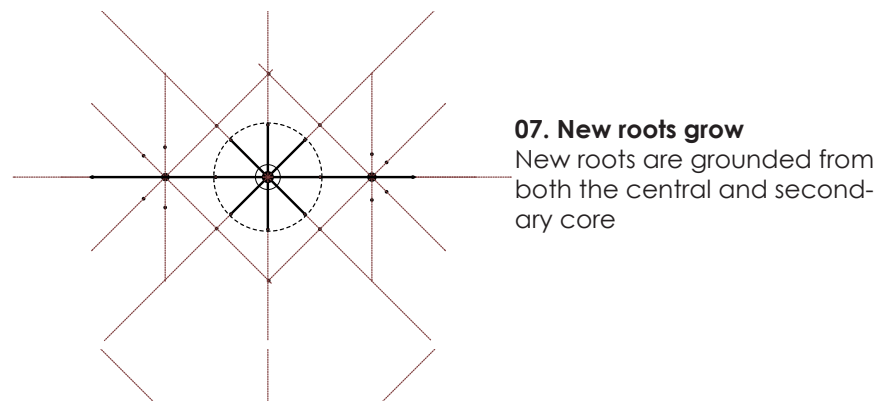

88. Branches extends further The more its grounded, the more it grows

09. Branches are merging Branches grows back to the central core

\section{Bracing the branches} Cores are reinforced through bracing

11. Outer branches creates external shell

Lighter branches creates the form 


\subsubsection{Community Engagement}

\section{Application of bamboo}

Bamboo was identified as a sustainable building material, for the structural and architectural benefits stated as it can also be cultivated and treated locally. Building with bamboo resonates with local communities who can be trained easily to grow, treat and build with the material. As such it is a livelihood source and can be made into a readily available environment friendly, cost effective and versatile building material suited for most forms of built structures as demonstrated by the Green School in Bali (Hardy J,2010) and similar contemporary complexes constructed entirely in bamboo using locally grown materials and skills (Minke G, 2016). Bamboo also has a wide range of uses in the community and not just for construction.

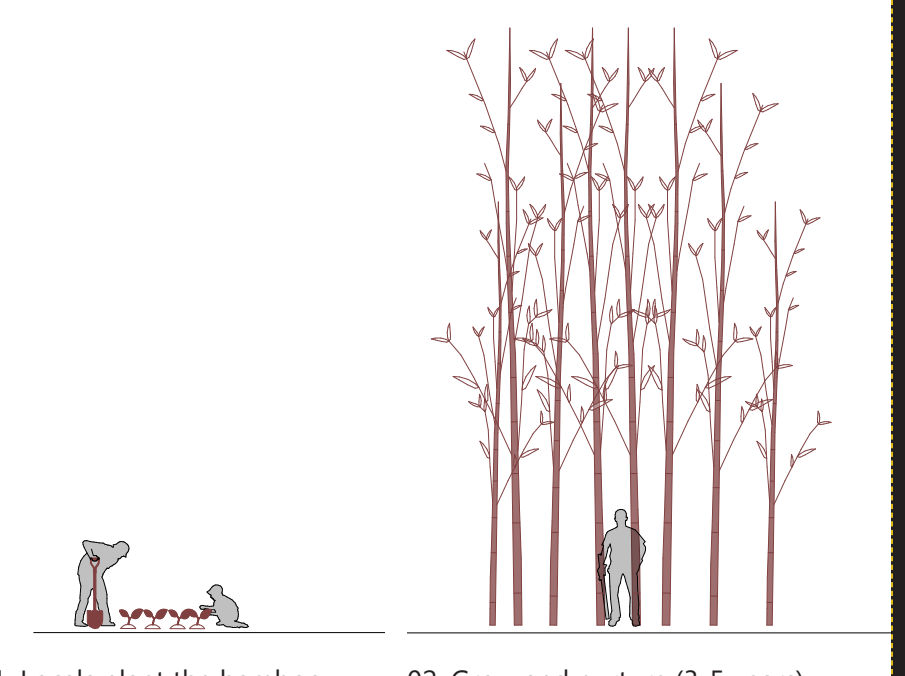

01. Locals plant the bamboo

02. Grow and nurture (3-5 years) 


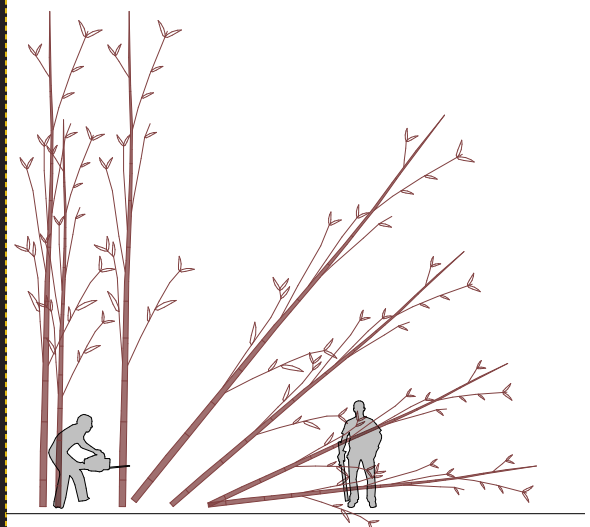

03. Harvest and prepared to sell or for treatment

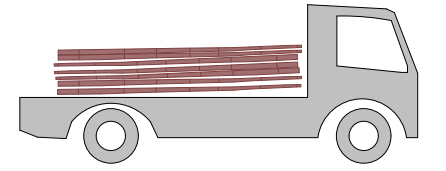

04. Transported to site

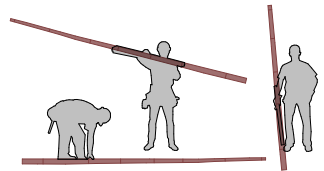

05. Local and builders work together

Figure 198. Community engagement through design and construction* Figure 199. 


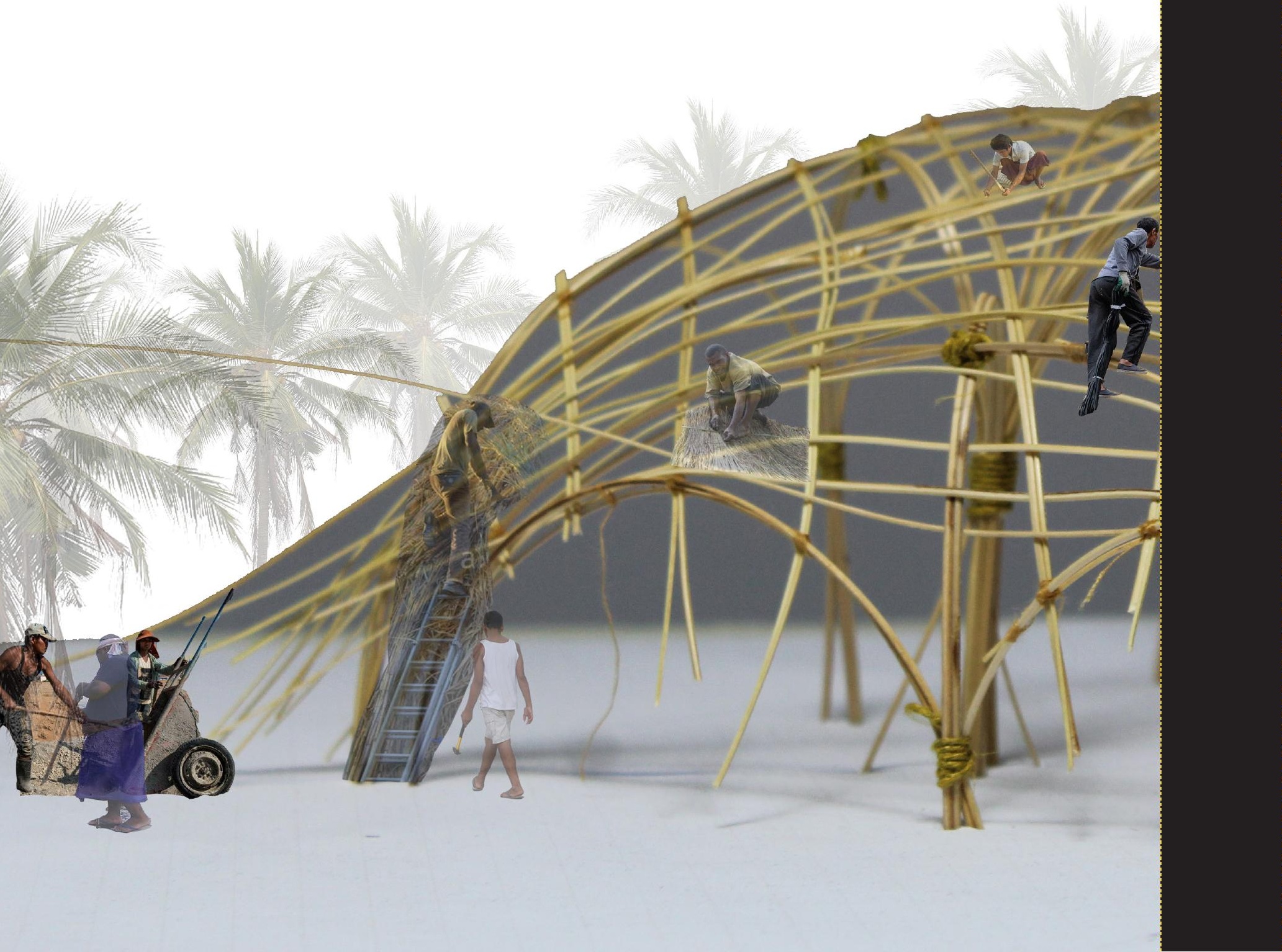




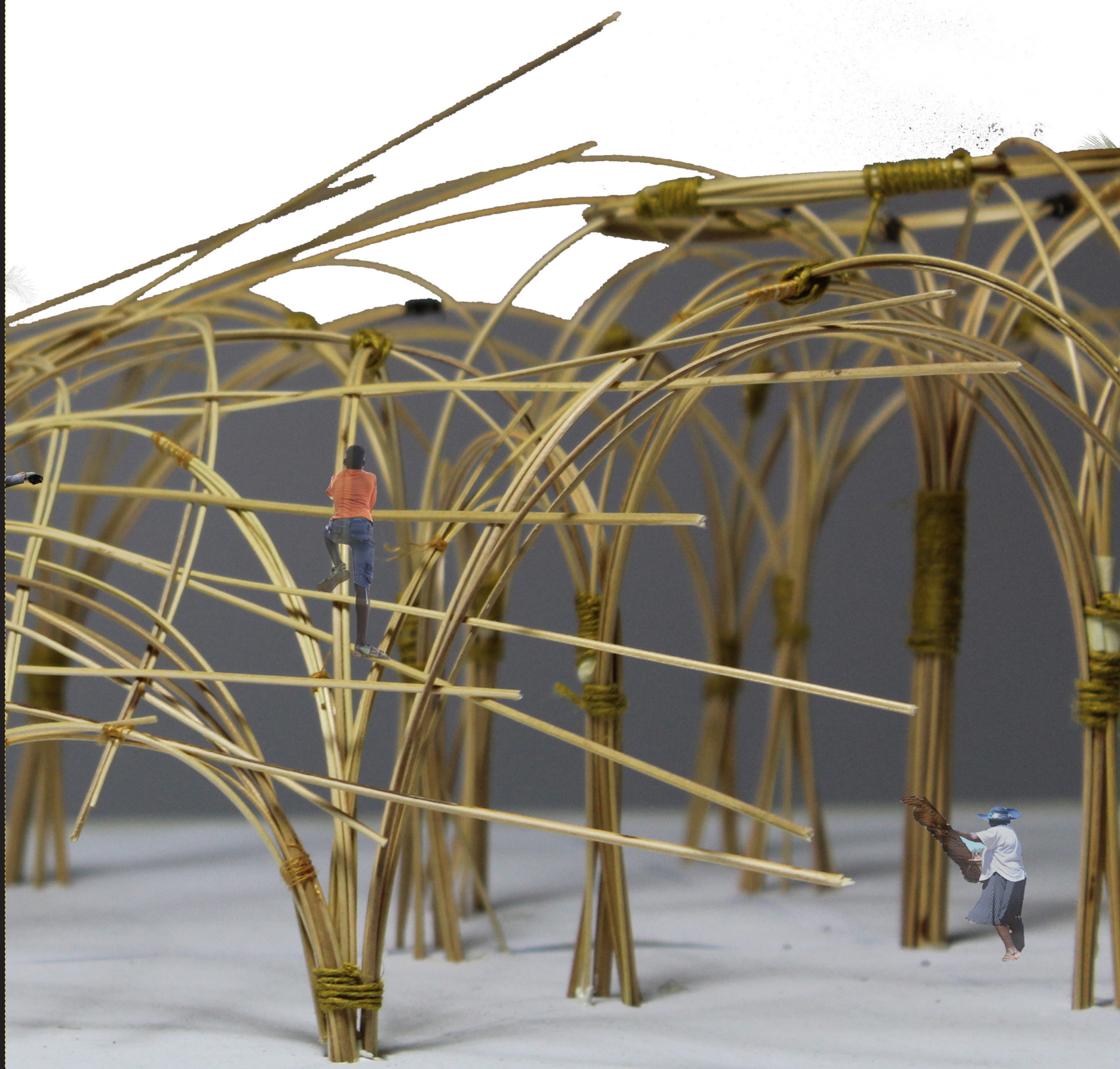




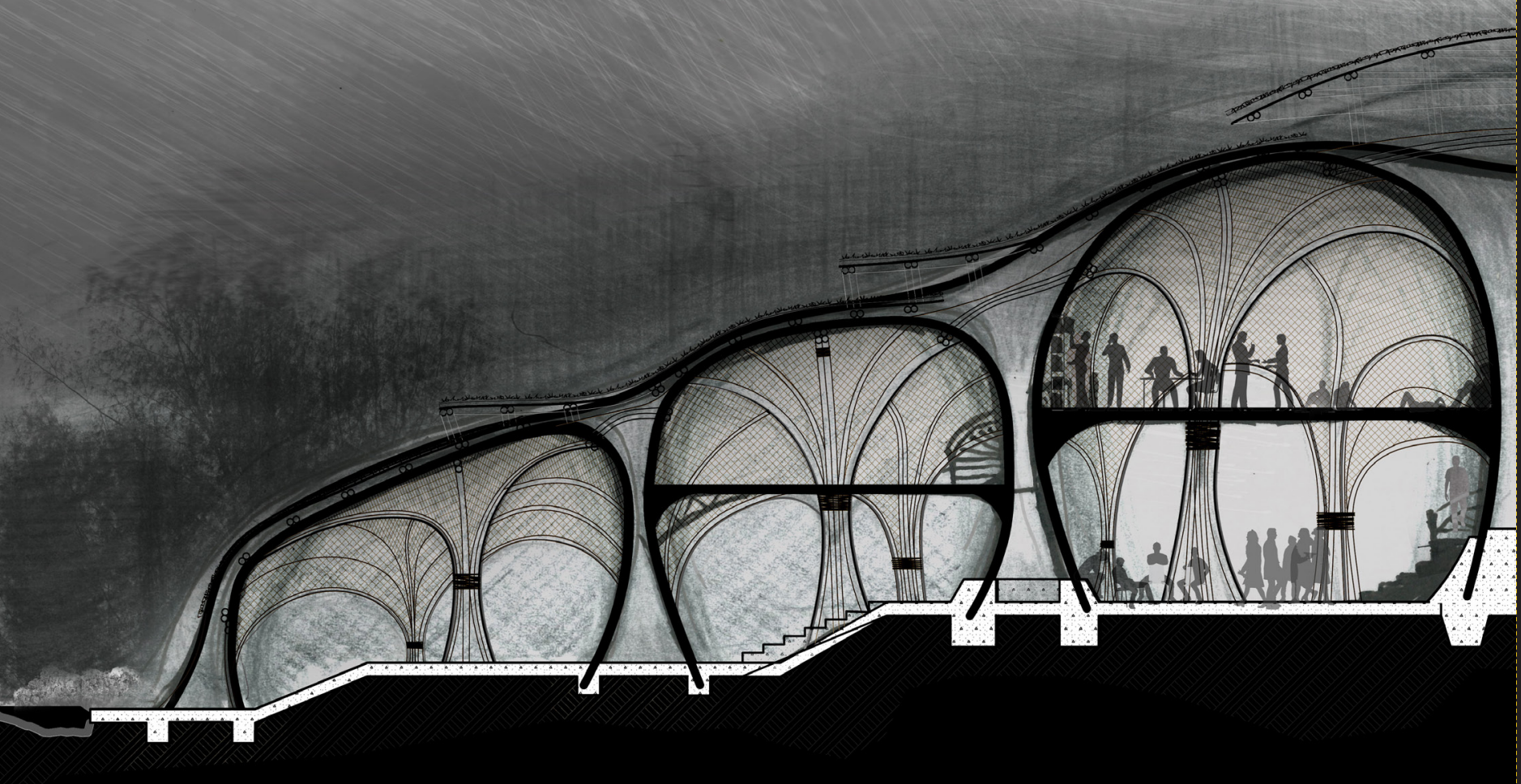

\subsubsection{Disaster Scenario}

\section{During a disaster}

In a disaster scenario, the building will act as an evacuation center for the local comunity and tourists.

As highlighted before, the central core space is the safest area where people can congregate and take refuge.

Main emergency programs will be located in this area including;

- Medical stations,

- Operational rooms,

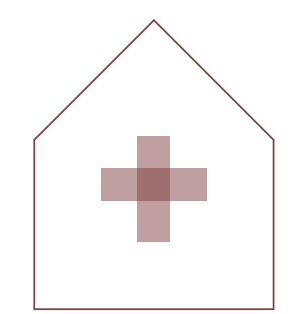

- Emergency back up generators,

EVACUATION CENTER

- Water supply,

- Food supply.

But the main purpose of this space is to act as a shelter that can hold and protect large crowds. 


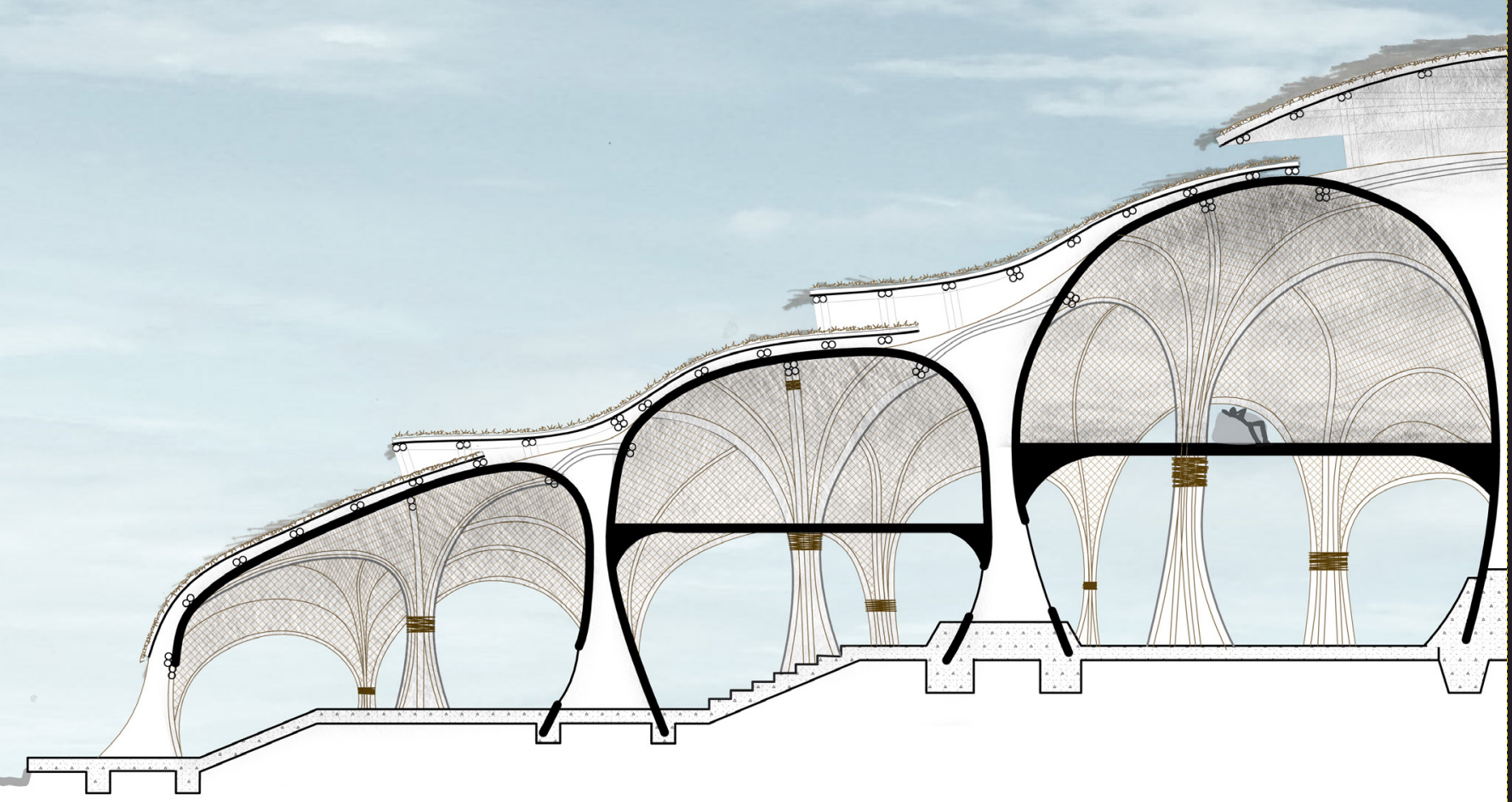

\subsubsection{Day to Day Scenario}

The unique design and the scale of the building will act as the central hub where social, cultural and business are celebrated. The use of the space is flexible and can be adapted for public and domestic scale events that Niue generally holds. 


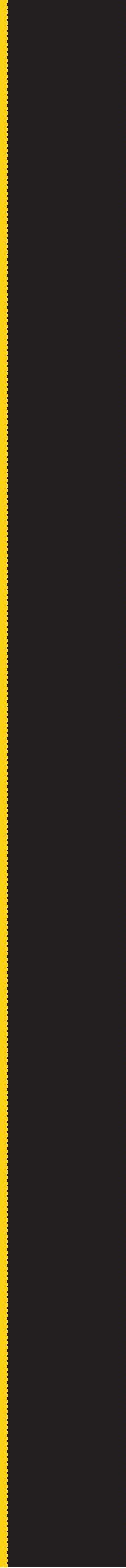




\section{Conclusion}




\section{Conclusion}

This thesis set out to answer the question of: How can Niue rebuild its cultural identity and develop a more resilient and sustainable vernacular architectural response to its cyclone prone environment?

An increase in the frequency of natural hazards and disasters, due to climate change has continued to severely impact Niue's fragile economy even threatening its future survival as a sovereign nation. Past and current western methods as highlighted in the research has only further compelled this situation. The dearth of research on sustainable and resilient planning, design and building practices, suited to the unique conditions of Niue and its people has further aggravated this situation. It has resulted in the indiscriminate adoption and application of western notions and knowledge in the built environment while subordinating Niuean vernacular architecture.

Drawing from the range of data collection methods employed: literature review, participatory design, questionnaires, key informant and focus group interviews, ethnographic observation, site analysis and in-depth critical design explorations has resulted in a design framework that reflects a unique Niuean architecture identity which will increase the resilience of the residents of Aliluki and infrastructure to future cyclones. This will be achieved through the design of a master plan and a cultural centre that is more resistant to the impacts of future tropical cyclones, and also offers socio-economic and environmental benefits.

Despite the dearth in research on the built environment in Niue, local or traditional knowledge offers some invaluable information on what constitutes key principles and knowledge that should underpin a Niuean architectural identity. The use of vernacular architecture will not only build resilience but also preserve the traditional knowledges and practices associated with the built environment.

Effective collaborations between different stakeholders, government organisations, donor community, NGO and community is vital in the reconstruction process of a community or projects after a disaster to ensure a more resilient and sustainable response. Maximum local engagement is critical in empowering communities to take ownership of all future development endeavours at various levels and capacities to ensure the suitability and sustainability of projects.

Using community engagement approaches are critical in enabling project to meet the diverse and multiple demands of different stakeholder groups. In this case the community's demands to have more business and social spaces reflects the importance of all development projects demonstrating the ability to make a positive contribution to the local economy, socio-culture and environment. 


\section{Contribution to the discipline}

This study has made a number of key contributions. First, the findings in the study can be used to inform policy and practices in Niue and the Pacific for developing a built environment suited to cyclone affected locations and relevant to the local context; Second, it contributes to addressing the research gap on vernacular architecture in the case of Niue, adds to the discourse on the topic, and provides the basis for future studies; Third, it documents some elements of traditional knowledge and practices related to the built environment in Niue; and Last but not least, the study presents an inspirational design framework drawn from Niue's natural environment using the Ovava tree to inform the identity of Niue's vernacular architecture. The Ovava Framework is underpinned by principles of resilience, sustainability, utility, and cultural significance, all qualities that are exhibited by the Ovava tree that are applicable in architecture. However, further work is required to refine and develop the Ovava Framework in particular its theoretical basis and credibility for use in architectural research and practice.

\section{Limitations}

This research has some imitations. First is the scope of the research. It addressed two separate issues of Urban and architectural scale shown through the master plan and cultural centre which is quite optimistic given the resource and time constraints. Each topic could have been a thesis on its own due to the lack of research on Niue's built environment. Second, the summary of interviews with key informants focuses only on the cyclone resistant structure techniques and did not document and preserve local knowledge associated with Niuean building traditions and cultural practices. Thirdly the integration of contemporary methods is lacking in the architectural development of the cultural centre. 


\section{Further Research}

The potential for further research is backed up by expertise on the field who during the final design review recognised the value in this project and hence strongly encouraged the author to pursue this project beyond the thesis and aim to make it a reality. Victoria University and the Niue government granted research funds for the author to attend two international conference as they saw the value of the research. The Ministry of Foreign Affairs and Trade also funded the field studies component of this research.

Attending and presenting in the Pacific climate change conference 2018 in Wellington and the International conference of Building and Construction Materials 2018 in Vietnam allowed the author to interact directly with top scholars, experts and professionals in the field. The feedback received was very encouraging and highlighted the need to make this research a real project and also identified some areas for further research.

Future studies should consider the following: First, the full documentation of Niue's vernacular and traditional practices; second, further refinement of the master plan developed in this study with the aim of proposing a viable solution that the government could I utilise to redevelop Aliluki; Third, further development of the architecture with the intention of testing and building a one to one scale model back in Niue. Last and not least, a study on bamboo architecture to better understand construction knowledge and the viability of growing bamboo at a large scale in Niue. 


\section{Sharing Research}
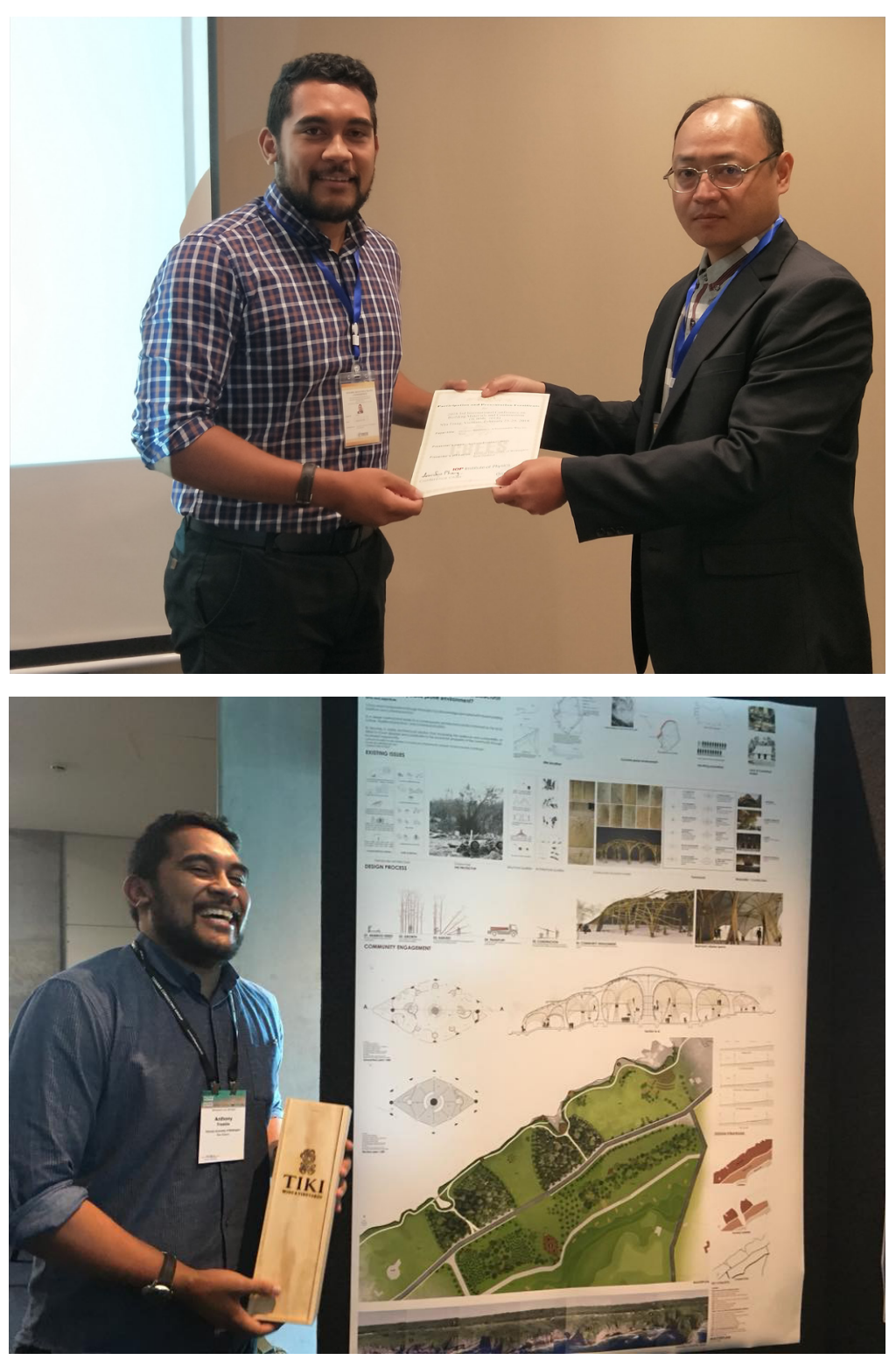

Figure 202. Author receiving presentation award at ICBMC 


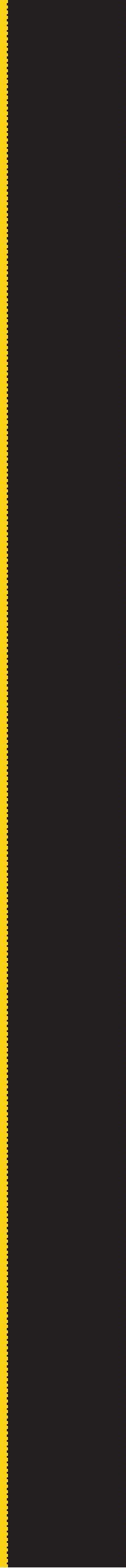




\section{Bibliography $\&$ List of Figures}




\section{Bibliography}

(2015). Niue Strategic Energy Road Map 2015-2025. Suva, Fiji: SOPAC.

(2016). Niue infrastructure plan: Water and waste water.

(2016). Niue Strategic plan 2016-2018.

(2017, 12 10). Retrieved from NZ Ministry of Foreign affairs and Trade: https://www.mfat.govt.nz/en/aidand-development/our-work-in-the-pacific/aid-partnership-with-niue/.

36(12), 4552-4557. https://doi.org/10.1016/j.enpol.2008.09.012

Anderson M, B. D. ( 2012). Time to Listen: Hearing People on the Receiving End of International Aid. . Cambridge, MA : CDA Collaborative Learning Projects.

Ankush A. (2007). Cyclone Resistant building architecture. UNDP, Disaster Risk managment programme.

Austin, M. (2001). Pacific Island Architecture. Fabrications: The journal of the society of architectural historians, Australia and New Zealand, 13-19.

Barker, C. J. (2000). Hurricanes and socio-economic development on Niue Island. Asia Pacific Viewpoint, 191-205.

Barnett, J. (2012). On the risk of engineering mobility to reduce vulnerability to climate change; insighs from a small island nation. UK: Cambridge university Press.

Barnett, J., \& Ellemor, H. (2007). Niue After Cyclone Heta. Australia: The Australia Journal of Emergency managment, Vol 22 No. 1.

Bruijin de K, B. J. (2017). Resilience in Practice: Five principles to enable societies to cope with extreme weather events. Environmental Science \& Policy, 21-30.

Cayford, E. (2017). Bamboo Fale: Climate of change. Retrieved from http://hdl.handle.net/10063/6940

Change, P. A. (2006). Niue Island: Report of In-Country Consultations. Retrieved May 15, 2017

Chapman, T. (1982). Niue Island: A history of the Island. USP, Fiji: Institute of Pacific Studies

Connell, J. (2008). Niue: Embracing a Culture of Migration. Journal of Ethnic and Migration Studies, 10211040. 
CustomWeather. (2018). Climate and weather averages in Alofi. Retrieved from Time and date: https:// www.timeanddate.com/weather/niue/alofi/climate

Daly, P. F. (2016). Rebuilding Asia-Pacific following natural disasters: Approachesto reconstruction in the Asia-Pacific Region. Cambridge: Cambridge university press.

Diasana Putra, I D. G. A., Lozanovska, M., Fuller, R. (2015). The transformation of the traditional Balinese House for Tourist Facilities: Managing a Home-Based Enterprise and Maintaining an Architectural Identity. Asia-Pacific Management and Business Application, 2(2), 120-131. doi:http://dx.doi. org/10.21776/ub.apmba.2013.002.02.4.

Feaunati, C. (2014). E Toe Sasa'a Le Fafao; Return to paradise. Retrieved from http://hdl.handle. net/10063/4843

Feleti, A. (2002). Uneven boundaries that do not flatten easily. Auckland.

Frearson, A. (2016, May 20). EFFEKT designs ReGen Villages that could produce all their own food and energy. Retrieved from Dezeen: https://www.dezeen.com/2016/05/20/effekt-designs-regen-villagesproduce-own-food-energy-danish-pavilion-venice-architecture-biennale-2016/

Government of Niue (2005). Cyclone Heta National Assessment. Planning Division, Premier's Department. Alofi, Niue Island: Author

Government of Niue. (2005). Cyclone Heta: National Assessment. Alofi, Niue Island. Author

Guaralda, M., Caldwell, G. A., \& Rittenbruch, M. (2015). Enriching architectural design education through interactive displays and local community engagement. Design and Culture: Journal of Design Studies Forum, 7(3), 433-439.

Hallegatte, S. (2009). Strategies to adapt to an uncertain climate change. Global Environmental Change. 19(2), 240-247. https://doi.org/10.1016/j.gloenvcha.2008.12.003

Hardy J. (2010). My Green school Dream Technology Entertainment Design (TED) Global,. Retrieved from TED talk: available from: https://www.ted.com/talks/john_hardy_my_green_school_dream

Johnson L, O. R. (2016). After Great Disasters: How Six countries managed community recovery. California: Lincoln Institute of Land Policy. 
Loeb, E. M. (1971). History and traditions of Niue. Suva, Fiji: University of the South Pacific.

Ly, P., Birkeland, J., \& Demirbilek, N. (2010) Vietnam must satisfy a growing demand for housing while confronting the issues of climate change, extreme weather events, nature conservation and cultural heritage. Towards sustainable housing for Vietnam. In Transitions to Sustainability: The Proceedings of 4th International Conference on Sustainability Engineering and Science, NZSSES, Faculty of Engineering, the University of Auckland, New Zealand.

Lyons M, S. T. (2010). Building Back Better, Delivering People-centered Housing Reconstruction at Scale . UK: Practical Action Publishing Ltd.

Macks, K. J. (1996). The A.B.C of Cyclone Rehabilitation. Australia: United nations educational, scienctific and cultural organisation.

Mahgoub, Y., (2007). Hyper identity: The Case of Kwaiti architecture. International Journal of Architectural Research, 1(1), 70-85. doi:http://dx.doi.org/10.26687/archnet-ijar.v1i1.9.

McKay, B. (2004). Maori Architecture: Transforming Western Notions of Architecture. The Journal of the Society of Architectural Historians, Australia and New Zealand, 14(1-2), 1-12. https://doi.org/10.1080/10 331867.2004.10525189

McKay, B. (2018). A field guide to the architecture of the Pacific. Retrieved from http://architecturenow. co.nz/articles/architecture-of-the-pacific/

Memmott, P. (2005). Positioning the traditional architecture of Aboriginal Australia in a world theory of Architecture. Informal Settlements and affordable housing (pp. 1-26). Department of Architecture ITS and the International Council for Research and Innovation in Building and Construction (CIB).

Minke G. (2016). Building with Bamboo: Design and Technology of a Sustainable Architecture, Edition 2. Birkhaus, Basel .

Newman P, M. A. ( 2013). Green Urbanism in Asia: The Emerging Green Tigers. Singapore: World Scientific Publishing Company Pte Ltd.

Oliver-Smith, A. (1996). Anthropological Research on Hazards and Disaters. Annual Review of Anthropology Vol 25, 303-328.

Pacific Community. (2018).Water sanitation programme. Retrieved from http://www.pacificwater.org/ 
pages.cfm/country-information/niue.html

Pickett S, C. M. (2013). Resilience in Ecological and Urban Design: Link Theory and practice for sustainable cities. Springer Science \& Business Media.

Post Tsunami Sustainable Reconstruction Plan for Constitucion. (2016, January 13). Retrieved from The Journal of the American institute of Architects: http://www.architectmagazine.com/project-gallery/ post-tsunami-sustainable-reconstruction-plan-of-constitucion_o

Refiti, A. L (2014). Mavae and Tofiga: Spatial exposition of the Samoan cosmogony and architecture. A theis submitted to the Auckland University of Technology in fulfillment of the requirement for the degree of Doctor of Philosophy. Auckland, New Zealand: AUT.

ReliefWeb. (2004). Niue recovery at 423 million, Alofi to be relocated. Retrieved from https://reliefweb. int/report/niue-new-zealand/niue-recovery-23-million-alofi-be-relocated

Roberts, S. (2008). Effects of climate change on the built environment. Energy Policy,

Sanghi A, R. S. ( 2010). Natural Hazards, UnNatural Disasters: The Economics of Prevention . Washington DC: International Bank for Reconstruction and Development (The World Bank) .

Schnoor, C. (2016). Imagery or Principles of the Pacific? An Investigation into Architecture in Samoa. The Journal of the Society of Architectural Historians, Australia .and New Zealand, 26(3),

286-311. https://doi.org/10.1080/10331867.2016.1233603

science, P. c. (2011). Curent and future climate of Niue. Australia.

Sheida, E. A. (2004). The role of culture in promoting architectural identity. Journal of Natural and Social Science, 410-418.

Smith, S. P. (1963). Niue: The island and its people. Suva, Fiji: University of the South Pacific.

Statistics Niue (2018). National statistics. Retrieved from http://niue.prism.spc.int/

Sumarlim, I. (1989). Vernacular Architecture of the South Pacific Islands and the East Indies. Retrieved from https://hdl.handle.net/11244/18053

Sumarlim, I. (1989). Vernacular architecture of the South Pacific Islands and the East Indies. Retrieved 
from https://hdl.handle.net/11244/18053

Taylor, J., \& Conner, J. (2014). Architecture in the South Pacific: The ocean of islands. Singapore, Singapore City.

Thompson B C. (1902). Savage Islanf: An Account of a Sojourn in Niue and Tonga. London: John Murray, Albemarle Street.

Time and Date (2018). Annual weather averages in Alofi. Retrieved from https://www.timeanddate.com/ weather/niue/alofi/climate

Tran, J. (n.d.). Static illusions: Architectural identity, meaning and history. Curtin University Retrieved from https://s3.amazonaws.com/academia.edu.documents/32697085/Architectural_Identity_Meaning_and_ History.pdf?

Tregear, E. (1893). Niue: or Savage Island. The Journal of the Polynesia Society, 11-16.

UN. (2008). Cliamte change and food security in Pacific countries: Issue and requirements. Rome.

UN. (2017, 12 21). World population prospect. Retrieved from World population review: http:// worldpopulationreview.com/countries/niue-population/

UNESCO. (2017). Safeguarding indigenous Architecture in Vanuatu. France: United Nations Educational, Scientific and cultural organisation.

UNISDR. ( 2015). Sendai Framework for Disaster Risk Reduction 2015-2030. Switzerland.

Van der Ryn, F. M. G. (2012). The difference walls make: Cultural dynamics and implications of change in Sāmoan architectural traditions and socio-spatial practices (1940-2006) Identifier: http://hdl.handle. net/2292/19389 


\section{List of Figures}

Authors own*

Taoga Niue^

Figure 1. Diagram of location of Niue*

Figure 2. Photograph of Physical model*

Figure 3. Photograph of author with the Ovava tree*

Figure 4. Authors final design review with research stream*

Figure 5. Image that summarizes Niuean people resilience ${ }^{\wedge}$

Figure 6. Diagram showing Niue's vulnerability to cyclone*

Figure 7. Diagram of the effects of environmental conditions on Niue's population*

Figure 8. Diagram of ease of access Niuean's overseas*

Figure 9. Diagram of Ailuki before Cyclone Heta*

Figure 10. Diagram of Ailuki after Cyclone Heta*

Figure 11. Drone image of Aliluki existing site.

BCN Niue

Figure 12. Diagram of thesis structure*

Figure 13. Niue Hotel after Cyclone Heta^

Figure 14. Diagram explaining the importance of contextual studies*

Figure 15. Diagram explaining the benefits the vernacular studies*

Figure 16. Diagram explaining the role of vernacular on context studies*

Figure 17. Photo of ripped corrugated roof in Amanau^ ${ }^{\wedge}$

Figure 18. Photo piles of destroyed construction material in Alofi^

Figure 19. Initial sketches of the way early settlements in Niue occupied the landscape*

Figure 20. Cyclone Wiston and its destruction of a village in Fiji

http://www.abc.net.au/news/2016-03-03/damage-in-rakiraki-fiji-from-cyclone-winston/7217686

Figure 21. Collapse of CTV building, Christchurch earthquake, 2011

https://www.stuff.co.nz/national/87666139/police-complete-report-into-ctv-collapse-no-decision-onprosecutions

Figure 22. Post-disaster destruction of traditional house by Cyclone Nagris

http://burmacampaign.org.uk/gallery/cyclone-nargis/

Figure 23. Girl in distraught after Earthquake hit Japan,2013

https://haikugirl.files.wordpress.com/2013/03/she-cries.jpg

Figure 24. Photograph of Arts installation using the scraps from Cyclone Heta*

Figure 25. Photograph of the Forest pavilion. One of the authors inspirational precedents

https://inhabitat.com/forest-pavilion-in-taiwan-is-made-from-a-series-of-bamboo-parabolic-arches/

Figure 26. Natural barrier through heavy planting.

http://www.architectmagazine.com/project-gallery/post-tsunami-sustainable-reconstruction-plan-ofconstitucion_o 
Figure 27. Re-activating the coastal edge through integration of landscape design.

http://www.ilparcocentralediprato.it/en/elemental-mitigation-anti-tsunami-park-inside-pressustainable-post-tsunami-reconstruction-plan-constitucion-chile-2010-2016-2/

Figure 28. Exterior view of Regen village proposal

https://www.effekt.dk/regenvillages/

Figure 29. Walking through the village, green house proposal

https://www.effekt.dk/regenvillages/

Figure 30. Exterior view of Green School

https://www.archdaily.com/81585/the-green-school-pt-bambu

Figure 31. Interior view showing the beautiful detail of bamboo

https://www.archdaily.com/81585/the-green-school-pt-bambu

Figure 32. Traditional Samoan fale under construction

https://commons.wikimedia.org/wiki/File:Seumanutafa\%27s_house_Apia_1896.jpg

Figure 33. Traditional Vanuatu Tamma hut

http://www.troppo.com.au/vanuatu/

Figure 34. Traditional Fijian Bure

https://hendogscrib.files.wordpress.com/2013/02/bure2.jpg

Figure 35. Study of the structural qualities of Vanuatu Tamma*

Figure 36. Study of the structural qualities of Fiji Bure*

Figure 37. Study of the structural qualities of Samoa Fale

Figure 38. Entrance to Brambuk Cultural center

http://www.brambuk.com.au/

Figure 39. Exterior view showing the unique form of the cultural center

http://www.gregoryburgessarchitects.com.au/projects/1995/uluru-kata-tjuta-cultural-centre/

Figure 40. Alofi South show day in Niue*

Figure 41. King Togea, Niue's third king

Figure 42 Women of the village performing traditional Ta me^

Figure 43. A traditional Galue for the village ${ }^{\wedge}$

Figure 44. Diagram showing Niue's unique terrain*

Figure 45. Diagram showing the lower terrace*

Figure 46. Collage showing two distinctive sides of Niue*

Figure 47. Niue vs Niuean's living overseas diagram*

Figure 48. Diagram showing current Niuean living in Niue*

Figure 49. Show day in Alofi South*

Figure 50. Niue high school sports day*

Figure 51. Kids swimming at the Alofi wharf

Figure 52. Kids hanging around Tuatea after school*

Figure 53. Students who are interested in studying architecture* 
Figure 54. Elders (matua fifine) gathering outside after church*

Figure 55. Typical taro plantation*

Figure 56. One of the rainy days in Niue*

Figure 58. Okimai restaurant, Tamakautoga*

Figure 59. Graph showing cyclone season period

Figure 60. Diagram showing probability of a Cyclone hitting Niue*

Figure 61. Existing water tank, Hikutavake*

Figure 62. Domestic rainwater collection installed

Figure 63. Petrol tank stored in Aliluki*

Figure 64. Solar panels installed in Alofi

Figure 65. Graph showing history of cyclones affecting Niue*

Figure 66. Diagram showing vulnerable side of Niue to cyclones*

Figure 67. Diagram identifying Cyclones and its effect on the population*

Figure 68. Aerial shot of Coastal area after Cyclone Heta^

Figure 69. Aerial shot of Inland village after Cyclone Heta^

Figure 70. Damaged petrol tanks after Cyclone Heta^

Figure 71. Boat arriving at Alofi wharf^

Figure 72. Full destruction of a house in Alofi^

Figure 73. Tropical destruction^ ${ }^{\wedge}$

Figure 74. Walking track in Tamakautoga*

Figure 75. Drone image overview of Aliluki coastal stretch

BCN Nive

Figure 76. Collage of Niue Island map*

Figure 77. Site map of Aliluki before Cyclone Heta*

Figure 78. Image of Aliluki before Cyclone Heta

https://nyc.nu/cyclone-heta-2004/

Figure 79. Site map of Aliluki post Heta*

Figure 80. Image of Aliluki wiped cleaned by Heta

https://nyc.nu/cyclone-heta-2004/

Figure 81. A study of cyclones characteristic*

Figure 82. Graph showing relationship between Cyclone strength and storm surge*

Figure 83. Graph highlighting damages per Cyclone category*

Figure 84. Collage of the path of Cyclone Heta

Figure 85. Study showing the different causes of Tsunami waves*

Figure 86. A Study showing the difference between Niues terrain and other low-lying Islands*

Figure 87. Satellite image of Aliluki taken couple days after Cylone Heta

Figure 88. Diagram vulnerable areas of the coast to Tsunami waves*

Figure 89. Diagram theorizing the waves directions* 
Figure 90. Existing site map of Alofi

Land and survey, Niue

Figure 91. Collage of existing infrastructure in Aliluki

Figure 92. Wider analysis of amenities in Alofi*

Figure 93. Drone image of junction between Aliluki, to airport and Alofi North

BCN Niue

Figure 94. Site map showing wider connections to the site*

Figure 95. Collage of images showing the unique costal cliff in Aliluki*

Figure 96. Foundation footing of the Huanaki cultural center still remains on site.*

Figure 95. Design workshop in session with the Head of Departments*

Figure 97. Design strategy options*

Figure 98. Participants engaging with the design strategies and program cards*

Figure 99. Initial sketches of design strategies outcome*

Figure 100. CNC model of Site with all the different programs ideas attached*

Figure 101. Program cards set up to initiate design conversation*

Figure 102. Results from design workshop with high school students*

Figure 103. Design workshop with the students*

Figure 104.Jack Willie Lipitoa*

Figure 105. Tukala Makamau Hekau*

Figure 106. Kemu Misiepo*

Figure 107. Misa Kulatea*

Figure 108. Morris Hemu Tafatu*

Figure 109. Pitasoni Mahalo Tanaki*

Figure 110. Billy Graham Talagi*

Figure 111. Hon. Vaiga Tukuitonga*

Figure 112. Family cave used for shelter during Cyclone*

Figure 113. Reconstruction of traditional Fale luku at the Taoga Niue Musuem*

Figure 114. Traditional Fale pola^

Figure 115. Construction of new building next to fale pola^

Figure 115. Traditional church in Alofi as seen have used corrugated iron roof^

Figure 116. Interior space of the first traditional church built in Alofi

https://commons.wikimedia.org/wiki/File:Inside.Church,Niue,Thomas_Andrew_1896.jpg

Figure 117. Traditional fale puga with corrugated iron roof^

Figure 118. A collage of sketches during interviews with the matuas*

Figure 119. 5 diagrams on the right highlights simple but effective methods used to resist cyclones traditionally*

Figure 120. Photo with the Head of Departments after design workshop*

Figure 121. Materials used to construct physical model* 
Figure 122. Concept one*

Figure 123. Concept two*

Figure 124. Concept three*

Figure 125. Design review one with professionals in the field*

Figure 126. A conceptual master plan*

Figure 127. Diagram showing the key design moves*

Figure 128. Image showing Niue Hotel post Heta and now*

Figure 129. A new more social feel, like the image*

Figure 130. A memorial for the loss in Aliluki*

Figure 131. No order in parking*

Figure 132. Process of areas to replant tress on site and also buildings*

Figure 133. Guidelines to rules and regulation on site*

Figure 134. Diagram the new identity for the site*

Figure 135. Forest pavilion. A great example of light architecture

https://www.arch2o.com/forest-pavilion-narchitects/

Figure 136. Green school Bali

https://inhabitat.com/the-green-school-showcases-bamboo-construction-in-indonesia/

Figure 137. Identifying prime coastal spots*

Figure 138. Diagram showing key point on the coastal edge for development*

Figure 139. Collage showing the existing historic areas, remanence and trees on site*

Figure 140. Concept design of a branch of the proposed community center*

Figure 141. Sketch explorations of different narratives and ideas*

Figure 142. Final conceptual design of the community center main branch*

Figure 143. Final conceptual design plan*

Figure 144.Conceptual design of a tourist house proposal*

Figure 145. Final conceptual design site plan* (Above)

Figure 146. Exterior view of the house* (Top right)

Figure 147. Section of the house*(Bottom right)

Figure 148. Photo of the great Ovava tree in Alofi*

Figure 149. Exploring the Ovava trees network of roots*

Figure 149. The Ovava tree stands tall even after the Cyclone* (left)

Figure 150. Early sketch exploration between the Ovava tree and architecture*

Figure 151. The underlying structural principles of the Ovava tree that will inform design*

Figure 152. Early sketch explorations of the spaces between thee root network*

Figure 153. (Refer to case studies)

Figure 154. (Refer to case studies)

Figure 155. Fig. Image above (middle left) shows the complex construction techniques used in Bamboo construction. 
https://www.archdaily.com/778269/diamond-island-community-center-vo-trong-nghia-architects/5660 a112e58ece70b600040d-diamond-island-community-center-vo-trong-nghia-architects-photo

Figure 156. Image bottom left, shows unique and elegant building with bamboo is.

Figure 157. Using Kaniu stick as the main material that mimics bamboo*

Figure 158. Using flax strand as the connection point*

Figure 159. Testing the material properties of Bamboo through the Kaniu stick

Figure 160. Testing material through form making*

Figure 161. The process of modelling with the design framework of the Ovava tree

Figure 162. Design framework derived from the Ovava tree through modelling*

Figure 163. Physical model following framework through trial and error

Figure 164. Placing the form generated on site to understand climatic and site constraints*

Figure 165. Response of form to site (important for resilience, sustainability and passive design

Figure 166. Spatial arrangement based on the Ovava tree framework of central core being the safest during cyclone*

Figure 167. Testing of this spatial arrangement on form. Protecting the middle with smaller minor spaces on the outer shell*

Figure 168. Final design review in November. Thumbs up because it went well*

Figure 169. Structure of roof being weaved together*

Figure 170. Final design masterplan proposal

Figure 171. Exterior shell of the model is interlinked with the central and secondary core*

Figure 172. The arching entry points provide structural rigidity to the form*

Figure 173. Interior structure and roof weaved on to the external skeleton structure*

Figure 174. Conceptual ground floor plan, showing organic and flexible space*

Figure 175. First floor plan, is more formal and rigid to add extra lateral support for building*

Figure 176. Sectional detail showing space and construction detail of building in response to physical modelling*

Figure 177. Interior space showing the large cave like space, with exposed weaving structure*

Figure 178. Interior render beginning to show the large generous central core space*

Figure 179. Image showing the dual purpose of the architecture*

Figure 180. Site section reacting to a cyclone and how it deals with it

Figure 181. Collage showing the local and international precedent that can be adapted to site*(refer to Master plan for reference)

Figure 182. Testing building position on site*

Figure 183. Structural form*

Figure 184. Sectional construction detail*

Figure 185 Close up of entry points towards the building.

Figure 186. Model expressing same principles*

Figure 187. Main concrete foundation to central core* 
Figure 188. Smaller concrete foundation for secondary core*

Figure 189. Main central core*

Figure 190. Expressing same principles*

Figure 191. Traditional tying technique to be used*

Figure 192. Bracing connection before roof weaved*

Figure 193. Expressing construction detail

Figure 194. Roof structure shown weaved*

Figure 195. Section showing buildings natural ventilation system.

Figure 196. Section showing rainwater system collection*

Figure 197. Ovava design framework

Figure 198. Community engagement through design and construction*

Figure 199. Vision of the community building the cultural center*

Figure 200. Section showing building during disaster*

Figure 201. Section showing building on a day to day*

Figure 202. Author receiving presentation award at ICBMC 2018*

Figure 203.Author receiving best poster award at the PCCC 2018* 


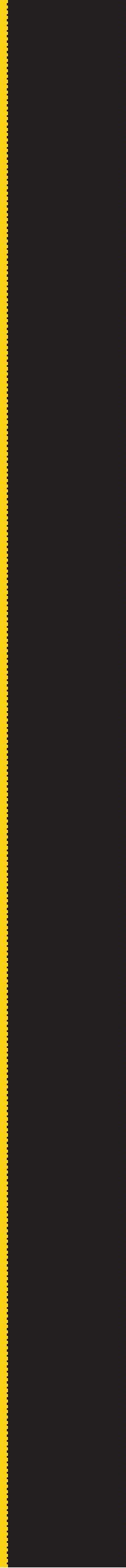


12. Appendix 


\section{MEMORANDUM}

\begin{tabular}{l|l}
\hline TO & Anthony Freddie \\
\hline COPY TO & Shenuka de Sylva \\
\hline FROM & AProf Susan Corbett, Convener, Human Ethics Committee \\
\hline
\end{tabular}

\begin{tabular}{l|l}
\hline DATE & 27 July 2017 \\
\hline PAGES & 1 \\
\hline
\end{tabular}

Thank you for your application for ethical approval, which has now been considered by the Standing Committee of the Human Ethics Committee.

Your application has been approved from the above date and this approval continues until 15 December 2017. If your data collection is not completed by this date you should apply to the Human Ethics Committee for an extension to this approval.

Best wishes with the research.

Kind regards
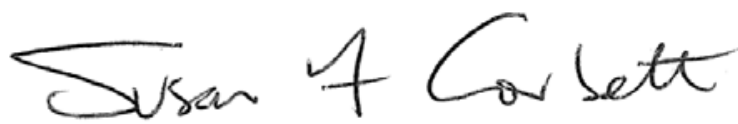

Susan Corbett

Convener, Victoria University Human Ethics Committee 


\section{ANEW WAF NILE/ STLDENTS}

DATER

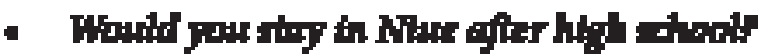

5

Mighe

No

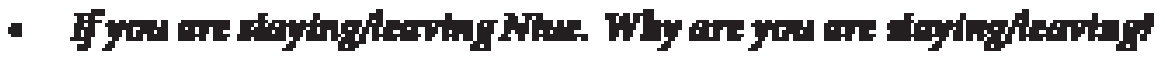

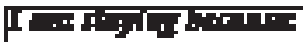

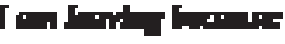

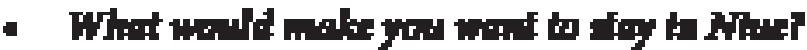

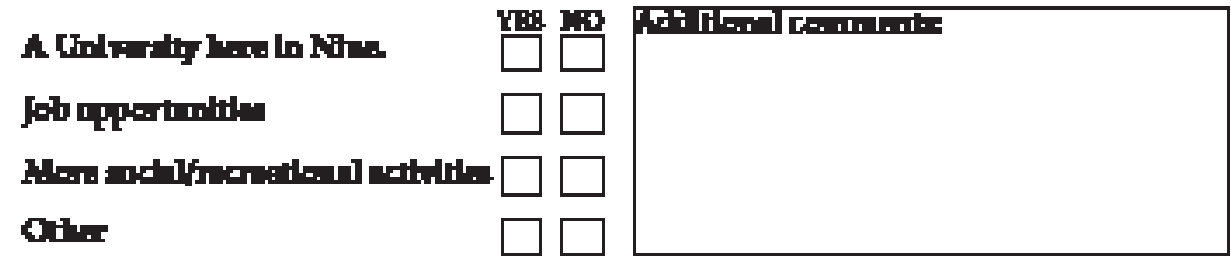

- What is the bet thing ebrit Nined

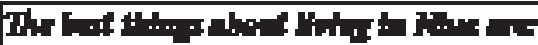




\section{A NEW WAY: NIUE-B}

DATE

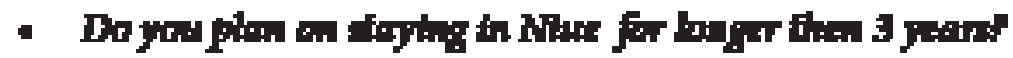

\$. $\square \quad$ Mopbe $\square \quad$ No $\square$

- What braygif yru bod fo Afurt

Itoppotuints

Finily

The Iforty

R:Pln for the Hald

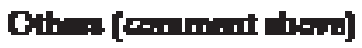

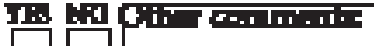

$\square \square$
$\square \square$
$\square \square$
$\square \square$
$\square \square$

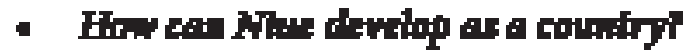

- What is the bet thatg ebrad Ninger

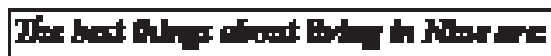




\section{A NEW WAY: NIUE-C}

DAIE

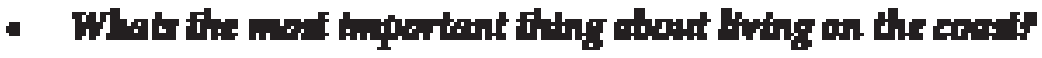

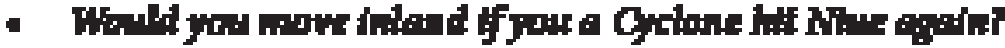

No $\square \quad$ Mula $\square \quad$ in $\square$

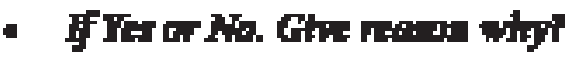

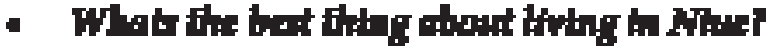




\section{A llow wry kne}

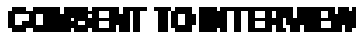

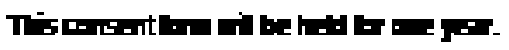

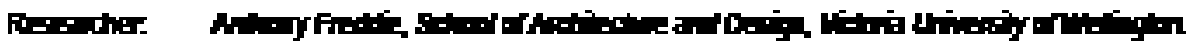

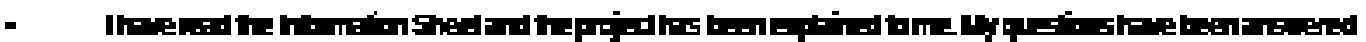

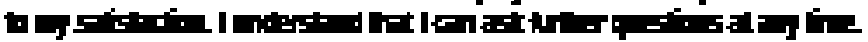

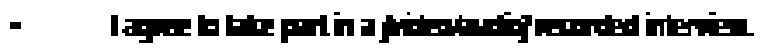

lunistint

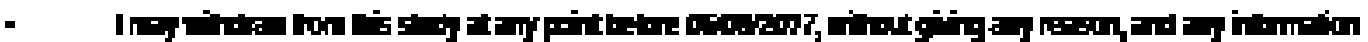

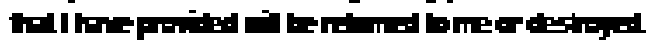

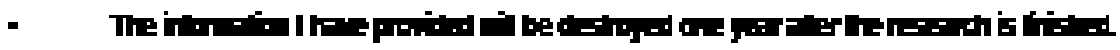

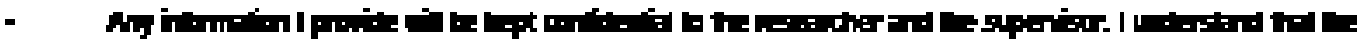

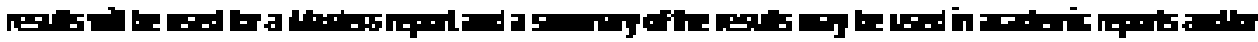

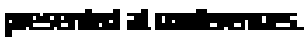

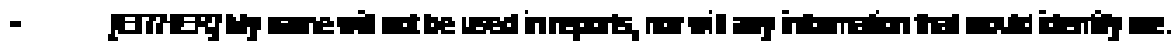

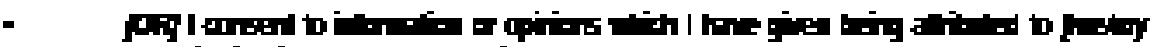

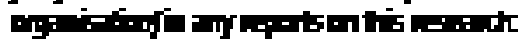

Ya $\mathbf{~ b D}$

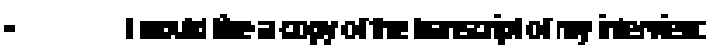

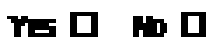

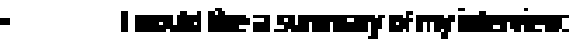
Ya D D

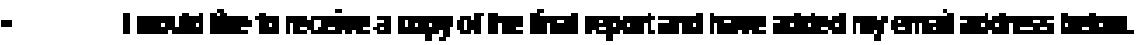

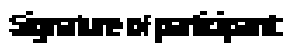

Heof priptit

Dets

cratts. 


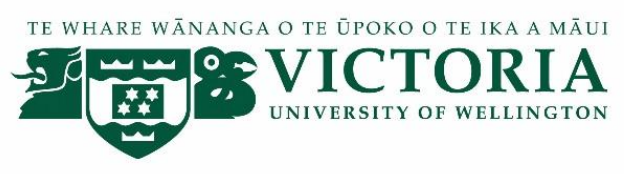

\author{
A New way; Niue
}

\title{
INTERVIEW INFORMATION
}

\section{$22 / 06 / 2017$}

To whom it may concern:

Fakalofa lahi atu

My name is Anthony Liuvaie Freddie and I am currently completing my Masters in Architecture (Professional) at Victoria University in Wellington, New Zealand. I am Niuean, from the village of Hakupu Atua.

I am flying over to Niue on the $5^{\text {th }}$ of March 2017 to the $28^{\text {th }}$ of July 2017 to conduct my field study which includes interviews with key stake holders and with our matuas.

\section{1) Background Research/Kakano ne taute ai e kumikumiaga nei.}

Cyclone Heta hit Niue in 2004, struck most of the costal edge of the island, particularly the South side of the Capital Alofi, Aliluki. The national hospital, the national museum, Niue Hotel, Amanau apartments, and most importantly, two precious lives were lost; that of a mother and her baby, the biggest loss experienced by this Island community. From then until now, Aliluki what once was one the centre of Niue is now but stigmatised by deconstruction, has deteriorated into a barren ruin overgrown by nature. Cyclone Heta didn't just destroy lives and significant buildings and infrastructure it also destroyed the fragile identity of a traditional Island people, who for several decades have struggled with the forces of modernisation.

This design research aims to identify a resilient architectural solution that is contemporary and supports Niue's future growth as a nation through the study of its traditional and vernacular architectural practices and methods.

\section{2) My research question/ Ko e hu hu ke lata moe kumikumiaga nei.}

How can Niue's economy and cultural identity be revived through the reconstruction of its cyclone destroyed coastal town?

One of the main objectives of this thesis is to document and preserve knowledge to do with traditional Niuean architecture and traditional Niuean building techniques so it can be used as an educational tool for the future Niuean generation and to also generate academic knowledge that can be used for further studies.

I understand and acknowledge that Niuean people pass down knowledge through oral traditions so I aim to use this method by interviewing the matuas. 


\section{3) How can you help? Maeke fefe a ko e ke lagomatai?}

Through interviewing our Matuas (Elders) I am hoping to find vital information to do with:

\section{Traditional Building Techniques}

- Traditional Niuean houses/ Tau fale fakamua I Niue

- Local materials used to build fale polas, fale puga and the traditional Niuean Church/Koe heigoa ne fakaaoga ke ta e tau fale pola/ fale puga/ fale tapu he vaha I tuai.

- Traditional methods used in buildings to withstand cyclones/ Tau puhala ne ta ai e tau fale ke mau tuli ka to ai e afa.

- Adapting to the Cyclone/ Ko e heigoa e falu a tau puhala ke puipui e tau fale he afa.

- What were the main locally sourced material used? Ko e heigoa e tau vala akau ne fakaaoga ke ta aki e tau fale.

\section{Traditional Niuean Architecture}

- History of the Taues and early settlements/ Talahauaga kehe tau taue moe tau maaga he magaaho fakamua.

- The formation of villages/Ko e kamataaga he tau maaga.

- The story behind building a traditional house/ Ko e heigoa e tau talahauaga mahuiga he tau fale fakamua.

- A narrative behind the traditional Church/Ko e kakano he fale tapu fakamua I Niue

- The influence of the missionaries on the development of the built environment/ Tau misionale moe ha lautolu a lagomatai kehe kamataga he tau maaga.

These bullet points are general guidelines to what this research aims to find but is not limited to this bullet points alone.

If you have any questions or queries, please don't hesitate to contact me or my supervisor.

Fakaue lahi

Anthony Liuvaie Freddie

Student:

Name: Anthony Liuvaie Freddie

University email address: freddianth@myvuw.ac.nz or aliuvaie@gmail.com

\section{Supervisor:}

Name: Shenuka de Sylva

Role: Lecturer

School: Architecture and Design

Phone:

Email: Shenuka.DeSylva@vuw.ac.nz 

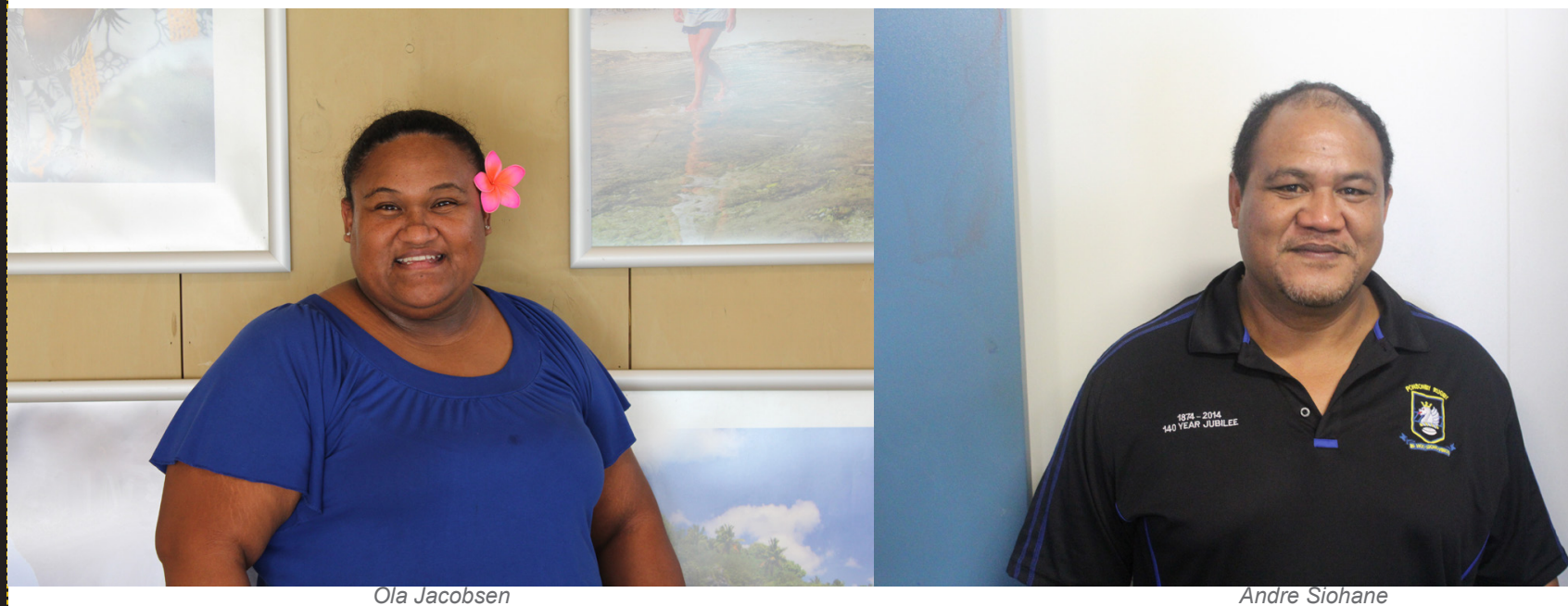

Andre Siohane
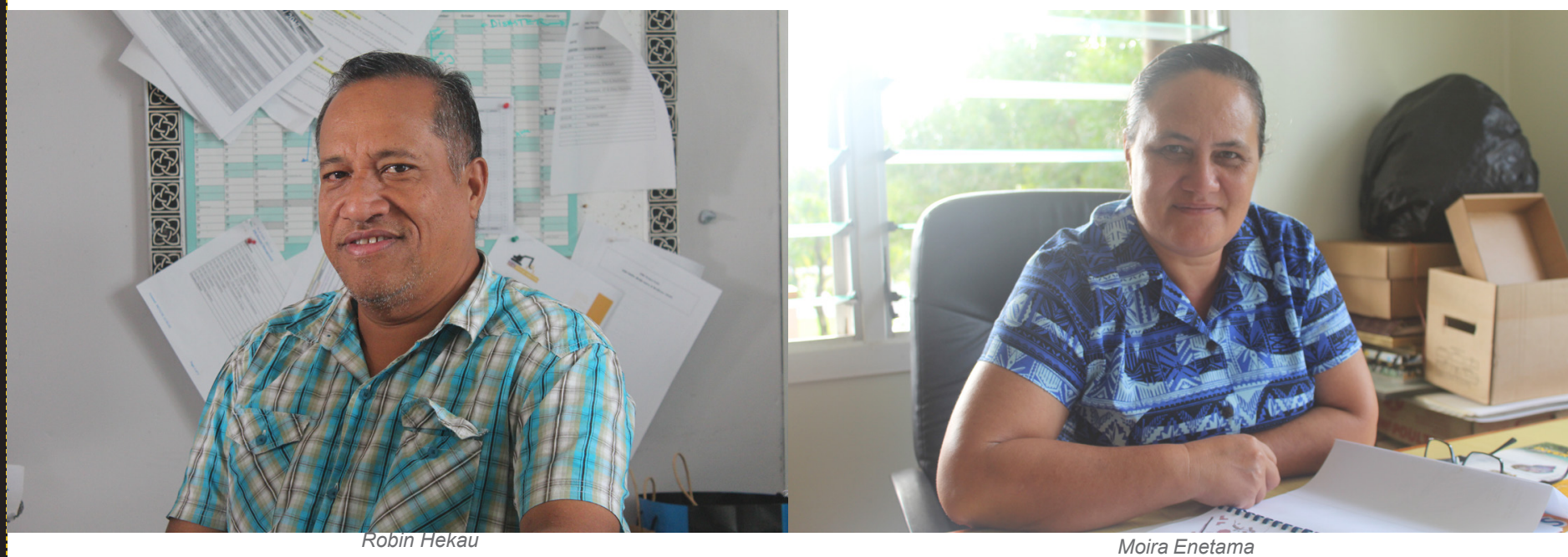

A special thank you to Niue Government and Management officer, Robin Hekau, Tourism the various departments involved in the research including, Director General of Infrastructure, Mr Andre Siohane, Director of Education, Birtha Tongahai, Director of Taoga Niue, Moira Enetama, Alofi South Village Council Leader and Disaster representative, Ola Jacobsen, and many more for the help and support during the authors field research to Niue.

\section{FAKAUE LAHI. NIUE KI MUA.}

